\title{
The development of early life gut microbiota in health and allergic disease
}

Harm Wopereis

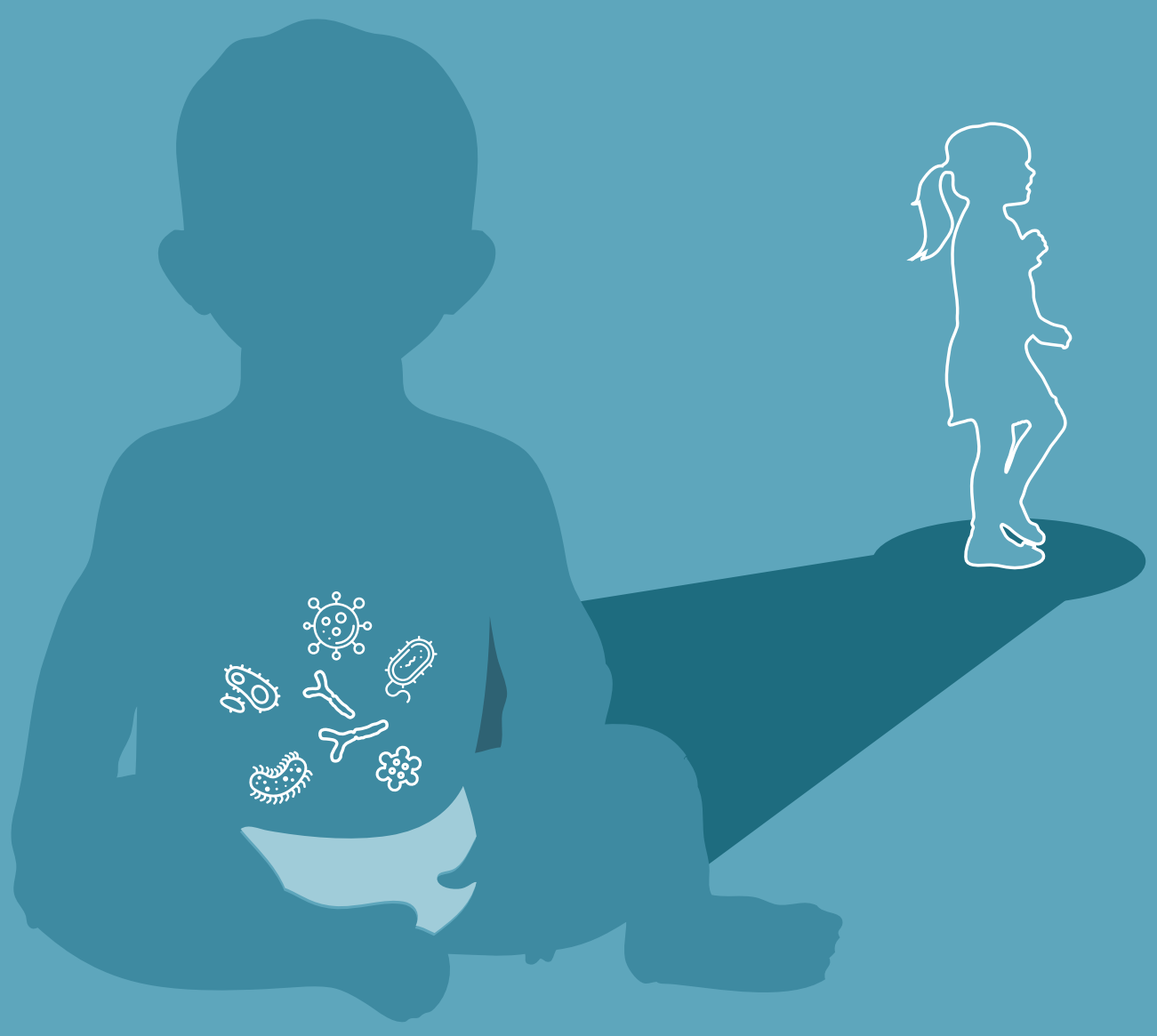




\section{Propositions}

1. The rate of gut microbiome maturation in early life influences the risk of developing allergic disease.

(this thesis)

2. Using the term 'dysbiosis' to describe microbial configurations in the context of complex diseases, such as allergy, is misleading. (this thesis)

3. If there is anything that distinguishes 'data science' from 'traditional statistics', it is the urge to learn from data.

4. Experiencing and, above all, creating music benefits your brain. (Ross B et al., J Neurosci. 2017;37(24):5948-59.)

5. Colour-blindness hinders the modern microbiologist more than ever!

6. A lie may have no legs but has become faster than ever.

Propositions belonging to the thesis, entitled:

The development of early life gut microbiota in health and allergic disease

Harm Wopereis

Wageningen, 22 May 2019 
The development of early life gut microbiota in health and allergic disease

Harm Wopereis 


\section{Thesis committee}

\section{Promotors}

Prof. Dr J. Knol

Special Professor Intestinal Microbiology of Early Life

Wageningen University \& Research

Prof. Dr W.M. de Vos

Distinguished Professor of Microbiology

Wageningen University \& Research

\section{Co-promotor}

Dr C. Belzer

Assistant Professor, Laboratory of Microbiology

Wageningen University \& Research

\section{Other members}

Prof. Dr H.J. Wichers, Wageningen University \& Research

Prof. Dr N.G. Papadopoulos, the University of Manchester, United Kingdom

Prof. Dr S. Salminen, University of Turku, Finland

Prof. Dr C. Stanton, University College Cork, Ireland

This research was conducted under the auspices of the Graduate School VLAG (Advanced studies in Food technology, Agrobiotechnology, Nutrition and Health Sciences) 


\section{The development of early life gut microbiota in health and allergic disease}

Harm Wopereis

\section{Thesis}

submitted in fulfilment of the requirements for the degree of doctor

at Wageningen University

by the authority of the Rector Magnificus,

Prof. Dr A.P.J. Mol,

in the presence of the

Thesis Committee appointed by the Academic Board

to be defended in public

on Wednesday 22 May 2019

at 4 p.m. in the Aula. 


\section{Harm Wopereis}

The development of early life gut microbiota in health and allergic disease, 184 pages.

PhD thesis, Wageningen University, Wageningen, the Netherlands (2019)

With references, with summary in English

ISBN 978-94-6343-415-7

DOI https://doi.org/10.18174/468890 


\section{Table of Contents}

Chapter 1: General introduction \& thesis outline

Chapter 2: The first thousand days - intestinal microbiology of early life: establishing a symbiosis.

Chapter 3: Improved detection of bifidobacteria with optimised 16S rRNA-gene based pyrosequencing 51

Chapter 4: Intestinal microbiota in high-risk infants: Effects of prebiotics and role in eczema development 73

Chapter 5: A specific synbiotic-containing amino acid-based formula restores gut microbiota in non-lgE mediated cow's milk allergic infants 99

Chapter 6: Gut microbiota from infant with cow's milk allergy leads to atopic orientation in a murine model 125

Chapter 7: General discussion \& Summary 157 Appendices 175 



\section{CHAPTER 1}

General introduction \& thesis outline 


\section{Introduction}

The microscopic observations of "putrefying bodies" (fungi) by Robert Hooke and of "animalcules" (bacteria) by Antoni van Leeuwenhoek between 1665 and 1683 uncovered for the first time the microbial world we live in. The observations by these two pioneers in microbiology, both fellows of the prestigious Royal Society of London, were made possible by the first versions of the microscope, which still is a central instrument in microbiology (1). Since these first discoveries, the techniques we use to understand this "invisible" world have evolved: from isolation and cultivation techniques (end of the $19^{\text {th }}$ century), to strictly anaerobic cultivation techniques (late 1960 's) and cultivation-independent molecular techniques (end of the $20^{\text {th }}$ century) (2). Finally, high throughput approaches to study microbial molecules at the level of DNA and RNA (through next generation sequencing), but also at the protein (through proteomics and metaproteomics) and metabolite levels (through metabolomics and metabonomics) revolutionized the field of microbiology. They enabled researchers to describe the composition and activities of the microbial communities found everywhere around us (3). Moreover, these culture-independent methods also allow researchers to explore the microbial diversity and functionality of the large 'not-yet culturable' fraction (2). Since the study of microbial communities is a relatively new field in microbiology, it is important to have clear definitions of the terms used. The terms, which have been adopted in this thesis come from those proposed by Marchesi and Ravel (4):

Microbiota: all the microorganisms (archaea, bacteria, viruses and microscopic eukaryotes) that live in a specific environment, e.g. the gut or the root nodule of a plant. The study of it mainly relies on the phylogenetic analysis of marker genes, such as those encoding for the prokaryotic $16 \mathrm{~S}$ ribosomal RNA (bacteria and archaea) and the eukaryotic $18 \mathrm{~S}$ rRNA. Although viruses are an integral part of the microbiota, they are non-cellular and lack a universal marker gene that can be used for taxonomic classification. However, viruses can be assessed through metagenomics, which is a technique that enables the study of the full microbial genetic content within an environment (5). Most studies so far merely measure or consider the bacterial 
members, which is also the scope for this thesis. Formerly, the microbiota was often referred to as "microflora", but this term is misleading as it implies to describe plants.

Microbiome: this term refers to the ecosystem or habitat, including all the microbes and the surrounding environmental conditions (for example: $\mathrm{pH}$, temperature, oxygen pressure). Often this term is limited to describing the collection of microbial genes and genomes, which however is more correctly referred to as metagenome. The prefix "meta" is used to designate the analysis of the collection of molecules from all microbes, instead of from a single organism. The profiling of the RNA-transcripts, the synthesized proteins or metabolites of the community is thus referred to as metatranscriptomics, metaproteomics, and metabolomics (or more correctly: metabonomics), respectively. These three methods go beyond the analysis of the taxonomic composition and genetic potential of the community and provide insight into the functional activity of the genes that are expressed under certain conditions (6).

\section{The human microbiome}

The most intensively researched microbial community in the last two decades is probably the human microbiome (7). Microbes are found everywhere the human body is exposed to the outside world; namely the skin, the urogenital tract, the respiratory tract and the digestive tract. The composition of the microbial communities is primarily determined by body habitat but is also unique to each person and relatively stable in adults (8). The average adult has a total estimated number of microbes in the order of magnitude of 10-100 trillion cells; the majority of which is found in the lower digestive (gastro-intestinal) tract (9). Along the gastro-intestinal tract (GI tract), an increasing bacterial density is observed from the stomach $\left(<10^{4}\right.$ cells/gram) to the small intestine $\left(10^{4}-10^{8} \mathrm{cells} / \mathrm{gram}\right)$, up to the most densely populated compartment, the large intestine $\left(10^{11}-10^{13}\right.$ cells/gram). This progressive increase is partially explained by the differences in hydrogen potential $(\mathrm{pH})$, oxygen levels and food transit times between the different digestive compartments (10).

Two large-scale research initiatives, i.e. the European Metagenomics of the Human Intestinal Tract (MetaHIT) (11) and the American Human Microbiome Project 
(HMP) (12), that were joint under the International Human Microbiome Consortium (IHMC) (13) provided vast amounts of metagenomic sequence data that aimed to improve our understanding of the human microbiome, and especially that of the gut, in health and in disease. The millions of microbial genes that were identified from the faecal specimens in these initiatives can be regarded as a functional expansion of our own $\sim 20.000$ human genes $(7,11,14)$. Most of the microbial genes in the gut were found to be of bacterial origin (>99\%) and are estimated to represent more than 1000 bacterial species, of which an individual person harbours at least 160 species (11). Although highly subject-specific community compositions were observed, a large fraction of species and genes identified were shared between individuals, which indicated the existence of a core metagenome. The bacterial species identified mostly belong to 5 phyla, namely Actinobacteria, Bacteroidetes, Firmicutes, Proteobacteria and Verrucomicrobia $(11,14)$. These first descriptions of the human gut microbiome have led to increased understanding and awareness of the roles these indigenous gut microbes have in human physiology, and how that may affect human health or disease.

\section{The human gut microbiome in health and disease}

The digestive tract is unique among the internal organs, because it forms a large interface with our external environment. This interface is greatly enlarged by the folds, villi and microvilli of the GI tract, resulting in an estimated surface area of $32 \mathrm{~m}^{2}$ (15). Naturally, it is the central organ for the digestion and absorption of the food we eat, but it is also tightly connected with the immune, neural and endocrine systems that all interact together to optimally process the food and sense the external environment (16).

The trillions of gut microbes developed several essential activities that complement our own metabolism through the digestion of complex dietary and host-derived substrates, resulting in the production of, for example, secondary bile acids, vitamins and short-chain fatty acids (SCFA), thereby contributing nutrients, energy and bioactive compounds $(17,18)$. Moreover, our gut inhabitants are known to react to or modify foreign chemical components (e.g. drugs, pollutants), eliminate 
exogenous toxins (19), and to provide protection against the colonization of potential pathogens by nutrient competition or through direct anti-microbial mechanisms (20).

Perhaps not surprising that due to the large surface area, the gut is known to house the largest number of immune cells in the body that need to maintain immune homeostasis locally and systemically. This involves a complex interaction of the innate and adaptive immune system in response to innocuous substances (commensal microbes, food-, and self-antigens) while protecting the body from potentially harmful ones (21-23). Given the interdependency we have with our microbial inhabitants, a relationship which has co-evolved over millions of years (24), and the essential roles they have in several physiological processes, it is not surprising that they are the focus of research into a broad range of chronic diseases. Indeed, a growing body of evidence implicate an altered composition and activity of the gut microbiome that influence the onset and persistence of several diseases that have rapidly increased in prevalence over the last decades. These range from metabolic-related diseases, such as obesity $(25,26)$ and type 2 diabetes (27), to immune-related diseases, such as inflammatory bowel disease (28) and allergies (29), to even neurological-related diseases, such as autism spectrum disorders (30). All these diseases have a multifactorial or polygenic aetiology, which means that they are partially explained by genetic susceptibility, but that lifestyle and environmental factors, such as diet, also contribute to the onset (31). Perturbations of the gut microbiome in early life are thought to increase the risk of developing some of these multifactorial diseases, while a child's immunity, metabolism and cognition are still developing (9).

\section{Early life, gut microbiota and immune development}

The host-microbe cross-talk is a crucial factor in the proper development of the immune system, a process that starts at birth, when the infant is first exposed to significant numbers of maternal and environmental microbes (32). Some studies have suggested that even within the healthy fetal milieu, exposure to microbes or microbial signals may occur (33), which is currently heavily debated in scientific literature (34, 35). Importantly, the maturation of the immune system is for a large part taking place in the first months and years of life, which is also the period when the gut microbiota gradually develops towards a mature adult-like ecosystem $(36,37)$. Initial microbial 


\section{Chapter 1}

inoculation strongly depends on maternal transfer of a select number of microbes, which mostly include strains from the genus Bifidobacterium and from the class Bacteroidia, to the vaginally born infant. These strains have been proven to originate from the maternal gut and are ecologically better adapted to persistently colonize the infant gut than strains acquired from other sources, such as the maternal skin and vagina (38). In contrast, caesarean-born infants show a striking lack of vertical transfer and delayed colonization of these pioneering microbes $(32,39,40)$.

The maternally transmitted strains show persistence in infancy with an additional continuous, but rare, influx of strains from the direct family environment (32, 41). The latter type of transmission, known as horizontal transfer, seems to be facilitated by endospore formation, which is common among gut-associated Clostridia, to survive the environment outside the gut $(32,42)$. Human milk, as the sole source of nutrition, is of major influence on the establishment of the gut microbiota in early life. Its influence is not limited to the period of exclusively breastfeeding but is still apparent in the period of complementary feeding until full transition to family foods around the age of 3 years (43-45). In addition to the essential nutrients, vitamins and antibodies, human milk contains numerous complex glycans known as human milk oligosaccharides (HMOs). These compounds pass the infant's digestive system, and are efficiently consumed by especially Bifidobacterium, which results in an infant gut microbiome that is predominated by this genus, which is in stark contrast with that of infants receiving formula based on cow's milk $(46,47)$. Additionally, human milk is also found to be a source of microbes including bifidobacteria $(38,48)$. This specific co-development observed for vaginally-born breastfed infants leads to a relatively stable infant microbiota which probably contributes to human health throughout life. $A$ detailed review on these 'first 1000 days' of gut microbiota and immune development, the pivotal role of early life nutrition herein, and the association of perturbations of gut microbiota on the development of allergic disease, is provided in Chapter 2.

\section{The rise of allergies}

The epidemic rise of allergies, such as food allergy, atopic eczema, allergic rhinitis and asthma in developed and developing countries during the last 60 years has led to an immense global health problem, which is expected to affect up to 4 
billion individuals in the 2050's (49). The recognition that several environmental factors and exposures, in addition to genetic risk factors, contributed to the 'allergy epidemic' was already postulated in 1989 by David Strachan in what became known as the hygiene hypothesis (50). Originally, Strachan proposed that the increased post-industrial hygiene standards and declining family sizes reduced the opportunities for cross-viral-infections, thereby increasing the risk of allergic disease, which was based on a strong inverse correlation in the incidence of hay fever in children with older siblings. More recently this hypothesis has been revisited and revived by implicating the early resident microbial communities in allergic disease $(51,52)$.

This renewed view of the hygiene hypothesis, which is sometimes referred to as the biodiversity hypothesis, proposes that significant perturbations of the resident microbial communities during early life immune development may disrupt the mechanisms of mucosal immunologic tolerance against innocuous antigens, such as food proteins (51-53). Several epidemiological observations yielded support for this hypothesis by the association of increased antibiotic-exposure (54-56), C-section delivery $(57,58)$, decreased breastfeeding-duration (59-61) and absence of exposure to pets $(62)$ and farm-environment due to urbanization $(63,64)$ with an increased risk of developing allergic diseases, such as food allergy. Moreover, the loss of ancient members of the gut microbiota, due to compromised transmission from one generation to the next, may have compromised the context of establishing a healthy symbiosis in early life $(52,65,66)$. Another important risk factor that more recently has been identified is reduced food diversity in the infants' diets and the delayed introduction of allergenic foods (67), the latter of which has led to changing the guidelines for complementary feeding to not unnecessarily avoid the introduction of allergenic foods after 4 months of age once weaning has started, irrespective of atopic heredity $(68,69)$. 
Dietary approaches in the primary prevention and management of cow's milk allergy

\section{Protein hydrolysates and amino acid-based formulas}

If breastfeeding is insufficient or not possible, international guidelines recommend partially hydrolysed cow's milk protein formulas (pHF) for infants with a family history of allergic disease (and therefore deemed 'high-risk for allergy') $(68,70)$. Clinical trials have shown the potential of reduced allergen exposure by specific pHF to reduce the risk of developing eczema in high-risk infants (71). This is, however, challenged by a 2016 meta-analysis that evaluated several different hydrolysed formulas and concluded there was no consistent evidence for prevention of allergy (72). The mixed outcomes may be explained by the combined evaluation of various types of hydrolysed formulas (71) and the differences in tolerogenic potential of the peptides present in formulas from different manufacturers (73).

For the dietary management of infants with cow's milk allergy (CMA) and when breastfeeding is not possible, expert opinion recommends the use of hypoallergenic formula, such as extensively hydrolysed cow's milk protein-based formula (eHF) and amino acid-based formula (AAF) to quickly resolve symptoms through allergen avoidance $(74,75)$. Although an eHF is suitable for most CMA infants and children, between $10-40 \%$ of patients require an AAF when allergic symptoms do not resolve with an eHF (76).

\section{Prebiotics, probiotics and synbiotics}

There is growing research into the potential role of the microbiome in patients with asthma, atopic dermatitis, and food allergy. This is complemented by an increasing number of trials that investigate prebiotics, probiotics or a combination of both (synbiotics) (77) to manipulate the microbiome to influence the development of sensitisation and allergy $(51,78)$, which generally reflects the move from allergen avoidance towards more active management of allergy (79). Probiotics are 'live microorganisms that, when administered in adequate amounts, confer a health benefit on the host', as defined by the Food and Agriculture Organization/World Health Organization in 2001 (80) and updated in 2014 by the International Scientific 
Association of Probiotics and Prebiotics (ISAPP) (81). The core-group of well-studied and widely applied bacterial species are strains of Bifidobacterium (adolescentis, animalis, bifidum, breve and longum) and Lactobacillus (acidophilus, casei, fermentum, gasseri, johnsonii, paracasei, plantarum, rhamnosus and salivarius), respectively (82). The next-generation probiotics may also include more recently identified key members of the human gut microbiota, which have been associated with healthy states in metagenomic studies (81). These include Akkermansia muciniphila (83) and butyrate-producing bacteria, such as Faecalibacterium prausnitzii, Roseburia spp., Anaerostipes spp. and Eubacterium hallii (84).

In 2017, the ISAPP reviewed the definition and scope of prebiotics as originally coined by Gibson and Roberfroid in 1995 (85) and updated the definition to 'substrates that are selectively utilized by host microorganisms conferring a health benefit' (86). This definition broadened the initial location of action beyond the gastro-intestinal tract and added the possibility of including non-carbohydrate substances. Currently established prebiotics are mostly carbohydrate-based fructo-oligosaccharides (FOS and inulin) and galactans (galacto-oligosaccharides or GOS) that have been shown to selectively stimulate Bifidobacterium spp. and/or Lactobacillus spp. in the Gl-tract (82). The mimicry of these compounds with HMOs, both in effects, building blocks and size, led at the beginning of this century to the development of the first infant formula that were enriched with specific short-chain galacto-oligosaccharides (scGOS) and long-chain fructo-oligosaccharides (IcFOS), which were added in a 9:1 ratio and at a total dosage of $0.8 \mathrm{~g} / 100 \mathrm{ml}$ to mimic the molecular weight profile and concentrations of HMOs in breast milk (87). This specific prebiotic mixture has since its introduction been investigated in several clinical investigations, which confirmed its safety and its efficacy in shifting microbiota composition, metabolic signatures, stool frequency and stool softness closer to that of breastfed infants. Moreover, these studies provided evidence towards the prevention of allergies and infections as has been summarized recently (87). 


\section{Evidence for prebiotics, probiotics and synbiotics in the prevention and treatment of allergy}

The most recent evaluation on the preventive effect of probiotics and prebiotics was performed in a joint effort of the World Allergy Organization (WAO) and the Department of Clinical Epidemiology \& Biostatistics at McMaster University using the Grading of Recommendations Assessment, Development and Evaluation (GRADE) approach, which resulted in the Guidelines for Atopic Disease Prevention (GLAD-P) $(88,89)$.

In relation to probiotics, the panel concluded that based on the available evidence (up to November 2014) probiotic supplementation did not reduce the risk that children will develop allergy (89). However, when considering all critical outcomes (costs, risk of adverse events), the panel determined that 'there is a likely net benefit from using probiotics resulting primarily from prevention of eczema' and suggested to use probiotics a) in pregnant women at high-risk of having an allergic child; b) in women who breastfeed infants at high-risk of developing allergy; and c) in infants at high-risk of developing allergy (89). Obviously, the evaluation included various types of probiotic strains (and species), plus a variety of study designs; no evaluation is currently made among the strains of the same species for example.

In relation to prebiotics, the panel suggested prebiotic supplementation in not-exclusively breastfed infants, both those at increased (based on family history of allergy) and normal risk for developing allergy. The majority of studies with infant formula (11 out of 15) included the specific scGOS:IcFOS (9:1) mixture. The effects of supplementing prebiotics during the first year of life was associated with reduced risk of developing asthma or recurrent wheezing, food allergy and probably eczema, however with low certainty due to risk of bias and imprecision of estimates (88).

Currently no recommendations are available concerning the use of prebiotics and/or probiotics in the treatment of allergy using a GRADE-like evaluation of available evidence. This probably is explained by the lack of studies that could be evaluated. However, recently a meta-analysis was performed by Chang and colleagues who evaluated the use of synbiotics for the treatment and prevention of atopic dermatitis, which offers encouraging findings based on a decrease in the 
severity scoring of atopic dermatitis (SCORAD) values observed when combining 6 treatment studies (90).

Further studies are required to confirm and determine the beneficial effects of specific prebiotics, probiotics and synbiotic combinations for prevention and treatment of allergy, which may ultimately translate to specific clinical recommendations.

\title{
Aim and outline of this thesis
}

\begin{abstract}
Aim
A suboptimal implementation of the gut microbiota in early life could contribute to the onset of allergy and/or enhancement of allergic symptoms. The main aim of this thesis was to investigate normal gut microbial trajectories in early life and to identify deviating patterns that are associated with allergic manifestations, such as atopic dermatitis and food allergy.
\end{abstract}

\section{Outline}

In Chapter 2, we give an overview of the development of the gut microbiota in early life, the factors impacting this development and the importance of the microbe-immune cross-talk to establish a healthy symbiosis. The review additionally includes a summary of paediatric studies on the association between gut microbiota composition and allergic disease.

Bifidobacteria are the most abundant bacteria in early life, but often under-represented in 16S rRNA-gene sequencing surveys of gut microbiota, due to poor DNA extraction techniques, poor PCR primer choice or a combination of both. When the research described in this thesis was initiated, we modified a commonly used 'universal' primer-set to improve the recovery of this genus and tested and validated its performance on a set of infant stools (Chapter 3 ).

In the research described in Chapter $\mathbf{4}$ we applied the 'bifidobacteria-optimized' 16S rRNA-gene sequencing method to analyse the gut microbiota of infants at high-risk of developing allergy, who participated in a clinical trial that investigated the effects of a partially hydrolysed protein formula supplemented with prebiotics on the 


\section{Chapter 1}

prevention of eczema. We investigated the effects of the nutritional intervention on the assembly of intestinal microbiome compared to infants receiving standard formula (without prebiotics) and the breastfed reference group. Additionally, in a nested case-control we investigated the association of microbiota with development of atopic dermatitis (AD).

When breastfeeding is not possible, infants suffering from CMA often require a hypoallergenic amino acid-based formula (AAF) to meet their nutritional needs and to quickly resolve allergic symptoms. In the clinical trial described in Chapter 5 we investigated the modulatory effects of an AAF supplemented with synbiotics on the gut microbiota in infants with suspected CMA with reference to healthy, breastfed infants.

In Chapter $\mathbf{6}$ we screened the intestinal microbiota of CMA-infants and healthy controls with reference to the observations done in the clinical trial described in Chapter 5. Next, we selected one representative donor per condition for faecal transfer to a murine model of CMA to investigate whether the alterations in gut microbiota composition contributed to the pathology of the disease.

Finally, the findings described in this thesis are summarized, discussed, and concluded in Chapter 7. 


\section{References}

1. Gest H. The discovery of microorganisms by Robert Hooke and Antoni Van Leeuwenhoek, fellows of the Royal Society. Notes Rec R Soc Lond. 2004;58(2):187-201.

2. Rajilic-Stojanovic M, de Vos WM. The first 1000 cultured species of the human gastrointestinal microbiota. FEMS Microbiol Rev. 2014;38(5):996-1047.

3. Hermes GD, Zoetendal EG, Smidt H. Molecular ecological tools to decipher the role of our microbial mass in obesity. Benef Microbes. 2015;6(1):61-81.

4. Marchesi JR, Ravel J. The vocabulary of microbiome research: a proposal. Microbiome. 2015;3(1):31.

5. Manrique P, Bolduc B, Walk ST, van der Oost J, de Vos WM, Young MJ. Healthy human gut phageome. Proc Natl Acad Sci U S A. 2016;113(37):10400-5.

6. Franzosa EA, Hsu T, Sirota-Madi A, Shafquat A, Abu-Ali G, Morgan XC, et al. Sequencing and beyond: integrating molecular 'omics' for microbial community profiling. Nat Rev Microbiol. 2015;13(6):360-72.

7. Bik EM. The Hoops, Hopes, and Hypes of Human Microbiome Research. Yale J Biol Med. 2016;89(3):363-73.

8. Costello EK, Lauber CL, Hamady M, Fierer N, Gordon JI, Knight R. Bacterial community variation in human body habitats across space and time. Science. 2009;326(5960):1694-7.

9. Gilbert JA, Blaser MJ, Caporaso JG, Jansson JK, Lynch SV, Knight R. Current understanding of the human microbiome. Nat Med. 2018;24(4):392-400.

10. Belzer C, de Vos WM. Microbes inside--from diversity to function: the case of Akkermansia. ISME J. 2012;6(8):1449-58.

11. Qin J, Li R, Raes J, Arumugam M, Burgdorf KS, Manichanh C, et al. A human gut microbial gene catalogue established by metagenomic sequencing. Nature. 2010;464(7285):59-65.

12. Turnbaugh PJ, Ley RE, Hamady M, Fraser-Liggett CM, Knight R, Gordon JI. The human microbiome project. Nature. 2007;449(7164):804-10.

13. Peterson J, Garges S, Giovanni M, Mclnnes P, Wang L, Schloss JA, et al. The NIH Human Microbiome Project. Genome Res. 2009;19(12):2317-23.

14. Li J, Jia H, Cai X, Zhong H, Feng Q, Sunagawa S, et al. An integrated catalog of reference genes in the human gut microbiome. Nat Biotechnol. 2014;32(8):834-41.

15. Helander HF, Fandriks L. Surface area of the digestive tract - revisited. Scand J Gastroenterol. 2014;49(6):681-9.

16. Cryan JF, Dinan TG. Mind-altering microorganisms: the impact of the gut microbiota on brain and behaviour. Nat Rev Neurosci. 2012;13(10):701-12.

17. Nicholson JK, Holmes E, Kinross J, Burcelin R, Gibson G, Jia W, et al. Host-gut microbiota metabolic interactions. Science. 2012;336(6086):1262-7.

18. Koh A, De Vadder F, Kovatcheva-Datchary P, Backhed F. From Dietary Fiber to Host Physiology: Short-Chain Fatty Acids as Key Bacterial Metabolites. Cell. 2016;165(6):1332-45.

19. Haiser HJ, Gootenberg DB, Chatman K, Sirasani G, Balskus EP, Turnbaugh PJ. Predicting and manipulating cardiac drug inactivation by the human gut bacterium Eggerthella lenta. Science. 2013;341(6143):295-8.

20. Kamada N, Chen GY, Inohara N, Nunez G. Control of pathogens and pathobionts by the gut microbiota. Nat Immunol. 2013;14(7):685-90. 


\section{Chapter 1}

21. Mason KL, Huffnagle GB, Noverr MC, Kao JY. Overview of gut immunology. Adv Exp Med Biol. 2008;635:1-14.

22. Peterson LW, Artis D. Intestinal epithelial cells: regulators of barrier function and immune homeostasis. Nat Rev Immunol. 2014;14(3):141-53.

23. Peterson CT, Sharma V, Elmen L, Peterson SN. Immune homeostasis, dysbiosis and therapeutic modulation of the gut microbiota. Clin Exp Immunol. 2015;179(3):363-77.

24. Mazmanian SK, Lee YK. Interplay between Intestinal Microbiota and Host Immune System. J Bacteriol Virol. 2014;44(1):1-9.

25. Tims S, Derom C, Jonkers DM, Vlietinck R, Saris WH, Kleerebezem M, et al. Microbiota conservation and BMI signatures in adult monozygotic twins. ISME J. 2013;7(4):707-17.

26. Le Chatelier E, Nielsen T, Qin J, Prifti E, Hildebrand F, Falony G, et al. Richness of human gut microbiome correlates with metabolic markers. Nature. 2013;500(7464):541-6.

27. Pedersen HK, Gudmundsdottir V, Nielsen HB, Hyotylainen T, Nielsen T, Jensen BA, et al. Human gut microbes impact host serum metabolome and insulin sensitivity. Nature. 2016;535(7612):376-81.

28. Halfvarson J, Brislawn CJ, Lamendella R, Vazquez-Baeza Y, Walters WA, Bramer LM, et al. Dynamics of the human gut microbiome in inflammatory bowel disease. Nat Microbiol. 2017;2:17004.

29. Fujimura KE, Sitarik AR, Havstad S, Lin DL, Levan S, Fadrosh D, et al. Neonatal gut microbiota associates with childhood multisensitized atopy and T cell differentiation. Nat Med. 2016;22(10):1187-91.

30. Kang DW, Adams JB, Gregory AC, Borody T, Chittick L, Fasano A, et al. Microbiota Transfer Therapy alters gut ecosystem and improves gastrointestinal and autism symptoms: an open-label study. Microbiome. 2017;5(1):10.

31. Lynch SV, Pedersen O. The Human Intestinal Microbiome in Health and Disease. N Engl J Med. 2016;375(24):2369-79.

32. Korpela K, Costea P, Coelho LP, Kandels-Lewis S, Willemsen G, Boomsma DI, et al. Selective maternal seeding and environment shape the human gut microbiome. Genome Res. 2018;28(4):561-8.

33. Aagaard K, Ma J, Antony KM, Ganu R, Petrosino J, Versalovic J. The placenta harbors a unique microbiome. Sci Transl Med. 2014;6(237):237ra65.

34. Perez-Munoz ME, Arrieta MC, Ramer-Tait AE, Walter J. A critical assessment of the "sterile womb" and "in utero colonization" hypotheses: implications for research on the pioneer infant microbiome. Microbiome. 2017;5(1):48.

35. Leiby JS, McCormick K, Sherrill-Mix S, Clarke EL, Kessler LR, Taylor LJ, et al. Lack of detection of a human placenta microbiome in samples from preterm and term deliveries. Microbiome. 2018;6(1):196.

36. Laursen MF, Bahl MI, Michaelsen KF, Licht TR. First Foods and Gut Microbes. Front Microbiol. $2017 ; 8: 356$.

37. Olin A, Henckel E, Chen Y, Lakshmikanth T, Pou C, Mikes J, et al. Stereotypic Immune System Development in Newborn Children. Cell. 2018;174(5):1277-92 e14.

38. Ferretti P, Pasolli E, Tett A, Asnicar F, Gorfer V, Fedi S, et al. Mother-to-Infant Microbial Transmission from Different Body Sites Shapes the Developing Infant Gut Microbiome. Cell Host Microbe. 2018;24(1):133-45 e5. 39. Makino H, Kushiro A, Ishikawa E, Muylaert D, Kubota H, Sakai T, et al. Transmission of intestinal Bifidobacterium longum subsp. longum strains from mother to infant, determined by multilocus sequencing typing and amplified fragment length polymorphism. Appl Environ Microbiol. 2011;77(19):6788-93. 
40. Makino H, Kushiro A, Ishikawa E, Kubota H, Gawad A, Sakai T, et al. Mother-to-infant transmission of intestinal bifidobacterial strains has an impact on the early development of vaginally delivered infant's microbiota. PLoS One. 2013;8(11):e78331.

41. Martin R, Makino H, Cetinyurek Yavuz A, Ben-Amor K, Roelofs M, Ishikawa E, et al. Early-Life Events, Including Mode of Delivery and Type of Feeding, Siblings and Gender, Shape the Developing Gut Microbiota. PLoS One. 2016;11(6):e0158498.

42. Nayfach S, Rodriguez-Mueller B, Garud N, Pollard KS. An integrated metagenomics pipeline for strain profiling reveals novel patterns of bacterial transmission and biogeography. Genome Res. 2016;26(11):1612-25.

43. Bergstrom A, Skov TH, Bahl MI, Roager HM, Christensen LB, Ejlerskov KT, et al. Establishment of intestinal microbiota during early life: a longitudinal, explorative study of a large cohort of Danish infants. Appl Environ Microbiol. 2014;80(9):2889-900.

44. Backhed F, Roswall J, Peng Y, Feng Q, Jia H, Kovatcheva-Datchary P, et al. Dynamics and Stabilization of the Human Gut Microbiome during the First Year of Life. Cell Host Microbe. 2015;17(5):690-703.

45. Stewart CJ, Ajami NJ, O'Brien JL, Hutchinson DS, Smith DP, Wong MC, et al. Temporal development of the gut microbiome in early childhood from the TEDDY study. Nature. 2018;562(7728):583-8.

46. Newburg DS, Morelli L. Human milk and infant intestinal mucosal glycans guide succession of the neonatal intestinal microbiota. Pediatr Res. 2015;77(1-2):115-20.

47. Marcobal A, Barboza M, Sonnenburg ED, Pudlo N, Martens EC, Desai P, et al. Bacteroides in the infant gut consume milk oligosaccharides via mucus-utilization pathways. Cell Host Microbe. 2011;10(5):507-14.

48. Makino H, Martin R, Ishikawa E, Gawad A, Kubota H, Sakai T, et al. Multilocus sequence typing of bifidobacterial strains from infant's faeces and human milk: are bifidobacteria being sustainably shared during breastfeeding? Benef Microbes. 2015;6(4):563-72.

49. Akdis CA, Agache I, Allergy EAo, Immunology C. Global Atlas of Allergy: European Academy of Allergy and Clinical Immunology; 2014.

50. Strachan DP. Hay fever, hygiene, and household size. BMJ. 1989;299(6710):1259-60.

51. Huang YJ, Marsland BJ, Bunyavanich S, O'Mahony L, Leung DY, Muraro A, et al. The microbiome in allergic disease: Current understanding and future opportunities-2017 PRACTALL document of the American Academy of Allergy, Asthma \& Immunology and the European Academy of Allergy and Clinical Immunology. J Allergy Clin Immunol. 2017;139(4):1099-110.

52. von Hertzen L, Beutler B, Bienenstock J, Blaser M, Cani PD, Eriksson J, et al. Helsinki alert of biodiversity and health. Ann Med. 2015;47(3):218-25.

53. Haahtela T, Holgate S, Pawankar R, Akdis CA, Benjaponpitak S, Caraballo L, et al. The biodiversity hypothesis and allergic disease: world allergy organization position statement. World Allergy Organ J. 2013;6(1):3. 54. Raciborski F, Tomaszewska A, Komorowski J, Samel-Kowalik P, Bialoszewski AZ, Walkiewicz A, et al. The relationship between antibiotic therapy in early childhood and the symptoms of allergy in children aged 6-8 years - the questionnaire study results. Int J Occup Med Environ Health. 2012;25(4):470-80.

55. Hirsch AG, Pollak J, Glass TA, Poulsen MN, Bailey-Davis L, Mowery J, et al. Early-life antibiotic use and subsequent diagnosis of food allergy and allergic diseases. Clin Exp Allergy. 2017;47(2):236-44.

56. Mitre E, Susi A, Kropp LE, Schwartz DJ, Gorman GH, Nylund CM. Association Between Use of Acid-Suppressive Medications and Antibiotics During Infancy and Allergic Diseases in Early Childhood. JAMA Pediatr. 2018;172(6):e180315. 


\section{Chapter 1}

57. Roduit C, Scholtens S, de Jongste JC, Wijga AH, Gerritsen J, Postma DS, et al. Asthma at 8 years of age in children born by caesarean section. Thorax. 2009;64(2):107-13.

58. Lee SY, Yu J, Ahn KM, Kim KW, Shin YH, Lee KS, et al. Additive effect between IL-13 polymorphism and cesarean section delivery/prenatal antibiotics use on atopic dermatitis: a birth cohort study (COCOA). PLoS One. 2014;9(5):e96603.

59. Watanabe JI, Tanaka K, Nagata C, Furukawa S, Arakawa M, Miyake Y. Breastfeeding duration is inversely associated with asthma in Japanese children aged 3 years. J Asthma. 2018;55(5):511-6.

60. van Ginkel CD, van der Meulen GN, Bak E, Flokstra-de Blok BMJ, Kollen BJ, Koppelman GH, et al. Retrospective observational cohort study regarding the effect of breastfeeding on challenge-proven food allergy. Eur J Clin Nutr. 2018;72(4):557-63.

61. Silvers KM, Frampton CM, Wickens K, Pattemore PK, Ingham T, Fishwick D, et al. Breastfeeding protects against current asthma up to 6 years of age. J Pediatr. 2012;160(6):991-6 e1.

62. Fujimura KE, Johnson CC, Ownby DR, Cox MJ, Brodie EL, Havstad SL, et al. Man's best friend? The effect of pet ownership on house dust microbial communities. J Allergy Clin Immunol. 2010;126(2):410-2, 2 e1-3.

63. Lynch SV, Wood RA, Boushey H, Bacharier LB, Bloomberg GR, Kattan M, et al. Effects of early-life exposure to allergens and bacteria on recurrent wheeze and atopy in urban children. J Allergy Clin Immunol. 2014;134(3):593-601 e12.

64. von Mutius E, Radon K. Living on a farm: impact on asthma induction and clinical course. Immunol Allergy Clin North Am. 2008;28(3):631-47, ix-x.

65. Blaser MJ. The theory of disappearing microbiota and the epidemics of chronic diseases. Nat Rev Immunol. 2017;17(8):461-3.

66. Sonnenburg ED, Smits SA, Tikhonov M, Higginbottom SK, Wingreen NS, Sonnenburg JL. Diet-induced extinctions in the gut microbiota compound over generations. Nature. 2016;529(7585):212-5.

67. Markevych I, Standl M, Lehmann I, von Berg A, Heinrich J. Food diversity during the first year of life and allergic diseases until 15 years. J Allergy Clin Immunol. 2017;140(6):1751-4 e4.

68. Muraro A, Halken S, Arshad SH, Beyer K, Dubois AE, Du Toit G, et al. EAACl food allergy and anaphylaxis guidelines. Primary prevention of food allergy. Allergy. 2014;69(5):590-601.

69. Fewtrell M, Bronsky J, Campoy C, Domellof M, Embleton N, Fidler Mis N, et al. Complementary Feeding: A Position Paper by the European Society for Paediatric Gastroenterology, Hepatology, and Nutrition (ESPGHAN) Committee on Nutrition. J Pediatr Gastroenterol Nutr. 2017;64(1):119-32.

70. Fleischer DM, Spergel JM, Assa'ad AH, Pongracic JA. Primary prevention of allergic disease through nutritional interventions. J Allergy Clin Immunol Pract. 2013;1(1):29-36.

71. Szajewska $\mathrm{H}$, Horvath A. A partially hydrolyzed $100 \%$ whey formula and the risk of eczema and any allergy: an updated meta-analysis. World Allergy Organ J. 2017;10(1):27.

72. Boyle RJ, lerodiakonou D, Khan T, Chivinge J, Robinson Z, Geoghegan N, et al. Hydrolysed formula and risk of allergic or autoimmune disease: systematic review and meta-analysis. BMJ. 2016;352:i974.

73. Gouw JW, Jo J, Meulenbroek L, Heijjer TS, Kremer E, Sandalova E, et al. Identification of peptides with tolerogenic potential in a hydrolysed whey-based infant formula. Clin Exp Allergy. 2018;0(ja).

74. Fiocchi A, Brozek J, Schunemann H, Bahna SL, von Berg A, Beyer K, et al. World Allergy Organization (WAO) Diagnosis and Rationale for Action against Cow's Milk Allergy (DRACMA) Guidelines. Pediatr Allergy Immunol. 2010;21 Suppl 21:1-125. 
75. Fiocchi A, Dahda L, Dupont C, Campoy C, Fierro V, Nieto A. Cow's milk allergy: towards an update of DRACMA guidelines. World Allergy Organ J. 2016;9(1):35.

76. Hill DJ, Murch SH, Rafferty K, Wallis P, Green CJ. The efficacy of amino acid-based formulas in relieving the symptoms of cow's milk allergy: a systematic review. Clin Exp Allergy. 2007;37(6):808-22.

77. Pandey KR, Naik SR, Vakil BV. Probiotics, prebiotics and synbiotics- a review. Journal of food science and technology. 2015;52(12):7577-87.

78. West CE, Dzidic M, Prescott SL, Jenmalm MC. Bugging allergy; role of pre-, pro- and synbiotics in allergy prevention. Allergol Int. 2017;66(4):529-38.

79. Anagnostou K, Stiefel G, Brough H, du Toit G, Lack G, Fox AT. Active management of food allergy: an emerging concept. Arch Dis Child. 2015;100(4):386-90.

80. FAO/WHO. Probiotics in food : health and nutritional properties and guidelines for evaluation. Rome :: Food and Agriculture Organization of the United Nations : World Health Organization, 2006.; 2001. viii, 50 p. : ill. ; $30 \mathrm{~cm} \mathrm{p}$.

81. Hill C, Guarner F, Reid G, Gibson GR, Merenstein DJ, Pot B, et al. Expert consensus document. The International Scientific Association for Probiotics and Prebiotics consensus statement on the scope and appropriate use of the term probiotic. Nat Rev Gastroenterol Hepatol. 2014;11(8):506-14.

82. Ceapa C, Wopereis H, Rezaiki L, Kleerebezem M, Knol J, Oozeer R. Influence of fermented milk products, prebiotics and probiotics on microbiota composition and health. Best Pract Res Clin Gastroenterol. 2013;27(1):139-55.

83. Everard A, Belzer C, Geurts L, Ouwerkerk JP, Druart C, Bindels LB, et al. Cross-talk between Akkermansia muciniphila and intestinal epithelium controls diet-induced obesity. Proc Natl Acad Sci U S A. 2013;110(22):9066-71.

84. Flint HJ, Scott KP, Louis $\mathrm{P}$, Duncan SH. The role of the gut microbiota in nutrition and health. Nat Rev Gastroenterol Hepatol. 2012;9(10):577-89.

85. Gibson GR, Roberfroid MB. Dietary modulation of the human colonic microbiota: introducing the concept of prebiotics. J Nutr. 1995;125(6):1401-12.

86. Gibson GR, Hutkins R, Sanders ME, Prescott SL, Reimer RA, Salminen SJ, et al. Expert consensus document: The International Scientific Association for Probiotics and Prebiotics (ISAPP) consensus statement on the definition and scope of prebiotics. Nat Rev Gastroenterol Hepatol. 2017;14(8):491-502.

87. Oozeer R, van Limpt K, Ludwig T, Ben Amor K, Martin R, Wind RD, et al. Intestinal microbiology in early life: specific prebiotics can have similar functionalities as human-milk oligosaccharides. Am J Clin Nutr. 2013;98(2):561S-71S.

88. Cuello-Garcia CA, Fiocchi A, Pawankar R, Yepes-Nunez JJ, Morgano GP, Zhang Y, et al. World Allergy Organization-McMaster University Guidelines for Allergic Disease Prevention (GLAD-P): Prebiotics. World Allergy Organ J. 2016;9(1):10.

89. Fiocchi A, Pawankar R, Cuello-Garcia C, Ahn K, Al-Hammadi S, Agarwal A, et al. World Allergy Organization-McMaster University Guidelines for Allergic Disease Prevention (GLAD-P): Probiotics. World Allergy Organ J. 2015;8(1):4.

90. Chang YS, Trivedi MK, Jha A, Lin YF, Dimaano L, Garcia-Romero MT. Synbiotics for Prevention and Treatment of Atopic Dermatitis: A Meta-analysis of Randomized Clinical Trials. JAMA Pediatr. 2016;170(3):236-42. 



\section{CHAPTER 2}

\section{The first thousand days - intestinal microbiology of early life: establishing a symbiosis}

Wopereis $\mathrm{H}^{1,2}$, Oozeer $\mathrm{R}^{1}$, Knipping $\mathrm{K}^{1}$, Belzer $\mathrm{C}^{2}$, Knol $\mathrm{J}^{1,2}$. 


\section{Abstract}

The development of the intestinal microbiota in the first years of life is a dynamic process significantly influenced by early life nutrition. Pioneer bacteria colonising the infant intestinal tract and the gradual diversification to a stable climax ecosystem play a crucial role in establishing host-microbe interactions essential for optimal symbiosis. This colonisation process and establishment of symbiosis may profoundly influence health throughout life. Recent developments in microbiological cultivation-independent methods allow a detailed view of the key players and factors involved in this process and may further elucidate their roles in a healthy gut and immune maturation. Aberrant patterns may lead to identifying key microbial signatures involved in developing immunological diseases into adulthood, such as asthma and atopic diseases. The central role of early life nutrition in the developmental human microbiota, immunity and metabolism offers promising strategies for prevention and treatment of such diseases.

This review provides an overview of the development of the intestinal microbiota, its bidirectional relationship with the immune system, and its role in impacting health and disease, with emphasis on allergy, in early life. 


\section{Our microbial world}

We live in a microbial world. Micro-organisms were amongst the very first life forms and still today form the greatest biomass on this planet (1). They hardly exist as single cells in nature, but rather live in complex communities coevolved and adapted to the habitats they colonise. Surveys of these complex communities are taking great advantage from the use of high-resolution cultivation-independent methods such as phylogenetic microarrays or next generation sequencing (2). Especially the study of human intestinal microbial species of which approximately $70 \%$ have not been isolated, cultivated or sequenced, due to the inability to reproduce necessary growth conditions in the lab. Sequencing of PCR amplified 16S ribosomal RNA (16S rRNA), a conserved gene routinely used for phylogenetic identification of bacteria, and whole genome surveys (metagenomic sequencing) are now starting to reveal the true microbial diversity of the human intestine and their role in health and disease. The human intestinal tract is colonised with about ten times more microbial cells than human body cells and contain about 150 times more microbial genes than the human genome (2). The intestinal microbiota is coexisting in a homeostatic relationship with the host (3). This host-microbial relationship is maintained in a bidirectional manner with the immune system. The intestinal microbiota benefits from a stable environment and nutrient supply that are provided in the intestinal tract, while the host gains products from microbial fermentation conversion of host indigestible components (dietary fibres) into short-chain fatty acids (SCFA; mainly acetate, propionate and butyrate) contributing to an estimated $10 \%$ of our energy requirement (4), vitamin $\mathrm{K}$ and B12 production $(5,6)$, and protection against potential pathogens through competitive exclusion $(7,8)$. The importance of the human microbiota is particularly clear as alterations of the intestinal microbiota have been associated with short and long-term health and disease issues, such as intestinal bowel disease (IBD), allergy, diabetes, obesity and autism (9).

The development of the intestinal microbiota is a dynamic process in the first years of life (10-12), a time frame that is also a critical period of gut and immune development and maturation (13). Indeed, the pioneer bacteria colonising the infant intestinal tract and the gradual diversification to a stable climax ecosystem play a 
crucial role in establishing host-microbe interactions essential for optimal symbiosis; and this colonisation process may profoundly influence health throughout life (8). Future research should focus on the analyses of longitudinal data that may identify the patterns of early intestinal microbiota and functionality of not yet-cultivated species that could affect health later in life (14).

\section{Microbial pioneers}

Theodor Escherich (1857-1911) pioneered the study of intestinal microbiology in early life (15). In 1886, Escherich published his 177-page postdoctoral thesis entitled, "The Intestinal Bacteria of the Infant and Their Relation to the Physiology of Digestion" (16). Escherich demonstrated that meconium was sterile, and that bacterial intestinal colonisation is attributable to the infants' environment and emphasized the value of breastfeeding herein.

The rise of molecular biology in the second half of the twentieth century and the more recent revolution in sequencing technologies identified the key players of the developmental intestinal microbiota in more detail. The majority is assigned to 4 phyla, namely the Actinobacteria (with genera like Bifidobacterium and Colinsella), the Bacteroidetes (with genera like Bacteroides and Prevotella), the Firmicutes (with genera like Lactobacillus, Clostridium, Eubacterium and Ruminococcus) and the Proteobacteria (e.g. Enterobacter spp.) (17). Another phylum identified throughout life is the Verrucomicrobia consisting of one major species, the mucin-degrading Akkermansia muciniphila (7).

The composition of the microbiota changes substantially at two stages in early life: from birth to weaning, and from weaning to adulthood driven by further diversification of diet (4). The pioneer species in neonates are facultative anaerobic bacteria, like Staphylococcus, Streptococcus, Enterococcus and Enterobacter spp., these bacteria create an anaerobic environment that promote the growth of obligate anaerobes, such as Bifidobacterium, Bacteroides, Clostridium and Eubacterium spp., predominating after one or two weeks. Escherich's observation of sterile meconium and thus supposed sterile intestine at birth has only recently been opposed with molecular surveys suggesting that microbial exposure may start before birth and that 
infants may already receive microorganisms from the mother during gestation (18, 19). Right after birth the early settlers are derived from the maternal microbiota (vaginal, faecal, human milk, mouth, skin) and the environment (20-22). Human milk forms an important continuous inoculum, while bacterial strains found in breast milk have also been detected in faecal samples from the corresponding infants $(21,23)$. These bacteria are postulated to translocate from the mothers' intestine to the mammary gland via the mesenteric lymph nodes, suggesting a possible route of inducing immunological tolerance to these commensals (24). Another possible or contributing route may include the establishment of the mothers' skin microbiota and infants' oral microbiota into the mammary gland (25). Host genotype, gestational age, medical practices (i.e., antibiotic use), mode of delivery (caesarean section vs. vaginal delivery), geographical origin and linked to that, cultural traditions, especially regarding diet, are factors profoundly influencing the microbiota development $(26,27)$. Breastfed infants typically have a microbiota dominated by bifidobacteria, while formula-fed infants have a more diverse microbiota. Infants born preterm or by caesarean section show a reduced diversity and a delayed colonisation by bifidobacteria compared to infants born at term or vaginally $(26,28)$. Some studies applying PCR amplification and sequencing did not reproduce the early predominance of Bifidobacterium (12), however efficient DNA extraction and careful selection of PCR primers have proven to be critical to effectively detect this genus (29).

Introduction of first solid foods around 4 to 6 months of age impacts the infant microbiota considerably. Although still "infant-like", with decreased but still dominating levels of bifidobacteria, a gradual diversification is seen towards more adult-type species, mainly Bacteroides spp. and Clostridium clusters IV and XIV, the latter two clusters known to contain numerous butyrate producers $(10,30)$. Interestingly the factors influencing the early colonisation process strongly influence the post-weaning colonisation pattern. Early diversification, as observed under formula-feeding not containing prebiotics, promotes earlier acquisition of an adult-type microbiota $(10,30)$. Further diversification of diet gradually increases diversity and abundance of Bacteroidetes and Firmicutes towards adult levels and generally low abundant levels 
of Bifidobacterium (27). Healthy adults have a stable microbiota; unique for individuals though sharing a core microbiome with other individuals, which may change and destabilise only at older age again $(4,31)$. Although low abundant in adults, Bifidobacterium species still play important metabolic roles in adults (32). On top of this ageing is generally associated with a significant decrease of bifidobacteria, along with other rearrangements and decreasing stability, all together associated with increased susceptibility to infections in elderly (31). The exact age at which a stable adult community is established is unclear but is thought to be reached around 3 years of age $(11,27)$. Changes in the genetic capacity of the microbiome with human development include changes in the abundance of genes involved in access to host-derived glycans (in human milk and intestinal mucosa) and vitamin biosynthesis, i.e. infants having more genes that encode enzymes involved in folate biosynthesis and adults more encoding for vitamin B12 (27). The influence of early colonisation patterns on the composition of the adult microbiome is not yet fully understood. However these patterns have been shown to influence gut maturation, immune development and host metabolism (8), and differences in composition driven by environmental factors in infancy may affect susceptibility to metabolic (e.g. obesity), immunological (e.g. IBD and allergy) and even behavioural (e.g. autism) disorders into adulthood (Figure 1), diseases which are increasingly prevalent in developed countries (9). The central role of diet in influencing the human microbiota, immunity and metabolism offers promising strategies for prevention and treatment of such diseases.

\section{Establishing a healthy symbiosis}

Neonates have a limited capacity to initiate immune responses and both innate and adaptive immune responses are not yet fully functional. In the months and years after birth the immune system gradually matures (8), concurrent with the infants' microbiota development. The largest immune component in the body, the mucosal immune system, comprised of the gut-associated lymphoid tissue (GALT); the mucosal lamina propria; and the mucosal surface, have a central role in this developmental process. 


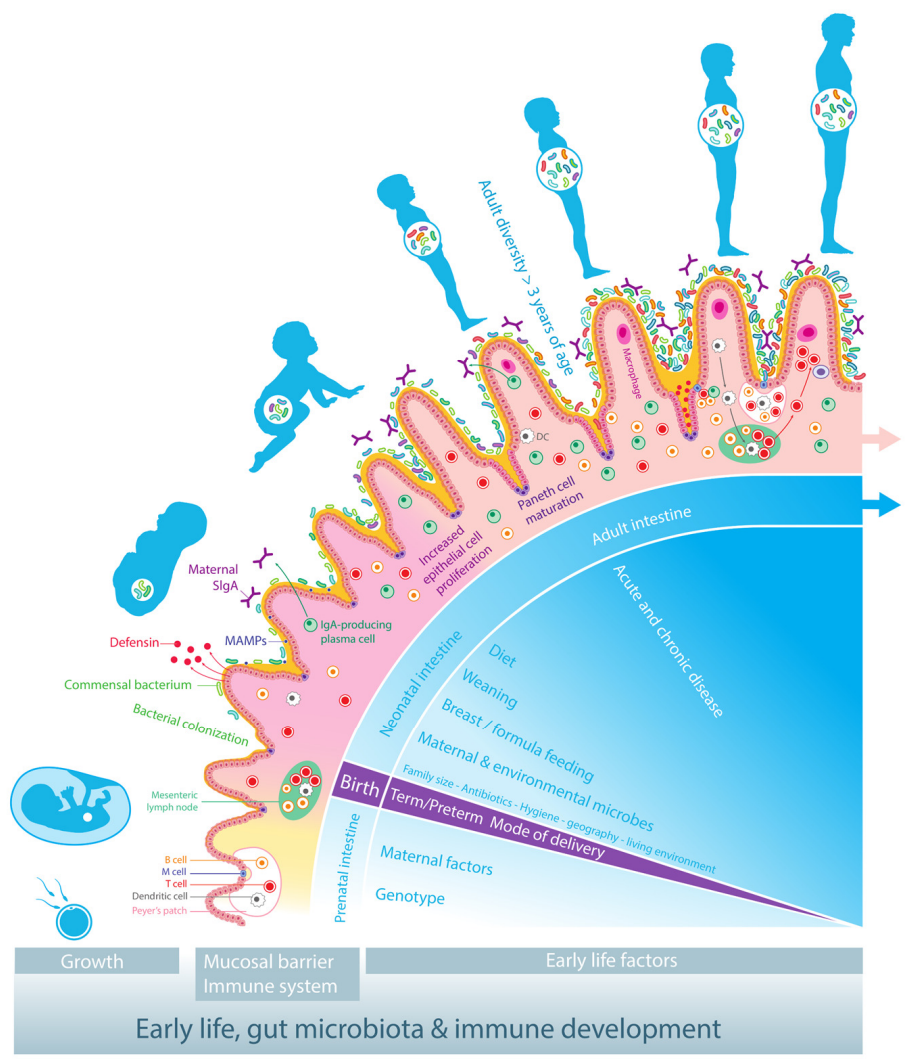

Figure 1: Early life, gut microbiota and immune development - establishing a symbiosis. The establishment of the intestinal host-microbiota symbiosis is driven by both developmental and environmental signals especially in early life, profoundly influencing health throughout life. The prenatal intestine is thought to be sterile and development depends most importantly on genotype as well as on maternal factors, including nutrition and health status. The cryptopatches and lymphoid tissues (mesenteric lymph nodes and Peyer's patches) with dendritic, T and B cells develop in preparation of the exposure to the extra-uterine world. During birth infants are inoculated with maternal and environmental microbes, and the type and patterns strongly depend on birth mode and gestational age. The gut microbial development in the neonatal period is influenced by several early life factors and especially diet (type, composition and timing) drives the further diversification towards an adult complexity, which is reached around 3 years of age. This postnatal colonization process provides several signals, known as microbe-associated molecular patterns (MAMPs), affecting the maturation of the immune system and the mucosal barrier, accompanied with increased mucus secretion. These signals also result in the proliferation of intestinal epithelial cells in crypts and the crypt-located Paneth cells, resulting in their increased depth and the production of antimicrobial peptides (defensins), respectively. Specialized epithelial cells ( $M$ cells), reside above Peyer's patches and facilitate direct interaction of the luminal content with the underlying lymphoid cells to stimulate mucosal immunity. SIgA is the most abundant immunoglobulin on mucosal surfaces and maternal SIgA is provided by human milk during the early postnatal period along with the initiation of the infants own SIgA. 
The mucosal immune system is providing protection from the external environment and directly interacts with the environmental antigens and commensal bacteria (13). The epithelial layer in neonates shows a higher permeability in both the respiratory and gastrointestinal tracts and secretion of proteases and antimicrobial peptides have not fully developed (33). The epithelial production of mucus forms an important first line of defence against microbes. The thickness and continuity of the intestinal mucus layer increases from the small intestine towards the colon correlating with increasing bacterial loads (13). Mucin glycans are nutrients for some constituents of the microbiota, such as Bifidobacterium, Bacteroides spp. and Akkermansia muciniphila, giving them an ecologically advantage to reside in the outer mucous layer close to the intestinal epithelial cells (IECs) (34). Niche occupation by such commensals is not only establishing a physical barrier excluding potential pathogens, also the production of acetate and lactate form an effective chemical barrier toxic for potential pathogens $(35,36)$. Levels of faecal SCFA of human milk fed infants are characterized by relatively higher proportions of acetate and lower proportions of propionate and almost complete absence of butyrate, when compared to adults. Also, lactate is more commonly detected in the faeces of infants, while undetected in healthy adults due to immediate onward conversion by lactate-utilizing bacteria. These elevated levels of acetate and lactate in human milk fed infants are reflecting the dominance of bifidobacteria and lactobacilli (37). Although faecal levels of butyrate are generally low in human milk fed infants, acetate and lactate may in turn be used to gradually establish butyrate producers within the Firmicutes $(4,38)$, which have recently been shown to be less abundant in colicky infants at 2 weeks of age at the expense of increased levels of potential pathogenic members of the Proteobacteria (39). Many of the direct effects of SCFA on epithelial cells associated with maintenance of the epithelium relate mostly to their role as an energy source and their inhibition of histone deacetylases, the latter is directly impacting human gene expression and e.g. shown to downregulate inflammation in patients with ulcerative colitis (40). The SCFA have also been shown to influence immune function beyond the gut by signalling through G-protein-coupled receptors (GPR) on IECs. Mice deficient of GPR43 have 
exacerbated and poorly resolving inflammation in inflammatory models of arthritis, allergic airway inflammation and colitis (41).

An important extra layer of innate mucosal defence in neonates is derived from human milk. In addition to a unique mix of human milk oligosaccharides (HMO), and antimicrobial proteins that influence the ecology of the neonatal microbiota, human milk provides abundant secretory immunoglobulin $A(\operatorname{sg} A)$, the specificities of which have been shaped by the maternal digestive system and microbiota (13). SlgA is the most abundant immunoglobulin on mucosal surfaces, where it neutralizes harmless food and microbial antigens and prevents them from penetrating the epithelium. However IgA can also function in high-affinity modes for neutralization of toxins and pathogenic microbes, and as a low-affinity system to contain the dense commensal microbiota within the intestinal lumen (42). Next to slgA, also maternal IgG-antigen complexes play a major role in shaping the infants' immune system. Antigen bound to IgG will be very efficiently transferred across the gut barrier using the neonatal Fc receptor (43). Therefore, both maternal slgA and IgG may be important in the development of non-responsiveness to harmless commensals and food antigens, i.e. induction of oral tolerance (44). The developmental microbiota is essential for the initiation of an infants' own slgA while germ-free mice show drastically reduced mucosal IgA-secreting cells. Studies using prebiotics or synbiotics (combination of pre- and probiotics) treatment given for 6 months to infants showed increased levels of faecal sigA $(45,46)$ and is linked to reduced risk of allergy before 2 years of age in one of these studies (46).

More evidence is mounting in how commensal bacteria directly influence adaptive immunity and oral tolerance and is focusing on the mechanisms involved in the cross-talk between the intestinal microbiota and the host. This cross-talk is mediated through pattern-recognition receptors (PRRs), such as toll-like receptors (TLRs), specifically recognising conserved microbial molecular structures, called microbe-associated molecular patterns (MAMPs) (8). Recognition of these patterns may promote pro-inflammatory responses or repress them and seem to depend on by whom (i) and where (ii) they are triggered (13). First (i), subtle differences between commensal bacteria, probiotic and pathogenic microorganisms may mediate different 
host responses (47) and second (ii), apical signalling normally promotes intestinal homeostasis, however basolateral signalling, implicating intestinal barrier disruption and infection, initiates inflammatory responses of innate and adaptive immune cells (13) and can lead to exacerbate intestinal inflammation (48). Pro-inflammatory responses are counterbalanced by specialized $\mathrm{T}$ cells known as regulatory $\mathrm{T}$ (Treg) cells and play a crucial role in maintaining immune homeostasis. Treg cells are characterized by production of IL-10, one of the main immunoregulatory cytokines required for immune tolerance of the intestinal microbiota (13). The role of TLR in sensing the microbiota in this process is evident by the absence of colonic inflammatory disease in germ-free IL-10-deficient mice and mice deficient for both IL-10 and myeloid differentiation factor 88 (MyD88). Remarkably IL-10-producing T cells can be induced to develop in response to specific commensals or their products. This was first shown for a common commensal, Bacteroides fragilis through its polysaccharide A (PSA) mediating through the TLR2-MyD88 pathway (49). More human symbionts are thought to exert comparable mechanisms to induce mucosal tolerance, i.e. a probiotic Bifidobacterium breve, but not a Lactobacillus casei strain, induced development of IL-10-producing Treg cells and were shown to prevent inflammation in a colitis model (50).

In these and other studies, MyD88-dependent TLR signalling has proven to be a key mediator for maintenance of intestinal homeostasis, requiring active communication among epithelial cells, immune cells, and the intestinal microbiota (48). Hill et al. (51) showed that antibiotic-mediated disruption of the microbiota is sufficient to predispose mice to allergic disease. The authors showed that the commensal microbiota modulates B-cell production of $\lg \mathrm{E}$ antibody in a MyD88-dependent manner and that perturbation leads to high circulating levels of basophils and high serum IgE concentration. Exposure of antibiotic-treated mice with DNA motifs specific for bacteria (unmethylated cytosine-guanosine CpG oligonucleotides), a known Toll-like receptor 9 (TLR9)-dependent microbial ligand, was sufficient to reduce serum $\lg \mathrm{E}$ as well as the frequency and total number of circulating basophils. These findings identify intriguing links between the adaptive 
immune system interacting with the intestinal microbiota and will further elucidate the specific microbes involved in promoting a healthy host-microbiota symbiosis.

\section{Early microbiota and allergy}

The prevalence of atopic manifestations (atopic dermatitis, food allergy, allergic rhinitis and asthma) has been increasing worldwide, predominantly in the western world and particularly among children (52). Expression of an allergic phenotype is dependent on the interaction between 2 major factors: a genetic predisposition and gene-environment interactions (e.g. lifestyle, diet). Infants suffering from atopic dermatitis and or food allergy are more susceptible to develop other allergies like allergic asthma later in life, a process known as the atopic march (53). There is mounting evidence that modifications in the pattern of microbial exposure early in life represents a critical factor underlying the development of an allergic phenotype (54-57), such as the protective effects observed for exposure to siblings or a farming environment $(58,59)$. Accumulating preclinical studies start to reveal pathways linking aberrant microbial patterns to atopic diseases $(51,60)$. The classical explanation for the increasing prevalence of allergies in western countries, and a possible role of "early" microbes, was postulated in the hygiene hypothesis in 1989 (61). This hypothesis focuses merely on decreased exposure to infectious agents under improved hygiene standards to explain the hypersensitive reaction of the immune system towards normally harmless substances in the environment. The supposed mechanism proposes a lack of shifting of allergen-specific responses from the $T$ Helper 2 to the T Helper 1 phenotype, because of reduced exposure to infectious agents in early childhood (62). More recently the possible implication of the resident human intestinal microbiota in developing allergy has been suggested to play a crucial role in the development of mucosal immunologic tolerance. The discovery of Treg cells and their role in immune suppression and self-tolerance (63), lead to an important explanatory mechanism of reduced activity of Treg to a loss of microbial symbionts, which may partly explain the increasing prevalence of other western diseases, like IBD, obesity and diabetes $(9,62)$. The role of the endogenous microbiota in developing allergy under this extended hygiene hypothesis is supported 
by the positive correlation of environmental factors, known to impact microbial colonisation, and allergic manifestations (i.e. antibiotic use and caesarean section), correlations with an altered microbiota composition and increasing evidence of successful prevention or reduction of allergy through microbiota modulating diets (52). Altered microbial composition and activity between healthy and atopic children have been shown in several cross-sectional epidemiologic studies and have been extensively reviewed up to January 2007 by Penders et al. (64). Table 1 gives an overview of observational studies summarised in a similar approach, from 2007 onwards, considering type of atopic disease under study, the study population, design and methodology to examine the intestinal microbiota. Interestingly, differences in the intestinal microbiota composition often precede the manifestation of atopic symptoms and atopic sensitization (65-69), although two studies reported no meaningful differences between groups $(70,71)$, possibly explained, as the authors suggest, by the application of cultivation methods overlooking the unculturable bacteria. Reduced bacterial diversity in the early microbiome has been associated with developing atopic disease by several comparative studies $(54,65,66,72,73)$. Abrahamsson et al., applying 16S rRNA sequencing, linked reduced bacterial diversity at 1 month to $\operatorname{lgE}$-associated eczema in infants at 2 years of age, which was subsequently confined to developing asthma at 7 years of age (74), supporting the importance of pioneer microbes in early immune maturation. This early reduced diversity was mainly attributed to a decreased diversity of Bacteroides spp. within the Bacteroidetes phylum. At 12 months of age a decreased diversity of Proteobacteria was observed and a tendency of higher levels of the phylum Firmicutes in atopic infants, a phylum indicating development towards a more "adult-type" microbiota. Nylund et al., applying a phylogenetic microarray, reported increased diversity at 18 months of age, but not at 6 months, in eczematous versus healthy infants. This increased diversity at 18 months of age was associated with higher abundances of Clostridium clusters IV and XIVa, members of the Firmicutes phylum. At this age healthy infants showed increased abundance of members within Bacteroidetes (56), a group of bacteria which may have been underestimated in early life, due to molecular bias (75). Notably species within the Bacteroidetes have been shown, next to Bifidobacterium spp., to be 
efficient fermenters of human milk oligosaccharides in contrast to species within the Firmicutes phylum (76). Interestingly a recent study showed that colonisation of germ-free mice with the faecal microbiota of a healthy infant rich in Bifidobacterium spp. and Bacteroides spp. protected against the development of cow's milk allergy following sensitization to $\beta$-lactoglobulin (77). The genera within the phyla Bacteroidetes and Firmicutes linked to allergy in both observational studies, may thus play important roles in the gradual succession of an infant-type microbiota, dominated by bifidobacteria, towards a stable adult-type microbiota.

The observations of both decreased and increased bacterial diversity linked to allergic manifestations may seem contradictory but were made at different stages of early life and development of allergic disease. Bacterial diversity as such is difficult to interpret in early childhood, while the early microbiota is highly dynamic with high inter-individual variation. Also, bacterial diversity gradually increases towards adulthood reaching adult levels no earlier than around 3 years of age $(11,27)$. There is an ongoing debate whether low total diversity of the gut microbiota in early childhood is more important than the altered prevalence of particular bacterial species in allergy development (78), but more likely the combination of both may lead to identifying the key microbial signatures for developing allergy and response to nutritional strategies.

\section{Early microbiota and nutrition}

The initial bacterial colonisers of our gastrointestinal tract may determine the composition of our intestinal microbiota throughout life. Furthermore, this early development occurs concomitantly to the development of our metabolism, cognitive and immune systems, which have been described to be closely linked to the intestinal microbiota. Knowing that the microbiota can significantly interfere with the human metabolic, cognitive, and immune systems, the initiation of symbiosis seems a crucial step for preparing optimal health later in life. Consequently, understanding the early interaction between the intestinal microbiota and the human body opens new avenues for important nutritional innovations, particularly for infants and young children. 


\section{Chapter 2}

Table 1: Human observational studies on the association between the gut microbiota composition and atopic diseases. Studies applying next generation sequencing or microarray technologies as microbial analysis tool are indicated in bold.

\begin{tabular}{|c|c|c|c|}
\hline Allergic phenotype & Study design (country) & Tool & Allergic vs non-allergic (ref) \\
\hline $\begin{array}{l}\text { Ecz (Williams' criteria) } \\
\text { and/or slgE+ until } 18 \mathrm{~m}\end{array}$ & $\begin{array}{l}\text { PC: } 324 \text { infants at risk for } \\
\text { allergy (SE, UK and IT) }\end{array}$ & Cultivation & No differences observed (70) \\
\hline $\begin{array}{l}\text { Allergic manifestations } \\
\text { (ISAAC questionnaire) } \\
\text { until } 2 y\end{array}$ & PC: 15 infants (JP) & qPCR & $\begin{array}{l}\text { Increased abundance of Bacteroidaceae at } \\
\text { the ages of } 1 \text { and } 2 \mathrm{~m} \text { of age }(67)\end{array}$ \\
\hline $\begin{array}{l}\text { Any allergic } \\
\text { manifestation or SPT+ } \\
\text { until } 6 \mathrm{~m}\end{array}$ & $\begin{array}{l}\text { CC: } 10 \text { allergic and } 16 \\
\text { non-allergic infants (JP) }\end{array}$ & PCR & $\begin{array}{l}\text { Higher prevalence of Bifidobacterium } \\
\text { catenulatum group at } 1 \mathrm{~m} \text { and higher } \\
\text { prevalence of } B \text {. bifidum at } 6 \mathrm{~m} \text { of age (79) }\end{array}$ \\
\hline Ecz (PD) until $6 m$ & $\begin{array}{c}\text { CC: } 9 \text { allergic and } 12 \\
\text { non-allergic infants (USA) }\end{array}$ & DGGE & Lower diversity at 1 and $4 \mathrm{~m}$ of age (73) \\
\hline Ecz (PD) until $6 m$ & $\begin{array}{c}\text { CC: } 37 \text { allergic and } 24 \\
\text { non-allergic infants (NZ) }\end{array}$ & $\begin{array}{l}\text { TTGE, } \\
\text { FISH }\end{array}$ & $\begin{array}{c}\text { Higher prevalence of Bifidobacterium } \\
\text { pseudocatenulatum (80) }\end{array}$ \\
\hline $\begin{array}{l}\text { API: wheezing }+ \text { Ecz } \\
\text { /wheezing }+ \text { allergic } \\
\text { heredity until 3y }\end{array}$ & PC: 117 infants $(B)$ & Cultivation & $\begin{array}{c}\text { Higher prevalence of Bacteroide fragilis at } 3 w \\
\text { of age }(81)\end{array}$ \\
\hline $\begin{array}{l}\text { Ecz (Williams' criteria) } \\
\text { and/or slgE+ until } 18 \mathrm{~m}\end{array}$ & $\begin{array}{c}\text { CC: } 15 \text { allergic and } 20 \\
\text { non-allergic infants (SE, } \\
\text { UK, IT) }\end{array}$ & $\begin{array}{l}\text { T-RFLP, } \\
\text { TTGE, } \\
\text { qPCR }\end{array}$ & $\begin{array}{l}\text { Lower diversity at } 1 \mathrm{w} \text { of age (72), same cohort } \\
\qquad \text { as (70) }\end{array}$ \\
\hline $\begin{array}{l}\text { Allergic manifestations } \\
\text { and at least } 1 \text { SPT+ } \\
\text { until } 5 y\end{array}$ & $\begin{array}{l}\text { CC: } 16 \text { allergic and } 31 \\
\text { non-allergic infants (SE) }\end{array}$ & qPCR & $\begin{array}{l}\text { Lower prevalence of Lactobacilli, } \\
\text { Bifidobacterium adolescentis and Clostridium } \\
\text { difficile during first } 2 \mathrm{~m} \text { of life (82) }\end{array}$ \\
\hline Ecz (PD) until 2y & $\begin{array}{l}\text { CC: } 3 \text { allergic and } 5 \\
\text { non-allergic, C-section } \\
\text { (USA) }\end{array}$ & $\begin{array}{l}\text { 16S rRNA } \\
\text { seq }\end{array}$ & $\begin{array}{l}\text { Lower abundance of Bifidobacterium, higher } \\
\text { abundance of Enterococcus, Klebsiella and } \\
\text { Shigella in } 1^{\text {st }} y \text { of life }(83)\end{array}$ \\
\hline $\begin{array}{l}\text { Allergic manifestations } \\
\qquad \text { (PD) until 1y }\end{array}$ & $\begin{array}{l}\text { CC: } 24 \text { allergic and } 72 \\
\text { non-allergic, VLBW (NL) }\end{array}$ & $\mathrm{FISH}$ & $\begin{array}{l}\text { Lower prevalence of Bifidobacterium at 1y of } \\
\text { age (84) }\end{array}$ \\
\hline $\begin{array}{l}\text { SPT+ and slgE+ } \\
\text { and/or allergic } \\
\text { manifestations (PD) } \\
\text { until } 6 y\end{array}$ & $\begin{array}{l}\text { PC: } 411 \text { infants with } \\
\text { maternal history of } \\
\text { asthma (DK) }\end{array}$ & $\begin{array}{l}\text { Cultivation } \\
\text { DGGE }\end{array}$ & $\begin{array}{l}\text { Low diversity at } 1 \text { and } 12 \mathrm{~m} \text { with } \mathrm{SPT}+/ \mathrm{slgE}+ \\
\text { and allergic rhinitis, but not with asthma or } \mathrm{AD} \\
(65)\end{array}$ \\
\hline $\begin{array}{l}\text { Allergic manifestations } \\
\text { and SPT+ and/or } \\
\text { slgE+ until } 5 y\end{array}$ & $\begin{array}{l}\text { CC: } 16 \text { allergic and } 19 \\
\text { non-allergic infants (SE) }\end{array}$ & qPCR & $\begin{array}{c}\text { Lower prevalence of lactobacilli (L.casei, } L \text {. } \\
\text { paracasei, L. rhamnosus) in } 1^{\text {st }} 2 \mathrm{~m} \text {, lower } \\
\text { prevalence of Bifidobacterium bifidum in } 1^{\text {st }} \mathrm{w} \\
\text { of life (55) }\end{array}$ \\
\hline $\begin{array}{l}\text { Allergic manifestations } \\
\text { (ISAAC questionnaire) } \\
\text { until } 2 y\end{array}$ & $\begin{array}{l}\text { CC: } 11 \text { allergic and } 11 \\
\text { non-allergic infants (JP) }\end{array}$ & $\begin{array}{l}\text { 16S rRNA } \\
\text { seq. }\end{array}$ & $\begin{array}{c}\text { Higher abundance of Bacteroides, lower } \\
\text { abundance of Clostridium and Proteobacteria } \\
\text { (other than Klebsiella) at } 1 \mathrm{~m} \text { and higher } \\
\text { abundance of Klebsiella at } 1 \text { and } 2 \mathrm{~m}(85) \text {. } \\
\text { Same cohort as (67) }\end{array}$ \\
\hline
\end{tabular}


Table 1 (continued)

\begin{tabular}{|c|c|c|c|}
\hline Allergic phenotype & Study design (country) & Tool & Allergic vs non-allergic (ref) \\
\hline $\begin{array}{l}\text { CMPA with SPT+, } \\
\text { slgE+ and DBPCFC+ } \\
\text { for cow's milk, age } 2 \\
\text { to } 12 \mathrm{~m}\end{array}$ & $\begin{array}{c}\text { CC: } 46 \text { allergic and } 46 \\
\text { non-allergic }(\mathrm{SP})\end{array}$ & FISH & $\begin{array}{c}\text { Increased abundance of Clostridium } \\
\text { coccoides group and Atopobium cluster, } \\
\text { increased concentrations of butyric acid and } \\
\text { branched-chain SCFA ( } 86)\end{array}$ \\
\hline $\begin{array}{l}\mathrm{API} \text { : wheezing }+\mathrm{Ecz} \\
\text { /wheezing and allergic } \\
\text { heredity until } 3 \mathrm{y}\end{array}$ & PC: 110 infants $(B)$ & DGGE & $\begin{array}{c}\text { Association of Clostridum coccoides XIVa } \\
\text { species and Bacteroides fragilis species at 3w } \\
\text { (68). Same cohort as (81) }\end{array}$ \\
\hline $\begin{array}{l}\text { SPT+ and/or positive } \\
\text { atopic patch test } \\
\text { and/or } \\
\text { radioallergosorbent } \\
\text { test, age from } 6-24 \mathrm{~m}\end{array}$ & $\begin{array}{c}\text { CC: } 10 \text { allergic and } 20 \\
\text { non-allergic infants (FR) }\end{array}$ & $\begin{array}{l}\text { Cultivation } \\
\text { TTGE } \\
\text { BOX-PCR }\end{array}$ & $\begin{array}{c}\text { No differences observed in bacterial groups } \\
\text { cultivated nor in the bifidobacterial-specific } \\
\text { fingerprinting (71) }\end{array}$ \\
\hline $\begin{array}{l}\text { Ecz with SPT+ and/or } \\
\text { slgE+ until } 2 y\end{array}$ & $\begin{array}{l}\text { CC: } 20 \text { allergic and } 20 \\
\text { non-allergic infants (SE) }\end{array}$ & $\begin{array}{l}\text { 16S rRNA } \\
\text { seq. }\end{array}$ & $\begin{array}{l}\text { Lower microbial diversity at } 1 \mathrm{~m} \text { of age, linked } \\
\text { to reduced Bacteroides spp. diversity }(54)\end{array}$ \\
\hline $\begin{array}{l}\text { Allergic manifestations } \\
\text { (PD) and/or slgE+, } \\
\text { age from } 4-14 y\end{array}$ & $\begin{array}{l}\text { CC: } 19 \text { allergic children } \\
\text { and } 12 \text { non-allergic (IT) }\end{array}$ & 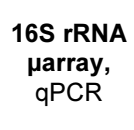 & $\begin{array}{l}\text { Decreased abundancies of Clostridium cluster } \\
\text { IV with Faecalibacterium prausnitzii, } \\
\text { Akkermansia muciniphila and increased } \\
\text { abundance of Enterobacteriaceae (87) }\end{array}$ \\
\hline $\begin{array}{c}\text { Ecz (PD) with or } \\
\text { without SPT+ until } \\
12 \mathrm{~m}\end{array}$ & $\begin{array}{l}\text { PC: } 98 \text { high risk infants } \\
\text { (AUS) }\end{array}$ & T-RFLP & $\begin{array}{l}\text { Low microbial diversity at } 1 \mathrm{w} \text { of age with Ecz } \\
\text { development but not with SPT+ or parental } \\
\text { allergic status (both/single) }(66)\end{array}$ \\
\hline $\begin{array}{l}\text { Allergic manifestations } \\
\text { and SPT+ until } 7 y\end{array}$ & CC: 47 infants (SE) & $\begin{array}{l}\text { 16S rRNA } \\
\text { seq. }\end{array}$ & $\begin{array}{c}\text { Low microbial diversity at } 1 \mathrm{w} \text { and } 1 \mathrm{~m} \text { in infants } \\
\text { having SPT+ associated Ecz in first } 2 \mathrm{y} \text { of life, } \\
\text { subsequently developing asthma at } 7 \mathrm{y} \text { of age } \\
\text { (74), same cohort as (54) }\end{array}$ \\
\hline $\begin{array}{c}\text { Ecz (PD) with or } \\
\text { without SPT+ until } 2 y\end{array}$ & $\begin{array}{l}\text { CC: } 15 \text { allergic and } 19 \\
\text { non-allergic high risk } \\
\text { infants }(\mathrm{FI})\end{array}$ & $\begin{array}{l}\text { 16S rRNA } \\
\text { Marray, } \\
\text { qPCR }\end{array}$ & $\begin{array}{l}\text { Higher diversity at } 18 \mathrm{~m} \text {, increase of } \\
\text { Clostridium clusters IV and XIVa and lower } \\
\text { abundance of Bacteroidetes members (56) }\end{array}$ \\
\hline $\begin{array}{l}\text { Ecz (PD) and/or slgE+ } \\
\text { until } 3 y\end{array}$ & $\begin{array}{l}\text { PC: } 606 \text { high risk infants } \\
\text { (DE) }\end{array}$ & qPCR & $\begin{array}{l}\text { Increased prevalence of Clostridium cluster I } \\
\text { at ages } 5 \text { and } 13 w \text { associated with Ecz, but } \\
\text { not slgE+ }(69)\end{array}$ \\
\hline $\begin{array}{l}\text { FA and SPT+, food } \\
\text { challenge and/or } \\
\text { slgE+, age from } \\
2-11 \mathrm{~m}\end{array}$ & $\begin{array}{l}\text { CC: } 34 \text { allergic and } 45 \\
\text { non-allergic infants }(\mathrm{CN})\end{array}$ & $\begin{array}{l}\text { 16S rRNA } \\
\text { seq. }\end{array}$ & $\begin{array}{c}\text { Lower abundance of phyla Bacteroidetes, } \\
\text { Proteobacteria, and Actinobacteria and } \\
\text { increase of Firmicutes }(88)\end{array}$ \\
\hline
\end{tabular}

CMPA: Cow's Milk Protein Allergy; CC/CS/PC: Case-controlled study/Cross-sectional study/Prospective cohort; DBPCFC+: positive for double-blind placebo control food challenge; DGGE/TTGE: denaturing gradient gel electrophoresis/ temporal temperature gel electrophoresis, Ecz: Eczema; FA: Food Allergy; FISH: Fluorescent In Situ Hybridisation; ISAAC: International Study of Asthma and Allergies in Childhood; (q)PCR: (quantitative) Polymerase Chain Reaction; PD: Physician-diagnosed; slgE+: positive serum specific IgE; SPT+: positive skin prick test; T-RFLP: terminal-restriction fragment length polymorphism, VLBW: very low birth weight infants. 
Human milk is the natural source of nutrition in early life and exclusive breastfeeding is recommended for at least 6 months by WHO. In allergy breastfeeding is thought to be protective because of both the presence of numerous allergens in human milk that are absent from artificial milks and their tolerogenic presentation due to human milk feeding related factors such as antigen handling by maternal gut, allergens found in immune complexes in milk, the presence of tolerogenic immune mediators in milk, increased gut maturation and a microbiota favouring tolerance induction in breastfed infants (44). The latter is linked to the HMO, naturally present in human milk. Consequently, a significant number of studies have been performed with different types of prebiotic oligosaccharides, defined as non-digestible carbohydrates that reach the colon intact and are known for their ability to selectively stimulate the growth and or activity of intestinal bacteria that impact health positively as postulated by Gibson \& Roberfroid (89). Interestingly, intervention with infant milk formulas containing a specific mixture of short-chain galacto-oligosaccharides and long-chain fructo-oligosaccharides (scGOS/lcFOS, 9:1 ratio, $8 \mathrm{~g} / \mathrm{L}$ ) till 6 months of age reduced the risk of atopic dermatitis and some allergic manifestations in infants with a familiar history of atopy not only at 6 months, but also at 2 and 5 years of age (90-92) and reduced the number of infectious episodes in healthy term infants (93) or infants with a high risk of developing allergy (90), underlining the importance of early nutrition on infant health. Efforts to prevent or manage atopic dermatitis and food allergy may prevent the onset of other atopic manifestations such as allergic asthma later in life. A study applying synbiotics gives indications that this may actually be possible. The combination of scGOS/IcFOS (9:1) and Bifidobacterium breve M16-V in a 12-week intervention in infants around 5 months of age showed reduced severity of atopic dermatitis in a subgroup of infants with elevated IgE levels but not in the whole study group. However, at one year of age it was found that the synbiotic group showed attenuated use of asthma medication and lower prevalence of asthma-like symptoms in the whole study group suggesting long-term effects of the intervention early in life (94). Microbial analysis of the dominant bacterial groups affected in this 12-week intervention showed an increase of bifidobacteria at the expense of mainly adult-type clostridial clusters XIV and clostridial clusters containing potential pathogens $C$. 
difficile and C. perfringens (95). Establishing such infant-type microbiota and reducing the adult-type clusters may lead to a more gradual diversification, while e.g. clostridial cluster XIV has been associated with atopic manifestations later in life (56). The exact mechanism of this synbiotic concept remains to be elucidated. Recently induction of galectin-9 (a soluble-type lectin expressed by IEC exhibiting binding specificity for $\beta$-galactosides) by this synbiotic concept has been suggested to be involved in suppression of IgE-mediated allergy (96). Galectin-9 was shown to neutralize $\lg E$ and to induce Th1 and Treg type immune responses and was indeed enhanced in serum of the synbiotic treated infants. The exact mechanism underlying induction of galectin-9 expression remains to be clarified, however the synergy shown for the combination of scGOS/lcFOS and Bifidobacterium breve $\mathrm{M}-16 \mathrm{~V}$ in enhancing serum galectin-9 levels in mice, suggest a possible interaction between microbe-induced TLR signalling and direct interaction of scGOS/lcFOS with IECs. Recently in-vitro studies confirmed that galectin- 9 is secreted by IEC apically exposed to TLR9 ligand (either synthetic or DNA derived from $B$. breve $\mathrm{M}-16 \mathrm{~V}$ ) in the presence of scGOS/lcFOS is involved in inducing Th1 and Treg immune responses (97). These results give important mechanistic insights and may be a promising target to prevent or treat allergic disease.

\section{Concluding remarks}

Clearly the first 1000 days in life are very important, since this is the period where we encounter external stimuli for the first time and the body is trained to respond to these stimuli. Longitudinal studies of this critical period are limited and include several confounding factors that complicate the identification of specific microbes associated with e.g. atopic disease. In the light of the recent revolution of next generation sequencing technologies we can gain important new insight how early-life events like type of feeding, mode of delivery, genetic background or geographical differences, may interfere with the colonisation pattern and therefore determine a predisposition to disease later in life. The challenge will be to go from taxonomic mapping to functionality of the microbiota. Omics-technologies, like transcriptomics, proteomics or metabolomics, will certainly catalyse our further 
understanding of the intestinal microbiota. Our genome is more or less fixed, but still the environment can have a major impact on the development. Processes like epigenetics are particularly interesting and we are just starting to understand how DNA methylation and histone modification mechanisms can regulate gene expression and confer phenotypical changes. And where our genome is fixed, we can still influence the epigenome and our microbiota. Knowing the importance of the intestinal microbiota for human physiology, the incredible development of infants in the first years of life, and the concurrent colonisation of the body with microbes makes it reasonable to believe that the intestinal colonisation of early life may be very important for health also in later life. Whether immunological, metabolic or neurological, all these systems are developing at this period. Therefore, it is important to understand the impact of factors like early life nutrition, but also the increase of caesarean deliveries or the increasing use of antibiotics. Disturbances in early life may lead to altered growth, immune diseases like allergy, metabolic diseases like obesity or cardiovascular diseases and maybe even brain and behavioural problems. Nutrition in early life and acquiring the essential microbes is probably a critical factor in this process. 


\section{References}

1. Cavalier-Smith T. Cell evolution and Earth history: stasis and revolution. Philos Trans R Soc Lond B Biol Sci. 2006;361(1470):969-1006.

2. Qin J, Li R, Raes J, Arumugam M, Burgdorf KS, Manichanh C, et al. A human gut microbial gene catalogue established by metagenomic sequencing. Nature. 2010;464(7285):59-65.

3. Hooper LV, Littman DR, Macpherson AJ. Interactions between the microbiota and the immune system. Science. 2012;336(6086):1268-73.

4. Flint HJ, Scott KP, Louis $\mathrm{P}$, Duncan $\mathrm{SH}$. The role of the gut microbiota in nutrition and health. Nat Rev Gastroenterol Hepatol. 2012;9(10):577-89.

5. Conly JM, Stein K, Worobetz L, Rutledge-Harding S. The contribution of vitamin K2 (menaquinones) produced by the intestinal microflora to human nutritional requirements for vitamin K. Am J Gastroenterol. 1994;89(6):915-23.

6. Albert MJ, Mathan VI, Baker SJ. Vitamin B12 synthesis by human small intestinal bacteria. Nature. 1980;283(5749):781-2.

7. Collado MC, Derrien M, Isolauri E, de Vos WM, Salminen S. Intestinal integrity and Akkermansia muciniphila, a mucin-degrading member of the intestinal microbiota present in infants, adults, and the elderly. Appl Environ Microbiol. 2007;73(23):7767-70.

8. Martin R, Nauta AJ, Ben Amor K, Knippels LM, Knol J, Garssen J. Early life: gut microbiota and immune development in infancy. Benef Microbes. 2010;1(4):367-82.

9. Shanahan F. The gut microbiota-a clinical perspective on lessons learned. Nat Rev Gastroenterol Hepatol. 2012;9(10):609-14.

10. Roger LC, McCartney AL. Longitudinal investigation of the faecal microbiota of healthy full-term infants using fluorescence in situ hybridization and denaturing gradient gel electrophoresis. Microbiology. 2010;156(Pt 11):3317-28.

11. Koenig JE, Spor A, Scalfone N, Fricker AD, Stombaugh J, Knight R, et al. Succession of microbial consortia in the developing infant gut microbiome. Proc Natl Acad Sci U S A. 2011;108 Suppl 1(Supplement 1):4578-85.

12. Palmer C, Bik EM, DiGiulio DB, Relman DA, Brown PO. Development of the human infant intestinal microbiota. PLoS Biol. 2007;5(7):e177.

13. Maynard CL, Elson CO, Hatton RD, Weaver CT. Reciprocal interactions of the intestinal microbiota and immune system. Nature. 2012;489(7415):231-41.

14. White RA, Bjørnholt JV, Baird DD, Midtvedt T, Harris JR, Pagano M, et al. Novel Developmental Analyses Identify Longitudinal Patterns of Early Gut Microbiota that Affect Infant Growth. PLoS Comput Biol. 2013;9(5):e1003042.

15. Shulman ST, Friedmann HC, Sims RH. Theodor Escherich: the first pediatric infectious diseases physician? Clin Infect Dis. 2007;45(8):1025-9.

16. Escherich T. Die darmbakterien des säuglings und ihre beziehungen zur physiologie der Verdauung: $F$. Enke; 1886.

17. Eckburg PB, Bik EM, Bernstein CN, Purdom E, Dethlefsen L, Sargent M, et al. Diversity of the human intestinal microbial flora. Science. 2005;308(5728):1635-8. 


\section{Chapter 2}

18. Jimenez E, Marin ML, Martin R, Odriozola JM, Olivares M, Xaus J, et al. Is meconium from healthy newborns actually sterile? Res Microbiol. 2008;159(3):187-93.

19. Satokari R, Gronroos T, Laitinen K, Salminen S, Isolauri E. Bifidobacterium and Lactobacillus DNA in the human placenta. Lett Appl Microbiol. 2009;48(1):8-12.

20. Matsumiya $\mathrm{Y}$, Kato N, Watanabe K, Kato $\mathrm{H}$. Molecular epidemiological study of vertical transmission of vaginal Lactobacillus species from mothers to newborn infants in Japanese, by arbitrarily primed polymerase chain reaction. J Infect Chemother. 2002;8(1):43-9.

21. Martin R, Langa S, Reviriego C, Jiminez E, Marin ML, Xaus J, et al. Human milk is a source of lactic acid bacteria for the infant gut. J Pediatr. 2003;143(6):754-8.

22. Makino H, Kushiro A, Ishikawa E, Muylaert D, Kubota H, Sakai T, et al. Transmission of intestinal Bifidobacterium longum subsp. longum strains from mother to infant, determined by multilocus sequencing typing and amplified fragment length polymorphism. Appl Environ Microbiol. 2011;77(19):6788-93.

23. Martin R, Jimenez E, Heilig H, Fernandez L, Marin ML, Zoetendal EG, et al. Isolation of bifidobacteria from breast milk and assessment of the bifidobacterial population by PCR-denaturing gradient gel electrophoresis and quantitative real-time PCR. Appl Environ Microbiol. 2009;75(4):965-9.

24. Perez PF, Dore J, Leclerc M, Levenez F, Benyacoub J, Serrant P, et al. Bacterial imprinting of the neonatal immune system: lessons from maternal cells? Pediatrics. 2007;119(3):e724-32.

25. Jeurink PV, van Bergenhenegouwen J, Jimenez E, Knippels LM, Fernandez L, Garssen J, et al. Human milk: a source of more life than we imagine. Benef Microbes. 2013;4(1):17-30.

26. Fallani M, Young D, Scott J, Norin E, Amarri S, Adam R, et al. Intestinal microbiota of 6-week-old infants across Europe: geographic influence beyond delivery mode, breast-feeding, and antibiotics. J Pediatr Gastroenterol Nutr. 2010;51(1):77-84.

27. Yatsunenko T, Rey FE, Manary MJ, Trehan I, Dominguez-Bello MG, Contreras M, et al. Human gut microbiome viewed across age and geography. Nature. 2012;486(7402):222-7.

28. Arboleya S, Binetti A, Salazar N, Fernandez N, Solis G, Hernandez-Barranco A, et al. Establishment and development of intestinal microbiota in preterm neonates. FEMS Microbiol Ecol. 2012;79(3):763-72.

29. Sim K, Cox MJ, Wopereis H, Martin R, Knol J, Li MS, et al. Improved detection of bifidobacteria with optimised 16S rRNA-gene based pyrosequencing. PLoS One. 2012;7(3):e32543.

30. Fallani M, Amarri S, Uusijarvi A, Adam R, Khanna S, Aguilera M, et al. Determinants of the human infant intestinal microbiota after the introduction of first complementary foods in infant samples from five European centres. Microbiology. 2011;157(Pt 5):1385-92.

31. Claesson MJ, Cusack S, O'Sullivan O, Greene-Diniz R, de Weerd H, Flannery E, et al. Composition, variability, and temporal stability of the intestinal microbiota of the elderly. Proc Natl Acad Sci U S A. 2011;108 Suppl 1(Supplement 1):4586-91.

32. Klaassens ES, Ben-Amor K, Vriesema A, Vaughan EE, de Vos W. The fecal bifidobacterial transcriptome of adults: A microarray approach. Gut Microbes. 2011;2(4):217-26.

33. Levy O. Innate immunity of the newborn: basic mechanisms and clinical correlates. Nat Rev Immunol. 2007;7(5):379-90.

34. Martens EC, Chiang HC, Gordon Jl. Mucosal glycan foraging enhances fitness and transmission of a saccharolytic human gut bacterial symbiont. Cell Host Microbe. 2008;4(5):447-57.

35. van Limpt C, Crienen A, Vriesema A, Knol J. Effect of Colonic Short Chain Fatty Acids, Lactate and Ph on the Growth of Common Gut Pathogens. Pediatric research. 2004;56(3):487, abstract 134. 
36. Fukuda S, Toh H, Hase K, Oshima K, Nakanishi Y, Yoshimura K, et al. Bifidobacteria can protect from enteropathogenic infection through production of acetate. Nature. 2011;469(7331):543-7.

37. Knol J, Scholtens P, Kafka C, Steenbakkers J, Gro S, Helm K, et al. Colon microflora in infants fed formula with galacto- and fructo-oligosaccharides: more like breast-fed infants. J Pediatr Gastroenterol Nutr. 2005;40(1):36-42.

38. Duncan SH, Louis P, Flint HJ. Lactate-Utilizing Bacteria, Isolated from Human Feces, That Produce Butyrate as a Major Fermentation Product. Appl Environ Microbiol. 2004;70(10):5810-7.

39. de Weerth C, Fuentes S, Puylaert P, de Vos WM. Intestinal microbiota of infants with colic: development and specific signatures. Pediatrics. 2013;131(2):e550-8.

40. Luhrs H, Gerke T, Muller JG, Melcher R, Schauber J, Boxberge F, et al. Butyrate inhibits NF-kappaB activation in lamina propria macrophages of patients with ulcerative colitis. Scand J Gastroenterol. 2002;37(4):458-66.

41. Maslowski KM, Vieira AT, Ng A, Kranich J, Sierro F, Yu D, et al. Regulation of inflammatory responses by gut microbiota and chemoattractant receptor GPR43. Nature. 2009;461(7268):1282-6.

42. Macpherson AJ, McCoy KD, Johansen FE, Brandtzaeg P. The immune geography of IgA induction and function. Mucosal Immunol. 2008;1(1):11-22.

43. Rath T, Kuo TT, Baker K, Qiao SW, Kobayashi K, Yoshida M, et al. The immunologic functions of the neonatal Fc receptor for IgG. J Clin Immunol. 2013;33 Suppl 1(1):S9-17.

44. Verhasselt $\mathrm{V}$. Oral tolerance in neonates: from basics to potential prevention of allergic disease. Mucosal Immunol. 2010;3(4):326-33.

45. Scholtens PAMJ, Alliet P, Raes M, Alles MS, Kroes H, Boehm G, et al. Fecal Secretory Immunoglobulin A Is Increased in Healthy Infants Who Receive a Formula with Short-Chain Galacto-Oligosaccharides and Long-Chain Fructo-Oligosaccharides. J Nutr. 2008;138(6):1141-7.

46. Kukkonen K, Kuitunen M, Haahtela T, Korpela R, Poussa T, Savilahti E. High intestinal IgA associates with reduced risk of IgE-associated allergic diseases. Pediatr Allergy Immunol. 2010;21(1 Pt 1):67-73.

47. Lebeer S, Claes IJ, Vanderleyden J. Anti-inflammatory potential of probiotics: lipoteichoic acid makes a difference. Trends Microbiol. 2012;20(1):5-10.

48. Frantz AL, Rogier EW, Weber CR, Shen L, Cohen DA, Fenton LA, et al. Targeted deletion of MyD88 in intestinal epithelial cells results in compromised antibacterial immunity associated with downregulation of polymeric immunoglobulin receptor, mucin-2, and antibacterial peptides. Mucosal Immunol. 2012;5(5):501-12.

49. Round JL, Lee SM, Li J, Tran G, Jabri B, Chatila TA, et al. The Toll-like receptor 2 pathway establishes colonization by a commensal of the human microbiota. Science. 2011;332(6032):974-7.

50. Jeon SG, Kayama H, Ueda Y, Takahashi T, Asahara T, Tsuji H, et al. Probiotic Bifidobacterium breve induces IL-10-producing Tr1 cells in the colon. PLoS Pathog. 2012;8(5):e1002714.

51. Hill DA, Siracusa MC, Abt MC, Kim BS, Kobuley D, Kubo M, et al. Commensal bacteria-derived signals regulate basophil hematopoiesis and allergic inflammation. Nat Med. 2012;18(4):538-46.

52. Noverr MC, Huffnagle GB. The 'microflora hypothesis' of allergic diseases. Clin Exp Allergy. 2005;35(12):1511-20.

53. Bieber T, Cork M, Reitamo S. Atopic dermatitis: a candidate for disease-modifying strategy. Allergy. 2012;67(8):969-75.

54. Abrahamsson TR, Jakobsson HE, Andersson AF, Bjorksten B, Engstrand L, Jenmalm MC. Low diversity of the gut microbiota in infants with atopic eczema. J Allergy Clin Immunol. 2012;129(2):434-40, 40 e1-2. 


\section{Chapter 2}

55. Johansson MA, Sjögren YM, Persson J-O, Nilsson C, Sverremark-Ekström E. Early Colonization with a Group of Lactobacilli Decreases the Risk for Allergy at Five Years of Age Despite Allergic Heredity. PLoS One. 2011;6(8):e23031.

56. Nylund L, Satokari R, Nikkila J, Rajilić-Stojanović M, Kalliomäki M, Isolauri E, et al. Microarray analysis reveals marked intestinal microbiota aberrancy in infants having eczema compared to healthy children in at-risk for atopic disease. BMC Microbiology. 2013;13(1):12.

57. Penders J, Thijs C, van den Brandt PA, Kummeling I, Snijders B, Stelma F, et al. Gut microbiota composition and development of atopic manifestations in infancy: the KOALA Birth Cohort Study. Gut. 2007;56(5):661-7.

58. Genuneit J. Exposure to farming environments in childhood and asthma and wheeze in rural populations: a systematic review with meta-analysis. Pediatr Allergy Immunol. 2012;23(6):509-18.

59. Genuneit J, Strachan DP, Buchele G, Weber J, Loss G, Sozanska B, et al. The combined effects of family size and farm exposure on childhood hay fever and atopy. Pediatr Allergy Immunol. 2013;24(3):293-8.

60. Lewis MC, Inman CF, Patel D, Schmidt B, Mulder I, Miller B, et al. Direct experimental evidence that early-life farm environment influences regulation of immune responses. Pediatr Allergy Immunol. 2012;23(3):265-9.

61. Strachan DP. Hay fever, hygiene, and household size. BMJ. 1989;299(6710):1259-60.

62. Romagnani S. Coming back to a missing immune deviation as the main explanatory mechanism for the hygiene hypothesis. Journal of Allergy and Clinical Immunology. 2007;119(6):1511-3

63. Sakaguchi S, Sakaguchi N, Asano M, Itoh M, Toda M. Immunologic self-tolerance maintained by activated T cells expressing IL-2 receptor alpha-chains (CD25). Breakdown of a single mechanism of self-tolerance causes various autoimmune diseases. The Journal of Immunology. 1995;155(3):1151-64.

64. Penders J, Stobberingh EE, van den Brandt PA, Thijs C. The role of the intestinal microbiota in the development of atopic disorders. Allergy. 2007;62(11):1223-36.

65. Bisgaard H, Li N, Bonnelykke K, Chawes BLK, Skov T, Paludan-Müller G, et al. Reduced diversity of the intestinal microbiota during infancy is associated with increased risk of allergic disease at school age. Journal of Allergy and Clinical Immunology. 2011;128(3):646-52.e5.

66. Ismail IH, Oppedisano F, Joseph SJ, Boyle RJ, Licciardi PV, Robins-Browne RM, et al. Reduced gut microbial diversity in early life is associated with later development of eczema but not atopy in high-risk infants. Pediatr Allergy Immunol. 2012;23(7):674-81.

67. Songjinda P, Nakayama J, Tateyama A, Tanaka S, Tsubouchi M, Kiyohara C, et al. Differences in developing intestinal microbiota between allergic and non-allergic infants: a pilot study in Japan. Bioscience, biotechnology, and biochemistry. 2007;71(9):2338-42.

68. Vael C, Vanheirstraeten L, Desager KN, Goossens H. Denaturing gradient gel electrophoresis of neonatal intestinal microbiota in relation to the development of asthma. BMC Microbiol. 2011;11(1):68.

69. Penders J, Gerhold K, Stobberingh EE, Thijs C, Zimmermann K, Lau S, et al. Establishment of the intestinal microbiota and its role for atopic dermatitis in early childhood. J Allergy Clin Immunol. 2013;132(3):601-7 e8.

70. Adlerberth I, Strachan DP, Matricardi PM, Ahrne S, Orfei L, Aberg N, et al. Gut microbiota and development of atopic eczema in 3 European birth cohorts. J Allergy Clin Immunol. 2007;120(2):343-50. 
71. Waligora-Dupriet AJ, Campeotto F, Romero K, Mangin I, Rouzaud G, Menard O, et al. Diversity of gut Bifidobacterium species is not altered between allergic and non-allergic French infants. Anaerobe. 2011;17(3):91-6.

72. Wang M, Karlsson C, Olsson C, Adlerberth I, Wold AE, Strachan DP, et al. Reduced diversity in the early fecal microbiota of infants with atopic eczema. J Allergy Clin Immunol. 2008;121(1):129-34.

73. Forno E, Onderdonk AB, McCracken J, Litonjua AA, Laskey D, Delaney ML, et al. Diversity of the gut microbiota and eczema in early life. Clin Mol Allergy. 2008;6(1):11.

74. Abrahamsson TR, Jakobsson HE, Andersson AF, Bjorksten B, Engstrand L, Jenmalm MC. Low gut microbiota diversity in early infancy precedes asthma at school age. Clin Exp Allergy. 2014;44(6):842-50.

75. Hoyles L, McCartney AL. What do we mean when we refer to Bacteroidetes populations in the human gastrointestinal microbiota? FEMS Microbiol Lett. 2009;299(2):175-83.

76. Marcobal A, Barboza M, Sonnenburg ED, Pudlo N, Martens EC, Desai P, et al. Bacteroides in the infant gut consume milk oligosaccharides via mucus-utilization pathways. Cell Host Microbe. 2011;10(5):507-14.

77. Rodriguez B, Prioult G, Hacini-Rachinel F, Moine D, Bruttin A, Ngom-Bru C, et al. Infant gut microbiota is protective against cow's milk allergy in mice despite immature ileal T-cell response. FEMS Microbiol Ecol. 2012;79(1):192-202.

78. Abrahamsson TR, Jakobsson HE, Andersson AF, Bjorksten B, Engstrand L, Jenmalm MC. Reply: To PMID 22153774. J Allergy Clin Immunol. 2013;131(1):248-9.

79. Suzuki S, Shimojo N, Tajiri Y, Kumemura M, Kohno Y. Differences in the composition of intestinal Bifidobacterium species and the development of allergic diseases in infants in rural Japan. Clin Exp Allergy. 2007;37(4):506-11.

80. Gore C, Munro K, Lay C, Bibiloni R, Morris J, Woodcock A, et al. Bifidobacterium pseudocatenulatum is associated with atopic eczema: a nested case-control study investigating the fecal microbiota of infants. J Allergy Clin Immunol. 2008;121(1):135-40.

81. Vael C, Nelen V, Verhulst SL, Goossens H, Desager KN. Early intestinal Bacteroides fragilis colonisation and development of asthma. BMC Pulm Med. 2008;8(1):19.

82. Sjogren YM, Jenmalm MC, Bottcher MF, Bjorksten B, Sverremark-Ekstrom E. Altered early infant gut microbiota in children developing allergy up to 5 years of age. Clin Exp Allergy. 2009;39(4):518-26.

83. Hong P-Y, Lee BW, Aw M, Shek LPC, Yap GC, Chua KY, et al. Comparative Analysis of Fecal Microbiota in Infants with and without Eczema. PLoS One. 2010;5(4):e9964.

84. Van Zwol A, Van Den Berg A, Knol J, Twisk JW, Fetter WP, Van Elburg RM. Intestinal microbiota in allergic and nonallergic 1-year-old very low birth weight infants after neonatal glutamine supplementation. Acta paediatrica (Oslo, Norway : 1992). 2010;99(12):1868-74.

85. Nakayama J, Kobayashi T, Tanaka S, Korenori Y, Tateyama A, Sakamoto N, et al. Aberrant structures of fecal bacterial community in allergic infants profiled by $16 \mathrm{~S}$ rRNA gene pyrosequencing. FEMS Immunol Med Microbiol. 2011;63(3):397-406.

86. Thompson-Chagoyan OC, Fallani M, Maldonado J, Vieites JM, Khanna S, Edwards C, et al. Faecal microbiota and short-chain fatty acid levels in faeces from infants with cow's milk protein allergy. Int Arch Allergy Immunol. 2011;156(3):325-32.

87. Candela M, Rampelli S, Turroni S, Severgnini M, Consolandi C, De Bellis G, et al. Unbalance of intestinal microbiota in atopic children. BMC Microbiol. 2012;12(1):95. 


\section{Chapter 2}

88. Ling Z, Li Z, Liu X, Cheng Y, Luo Y, Tong X, et al. Altered fecal microbiota composition associated with food allergy in infants. Appl Environ Microbiol. 2014;80(8):2546-54.

89. Gibson GR, Roberfroid MB. Dietary modulation of the human colonic microbiota: introducing the concept of prebiotics. J Nutr. 1995;125(6):1401-12.

90. Arslanoglu S, Moro GE, Schmitt J, Tandoi L, Rizzardi S, Boehm G. Early dietary intervention with a mixture of prebiotic oligosaccharides reduces the incidence of allergic manifestations and infections during the first two years of life. J Nutr. 2008;138(6):1091-5.

91. Arslanoglu S, Moro GE, Boehm G, Wiens F, Stahl B, Bertino E. Early prebiotic oligosaccharide supplementation reduces the incidence of some allergic manifestations in the first 5 years of life. Journal of Biology Regulation \& Homeostatic Agents. 2012;26(3):49-59.

92. Moro G, Arslanoglu S, Stahl B, Jelinek J, Wahn U, Boehm G. A mixture of prebiotic oligosaccharides reduces the incidence of atopic dermatitis during the first six months of age. Arch Dis Child. 2006;91(10):814-9.

93. Bruzzese E, Volpicelli M, Squeglia V, Bruzzese D, Salvini F, Bisceglia M, et al. A formula containing galacto- and fructo-oligosaccharides prevents intestinal and extra-intestinal infections: an observational study. Clin Nutr. 2009;28(2):156-61.

94. van der Aa LB, van Aalderen WM, Heymans HS, Henk Sillevis Smitt J, Nauta AJ, Knippels LM, et al. Synbiotics prevent asthma-like symptoms in infants with atopic dermatitis. Allergy. 2011;66(2):170-7.

95. van der Aa LB, Heymans HS, van Aalderen WM, Sillevis Smitt JH, Knol J, Ben Amor K, et al. Effect of a new synbiotic mixture on atopic dermatitis in infants: a randomized-controlled trial. Clin Exp Allergy. 2010;40(5):795-804.

96. de Kivit S, Saeland E, Kraneveld AD, van de Kant HJG, Schouten B, van Esch B, et al. Galectin-9 induced by dietary synbiotics is involved in suppression of allergic symptoms in mice and humans: Allergy. 2012;67(3):343-352.; 2012.

97. de Kivit S, Overbeek SA, Hoffmans RM, Knippels LM, Kraneveld AD, Garssen J, et al. Exposure of intestinal epithelial cells to CpG DNA and galacto-/fructo-oligosaccharides protects against epithelial barrier disruption in vitro. Restoring mucosal tolerance by non-digestible oligosaccharides under inflammatory conditions. 2013:169. 
Establishing a symbiosis 



\section{CHAPTER 3}

\section{Improved detection of bifidobacteria with optimised 16S rRNA-gene based pyrosequencing}

$\operatorname{Sim} \mathrm{K}^{1^{*}}$, Cox $\mathrm{MJ}^{\mathrm{J}^{*}}$, Wopereis $\mathrm{H}^{3}$, Martin $\mathrm{R}^{3}$, Knol J3 , Li M-S ${ }^{1}$, Cookson $\mathrm{WO}^{2}$, Moffatt MF², Kroll JS ${ }^{1}$.

*Joint first

${ }^{1}$ Imperial College London, St. Mary's Campus, London, United Kingdom ${ }^{2}$ Imperial College London, National Heart and Lung Institute, South Kensington Campus, London, United Kingdom ${ }^{3}$ Danone Nutricia Research, Wageningen, The Netherlands 


\section{Abstract}

The 16S rRNA gene is conserved across all bacteria and as such is routinely targeted in PCR surveys of bacterial diversity. PCR primer design aims to amplify as many different $16 \mathrm{~S}$ rRNA gene sequences from as wide a range of organisms as possible, though there are no suitable $100 \%$ conserved regions of the gene, leading to bias. In the gastrointestinal tract, bifidobacteria are a key genus, but are often under-represented in 16S rRNA surveys of diversity. We have designed modified, 'bifidobacteria-optimised' universal primers, which we have demonstrated allow detection of bifidobacterial sequence present in DNA mixtures at $2 \%$ abundance, the lowest proportion tested. Optimisation did not compromise the detection of other organisms in infant faecal samples. Separate validation using fluorescence in situ hybridisation (FISH) shows that the proportions of bifidobacteria detected in faecal samples were in agreement with those obtained using 16S rRNA based pyrosequencing. For future studies looking at faecal microbiota, careful selection of primers will be key in order to ensure effective detection of bifidobacteria. 


\section{Introduction}

With the advent of next-generation sequencing, semi quantitative, in-depth characterisation of microbial communities that has never been practically possible is now becoming increasingly accessible to researchers. In samples from the gastrointestinal (GI) tract, use of universal primers for amplification of the bacterial 16S rRNA gene followed by pyrosequencing is beginning to reveal the role of the GI microbiome in diverse diseases such as obesity (1), atopic disease $(2,3)$, colonic cancer (4) and necrotizing enterocolitis (5). Two of the key questions surrounding the role of the GI microbiota in health are how the microbiota is involved in immunomodulation $(6,7)$, and how imbalance may lead to disease states. Organisms such as the bifidobacteria, which rapidly colonise the gastrointestinal microbiota in the first year of life are thought to be central in the establishment and maintenance of a 'healthy microbiota'.

Universal PCR primers allow amplification, and therefore detection of all the bacteria in a mixed population. A number of primer sets amplifying different regions of the 16S rRNA gene exist and are in common use $(8,9)$. A truly universal primer pair that binds to the 16S rRNA of all eubacteria is impossible to design since the longest number of consecutive nucleotides in the gene that are $100 \%$ conserved is 11 (Escherichia coli 16S rDNA positions 788 to 798), and in general, the number of sequential absolutely conserved nucleotides in other regions of the gene is four (10). The decreased amplification efficiency due to differential annealing of universal primers when a heterogeneous template is used leads to bias against the detection of certain taxa (11). For example, even well designed primers matching over $95 \%$ of sequences in the Ribosomal Database Project (RDP) (12) from the dominant bacterial phyla present in the gut, may miss specific taxa; primer 967F (13) will detect less than five percent of Bacteroidetes whilst primer 1492R (14) detects only $61 \%$ of Actinobacteria and 54\% of Proteobacteria (15). Mismatches towards the 3 ' end are likely to lead to greater amplification inefficiency than that at the 5 ' end (16). Pragmatic approaches to primer use are often taken, accepting that not all bacteria will be fully represented, but that between sample comparisons making use of the 
same primer pair are valid and that particular organisms of interest are successfully amplified.

In order to address this issue, different approaches may be adopted to ensure that detection of the specific taxa of interest to the study are maximised. The universal primer set used can be optimised by either introducing a degenerate base pair at the positions of mismatch. Alternatively, taxa-specific primers can be added to the primer pool. Frank et al. (16) used a primer pool consisting of seven different primer sequences (fourfold-degenerate primers and three primers specific for amplifying Bifidobacteriaceae, Borrelia and Chlamydiales) and were able to dramatically increase the detection of genera which were previously missed from clinical samples. Increasing the number of degenerate bases in the primer set may however introduce a bias in the template to product ratios when a heterogenous template is used since templates with a greater GC content at the primer site will be preferentially amplified (17). Furthermore, inclusion of a large number of degenerate bases equates to dilution of the primer pool, and the number of templates which exactly match each primer sequence is reduced, resulting in a potential decrease in the overall annealing efficiency (16). Using an inosine residue at the mismatched positions is an alternative approach (10), but as it forms a stable bond with all four nucleotides, this may lead to erroneous PCR products (16).

\section{Bifidobacteria}

Bifidobacteria are considered to be a major component of the GI microbiota in healthy breast-fed infants $(18,19)$. This is mainly driven by a high level of complex oligosaccharides (10-12 $\mathrm{g} / \mathrm{L})$ available as a natural prebiotic in breast-milk (20). Their use as a probiotic, or their stimulation by adding prebiotics (synbiotics) has become increasingly widespread. Specific prebiotics or synbiotics added to infant milk formula have been shown to induce a more 'breastfed-like' microbiota with associated physiological changes (metabolic end products and $\mathrm{pH}$ ) compared to standard formula $(21,22)$. These changes are considered as an important mechanism for the inhibition of pathogens in the gut (23). Used as a prophylactic infant feed supplement bifidobacteria have been found to be effective at reducing both the severity as well as the risk of developing rotavirus diarrhoea. Their use also appears to reduce the risk of 
antibiotic-associated diarrhoea (24). Moreover, bifidobacteria may be beneficial in the treatment of atopic disease (25) and a synbiotic infant formula has been found to prevent asthma-like symptoms in infants with atopic dermatitis (26).

Bifidobacteria were found to constitute only a minor component of the faecal microbiota in healthy, full term infants (27). The authors acknowledge that this was surprising and speculated that this result might arise through the $8 \mathrm{~F}$ universal primer having a three base pair mismatch against Bifidobacterium longum, and that the genus in general does not have $100 \%$ sequence identity to the $8 \mathrm{~F}$ primer sequence. In our study, we have therefore sought to assess the impact of using a standard 'universal' primer set with one exactly matched to the target region of bifidobacteria, in detecting this genus.

We designed a 'bifidobacteria-optimised' universal primer set by modification of a well-established primer set 357F/926R, originally designed by the Muyzer group $(28,29)$ for denaturing gradient gel electrophoresis. Primer set $357 F / 926 R$ is one of two primer pairs recommended by the NIH Human Microbiome Project protocols (30, 31) for $16 \mathrm{~S}$ rRNA amplicon pyrosequencing. We demonstrate that our 'bifidobacteria-optimised' primer set increased the bifidobacteria detection rate in both pure DNA mixtures as well as faecal samples, without compromising the detection of other genera. In addition, we have independently confirmed the relative abundance of bifidobacteria detected using fluorescence in situ hybridisation (FISH).

\section{Results}

\section{Pyrosequencing}

Pyrosequencing of the standard mixes and the faecal samples was carried out in a single multiplexed run on the GS Junior platform and resulted in 85126 reads. After denoising and chimera-removal 60794 high quality reads remained and these were assigned to samples using the barcode sequences, 37977 reads for faecal samples, 22817 for the standard DNA mixtures. 


\section{DNA mixtures}

Standard universal primers detected Streptococcus pneumoniae and Moraxella catarrhalis sequences in correct relative proportions in the DNA mixtures. The primers however, consistently failed to correctly quantify the bifidobacterial sequences present. The standard universal primers failed to amplify bifidobacterial DNA to a level above $1 \%$ in four out of the five mixtures, and the maximum proportion of bifidobacteria that was detected was $1.6 \%$, even when the bifidobacterial DNA constituted $90 \%$ of the mixture.

This was in contrast to the relative proportions of species-specific reads obtained with 'bifidobacteria-optimised' universal primers, which correlated far better with the original proportions of the species' DNA in the mixture $\left(R^{2}=0.955\right)$ (Table 1 , Figure 1). With the 'bifidobacteria-optimised' primers, bifidobacterial DNA could be detected at the lowest concentration tested $(2 \%)$.

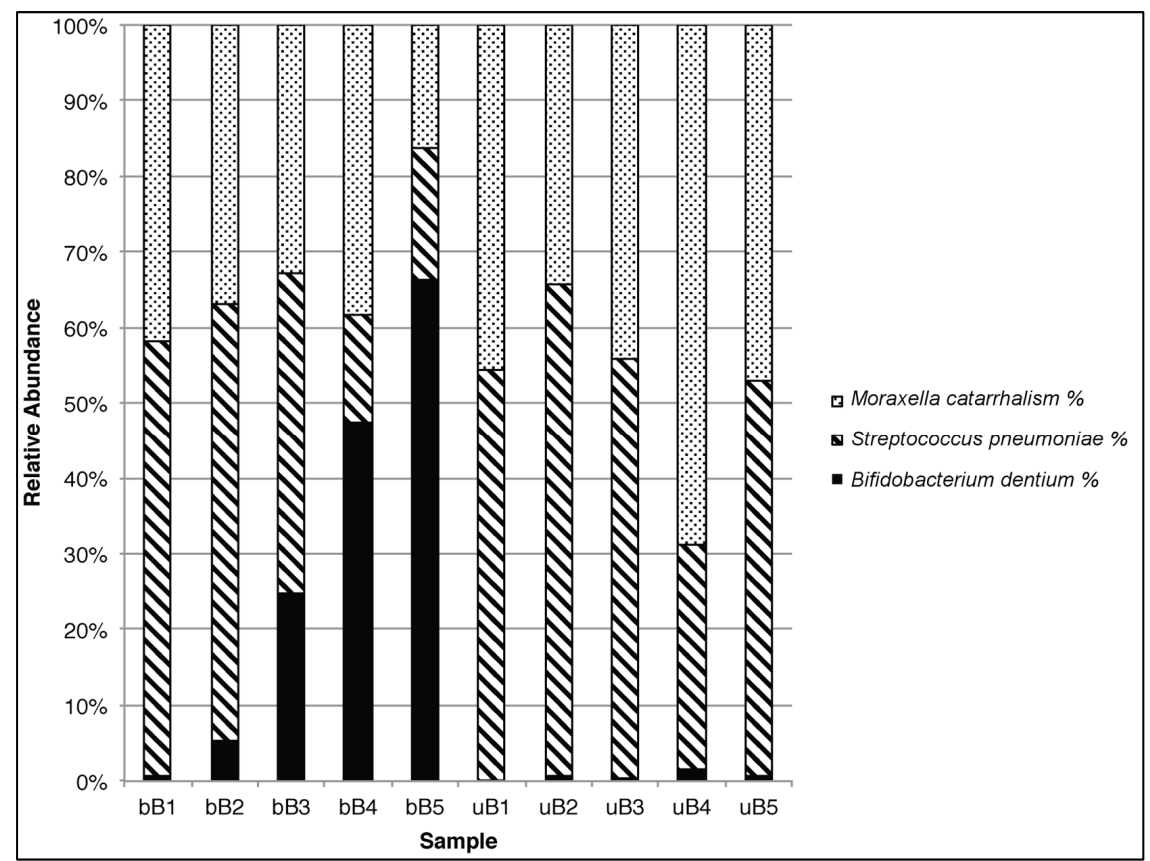

Figure 1: Proportions of 454 sequencing reads obtained using both primer sets. Increased detection rate of Bifidobacterium dentium demonstrated using the 'bifidobacteria-optimised' universal primers (b) compared to regular universal primers $(u)$. 
Table 1: Proportions of DNA in each mixture.

\begin{tabular}{|c|c|c|c|}
\hline Sample & $\begin{array}{c}\text { Bifidobacterium } \\
\text { dentium }\end{array}$ & $\begin{array}{c}\text { Streptococcus } \\
\text { pneumoniae }\end{array}$ & $\begin{array}{c}\text { Moraxella } \\
\text { catarrhalis }\end{array}$ \\
\hline 1 & $2 \%$ & $49 \%$ & $49 \%$ \\
\hline 2 & $15 \%$ & $50 \%$ & $35 \%$ \\
\hline 3 & $50 \%$ & $25 \%$ & $25 \%$ \\
\hline 4 & $75 \%$ & $5 \%$ & $20 \%$ \\
\hline 5 & $90 \%$ & $5 \%$ & $5 \%$ \\
\hline
\end{tabular}

\section{Faecal samples}

Operational taxonomic unit (OTU) analysis

The most abundant taxa at phylum level were the Firmicutes and Actinobacteria, followed by Proteobacteria and Bacteroidetes, irrespective of which primer set was used. The ten samples all comprised of different numbers of OTUs and OTU abundances (Figure 2), but, the most striking difference was the increased number of bifidobacterial reads present in the sample set analysed with the 'bifidobacteria-optimised' universal primers.

\section{Fluorescence in situ hybridisation (FISH) analysis}

Table 2 shows the proportion of faecal bifidobacteria, expressed as a percentage of the total number of bacteria in faeces as enumerated by FISH and the relative read abundances by 454 -sequencing.

Comparing data obtained with the two primer sets to the FISH using Pearson correlation shows significant correlation of FISH with the pyrosequencing using the 'bifidobacteria-optimised' primer set (Table 3). To confirm good agreement between two methods Bland-Altman agreement tests were performed (32). The agreement between two methods is tested by comparing the differences between two methods against the average of the methods. The results from bifidobacteria-optimised pyrosequencing against the FISH method shows agreement in determining the level of bifidobacteria in the faecal samples tested (Table 4). 


\section{Chapter 3}

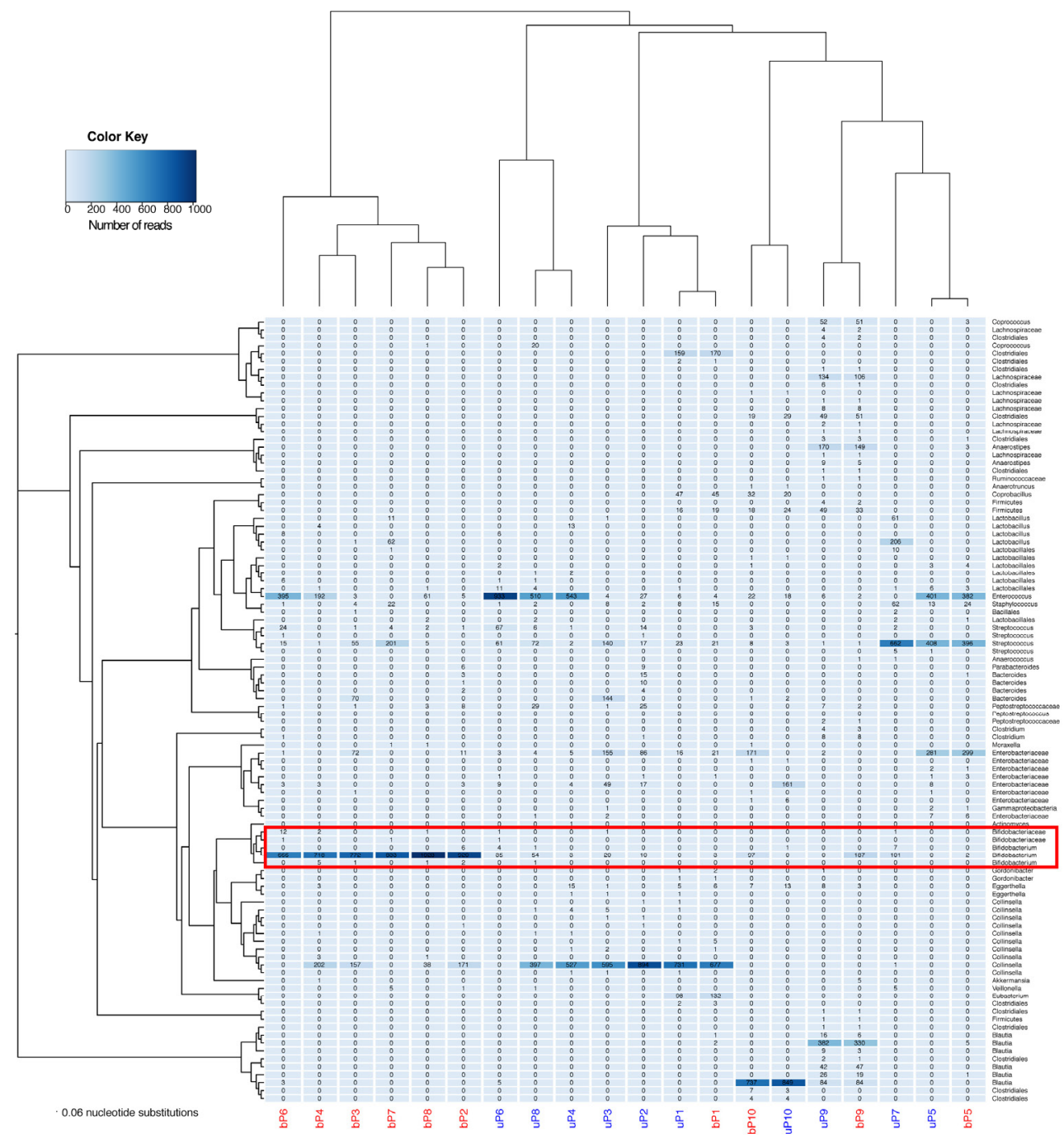

Figure 2: Heatmap displaying the relative abundance of OTUs per sample. Samples are grouped by hierarchical cluster analysis on the $x$-axis and by neighbour-joining phylogenetic tree with nearest neighbour interchange on the $y$-axis. Samples amplified with 'bifidobacteria-optimised' primers are in red and with the standard primers in blue. Bifidobacterial OTUs are highlighted in the red box. 
Table 2: Relative proportions of faecal bifidobacteria in ten faecal samples as determined by FISH and 454-sequencing using 'bifidobacteria-optimised' universal primers (926Rb) or regular universal primers (926R).

\begin{tabular}{|c|c|c|c|}
\hline Sample & 926Rb & 926R & FISH \\
\hline P1 & $0.2 \%$ & $0.0 \%$ & $0.3 \%$ \\
\hline P2 & $81.1 \%$ & $1.0 \%$ & $61.2 \%$ \\
\hline P3 & $69.0 \%$ & $1.7 \%$ & $70.9 \%$ \\
\hline P4 & $63.5 \%$ & $0.4 \%$ & $75.8 \%$ \\
\hline P5 & $0.2 \%$ & $0.0 \%$ & $0.6 \%$ \\
\hline P6 & $62.7 \%$ & $4.4 \%$ & $67.3 \%$ \\
\hline P7 & $74.1 \%$ & $10.8 \%$ & $47.5 \%$ \\
\hline P8 & $90.6 \%$ & $5.3 \%$ & $75.0 \%$ \\
\hline P9 & $16.9 \%$ & $0.0 \%$ & $10.4 \%$ \\
\hline P10 & $8.0 \%$ & $0.1 \%$ & $67.0 \%$ \\
\hline
\end{tabular}

Table 3: Correlation matrix (Pearson) shows the Pearson correlation coefficients and p-values. Values in bold are different from 0 with a significance level alpha $=0.05$.

\begin{tabular}{|c|c|c|c|}
\hline Variables & 926Rb & 926R & FISH \\
\hline 926Rb & $n / a$ & $0.593(p=0.071)$ & $\mathbf{0 . 7 6 1}(\mathbf{p}=\mathbf{0 . 0 1 1})$ \\
\hline $926 R$ & $0.593(p=0.071)$ & $n / a$ & $0.297(p=0.404)$ \\
\hline FISH & $\mathbf{0 . 7 6 1 ( p = 0 . 0 1 1 )}$ & $0.297(p=0.404)$ & $n / a$ \\
\hline
\end{tabular}

Table 4: $P$-values resulting from Bland-Altman agreement tests. Values in bold are different from 0 with a significance level alpha $=0.05$.

\begin{tabular}{|c|c|c|c|}
\hline Variables & 926Rb & 926R & FISH \\
\hline 926Rb & $\mathrm{n} / \mathrm{a}$ & $\mathbf{0 . 0 0 2 6}$ & 0.8974 \\
\hline 926R & $\mathbf{0 . 0 0 2 6}$ & $\mathrm{n} / \mathrm{a}$ & $\mathbf{0 . 0 0 1 1}$ \\
\hline FISH & 0.8974 & $\mathbf{0 . 0 0 1 1}$ & n/a \\
\hline
\end{tabular}

Principal Coordinate Analysis and statistics

In order to ensure that detection of other organisms was not compromised or that abundance levels were not altered by using 'bifidobacteria-optimised' primers, principal coordinate analysis (PCoA) was performed. PCoA using the weighted UniFrac metric (33) (Figure 3a) (which takes into consideration both the presence/absence as well as abundance of sequences, ) demonstrates clustering of samples by primer set used except for pairs P1 and P5 (circled). On OTU analysis, (Figure 2) these are shown to have very small or only moderate numbers of bifidobacteria present. Removing bifidobacterial sequences from the principal 


\section{Chapter 3}

coordinate analysis (Figure $3 b$ ) resulted in tight clustering of all pairs of samples. This indicates that the main differences between the two principal coordinate analyses are due to the detection of bifidobacteria, and that 'bifidobacteria-optimised' universal primers do not compromise the quantitative detection of other organisms.

Using a paired T-Test to compare OTUs and read abundance of the two sample sets ('bifidobacteria-optimised' universal primers vs. regular universal primers) there was a highly significant difference between the read abundance of bifidobacteria using 'bifidobacteria-optimised' primers compared to regular primers $(P=0.039, \mathrm{t}=$ 0.0026, with Bonferonni correction for multiple testing), but no significant differences between any of the other OTUs $(P>1.4)$.

A

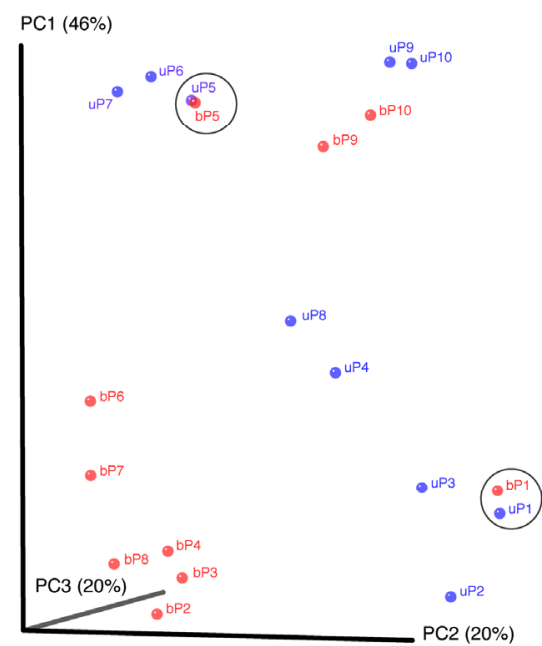

B

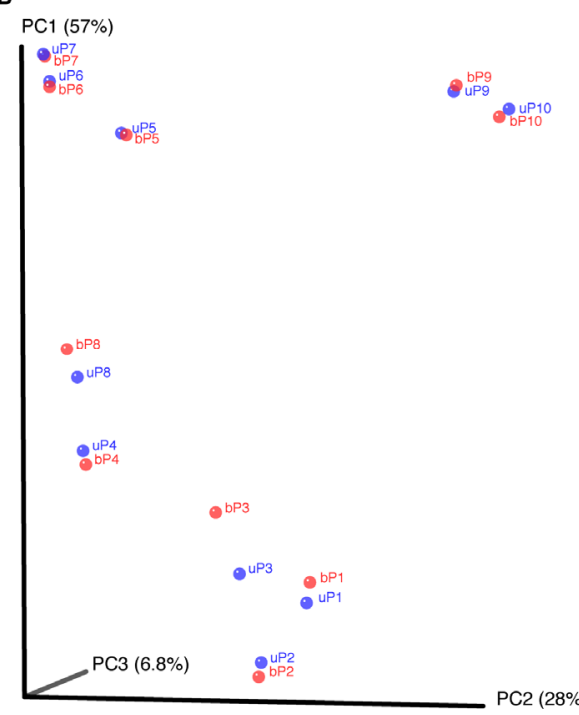

Figure 3: Principal Coordinate Analysis using the weighted UniFrac metric. (A) Sample pairs P9, P10 and in particular P1 and P5 cluster tightly together. These samples contain small or moderate numbers of bifidobacteria reads. (B) After removing bifidobacteria sequences from the analysis, all sample pairs cluster tightly showing that the main differences between the sets are due to the bifidobacteria sequences. $U=$ regular universal primers (926R), B - 'bifidobacteria-optimised' universal primers (926Rb). 


\section{Primers}

Primer specificity of the 926Rb primer was compared in silico against that of 926R using the Ribosomal Database Project's (RDP) Probe Match tool. Only sequences longer than $1200 \mathrm{bp}$, defined as good quality by the RDP were included and $92.4 \%$ of these were hit with 0 mismatches with primer $926 \mathrm{R}$ compared to $94.5 \%$ with $926 \mathrm{Rb}$. Although this overall increase was modest, the difference on looking specifically at the order Bifidobacteriales was very marked and highly significant: 926R hit just $0.2 \%$ of sequences compared to $97.1 \%$ with the 'bifidobacteria-optimised' primer.

\section{Discussion}

Appropriate primer selection in microbiota studies using a 16S rRNA approach is essential to enable faithful representation of the organisms present in the samples. The study of Palmer et al. (27) revealed that the overall efficiency of amplification of DNA from bifidobacterial species was eight-fold lower than that from non-bifidobacterial species using the $8 F / 1391 \mathrm{R}$ primer pair. Our results show that even a one base pair mismatch not at the 3' end of a primer can lead to a dramatic failure to amplify these organisms at all.

It is well known that Gram-positive organisms (such as bifidobacteria) can be underrepresented in microbial profiling studies due to the presence of their thick cell wall (34). Due to concern that poor representation of bifidobacteria from faecal samples may be due to difficulties in cell lysis during DNA extraction, we first assessed target sequence recovery from pure DNA mixtures. We were able to demonstrate with the DNA mixtures that the bias observed against the detection of bifidobacteria was due to the PCR step. This was also confirmed by using FISH analysis which does not require cell lysis. From the FISH results, the bifidobacteria proportions present in the faecal samples were in agreement with those generated from our robust DNA extraction method combined with our 'bifidobacteria-optimised' universal primers and pyrosequencing. 
Burgeoning interest in the development of the normal GI microbiota, and its impact on child and adult health, has led to increasing numbers of studies focusing on the bacterial colonisation of the gut (7). Metchnikoff's (35) suggestion that it is "possible to adopt measures to modify the flora in our bodies and to replace the harmful microbes by useful microbes" over a hundred years ago has led to the concept of manipulating the $\mathrm{GI}$ microbiota to counter disease. Furthermore, the use of probiotics as a treatment or prophylaxis strategy not only for disease, but also for modulating the immune system has now become a focus of intense attention (36). Due to the escalating use of probiotics, the World Health Organization have published specific criteria that a probiotic must fulfil (37). One important quality of a probiotic is that it must be able to survive the GI tract, even if this is transient. This means that studies assessing the effectiveness of probiotics must be able to accurately detect in at least semi-quantitative fashion these probiotics organisms in the GI microbiota.

We have demonstrated that erroneous conclusions as to the presence or absence, or relative proportions of, bifidobacteria are likely if universal primers which do not sufficiently complement the target sequence are used. The primers we have designed are able to detect bifidobacteria at low level abundance and can be used semi-quantitatively without distorting the proportions detected of other genera. This primer set can be successfully used in 16S rRNA pyrosequencing-based GI microbiota studies.

\section{Materials and methods}

\section{PCR primer design}

Primers 357F/926R (357F - CCTACGGGAGGCAGCAG, 926R CCGTCAATTCMTTTRAGT) were assessed for specificity using the ARB software package (38) and the SILVA 108 SSU Ref 16S rRNA database release (39). Almost all bifidobacteria (as well as some closely related Actinobacteria) were found to have a one base pair mismatch $(C \rightarrow T)$ to the 926R primer (CCGTCAATTCMTTTRAGT, mismatch in bold). 
A new 'bifidobacteria-optimised' universal primer (926Rb) was therefore synthesised in which a T/C redundancy was incorporated at the mismatch position: CCGTCAATTYMTTTRAGT (where $\mathrm{Y}$ is $\mathrm{T}$ or $\mathrm{C}$ ).

\section{Standard DNA Mixtures}

DNA was extracted from pure cultures of Bifidobacterium dentium, Streptococcus pneumoniae and Moraxella catarrhalis using the MP Bio Fast Soil DNA kit $囚$. An extra bead-beating step (40 seconds, speed $6.0 \mathrm{~m} / \mathrm{s}$ using the FastPrep $®$ FP120 Instrument, MP Biomedicals) was incorporated in order to ensure efficient lysis.

Total genomic DNA concentration was measured using the Quant-iT, PicoGreen DNA assay (Invitrogen).

Pre-defined mixtures using varying proportions of Bifidobacterium dentium, Streptococcus pneumoniae and Moraxella catarrhalis DNAs were prepared (Table 1). All three bacterial strains have 4 copies of the $16 \mathrm{~S}$ rRNA operon. Consequently, gene copy number is dependent only on the number of bacteria present.

\section{Faecal samples}

Faecal samples were collected from five healthy term infants at two time points, 4 weeks and 26 weeks of age. The samples were immediately frozen $\left(-12^{\circ} \mathrm{C}\right.$ to $\left.-20^{\circ} \mathrm{C}\right)$ prior to transfer (within one week of sampling) to $-80^{\circ} \mathrm{C}$ prior to evaluation.

Total DNA was extracted as described by Matsuki et al. (40) except that DNA was re-suspended in $0.1 \mathrm{ml}$ of TE (10 mM Tris- $\mathrm{HCl}, 1 \mathrm{mM}$ EDTA, $\mathrm{pH}$ 8.0).

\section{Barcoded 16S rRNA PCR and pyrosequencing}

The V3-V5 regions of the bacterial 16S rRNA gene were amplified using primers 357F with adaptor B from 454 Life Sciences for pyrosequencing: 5' CTATCCCCTGTGTGCCTTGGCAGTCTCAGCCTACGGGAGGCAGCAG 3', and either the standard 926R or the 'bifidobacteria-optimised' primer 926Rb ( $\mathrm{Y}$ in place of C, in bold): 5' CCATCTCATCCCTGCGTGTCTCCGACTCAG NNNNNNNNNNNN CCGTCAATTCMTTTRAGT 3'. In addition the reverse primers included the 454 Life Sciences adaptor $A$ and a unique 12 base-pair error-correcting Golay (41) barcode 
(denoted by 'Ns', see Table S1). This allows multiplexing of samples in a single run. Primers were obtained from Eurofins MWG Operon (Ebersberg, Germany) and HPSF purified.

PCR was carried out in quadruplicate to reduce random mispriming bias (17), and no-template PCR controls were included. Each $25 \mu$ reaction contained $1 \mu \mathrm{L}$ each of forward and reverse primers $(10 \mu \mathrm{M}), 1 \mu \mathrm{l}$ of template DNA, $0.25 \mu \mathrm{l}$ of $5 \mathrm{U} / \mu \mathrm{l}$ FastStart HiFi Polymerase (Roche, Mannheim, Germany), $1 \mu \mathrm{l}$ of $20 \mathrm{~g} / \mathrm{mL}$ BSA (Sigma, Dorset, United Kingdom), and $6.5 \mu$ l of $5 \mathrm{M}$ Betaine (Sigma). PCR reactions were assembled within a PCR hood in under clean conditions. Thermal cycling consisted of initial denaturation at $94^{\circ} \mathrm{C}$ for 2 minutes followed by 30 cycles of denaturation at $94^{\circ} \mathrm{C}$ for 20 seconds, annealing at $50^{\circ} \mathrm{C}$ for 30 seconds, and extension at $72^{\circ} \mathrm{C}$ for 5 minutes. The replicate amplicons were pooled, PEG precipitated (42) (20\%, MW $8000 \mathrm{~g} / \mathrm{mol})$ and visualized by staining with ethidium bromide $(10 \mathrm{mg} / \mathrm{mL})$ on a $1.0 \%$ agarose gel.

\section{Amplicon quantitation, pooling and pyrosequencing}

Amplicons were combined in a single tube in equimolar concentrations. The pooled amplicon mixture was purified twice (AMPure XP kit, Agencourt, Takeley, United Kingdom) and the cleaned pool requantified using the PicoGreen assay. This pool was then diluted in TE such that it contained $10^{5}$ molecules $/ \mu \mathrm{l}$. $30 \mu \mathrm{l}$ of this pool was added to the emulsion $\mathrm{PCR}$ reaction to attain a ratio of 0.3 molecules of amplicon per bead. Pyrosequencing was carried out on a 454 Life Sciences GS Junior instrument (Roche) following the Roche Amplicon Lib-L protocol.

\section{Bioinformatics}

Shotgun processed data was denoised using AmpliconNoise (43) as part of the QIIME (44) (Quantitative Insights Into Microbial Ecology) package followed by chimera-removal with Perseus (43). The sequences were aligned using the Greengenes core alignment set as reference (DeSantis et al 2006) and clustered at $97 \%$ sequence identity into OTUs. Representative sequences (most abundant) for each OTU were selected and classified using the Ribosomal Database Project Classifier. Rarefaction was performed so that the number of reads per sample would be identical. Beta diversity assessment of the reads obtained from the faecal samples 
using the two primer sets was carried out using the weighted UniFrac metric to generate principal coordinate analyses. Identification of OTUs that were significantly different in abundance was carried out in QIIME using a paired T-test with Bonferroni correction.

\section{Fluorescence in situ hybridisation}

To enumerate the Bifidobacterium genus by means of $\mathrm{FISH}$ the $16 \mathrm{~S}$ rRNA-targeted oligonucleotide probe: Bif164-mod 5'- CATCCGGYATTACCACCC-3' was used $(45,46)$. The probe was commercially synthesized and 5'-labelled with Cy3 (Biolegio B.V., Nijmegen, the Netherlands).

The FISH analysis was performed according to the method of Thiel (47), with some modifications. Briefly, portions of each faecal sample were fixed with $3 \%$ paraformaldehyde at $4^{\circ} \mathrm{C}$ for 16 hours. Following fixation, $1 \mathrm{ml}$ of the cell suspension was centrifuged at $8000 \times \mathrm{g}$ for $3 \mathrm{~min}$ and the cell pellet resuspended in $500 \mu \mathrm{l}$ of PBS buffer, mixed with $500 \mu \mathrm{l}$ of ethanol and then stored at $-20^{\circ} \mathrm{C}$ until use. $3 \mu \mathrm{l}$ of the fixed-cell suspension of the appropriate dilution (80, 160, 320 and 640-fold dilutions) was applied to chrome gelatine coated 18-well slides (Cel-Line HTC Super cured, Thermo Scientific Portsmouth, $\mathrm{NH}$ ) and the cell smears were dehydrated for 3 min each in $60 \%, 80 \%$ and $96 \%$ ethanol. After hybridization of the probe at $50^{\circ} \mathrm{C}$ for 16 hours, the slides were washed, dried, counterstained with 4',6-diamidino-2-phenylindole (DAPI) and mounted with Citifluor AF1 (Citifluor Ltd, London, United Kingdom).

Image acquisition and image analysis was performed using the $\operatorname{scan}^{\wedge} \mathrm{R}$ screening station (Olympus, Hamburg, Germany). The count and percentage of labelled bacteria per sample was determined in 25 positions divided over the well by counting all DAPI-stained bacteria and all doubly stained bacteria (DAPI and Cy3) in the same field of view using a quadruple band filter set (Set 84000, Chroma Technology Corp., Brattleboro, VT, USA). 


\section{Data Availability}

MIMARKS compliant (39) 16S rRNA amplicon data for the faecal samples has been deposited at MG-RAST (48) under accession numbers 4483884.3 to 4483903.3 (static link http://metagenomics.anl.gov/linkin.cgi?project=329).

\section{Ethics Statement}

The National Research Ethics Service (NRES) Committee London (Fulham) approved all protocols and procedures (ref: 10/H0711/39) and parents gave their full written consent for faecal sample collection.

\section{Acknowledgements}

Prof William Wade (King's College, London, United Kingdom) - for providing the Bifidobacterium dentium stocks. Mr. Geraint Barton (Bioinformatic Support Service - Imperial College London, United Kingdom) - for producing the heatmap and phylogenetic tree figures. The Winnicott Foundation for funding this study. 


\section{Supporting information}

Table S1: Barcoded primer sequences for $16 \mathrm{~S}$ rRNA PCR.

\begin{tabular}{|c|c|c|c|}
\hline \#SampleID & BarcodeSequence & LinkerPrimerSequence & MID \\
\hline uP1 & AACGCACGCTAG & CCGTCAATTCMTTTRAGT & MID1 \\
\hline uP2 & ACACTGTTCATG & CCGTCAATTCMTTTRAGT & MID2 \\
\hline uP3 & ACCAGACGATGC & CCGTCAATTCMTTTRAGT & MID3 \\
\hline uP4 & ACGCTCATGGAT & CCGTCAATTCMTTTRAGT & MID4 \\
\hline uP5 & ACTCACGGTATG & CCGTCAATTCMTTTRAGT & MID5 \\
\hline uP6 & AGACCGTCAGAC & CCGTCAATTCMTTTRAGT & MID6 \\
\hline uP7 & AGCACGAGCCTA & CCGTCAATTCMTTTRAGT & MID7 \\
\hline uP8 & ACAGACCACTCA & CCGTCAATTCMTTTRAGT & MID8 \\
\hline uP9 & ACCAGCGACTAG & CCGTCAATTCMTTTRAGT & MID9 \\
\hline uP10 & ACGGATCGTCAG & CCGTCAATTCMTTTRAGT & MID10 \\
\hline uB1 & AGCTTGACAGCT & CCGTCAATTCMTTTRAGT & MID11 \\
\hline uB2 & AACTGTGCGTAC & CCGTCAATTCMTTTRAGT & MID12 \\
\hline uB3 & ACCGCAGAGTCA & CCGTCAATTCMTTTRAGT & MID13 \\
\hline uB4 & ACGGTGAGTGTC & CCGTCAATTCMTTTRAGT & MID14 \\
\hline uB5 & ACTCGATTCGAT & CCGTCAATTCMTTTRAGT & MID15 \\
\hline bP1 & AGACTGCGTACT & CCGTCAATTYMTTTRAGT & MID1b \\
\hline bP2 & AGCAGTCGCGAT & CCGTCAATTYMTTTRAGT & MID2b \\
\hline bP3 & AGGACGCACTGT & CCGTCAATTYMTTRAGT & MID3b \\
\hline bP4 & AAGAGATGTCGA & CCGTCAATTYMTTTRAGT & MID4b \\
\hline bP5 & ACAGCAGTGGTC & CCGTCAATTYMTTTRAGT & MID5b \\
\hline bP6 & ACGTACTCAGTG & CCGTCAATTYMTTTRAGT & MID6b \\
\hline bP7 & ACTCGCACAGGA & CCGTCAATTYMTTTRAGT & MID7b \\
\hline bP8 & AGAGAGCAAGTG & CCGTCAATTYMTTTRAGT & MID8b \\
\hline bP9 & AGCATATGAGAG & CCGTCAATTYMTTTRAGT & MID9b \\
\hline bP10 & AGGCTACACGAC & CCGTCAATTYMTTTRAGT & MID10b \\
\hline bB1 & AAGCTGCAGTCG & CCGTCAATTYMTTTRAGT & MID11b \\
\hline bB2 & ACAGCTAGCTTG & CCGTCAATTYMTTTRAGT & MID12b \\
\hline bB3 & ACCTGTCTCTCT & CCGTCAATTYMTTTRAGT & MID13b \\
\hline bB4 & ACGTCTGTAGCA & CCGTCAATTYMTTTRAGT & MID14b \\
\hline bB5 & AGAGCAAGAGCA & CCGTCAATTYMTTTRAGT & MID15b \\
\hline & & & \\
\hline & & & \\
\hline
\end{tabular}




\section{References}

1. Turnbaugh PJ, Ley RE, Mahowald MA, Magrini V, Mardis ER, Gordon JI. An obesity-associated gut microbiome with increased capacity for energy harvest. Nature. 2006;444(7122):1027-31.

2. Forno E, Onderdonk AB, McCracken J, Litonjua AA, Laskey D, Delaney ML, et al. Diversity of the gut microbiota and eczema in early life. Clin Mol Allergy. 2008;6(1):11.

3. Hong P-Y, Lee BW, Aw M, Shek LPC, Yap GC, Chua KY, et al. Comparative Analysis of Fecal Microbiota in Infants with and without Eczema. PLoS One. 2010;5(4):e9964.

4. Zhu Y, Michelle Luo T, Jobin C, Young HA. Gut microbiota and probiotics in colon tumorigenesis. Cancer Lett. 2011;309(2):119-27.

5. Mshvildadze M, Neu J, Shuster J, Theriaque D, Li N, Mai V. Intestinal microbial ecology in premature infants assessed with non-culture-based techniques. J Pediatr. 2010;156(1):20-5.

6. Ivanov I, Littman DR. Modulation of immune homeostasis by commensal bacteria. Curr Opin Microbiol. 2011;14(1):106-14.

7. Fujimura KE, Slusher NA, Cabana MD, Lynch SV. Role of the gut microbiota in defining human health. Expert Rev Anti Infect Ther. 2010;8(4):435-54.

8. Weisburg WG, Barns SM, Pelletier DA, Lane DJ. 16S ribosomal DNA amplification for phylogenetic study. J Bacteriol. 1991;173(2):697-703.

9. Lane DJ, Pace B, Olsen GJ, Stahl DA, Sogin ML, Pace NR. Rapid determination of 16S ribosomal RNA sequences for phylogenetic analyses. Proc Natl Acad Sci U S A. 1985;82(20):6955-9.

10. Baker GC, Smith JJ, Cowan DA. Review and re-analysis of domain-specific 16S primers. J Microbiol Methods. 2003;55(3):541-55.

11. Wang Y, Qian PY. Conservative fragments in bacterial 16S rRNA genes and primer design for 16S ribosomal DNA amplicons in metagenomic studies. PLoS One. 2009;4(10):e7401.

12. Cole JR, Wang Q, Cardenas E, Fish J, Chai B, Farris RJ, et al. The Ribosomal Database Project: improved alignments and new tools for rRNA analysis. Nucleic Acids Res. 2009;37(Database issue):D141-5.

13. Sogin ML, Morrison HG, Huber JA, Welch DM, Huse SM, Neal PR, et al. Microbial diversity in the deep sea and the underexplored "rare biosphere". Proceedings of the National Academy of Sciences of the United States of America. 2006;103(32):12115 - 20.

14. Meyer AF, Lipson DA, Martin AP, Schadt CW, Schmidt SK. Molecular and metabolic characterization of cold-tolerant alpine soil Pseudomonas sensu stricto. Appl Environ Microbiol. 2004;70(1):483-9.

15. Hamady M, Knight R. Microbial community profiling for human microbiome projects: Tools, techniques, and challenges. Genome Res. 2009;19(7):1141-52.

16. Frank JA, Reich CI, Sharma S, Weisbaum JS, Wilson BA, Olsen GJ. Critical evaluation of two primers commonly used for amplification of bacterial 16S rRNA genes. Appl Environ Microbiol. 2008;74(8):2461-70.

17. Polz MF, Cavanaugh CM. Bias in template-to-product ratios in multitemplate PCR. Appl Environ Microbiol. 1998;64(10):3724-30.

18. Roger LC, McCartney AL. Longitudinal investigation of the faecal microbiota of healthy full-term infants using fluorescence in situ hybridization and denaturing gradient gel electrophoresis. Microbiology. 2010;156(Pt 11):3317-28.

19. Favier CF, de Vos WM, Akkermans AD. Development of bacterial and bifidobacterial communities in feces of newborn babies. Anaerobe. 2003;9(5):219-29. 
20. Boehm G, Stahl B, Jelinek J, Knol J, Miniello V, Moro GE. Prebiotic carbohydrates in human milk and formulas. Acta Paediatr Suppl. 2005;94(449):18-21.

21. Knol J, Scholtens P, Kafka C, Steenbakkers J, Gro S, Helm K, et al. Colon microflora in infants fed formula with galacto- and fructo-oligosaccharides: more like breast-fed infants. J Pediatr Gastroenterol Nutr. 2005;40(1):36-42.

22. Boesten R, Schuren F, Ben Amor K, Haarman M, Knol J, de Vos WM. Bifidobacterium population analysis in the infant gut by direct mapping of genomic hybridization patterns: potential for monitoring temporal development and effects of dietary regimens. Microb Biotechnol. 2011;4(3):417-27.

23. van Limpt C, Crienen A, Vriesema A, Knol J. Effect of Colonic Short Chain Fatty Acids, Lactate and Ph on the Growth of Common Gut Pathogens. Pediatric research. 2004;56(3):487, abstract 134.

24. Picard C, Fioramonti J, Francois A, Robinson T, Neant F, Matuchansky C. Review article: bifidobacteria as probiotic agents -- physiological effects and clinical benefits. Aliment Pharmacol Ther. 2005;22(6):495-512.

25. Ouwehand AC. Antiallergic effects of probiotics. J Nutr. 2007;137(3 Suppl 2):794S-7S.

26. van der Aa LB, van Aalderen WM, Heymans HS, Henk Sillevis Smitt J, Nauta AJ, Knippels LM, et al. Synbiotics prevent asthma-like symptoms in infants with atopic dermatitis. Allergy. 2011;66(2):170-7.

27. Palmer C, Bik EM, DiGiulio DB, Relman DA, Brown PO. Development of the human infant intestinal microbiota. PLoS Biol. 2007;5(7):e177.

28. Muyzer G, de Waal EC, Uitterlinden AG. Profiling of complex microbial populations by denaturing gradient gel electrophoresis analysis of polymerase chain reaction-amplified genes coding for $16 \mathrm{~S}$ rRNA. Appl Environ Microbiol. 1993;59(3):695-700.

29. Muyzer G, Teske A, Wirsen CO, Jannasch HW. Phylogenetic relationships of Thiomicrospira species and their identification in deep-sea hydrothermal vent samples by denaturing gradient gel electrophoresis of 16S rDNA fragments. Arch Microbiol. 1995;164(3):165-72.

30. Peterson J, Garges S, Giovanni M, Mclnnes P, Wang L, Schloss JA, et al. The NIH Human Microbiome Project. Genome Res. 2009;19(12):2317-23.

31. NIH Human Microbiome Project website. Accessed 2012 Feb 2. [Available from: https://www.hmpdacc.org/hmp/doc/16S Sequencing SOP 4.2.2.pdf.

32. Martin Bland J, Altman D. Statistical Methods for Assessing Agreement between Two Methods of Clinical Measurement. The Lancet. 1986;327(8476):307-10.

33. Lozupone C, Hamady M, Knight R. UniFrac--an online tool for comparing microbial community diversity in a phylogenetic context. BMC bioinformatics. 2006;7:371.

34. de Boer R, Peters R, Gierveld S, Schuurman T, Kooistra-Smid M, Savelkoul P. Improved detection of microbial DNA after bead-beating before DNA isolation. J Microbiol Methods. 2010;80(2):209-11.

35. Metchnikoff E. Lactic acid as inhibiting intestinal putrefaction. In: The prolongation of life: Optimistic studies. London: W Heinemann. 1907:161-83.

36. Macpherson AJ, Harris NL. Interactions between commensal intestinal bacteria and the immune system. Nat Rev Immunol. 2004;4:478 - 85.

37. FAO/WHO. Probiotics in food : health and nutritional properties and guidelines for evaluation. Rome :: Food and Agriculture Organization of the United Nations : World Health Organization, 2006.; 2001. viii, 50 p. : ill. ; $30 \mathrm{~cm} \mathrm{p}$.

38. Ludwig W, Strunk O, Westram R, Richter L, Meier H, Yadhukumar, et al. ARB: a software environment for sequence data. Nucleic Acids Res. 2004;32(4):1363-71. 


\section{Chapter 3}

39. Field D, Garrity G, Gray T, Morrison N, Selengut J, Sterk P, et al. The minimum information about a genome sequence (MIGS) specification. Nature Biotechnology. 2008;26:541.

40. Matsuki T, Watanabe K, Fujimoto J, Kado Y, Takada T, Matsumoto K, et al. Quantitative PCR with 16S rRNA-gene-targeted species-specific primers for analysis of human intestinal bifidobacteria. Appl Environ Microbiol. 2004;70(1):167-73.

41. Fierer N, Hamady M, Lauber CL, Knight R. The influence of sex, handedness, and washing on the diversity of hand surface bacteria. Proc Natl Acad Sci U S A. 2008;105(46):17994-9.

42. Sambrook J, Russell D. Molecular Cloning: A Laboratory Manual: New York: Cold Spring Harbor Laboratory Press; 2001.

43. Quince C, Lanzen A, Davenport RJ, Turnbaugh PJ. Removing noise from pyrosequenced amplicons. BMC Bioinformatics. 2011;12(1):38.

44. Caporaso JG, Kuczynski J, Stombaugh J, Bittinger K, Bushman FD, Costello EK, et al. QIIME allows analysis of high-throughput community sequencing data. Nat Methods. 2010;7(5):335-6.

45. Langendijk PS, Schut F, Jansen GJ, Raangs GC, Kamphuis GR, Wilkinson MH, et al. Quantitative fluorescence in situ hybridization of Bifidobacterium spp. with genus-specific 16S rRNA-targeted probes and its application in fecal samples. Appl Environ Microbiol. 1995;61(8):3069-75.

46. Satokari RM, Vaughan EE, Akkermans AD, Saarela M, De Vos WM. Polymerase chain reaction and denaturing gradient gel electrophoresis monitoring of fecal bifidobacterium populations in a prebiotic and probiotic feeding trial. Syst Appl Microbiol. 2001;24(2):227-31.

47. Thiel R, Blaut M. An improved method for the automated enumeration of fluorescently labelled bacteria in human faeces. J Microbiol Methods. 2005;61(3):369-79.

48. Meyer F, Paarmann D, D'Souza M, Olson R, Glass EM, Kubal M, et al. The metagenomics RAST server a public resource for the automatic phylogenetic and functional analysis of metagenomes. BMC Bioinformatics. 2008;9:386. 
Improved detection of bifidobacteria 



\section{CHAPTER 4}

\section{Intestinal microbiota in high-risk \\ infants: Effects of prebiotics and role in eczema development}

Wopereis $\mathrm{H}^{1,2}, \operatorname{Sim~} \mathrm{K}^{3}$, Shaw $\mathrm{A}^{3}$, Warner $\mathrm{JO}^{3}$, Knol $\mathrm{J}^{1,2}$, Kroll $\mathrm{JS}^{3}$.

${ }^{1}$ Danone Nutricia Research, Utrecht, the Netherlands ${ }^{2}$ Laboratory of Microbiology, Wageningen University, Wageningen, the Netherlands ${ }^{3}$ Department of Medicine, Section of Paediatrics, Imperial College London, London, UK Journal of Allergy and Clinical Immunology 2018;141(4):1334-42 e5. (minor modifications). 


\section{Abstract}

Background: The development of gut microbiota in infancy is important in the maturation of the immune system. Deviations in colonization patterns have been associated with allergic manifestations, but exact microbiome dysfunctions underlying allergies remain unclear. We studied the gut microbiota of 138 infants at increased risk of developing allergy, participating in a clinical trial investigating the effectiveness of a partially hydrolyzed protein formula supplemented with non-digestible oligosaccharides (pHF-OS) on the prevention of eczema.

Objective: The effects of the interventions and breastfeeding on fecal microbiota were investigated. Additionally, we aimed to identify microbial patterns associated with the onset of eczema.

Methods: Bacterial taxonomic compositions in the first 26 weeks of life were analyzed using $16 \mathrm{~S}$ rRNA-gene sequencing. Additionally, fecal $\mathrm{pH}$ and microbial metabolites were measured.

Results: Fecal microbial composition, metabolites and $\mathrm{pH}$ of infants receiving pHF-OS was closer to breastfed infants than to infants receiving standard cow's milk formula. Infants with eczema by 18 months showed discordant development of bacterial genera of Enterobacteriaceae and Parabacteroides spp. in the first 26 weeks, as well as decreased acquisition of lactate-utilizing bacteria producing butyrate, namely Eubacterium and Anaerostipes spp., supported by increased lactate and decreased butyrate levels at 26 weeks.

Conclusions: We showed that a pHF with specific prebiotics modulated the gut microbiota closer to that of breastfed infants. Additionally, we identified a potential link between the microbial activity and onset of eczema, which may reflect a suboptimal implementation of gut microbiota at specific developmental stages in infants at high-risk for allergy. 


\section{Graphical abstract}

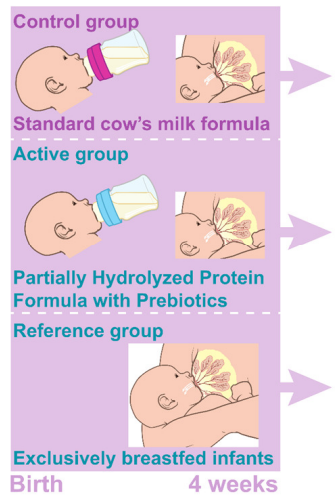

Birth
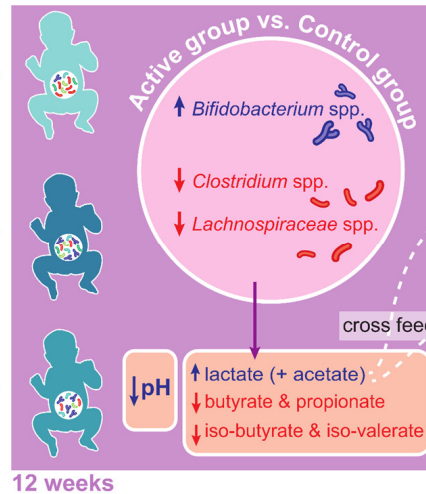

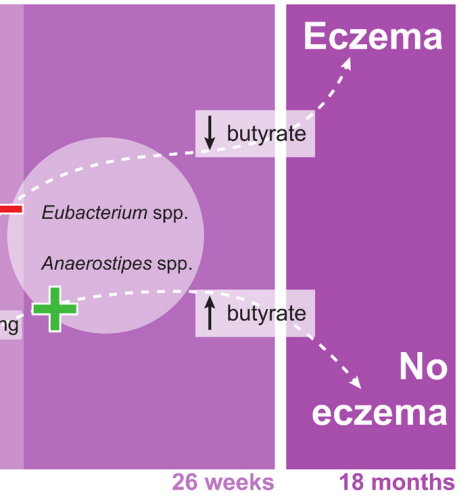

\section{Introduction}

Gut microbial development in the first years of life occurs concomitantly to the development of our cognitive, metabolic and immune systems, and form an interactive signaling network (1). The gradual diversification towards a relatively stable adult-like composition is a dynamic process influenced by several environmental factors such as birth mode, gestational age at birth and early life nutrition. Alterations in the early colonization process, e.g. through antibiotic-use or C-section delivery, have been associated with development of allergic manifestations later in life, but the exact microbiome dysfunction underlying this disease remains unclear (2).

Eczema is typically the first allergic manifestation to appear, and its incidence is still increasing in many countries around the world. Considering the concurrent maturation of the immune system, the succession of species into a stable adult-type community, a process naturally guided by human milk, may be critically important. Breastfeeding is thought to protect against the development of allergy, via the presence of allergens and immune mediators in human milk that are absent from artificial milks (3), as well as via the presence of human milk oligosaccharides stimulating a gut microbiota which may favor tolerance induction (4).

Therefore, several studies have been performed with different types of infant formulas (IF) enriched with non-digestible oligosaccharides, known as prebiotics. 
Prebiotics typically reach the colon intact and selectively stimulate the growth and activity of specific beneficial members of the microbiota $(5,6)$. Interestingly, significant reductions in eczema risk were observed in intervention trials with IF supplemented with specific prebiotics (7-9).

The present study arises from a parent registered study (PATCH trial) investigating the effects of a partially hydrolyzed formula containing specific oligosaccharides (pHF-OS) on the prevention of eczema in infants at increased risk to develop allergy. The pHF-OS was shown to induce hypo-antigenic and immune-modulatory effects including increased regulatory $T$ cell numbers (Treg), but did not reduce eczema incidence by 12 or 18 months, when compared with infants receiving standard cow's milk formula (10).

In this work, 16S ribosomal RNA (rRNA)-gene sequencing was applied to obtain an in-depth characterization of the microbiota composition of feces collected at 4 and 26 weeks of age in a subset of vaginally born infants, including breastfed infants $(n=30)$ and infants randomized to receive pHF-OS $(n=51)$ or standard cow's milk formula (control, $\mathrm{n}=57$ ). In addition, fecal $\mathrm{pH}$, levels of lactate and short-chain fatty acids (SCFA) were determined in the stool specimens collected at 4, 12 and 26 weeks of age.

There were two primary aims of this study: (i) to investigate whether a pHF-OS could modulate the developing gut microbiota closer to that of breastfed infants, and (ii) to identify patterns in the developing gut microbiota that may be implicated in the onset of eczema. The findings in this study confirm the major influence of early life nutrition on the assembly of the gut microbiota and provide new insights in how deviations in this assembly are associated with the development of eczema.

\section{Materials and methods}

\section{Study design and fecal sample selection}

This study arises from a double-blind, randomized, controlled parallel-group nutritional intervention trial in infants with a parental history of allergic disease, conducted in 10 specialist pediatric centers in Australia, Singapore, England and 
Ireland from April 2006 to March 2011 as described elsewhere (10). In total 1047 infants were recruited and consisted of three groups of participants. The breastfed reference group consisted of exclusively breastfed infants for the first 18 weeks of life. Participants who chose to stop breastfeeding or to supplement with formula before 18 weeks of age, were randomized to receive either partially hydrolyzed whey protein-dominant infant formula containing short-chain galacto-oligosaccharides and long-chain fructo-oligosaccharides (scGOS/lcFOS) $(9: 1) \quad(0.68 \mathrm{~g} / 100 \mathrm{ml}$ ) and pectin-derived acidic oligosaccharides (pAOS) $(0.12 \mathrm{~g} / 100 \mathrm{ml})$, or standard cow's milk formula (control), up to 26 weeks of age. Information of trial ethics approvals, monitoring and regulatory compliance are summarized in the Online Repository (PATCH trial, study registration ISRCTN65195597 14th February 2006).

Fecal samples for microbial analysis were selected from infants that met the following criteria: infants (I) were randomized to investigational formula before 4 weeks of age, or were part of the breastfed reference group ( $n=942$ infants), (II) vaginally-born (normal or instrumental delivery) ( $n=673$ infants), (III) with stool specimens available at 4 and 26 weeks of age ( $n=324$ infants). A subset of these infants was randomly selected to obtain 60 infants for each formula group and 30 breastfed reference infants ( $n=150$ infants).

\section{Sample collection and preparation}

The infants' fecal samples were collected by the parents into $10 \mathrm{ml}$ stool containers (Greiner Bio-One, Kremsmünster, Austria), immediately frozen $\left(-12^{\circ} \mathrm{C}\right.$ to $-20^{\circ} \mathrm{C}$ ) and transported within three months to the hospital. Upon arrival at the hospital and prior to evaluation at the laboratory, samples were kept and transported at $-80^{\circ} \mathrm{C}$. Frozen stool samples were defrosted on ice and stool $\mathrm{pH}$ was measured using a $\mathrm{pH}$ meter equipped with a glass-body $\mathrm{pH}$ electrode (Mettler-Toledo, Columbus, USA). Fecal samples were 10-fold diluted in PBS buffer (150 mM NaCl, 10 $\mathrm{mM} \mathrm{Na} 2 \mathrm{HPO} 4,20 \mathrm{mM} \mathrm{NaH}_{2} \mathrm{PO}_{4}, \mathrm{pH} 7.4$ ), and 5-10 glass beads (3 mm in diameter) were added to homogenize the sample by vortexing for 3 minutes, followed by centrifugation (300×g for 1 minute). Several $1 \mathrm{ml}$ portions of supernatant were stored at $-80^{\circ} \mathrm{C}$ for downstream processing. 


\section{S rRNA gene sequencing and bioinformatics}

Fecal suspensions of $200 \mu$ l were mixed with $450 \mu$ l DNA extraction buffer (100 $\mathrm{mM}$ Tris- $\mathrm{HCl}, 40 \mathrm{mM}$ EDTA, $\mathrm{pH}$ 9.0) and $50 \mu \mathrm{l}$ of $10 \%$ sodium dodecyl sulfate. Phenol-chloroform extractions combined with beat-beating were performed as described by Matsuki, et al. (11) except that extracted DNA was re-suspended in 0.1 $\mathrm{ml}$ of TE (10 mM Tris-HCl, 1 mM EDTA, pH 8.0).

The V3-V5 regions of the 16S rRNA gene were amplified using forward primer 357F, and a 'bifidobacteria-optimised' reverse primer 926Rb (12). 16S rDNA PCR was carried out in quadruplicate and pyrosequenced in three 454 GS FLX (Roche, Branford, CT, USA) runs as previously described (12). Raw pyrosequencing data for all samples has been deposited in the Sequence Read Archive under accession number PRJEB19801.

The 'Quantitative Insights Into Microbial Ecology' (QIIME) v1.5.0 package was used to analyse sequence data (13) as previously described (12), except that alignments were carried out using the SILVA rRNA database (SSU_REF108) (14).

\section{Fecal SCFA and lactic acid}

Fecal suspensions were thawed on ice and centrifuged for 10 minutes at $14.000 \times \mathrm{g}$. Then, $350 \mu \mathrm{l}$ supernatant was inactivated by heating for 10 minutes at $100^{\circ} \mathrm{C}$, followed by centrifugation. A portion of the supernatant was used to quantitatively determine the SCFAs: acetic, propionic, n-butyric, iso-butyric, iso-valeric and n-valeric acid by gas chromatography, as described previously (15). Another portion of the supernatant was used to enzymatically analyze levels of lactate using a D-/L-lactic acid assay kit (Megazyme, Wicklow, Ireland).

\section{Data handling and statistical analyses}

Multivariate statistical analyses of $16 \mathrm{~S}$ rRNA-gene sequencing data (taxonomic dataset) and levels of SCFAs and lactate (metabolite dataset) were performed by a combination of constrained ordination methods using the Canoco 5 software (16), and differential abundance testing using the R-package MetagenomeSeq (17).

Counts of Operational Taxonomic Units (OTUs) were aggregated at genus level (resulting in 142 genera), normalized by total sum scaling and $\log _{2}$-transformed. 
Genera present in less than 10 samples were discarded to remove sparse taxa, resulting in 58 features that were used as input for statistical analyses.

Monte Carlo Permutation tests (MCPT) were used to evaluate statistical significance $(P \leq 0.05)$ of explanatory variables (constraints) in the ordination analyses performed. Benjamini-Hochberg false-discovery rate was used to account for multiple comparisons (18), with significance for adjusted P-values (P-adj) at 0.05, except for taxonomic features associated with eczema development, for which significance was considered at 0.1 .

Canonical correspondence analysis (CCA) was applied on the taxonomic dataset, as the unimodal model was found to best fit the relative abundances of the bacterial genera (19). Forward selection was applied to identify sample covariates that best explained the variation in microbial taxonomic composition (20), and these were subsequently used in all multivariate models and comparisons performed, either as explanatory variables or as covariates. Temporal changes of bacterial metabolites were assessed using a linear ordination method, known as principal response curves (PRC) (21), as the linear model was found to best fit the bacterial metabolite dataset.

Univariate data analyses were performed using GraphPad Prism version 6.02 for Windows (GraphPad Software, La Jolla, California, USA), applying Mann-Whitney test for two-group comparisons, and one-way ANOVA with Bonferroni's multiple comparisons test for three-group comparisons, with significance at 0.05 .

\section{Results}

\section{Effects of pHF-OS on microbial richness and diversity.}

In total, 12 of the 150 selected infants did not have stool specimens available at 4 and 26 weeks. The characteristics of the remaining 138 participants are summarized in Table 1. Pyrosequencing was performed on stool specimens collected at 4 and 26 weeks of age, representing the specimens taken after randomization and at the end of the intervention period, respectively. Most of the randomized infants were already receiving formula before 4 weeks of age (Table 1). A total of 8 specimens collected at 4 weeks had insufficient amounts for preparation. The 
remaining 268 samples were successfully sequenced with a mean sequence depth of 6211 reads and a mean read length of 521 nucleotides (Table S1).

Microbial richness and diversity of the different feeding groups was assessed at a sequence depth of 1636 reads. Richness was expressed as the number of unique OTUs (observed species) and diversity was assessed using the shannon index for diversity (22). No differences between the randomization groups were observed, but the breastfed reference group showed a significantly lower richness at 26 weeks when compared to control-fed infants (1-way ANOVA, $\mathrm{P}<0.05)$ (Figure $1 \mathrm{~A}$ ) and lower diversity at both 4 and 26 weeks (1-way ANOVA, $P<0.01$ and $P<0.05$, respectively) (Figure 1B).

A

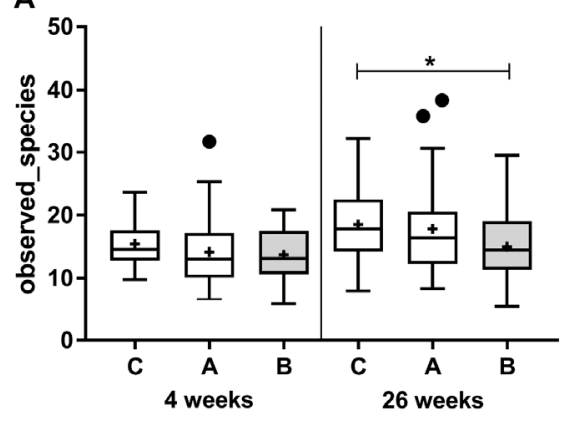

B

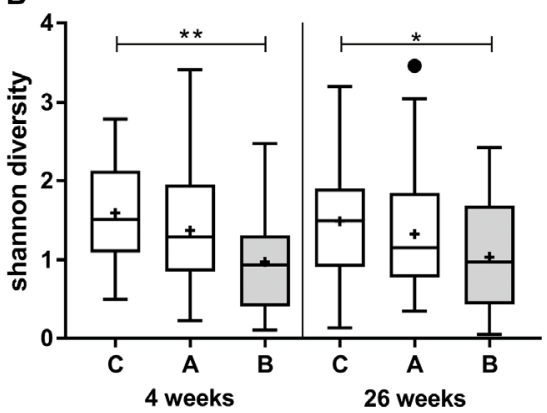

Figure 1: Box-whisker plots (Tukey method) summarizing microbial intestinal richness (Fig. 1A) and shannon diversity (Fig. 1B) at 4 and 26 weeks of age in breastfed infants $(B)$ and infants receiving pHF-OS $(A)$ or control formula $(C)$. The centre line shows the median, the + denotes the mean, and the boxes cover the 25 th and 75 th percentiles with the whiskers extending to the data points, which are no more than 1.5 times the length away from the box. Points outside the whiskers represent outlier samples. Comparisons were done at a sequencing depth of 1636 reads per sample. Statistics were performed by a one-way ANOVA with Bonferroni's multiple comparison correction $\left({ }^{*}=\mathrm{P}<0.05,{ }^{* *}=\mathrm{P}<0.01\right)$. 
Table 1: Characteristics of the study population.

\begin{tabular}{|c|c|c|c|}
\hline & $\begin{array}{c}\text { Control } \\
(\mathbf{n = 5 7 )}\end{array}$ & $\begin{array}{c}\text { pHF-OS } \\
(\mathbf{n = 5 1 )}\end{array}$ & $\begin{array}{c}\text { Breastfed } \\
\text { (n=30) }\end{array}$ \\
\hline Started formula before 4w & $54(95 \%)$ & $48(84 \%)$ & N/A \\
\hline Male Sex & $23(40 \%)$ & $30(59 \%)$ & $18(60 \%)$ \\
\hline Birthweight (g) & $3317(502)$ & $3461(442)$ & $3606(393)$ \\
\hline Both parents allergic & $11(19 \%)$ & $6(12 \%)$ & $11(37 \%)$ \\
\hline Only mother allergic & $33(58 \%)$ & $29(57 \%)$ & $11(37 \%)$ \\
\hline Only father allergic & $13(23 \%)$ & $16(31 \%)$ & $8(27 \%)$ \\
\hline Pet at home & $11(19 \%)$ & $22(43 \%)$ & $7(23 \%)$ \\
\hline At least one sibling & $28(49 \%)$ & $27(53 \%)$ & $22(73 \%)$ \\
\hline Vaginal delivery & $46(81 \%)$ & $41(80 \%)$ & $25(83 \%)$ \\
\hline Instrumental delivery & $11(19 \%)$ & $10(20 \%)$ & $5(17 \%)$ \\
\hline Caucasian ethnicity & $16(28 \%)$ & $28(55 \%)$ & $25(83 \%)$ \\
\hline Asian ethnicity & $35(61 \%)$ & $21(41 \%)$ & $2(7 \%)$ \\
\hline Other ethnicity & $6(12 \%)$ & $2(4 \%)$ & $3(10 \%)$ \\
\hline Australia & $13(23 \%)$ & $14(27 \%)$ & $13(43 \%)$ \\
\hline Ireland & $4(7 \%)$ & $10(20 \%)$ & $5(17 \%)$ \\
\hline Singapore & $35(61 \%)$ & $21(41 \%)$ & $2(7 \%)$ \\
\hline UK & $5(9 \%)$ & $6(12 \%)$ & $10(33 \%)$ \\
\hline Eczema by 12 months & $15(26 \%)$ & $17(33 \%)$ & $12(40 \%)$ \\
\hline Eczema by 18 months & $18(32 \%)$ & $20(39 \%)$ & $14(47 \%)$ \\
\hline Antibiotics by 26 weeks & $6(11 \%)$ & $12(24 \%)$ & $3(10 \%)$ \\
\hline
\end{tabular}

Continuous data are presented as mean (standard deviation). N/A: Not Applicable.

\section{pHF-OS modulates the microbial composition closer to breastfed infants.}

The majority of OTUs were assigned to 4 phyla, namely Actinobacteria (65.0\%), Firmicutes (24.8\%), Proteobacteria (8.6\%) and Bacteroidetes (1.5\%) (Table S2). The weighted UniFrac distance metric, which is based on phylogenetic distances and relative abundances of bacterial taxa in a pairwise comparison of samples (23), was used to assess the overall (dis)similarity in bacterial composition comparing pHF-OS with the control group and their respective distances to the breastfed reference group. Gut microbial compositions of infants receiving pHF-OS were found to be significantly more similar to those of breast-fed infants than the compositions of control group to breast-fed infants at 26 weeks (1-way ANOVA, $\mathrm{P}<0.0001)$ (Figure 2A). 
A

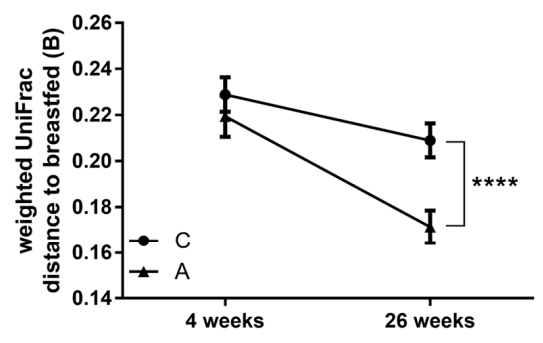

C

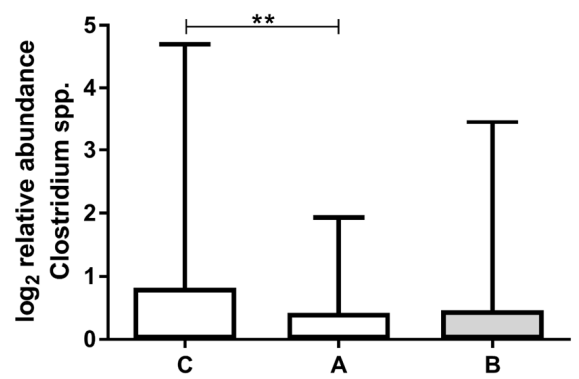

B

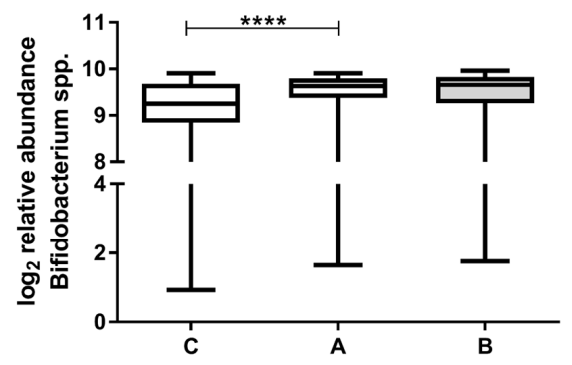

D

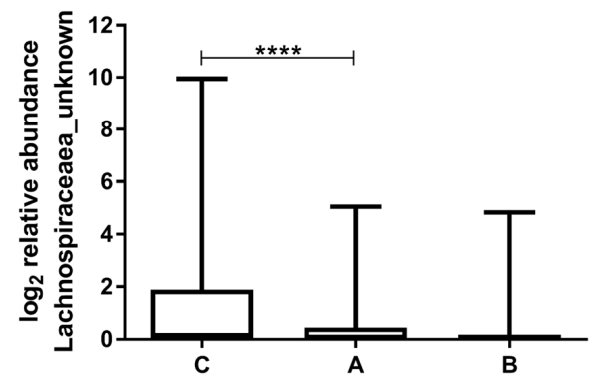

Figure 2: A, Line plots (mean with $95 \%$ confidence interval) summarizing weighted UniFrac distances at 4 and 26 weeks in infants receiving pHF-OS (A) or control formula (C) relative to breastfed infants (B). Distances are measured on a scale from $0-1$, with 0 meaning $100 \%$ identical and 1 meaning $0 \%$ identical gut microbial composition. Statistical comparison of weighted UniFrac was performed by a one-way ANOVA with Bonferroni's multiple comparison correction ( ${ }^{* * * *}=\mathrm{P}$-adj<0.0001). B-D, Boxplots summarizing log2-transformed levels of differential abundant genera, present in $>15 \%$ of the samples and a mean relative abundance $>0.1 \%$, when comparing pHF-OS with control formula at 26 weeks, namely: Bifidobacterium species (Fig. 2B), Clostridium species (Fig. 2C) and an unassigned genus of Lachnospiraceae (Fig. 2D). Differential abundances were computed with MetagenomeSeq with correction for effects of ethnicity and having siblings and adjustment of significance values for multiple comparisons using Benjamini-Hochberg false discovery rate ${ }^{* *}=\mathrm{P}$-adj $<0.01,{ }^{* * * *}$ $=\mathrm{P}-\mathrm{adj}<0.0001$.

In order to identify sample covariates that best explained the taxonomic composition of the fecal samples, canonical correspondence analysis (CCA) was combined with forward selection of variables (20). This analysis identified time (age in weeks), ethnicity (Asian, Caucasian, other), feeding group (control, pH-OS, breastfed) and having siblings (yes/no) as the factors significantly explaining the taxonomic variation ( $\mathrm{P}$-adj $<0.05$, Table S3). MetagenomeSeq (17) was subsequently used to 
assess which bacterial taxa accounted for the differences observed in weighted UniFrac at 26 weeks, while correcting for the covariates identified. Infants receiving pHF-OS were discriminated from control by increased levels of Bifidobacterium and decreased levels of Clostridium and an unassigned genus of Lachnospiraceae (Figure 2B-D).

\section{pHF-OS modulates the microbial activity closer to breastfed infants.}

Principal response curves (PRC) were used to assess temporal effects of the feeding groups on fecal compositions of SCFA and lactate in stool specimens collected at 4,12 and 26 weeks, respectively.

A

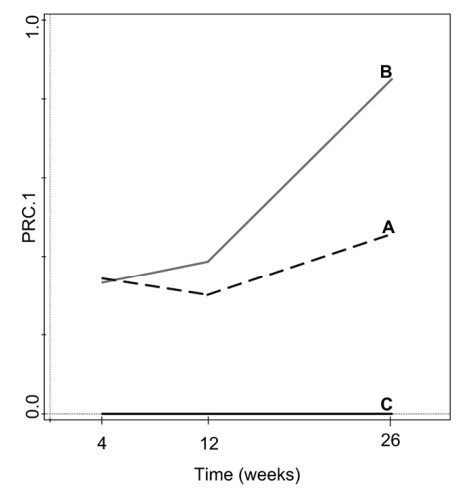

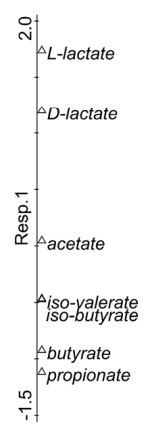

B

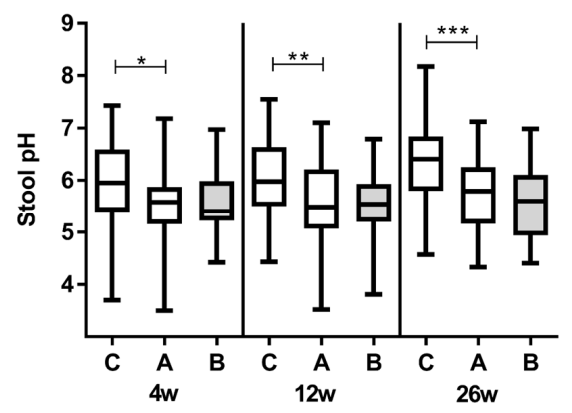

Figure 3: A, Principal Response Curves showing changes in bacterial metabolites (levels of SCFA and lactic acids) across time and its interaction with the different feeding groups. The horizontal axis represents time and the vertical axis the PRC score values. Fecal metabolite composition of infants receiving control formula (C) was used as reference level and has zero PRC values and so its curve lays over the horizontal axis. Changes for infants being breastfed (B) or receiving PHF-OS (A) are shown as response curves relative to this reference. Metabolite response scores are shown on the separate vertical (one-dimensional) plot. The multiple of the PRC score with the response score provides a quantitative interpretation as well as the direction of the change at the respective timepoints (4, 12 and 26 weeks). Significance of the interaction, corrected for covariates, was tested using MCPT ( $P=0.002,499$ permutations). B, Boxplots summarizing stool pH at 4, 12 and 26 weeks for the different feeding groups. Statistical comparison was performed by a one-way ANOVA with Bonferroni's multiple comparison correction comparing pHF-OS to control formula $\left({ }^{*}=\mathrm{P}-\operatorname{adj}<0.05,{ }^{* *}=\mathrm{P}-\mathrm{adj}<0.01,{ }^{* * *}=\mathrm{P}\right.$-adj $\left.<0.001\right)$. 
The interaction of feeding group with time, corrected for ethnicity and having siblings, was significant on the first constrained axis (explained variation $=80.3 \%$, MCPT: $\mathrm{P}=0.002$ with 499 permutations). Both the metabolite composition of breastfed infants and infants receiving pHF-OS were characterized by increased proportions of D- and L-lactate at 4, 12 and 26 weeks and decreased proportions of propionate, butyrate and branched-chain SCFA (iso-butyrate and iso-valerate) in contrast to the control group (Figure $3 \mathrm{~A}$ ). Moreover, infants receiving pHF-OS were found to have significantly decreased stool $\mathrm{pH}$ at all timepoints compared to infants receiving control formula with ranges similar as observed for breastfed infants (Figure 3B).

\section{Aberrant temporal dynamics in infants developing eczema in the first 18 months of life.}

In total, 52 of the 138 infants developed eczema in the first 18 months of life (Table 1). No differences in bacterial richness or diversity were observed at 4 or 26 weeks comparing eczematous to non-eczematous infants (Figure S1). PRC were used to investigate the fecal metabolite composition over time for infants developing eczema as compared to infants that did not, while correcting for the covariates identified (ethnicity, feeding group and having siblings). Significant temporal differences on the first constrained axis produced (explained variation $=84.4 \%$, MCPT: $P=0.034$ with 499 permutations) were observed for the interaction (Figure $4 A$ ). Differential dynamics were most pronounced from 12 to 26 weeks of age. Infants developing eczema were characterized by decreased levels of both isomers of lactate and increased levels of propionate and butyrate at 12 weeks. This pattern was reversed at 26 weeks of age, with infants developing eczema showing increased levels of lactate and decreased levels of propionate and butyrate. No significant differences were observed in stool pH (Figure 4B). 
A

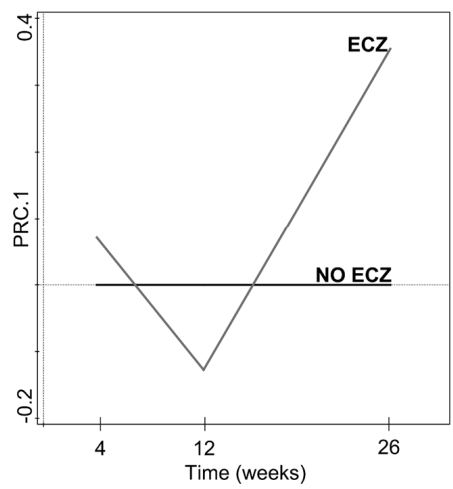

B

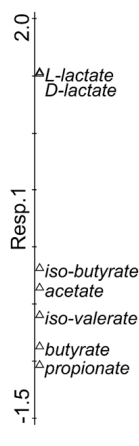

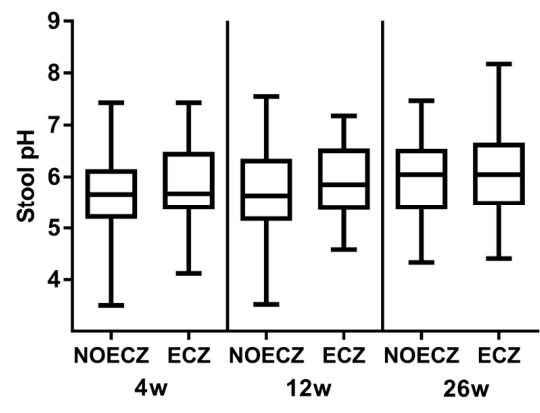

Figure 4: A, Principal Response Curves showing changes in bacterial metabolites (levels of SCFA and lactic acids) across time and its interaction with developing eczema. The horizontal axis represents time and the vertical axis the PRC score values. The fecal metabolite composition of infants not developing eczema (NOECZ) were used as reference level and has zero PRC values. The change for infants developing eczema in the first 18 months of life (ECZ) is shown as a response curve relative to this reference. Metabolite response scores are shown on the separate vertical (one-dimensional) plot. Significance of the interaction, corrected for the effects of feeding group, ethnicity and having siblings, was tested using MCPT ( $P=0.034$, 499 permutations). B, Boxplots summarizing stool $\mathrm{pH}$ at 4,12 and 26 weeks in infants developing eczema vs. healthy infants. Statistical comparison was performed by a one-way ANOVA with Bonferroni's multiple comparison correction (not significantly different).

\section{Decreased microbial conversion of lactic acid into butyrate in infants developing eczema.}

MetagenomeSeq was used to assess differential abundances of bacterial taxa over time and which of those were discordant in infants with eczema compared to infants without eczema. The comparisons were corrected for the identified covariates (Figure 5A). Decreases of Staphylococcus and Streptococcus over time were observed in both healthy infants and infants developing eczema. Two genera of Lachnospiraceae (Blautia and an unassigned genus designated as "Other") and Erysipelotrichaceae were found to increase over time in both groups. The genus Bifidobacterium was found to increase over time in healthy infants and to decrease in infants developing eczema, however this pattern was not significantly different comparing the two groups $(\mathrm{P}-\mathrm{adj}=0.115)$. Discordant patterns over time were 
observed for two genera of Enterobacteriaceae, namely Enterobacter (P-adj<0.001) and an unassigned genus of Enterobacteriaceae (P-adj< $<0.1)$.

A

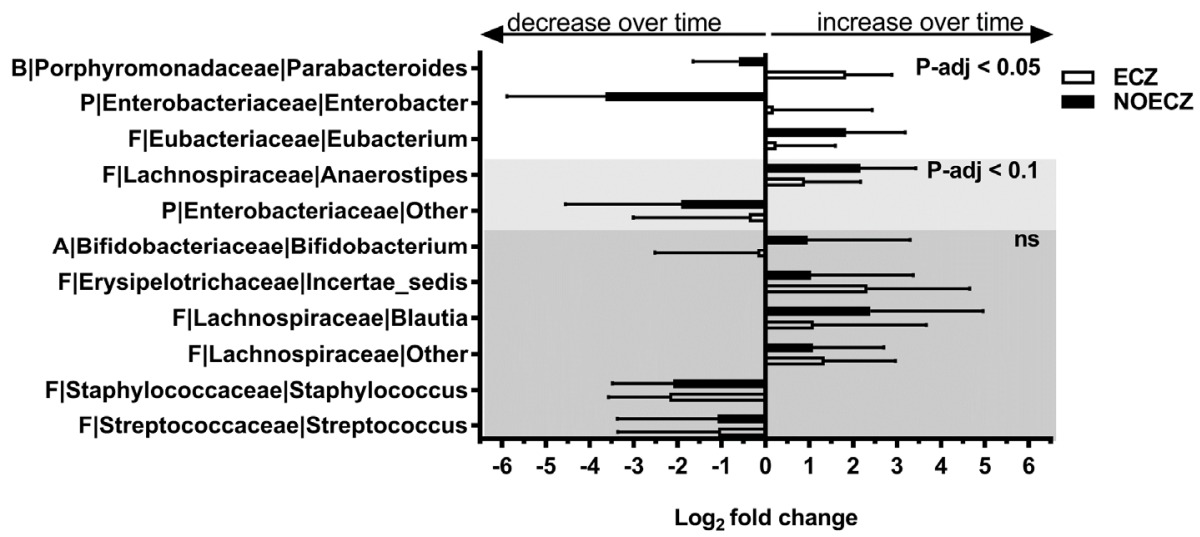

B

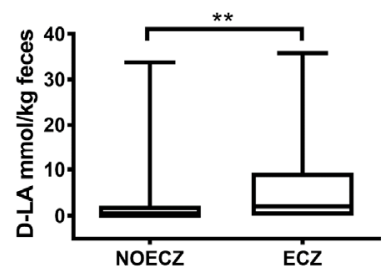

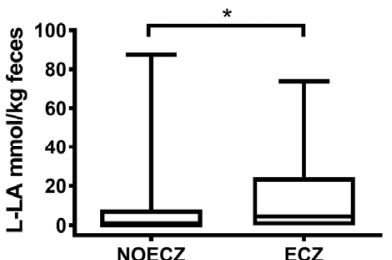

D

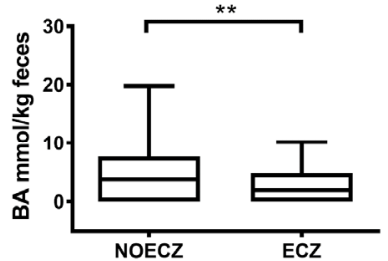

Figure 5: A, Plot with bacterial taxa that change over time (from 4 to 26 weeks of age) in healthy infants (ECZ) and in infants developing eczema (NOECZ), as well as taxa that are differential over time in infants developing eczema compared to healthy infants. Data are shown as fold changes with standard deviations of $\log _{2}$-transformed data. Taxa are detailed at phylum ( $\mathrm{B}=$ Bacteroidetes, $\mathrm{F}=$ Firmicutes, $\mathrm{P}=$ Proteobacteria), family and genus level, respectively. The contrasts were computed by MetagenomeSeq and corrected for the effects of feeding group, ethnicity and having siblings. Adjustment of significance values for multiple comparisons was done using Benjamini-Hochberg false discovery rate. Differential taxa with an adjusted $\mathrm{P}$-value $(\mathrm{P}$-adj) $<0.05$ for all contrasts, if present in $>15 \%$ of the samples and a mean abundance $>0.1 \%$, are shown. Taxa plotted in dark grey background showed no significant (ns) temporal differences when comparing healthy infants with eczematous infants. Taxa plotted in light grey and white background were different with $\mathrm{P}$-adj $<0.1$ and $\mathrm{P}$-adj $<0.05$, respectively. B, Fecal concentration of D-lactic acid (D-LA) at 26 weeks in healthy infants compared to infants developing eczema. C, Fecal concentration of L-lactic acid (L-LA) at 26 weeks in healthy versus eczema. D, Fecal concentration of butyrate $(B A)$ at 26 weeks in healthy versus eczema. Significance was tested with a Mann-Whitney two-group comparison $\left(^{*}=\right.$ P-value $<0.05,{ }^{* *}=\mathrm{P}$-value $\left.<0.001\right)$. 
These discordances were mostly driven by increased levels of both genera in healthy infants at 4 weeks of age, and a subsequent decrease over time (Figure S2A and $\mathrm{S} 2 \mathrm{~B})$. This pattern was less pronounced in infants developing eczema. Discordant development over time was also observed for Parabacteroides ( $P$-adj $<0.0001)$, with decreasing relative abundances in healthy infants, and generally increasing relative abundances in infants developing eczema (Figure S2C). Furthermore, the increased relative abundances over time observed for Eubacterium $(P$-adj $<0.05)$ and Anaerostipes spp. ( $\mathrm{P}$-adj<0.1), were more pronounced in healthy infants as compared to infants developing eczema (Figure S2D and S2E). Both genera are associated with a specialist group of microbes known to convert lactate together with acetate into mainly butyrate, hence referred to as lactate-utilizing and butyrate producing bacteria (LUB) $(24,25)$. Interestingly, decreased levels of both D- and L-lactate (Figure 5B and $5 \mathrm{C}$ ) and increased levels of butyrate (Figure 5D) were observed at 26 weeks of age in healthy infants compared to infants developing eczema.

\section{Discussion}

In this study, we found that a partially hydrolyzed protein formula, supplemented with a specific oligosaccharide mixture (pHF-OS), modulates the developing gut microbiota of infants towards a pattern closer to that of breastfed infants, both in bacterial taxonomic composition as in metabolite composition. Infants receiving pHF-OS from 4 to 26 weeks of age, showed increased relative abundances of the genus Bifidobacterium, which was contrasted by decreases of Clostridium and an unassigned genus of Lachnospiraceae, when compared to infants receiving standard cow's milk formula. These modulations were reflected in marked differences in gut physiology, characterized by lower stool $\mathrm{pH}$, increased proportions of lactate and decreased proportions of propionate, butyrate, iso-butyrate and iso-valerate.

Furthermore, we found that infants developing eczema in the first 18 months of life showed aberrant gut microbiota development in the first 26 weeks of life with significant temporal differences of the genus Parabacteroides and two genera of Enterobacteriaceae. These were found to decrease over time in healthy infants, a 
pattern which was reversed or less evident in infants with eczema. Additionally, infants with eczema showed a lower establishment over time of lactate-utilizing bacteria known to produce butyrate (LUBs), namely Eubacterium and Anaerostipes spp., supported by significantly increased fecal concentrations of lactate, and decreased concentrations of butyrate at 26 weeks of age, a pattern which was independent of feeding group, ethnicity or having siblings.

To assess modulatory effects of nutrition and the role of specific microbes in developing eczema, it is of critical importance to consider the dynamic nature of the infant gut microbiota, and the environmental factors that influence its assembly (26). Hence, we excluded infants born by caesarean section to eliminate its confounding effects (27). Moreover, multivariate comparisons were controlled for sample covariates that best explained the fecal compositional variation, namely age, feeding group, ethnicity and having siblings.

Other studies investigating the gut microbiota in relation to developing allergy, typically reported differences at specific points in time, especially in the first weeks of life, with most commonly reduced diversity and richness associated, but often no specific microbes being identified (2). We did not observe differences in diversity or richness, but rather identified differences in the colonization patterns of infants with eczema compared with those without eczema by 18 months of age.

Some of these patterns were driven by early differences at 4 weeks of age, like the increased levels of two genera within the family of Enterobacteriaceae in subsequent healthy infants, which was followed by sharp decreases over time. Facultative anaerobic bacteria, like the Enterobacteriaceae, are typically high in the early colonization process before replacement with anaerobic bacteria. This pattern being less pronounced in infants developing eczema may indicate a reduced immune-stimulus from species within this family. These include several potential pathogens, which may be needed for adequate development of the adaptive immune system. A recent study by West, et al. (28) indeed associated low abundance of Enterobacteriaceae at 1 month, with an exaggerated immune response at 6 months. This deviating pattern was confirmed in infants subsequently developing allergy (28-30). 
It is known, and confirmed in this study, that breastfed infants compared to formula fed infants have a lower stool $\mathrm{pH}$, increased amounts of colonic acetate and lactate, and decreased amounts of propionate and butyrate. This reflects the dominance of Bifidobacterium species that produce acetate and L-lactate (31). This specific colonic environment, also observed for infants receiving pHF-OS, is known to form an effective chemical barrier against potential pathogens $(32,33)$, and is thought to contribute to the protective effects of breastfeeding against infections $(34,35)$.

We hypothesize that this typical infant-type colonic environment may also be crucial for the establishment of LUB, like Eubacterium and Anaerostipes spp, which were found to be poorly established at 26 weeks of age in infants developing eczema. Indeed, these infants showed first decreased levels of lactate at 12 weeks, followed by increased levels of lactate and decreased levels of butyrate at 26 weeks of age. This may indicate the importance of LUB in guiding the transition around the weaning-period (between 4-6 months of age) from a lactate and acetate-rich environment, towards a more adult-like butyrogenic milieu $(2,36)$. Moreover, the consumption of lactate may contribute to the development of a stable and healthy microbial ecosystem (37). Indeed lactate, although commonly detected in infant' feces, is undetectable in healthy adults (38), while accumulation of colonic lactate in adults has been associated with ulcerative colitis $(39,40)$.

The weaning-period also exposes the infant to an increasing level of antigens from the diet, which requires the immune system to adequately respond to these harmless substances. A study investigating the correlation of specific microbial signatures with the severity of eczema in 6-month old infants found an inverse correlation with the levels of butyrate-producing bacteria and suggested a role in the observed alleviation of symptoms (41). The role of SCFA on the host, especially butyrate, has received increased interest due to accumulating evidence from murine studies showing their regulatory effects on host immunity, including anti-inflammatory and anti-allergic effects (42-45). The establishment of butyrate-producing bacteria around 26 weeks of age, possibly specifically those cross-feeding on lactate and acetate, may therefore prove important for establishing and maintaining homeostasis with our immune system during this critical stage of development. 
In conclusion, this study confirms the impact of early life nutrition on the establishment of the infant gut microbiota. Moreover, it indicates a potential link between the activity of the microbiota and the expression of eczema in early life. It emphasizes the importance of the microbial succession of species and metabolite cross-feeding, to develop a gut physiology that supports gut development, and supports development of normal immune responses towards environmental triggers. These observations could aid the development of optimal nutritional strategies to support the timely gut colonization of keystone species in the gradually diversifying infant gut.

\section{Acknowledgement}

We want to thank all infants and their families who took part in the study and all the PATCH investigators for their collaboration in this study. 


\section{Supporting information}

Table S1: Sample size and sequence details for sequences passing quality filters summarized per feeding group.

\begin{tabular}{|c|c|c|c|c|c|}
\hline Feeding Group & Age & $\begin{array}{c}\text { Count of } \\
\text { subjects }\end{array}$ & Sum of reads & $\begin{array}{c}\text { Average seq. } \\
\text { depth }\end{array}$ & SD of seq. depth \\
\hline \multirow{2}{*}{ CONTROL } & $\mathbf{4 w}$ & 55 & 326169 & 5930 & 3300 \\
\cline { 2 - 6 } & $\mathbf{2 6 w}$ & 57 & 345935 & 6069 & 2959 \\
\hline \multirow{2}{*}{ pHF-OS } & $\mathbf{4 w}$ & 49 & 305530 & 6235 & 4459 \\
\cline { 2 - 6 } & $\mathbf{2 6 w}$ & 51 & 299308 & 5869 & 4113 \\
\hline \multirow{2}{*}{ BREASTFED } & $\mathbf{4 w}$ & 26 & 166838 & 6417 & 3950 \\
\cline { 2 - 6 } & $\mathbf{2 6 w}$ & 30 & 220892 & 7363 & 4014 \\
\hline Total & & $\mathbf{2 6 8}$ & $\mathbf{1 6 6 4 6 7 2}$ & $\mathbf{6 2 1 1}$ & $\mathbf{3 7 6 7}$ \\
\hline
\end{tabular}

Table S2: Summary of gut microbial compositions of breastfed infants (B), pHF-OS (A) and control (C) at 4 and 26 weeks of age.

\begin{tabular}{|c|c|c|c|c|c|c|c|}
\hline \multirow{2}{*}{$\begin{array}{c}\text { Taxa } \\
\text { Phylum|Family }\end{array}$} & \multicolumn{3}{|c|}{4 weeks } & \multicolumn{3}{|c|}{26 weeks } & \multirow[t]{2}{*}{ Total } \\
\hline & C & A & B & C & A & B & \\
\hline $\begin{array}{c}\text { Total } \\
\text { Actinobacteria }\end{array}$ & $\begin{array}{c}55.28 \\
(32.66) \%\end{array}$ & $\begin{array}{c}61.83 \\
(31.56) \%\end{array}$ & $\begin{array}{c}69.66 \\
(35.33) \%\end{array}$ & $\begin{array}{c}63.01 \\
(28.43) \%\end{array}$ & $\begin{array}{c}73.25 \\
(27.08) \%\end{array}$ & $\begin{array}{c}73.12 \\
(28.76) \%\end{array}$ & $\begin{array}{c}64.92 \\
(31.21) \%\end{array}$ \\
\hline $\begin{array}{c}\text { A|Bifidobacteriac } \\
\text { eae }\end{array}$ & $\begin{array}{c}51.39 \\
(32.25) \% \\
\end{array}$ & $\begin{array}{c}60.18 \\
(31.18) \%\end{array}$ & $\begin{array}{c}68.95 \\
(35.13) \%\end{array}$ & $\begin{array}{c}59.99 \\
(27.59) \%\end{array}$ & $\begin{array}{c}71.02 \\
(26.73) \%\end{array}$ & $\begin{array}{c}72.38 \\
(28.52) \%\end{array}$ & $\begin{array}{c}62.6 \\
(30.98) \%\end{array}$ \\
\hline $\begin{array}{c}\text { A|Coriobacteriace } \\
\text { ae }\end{array}$ & $\begin{array}{c}3.56 \\
(9.53) \% \\
\end{array}$ & $\begin{array}{c}1.19 \\
(3.14) \% \\
\end{array}$ & $\begin{array}{c}0.34 \\
(1.01) \% \\
\end{array}$ & $\begin{array}{c}2.99 \\
(6.92) \%\end{array}$ & $\begin{array}{c}2.2 \\
(4.13) \%\end{array}$ & $\begin{array}{c}0.65 \\
(1.63) \%\end{array}$ & $\begin{array}{c}2.12 \\
(6.01) \%\end{array}$ \\
\hline $\begin{array}{c}\text { A|Propionibacteri } \\
\text { aceae }\end{array}$ & $\begin{array}{c}0.28 \\
(0.86) \%\end{array}$ & $\begin{array}{c}0.4 \\
(1.24) \% \\
\end{array}$ & $\begin{array}{c}0.26 \\
(1.01) \% \\
\end{array}$ & $\begin{array}{c}0.01 \\
(0.04) \% \\
\end{array}$ & $\begin{array}{c}0.01 \\
(0.05) \%\end{array}$ & $0(0) \%$ & $\begin{array}{c}0.15 \\
(0.74) \% \\
\end{array}$ \\
\hline AlOther & $\begin{array}{c}0.06 \\
(0.09) \% \\
\end{array}$ & $\begin{array}{c}0.06 \\
(0.27) \%\end{array}$ & $\begin{array}{c}0.11 \\
(0.23) \%\end{array}$ & $\begin{array}{c}0.02 \\
(0.04) \%\end{array}$ & $\begin{array}{c}0.02 \\
(0.05) \%\end{array}$ & $\begin{array}{c}0.08 \\
(0.21) \%\end{array}$ & $\begin{array}{c}0.05 \\
(0.16) \%\end{array}$ \\
\hline $\begin{array}{c}\text { Total } \\
\text { Bacteroidetes }\end{array}$ & $\begin{array}{c}1.88 \\
(8.01) \% \\
\end{array}$ & $\begin{array}{c}1.15 \\
(3.65) \% \\
\end{array}$ & $\begin{array}{c}3.06 \\
(5.45) \% \\
\end{array}$ & $\begin{array}{c}0.33 \\
(1.42) \% \\
\end{array}$ & $\begin{array}{c}1.53 \\
(4.49) \% \\
\end{array}$ & $\begin{array}{c}1.94 \\
(5.82) \% \\
\end{array}$ & $\begin{array}{c}1.49 \\
(5.26) \% \\
\end{array}$ \\
\hline B|Bacteroidaceae & $\begin{array}{c}1.77 \\
(7.9) \% \\
\end{array}$ & $\begin{array}{c}1.0 \\
(3.17) \% \\
\end{array}$ & $\begin{array}{c}2.45 \\
(5.21) \% \\
\end{array}$ & $\begin{array}{c}0.31 \\
(1.39) \%\end{array}$ & $\begin{array}{c}1.17 \\
(3.48) \%\end{array}$ & $\begin{array}{c}1.44 \\
(3.5) \%\end{array}$ & $\begin{array}{c}1.25 \\
(4.71) \%\end{array}$ \\
\hline $\begin{array}{c}\text { B|Porphyromona } \\
\text { daceae }\end{array}$ & $\begin{array}{c}0.10 \\
(0.63) \%\end{array}$ & $\begin{array}{c}0.14 \\
(0.83) \%\end{array}$ & $\begin{array}{c}0.22 \\
(0.73) \%\end{array}$ & $\begin{array}{c}0.01 \\
(0.04) \%\end{array}$ & $\begin{array}{c}0.31 \\
(1.58) \%\end{array}$ & $\begin{array}{c}0.48 \\
(2.45) \%\end{array}$ & $\begin{array}{c}0.18 \\
(1.2) \% \\
\end{array}$ \\
\hline B|Other & $\begin{array}{c}0.01 \\
(0.02) \%\end{array}$ & $\begin{array}{c}0.01 \\
(0.03) \%\end{array}$ & $\begin{array}{c}0.39 \\
(1.9) \%\end{array}$ & $\begin{array}{c}0.01 \\
(0.04) \%\end{array}$ & $\begin{array}{c}0.05 \\
(0.24) \%\end{array}$ & $\begin{array}{c}0.02 \\
(0.04) \%\end{array}$ & $\begin{array}{c}0.06 \\
(0.63) \%\end{array}$ \\
\hline Total Firmicutes & $\begin{array}{c}31.09 \\
(24.75) \%\end{array}$ & $\begin{array}{c}23.34 \\
(21.26) \% \\
\end{array}$ & $\begin{array}{c}8.63 \\
(8.59) \% \\
\end{array}$ & $\begin{array}{c}32.04 \\
(24.86) \% \\
\end{array}$ & $\begin{array}{c}21.85 \\
(22.06) \% \\
\end{array}$ & $\begin{array}{c}21.16 \\
(25.58) \% \\
\end{array}$ & $\begin{array}{c}24.81 \\
(23.72) \% \\
\end{array}$ \\
\hline $\begin{array}{c}\text { F|Staphylococcac } \\
\text { eae }\end{array}$ & $\begin{array}{c}0.52 \\
(1.44) \%\end{array}$ & $\begin{array}{c}0.44 \\
(1.17) \%\end{array}$ & $\begin{array}{c}0.72 \\
(1.57) \% \\
\end{array}$ & $\begin{array}{c}0.03 \\
(0.06) \% \\
\end{array}$ & $\begin{array}{c}0.03 \\
(0.14) \% \\
\end{array}$ & $\begin{array}{c}0.02 \\
(0.06) \%\end{array}$ & $\begin{array}{c}0.27 \\
(1.00) \% \\
\end{array}$ \\
\hline $\begin{array}{c}\text { F|Enterococcace } \\
\text { ae }\end{array}$ & $\begin{array}{c}8.69 \\
(13.3) \%\end{array}$ & $\begin{array}{c}1.19 \\
(2.53) \%\end{array}$ & $\begin{array}{c}0.6 \\
(2.02) \%\end{array}$ & $\begin{array}{c}4.84 \\
(8.26) \%\end{array}$ & $\begin{array}{c}4.11 \\
(5.92) \%\end{array}$ & $\begin{array}{c}2.38 \\
(4.33) \%\end{array}$ & $\begin{array}{c}4.18 \\
(8.36) \%\end{array}$ \\
\hline $\begin{array}{c}\text { F|Streptococcace } \\
\text { ae }\end{array}$ & $\begin{array}{c}12.68 \\
(16.91) \% \\
\end{array}$ & $\begin{array}{c}12.42 \\
(16.31) \% \\
\end{array}$ & $\begin{array}{c}3.05 \\
(4.92) \% \\
\end{array}$ & $\begin{array}{c}8.85 \\
(16.43) \% \\
\end{array}$ & $\begin{array}{c}5.34 \\
(8.99) \% \\
\end{array}$ & $\begin{array}{c}3.94 \\
(10.11) \% \\
\end{array}$ & $\begin{array}{c}8.44 \\
(14.37) \% \\
\end{array}$ \\
\hline F|Eubacteriaceae & $\begin{array}{c}0.06 \\
(0.25) \%\end{array}$ & $\begin{array}{c}0.0 \\
(0.01) \%\end{array}$ & $\begin{array}{c}0.0 \\
(0.01) \%\end{array}$ & $\begin{array}{c}0.34 \\
(1.38) \%\end{array}$ & $\begin{array}{c}0.12 \\
(0.38) \%\end{array}$ & $\begin{array}{c}0.08 \\
(0.28) \%\end{array}$ & $\begin{array}{c}0.12 \\
(0.69) \%\end{array}$ \\
\hline $\begin{array}{c}\text { F|Lachnospiracea } \\
e\end{array}$ & $\begin{array}{c}2.74 \\
(8.59) \% \\
\end{array}$ & $\begin{array}{c}5.7 \\
(15.79) \%\end{array}$ & $\begin{array}{c}2.59 \\
(5.52) \%\end{array}$ & $\begin{array}{c}13.56 \\
(22.46) \%\end{array}$ & $\begin{array}{c}7.87 \\
(15.07) \%\end{array}$ & $\begin{array}{c}8.5 \\
(20.01) \%\end{array}$ & $\begin{array}{c}7.17 \\
(16.55) \%\end{array}$ \\
\hline F|Clostridiaceae & $\begin{array}{c}0.29 \\
(1.21) \%\end{array}$ & $\begin{array}{c}0.05 \\
(0.15) \%\end{array}$ & $\begin{array}{c}0.11 \\
(0.51) \%\end{array}$ & $\begin{array}{c}0.17 \\
(0.46) \%\end{array}$ & $\begin{array}{c}0.04 \\
(0.08) \%\end{array}$ & $\begin{array}{c}0.07 \\
(0.19) \%\end{array}$ & $\begin{array}{c}0.13 \\
(0.64) \%\end{array}$ \\
\hline $\begin{array}{c}\text { F|Peptostreptoco } \\
\text { ccaceae }\end{array}$ & $\begin{array}{c}0.08 \\
(0.29) \%\end{array}$ & $\begin{array}{c}0.00 \\
(0.01) \%\end{array}$ & $\begin{array}{c}0.00 \\
(0.00) \%\end{array}$ & $\begin{array}{c}0.14 \\
(0.35) \%\end{array}$ & $\begin{array}{c}0.08 \\
(0.18) \%\end{array}$ & $\begin{array}{c}0.20 \\
(0.66) \%\end{array}$ & $\begin{array}{c}0.09 \\
(0.33) \%\end{array}$ \\
\hline
\end{tabular}




\section{Chapter 4}

Table S2 (continued)

\begin{tabular}{|c|c|c|c|c|c|c|c|}
\hline Taxa & \multicolumn{3}{|c|}{4 weeks } & \multicolumn{3}{|c|}{26 weeks } & \multirow[t]{2}{*}{ Total } \\
\hline Phylum|Family & C & A & B & C & A & B & \\
\hline F|Ruminococcace & 0.01 & 0.00 & 0.01 & 0.15 & 0.34 & 0.13 & 0.11 \\
\hline ae & $(0.05) \%$ & $(0.00) \%$ & $(0.03) \%$ & $(0.96) \%$ & $(2.14) \%$ & $(0.56) \%$ & $(1.05) \%$ \\
\hline F|Veillonellaceae & $\begin{array}{c}0.87 \\
(2.23) \%\end{array}$ & $\begin{array}{c}0.05 \\
(0.14) \%\end{array}$ & $\begin{array}{c}0.11 \\
(0.29) \%\end{array}$ & $\begin{array}{c}0.06 \\
(0.19) \%\end{array}$ & $\begin{array}{c}0.18 \\
(0.53) \%\end{array}$ & $\begin{array}{c}0.41 \\
(1.33) \%\end{array}$ & $\begin{array}{c}0.30 \\
(1.2) \%\end{array}$ \\
\hline $\begin{array}{c}\text { F|Erysipelotrichac } \\
\text { eae }\end{array}$ & $\begin{array}{c}2.51 \\
(9.88) \%\end{array}$ & $\begin{array}{c}0.63 \\
(1.73) \%\end{array}$ & $\begin{array}{c}0.63 \\
(2.1) \%\end{array}$ & $\begin{array}{c}1.83 \\
(3.63) \%\end{array}$ & $\begin{array}{c}2.65 \\
(7.78) \%\end{array}$ & $\begin{array}{c}4.08 \\
(10.63) \%\end{array}$ & $\begin{array}{c}2.06 \\
(7.07) \%\end{array}$ \\
\hline F|Other & $\begin{array}{c}0.07 \\
(0.18) \% \\
\end{array}$ & $\begin{array}{c}0.03 \\
(0.09) \% \\
\end{array}$ & $\begin{array}{c}0.04 \\
(0.05) \% \\
\end{array}$ & $\begin{array}{c}0.05 \\
(0.05) \% \\
\end{array}$ & $\begin{array}{c}0.03 \\
(0.07) \% \\
\end{array}$ & $\begin{array}{c}0.05 \\
(0.12) \% \\
\end{array}$ & $\begin{array}{c}0.05 \\
(0.11) \% \\
\end{array}$ \\
\hline $\begin{array}{c}\text { Total } \\
\text { Proteobacteria } \\
\end{array}$ & $\begin{array}{c}11.72 \\
(19.76) \% \\
\end{array}$ & $\begin{array}{l}13.67 \\
(22) \% \\
\end{array}$ & $\begin{array}{c}18.64 \\
(30.75) \% \\
\end{array}$ & $\begin{array}{c}4.07 \\
(13.77) \% \\
\end{array}$ & $\begin{array}{c}3.13 \\
(8.88) \% \\
\end{array}$ & $\begin{array}{c}3.78 \\
(11.22) \% \\
\end{array}$ & $\begin{array}{c}8.61 \\
(19.03) \% \\
\end{array}$ \\
\hline $\begin{array}{c}\text { P|Enterobacteriac } \\
\text { eae }\end{array}$ & $\begin{array}{c}11.54 \\
(19.24) \%\end{array}$ & $\begin{array}{c}13.61 \\
(21.96) \%\end{array}$ & $\begin{array}{c}18.5 \\
(30.7) \% \\
\end{array}$ & $\begin{array}{c}4 \\
(13.74) \%\end{array}$ & $\begin{array}{c}3.11 \\
(8.86) \% \\
\end{array}$ & $\begin{array}{c}3.53 \\
(11.08) \%\end{array}$ & $\begin{array}{c}8.5 \\
(18.87) \% \\
\end{array}$ \\
\hline PlOther & $\begin{array}{c}0.18 \\
(0.83) \% \\
\end{array}$ & $\begin{array}{c}0.06 \\
(0.12) \% \\
\end{array}$ & $\begin{array}{c}0.14 \\
(0.32) \% \\
\end{array}$ & $\begin{array}{c}0.07 \\
(0.33) \% \\
\end{array}$ & $\begin{array}{c}0.02 \\
(0.05) \% \\
\end{array}$ & $\begin{array}{c}0.25 \\
(0.83) \% \\
\end{array}$ & $\begin{array}{c}0.11 \\
(0.52) \% \\
\end{array}$ \\
\hline $\begin{array}{c}\text { V|Verrucomicrob } \\
\text { iaceae }\end{array}$ & $\begin{array}{c}0.01 \\
(0.09) \%\end{array}$ & $\begin{array}{c}0.01 \\
(0.07) \%\end{array}$ & $\begin{array}{c}0.00 \\
(0.00) \%\end{array}$ & $\begin{array}{c}0.54 \\
(2.74) \%\end{array}$ & $\begin{array}{c}0.23 \\
(0.88) \% \\
\end{array}$ & $\begin{array}{c}0.00 \\
(0.00) \%\end{array}$ & $\begin{array}{c}0.16 \\
(1.35) \%\end{array}$ \\
\hline Other & $\begin{array}{c}0.02 \\
(0.06) \%\end{array}$ & $\begin{array}{c}0.01 \\
(0.02) \%\end{array}$ & $\begin{array}{c}0.01 \\
(0.02) \%\end{array}$ & $\begin{array}{c}0.01 \\
(0.02) \%\end{array}$ & $\begin{array}{c}0.01 \\
(0.02) \% \\
\end{array}$ & $\begin{array}{c}0.01 \\
(0.01) \%\end{array}$ & $\begin{array}{c}0.01 \\
(0.03) \%\end{array}$ \\
\hline
\end{tabular}

Relative abundances with SDs in percentages for taxa present in more than $15 \%$ of the samples and average relative abundances of greater than $0.1 \%$ at the bacterial family-level. Taxa of lower abundance are grouped as "other." Phylum-levels are indicated as follows: A, Actinobacteria; B, Bacteroidetes; F, Firmicutes; P, Proteobacteria; V, Verrucomicrobia. Boldface text represents subtotals.

Table S3: Results of forward selection based on canonical correspondence analysis (CCA) of fecal taxonomic compositions.

\begin{tabular}{|c|c|c|c|}
\hline Sample covariates (variables) & Explains \% & $\mathbf{P}$ & $\mathbf{P}$-adj \\
\hline Age (4 weeks, 26 weeks) & $\mathbf{5 . 2}$ & $\mathbf{0 . 0 0 2}$ & $\mathbf{0 . 0 1 7 3 3}$ \\
\hline Ethnicity (asian, caucasian, other) & $\mathbf{3 . 7}$ & $\mathbf{0 . 0 0 2}$ & $\mathbf{0 . 0 1 0 4}$ \\
\hline Feedinggroup (control, pHF-OS, breastfed) & $\mathbf{2 . 6}$ & $\mathbf{0 . 0 0 2}$ & $\mathbf{0 . 0 0 8 6 7}$ \\
\hline Siblings (yes, no) & $\mathbf{1 . 6}$ & $\mathbf{0 . 0 0 2}$ & $\mathbf{0 . 0 0 8 6 7}$ \\
\hline Antibiotics before 26 weeks (yes, no) & 1.2 & 0.022 & 0.08089 \\
\hline Birth weight (continuous data) & 0.6 & 0.028 & 0.104 \\
\hline Gender (male, female) & 0.8 & 0.206 & 0.44 \\
\hline Weaning before 18 weeks (yes, no) & 0.8 & 0.226 & 0.41947 \\
\hline Parental allergic history (mother, father, both) & 1 & 0.266 & 0.43225 \\
\hline
\end{tabular}

The sample covariates shown were included based on the percentage explained of the total taxonomic variation (Explains \%). Inclusion of sample covariates was stopped to prevent overfitting of the ordination model leading to the identification of the 9 factors (and variables) listed in the table. False discovery rate (FDR) method for P-value correction was used to identify the major covariates with an adjusted P-value (P-adj) $<0.05$ (in bold) and shown alongside with the uncorrected $P$-value $(P)$. 

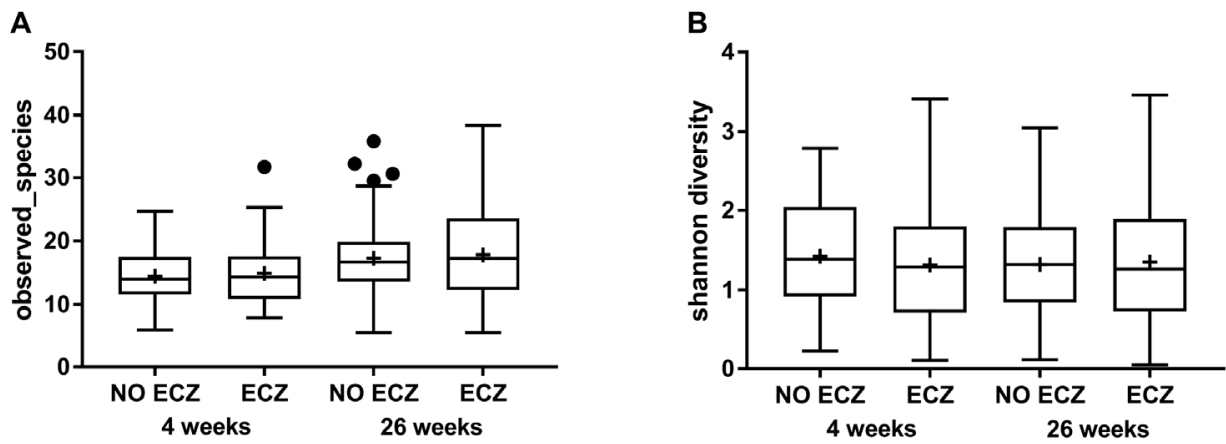

Figure S1: Box-whisker plots (Tukey method) summarizing the microbial intestinal richness (Fig. S1A) and shannon diversity (Fig. S1B) at 4 and 26 weeks of age in infants developing eczema (ECZ) compared to infants not developing eczema (NOECZ). The centre line shows the median, the + denotes the mean, and the boxes cover the 25th and 75th percentiles with the whiskers extending to the data points, which are no more than 1.5 times the length away from the box. Points outside the whiskers represent outlier samples. Comparisons were done at a sequencing depth of 1636 reads per sample. Statistics were performed by a one-way ANOVA with Bonferroni's multiple comparison correction (not significantly different). 
A

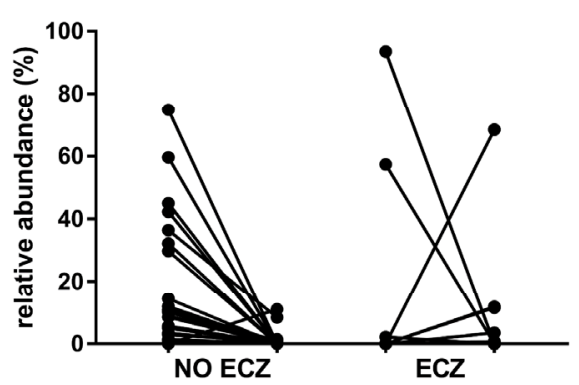

C

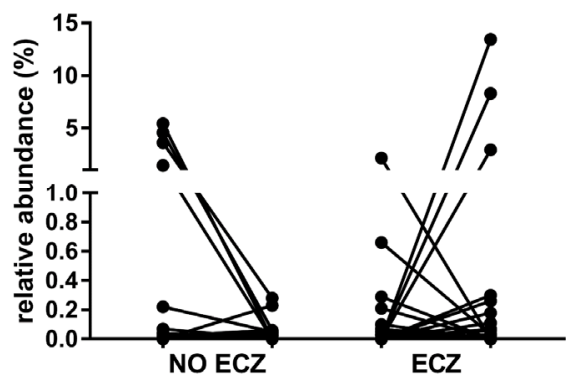

E

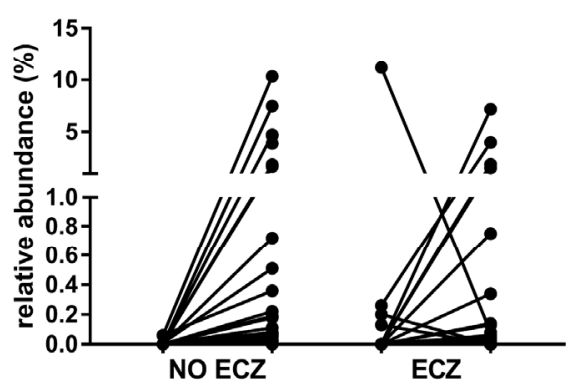

\section{B Enterobacteriaceae unknown}

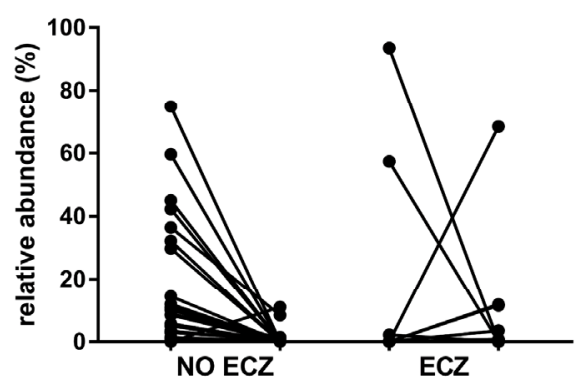

D

Eubacterium

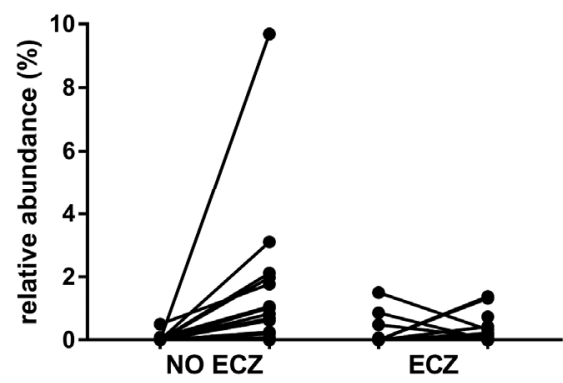

Figure S2: Taxa identified with MetagenomeSeq that show differential relative abundances over time $(P$-adj $<0.1)$ comparing infants not developing eczema (NO ECZ, n=82 sample-pairs) with infants developing eczema (ECZ, $\mathrm{n}=48$ sample-pairs). Before-after plots of relative abundances (\%) are shown from 4 to 26 weeks for Enterobacter spp. (Fig. S2A), an unknown genus of Enterobacteriaceae (Fig. S2B), Parabacteroides spp. (Fig. S2C), Eubacterium spp. (Fig. S2D), and Anaerostipes spp. (Fig. S2E), respectively. 


\section{References}

1. Shanahan F. The gut microbiota-a clinical perspective on lessons learned. Nat Rev Gastroenterol Hepatol. 2012;9(10):609-14.

2. Wopereis $\mathrm{H}$, Oozeer R, Knipping K, Belzer C, Knol J. The first thousand days - intestinal microbiology of early life: establishing a symbiosis. Pediatr Allergy Immunol. 2014;25(5):428-38.

3. Verhasselt $\mathrm{V}$. Oral tolerance in neonates: from basics to potential prevention of allergic disease. Mucosal Immunol. 2010;3(4):326-33.

4. Oozeer R, van Limpt K, Ludwig T, Ben Amor K, Martin R, Wind RD, et al. Intestinal microbiology in early life: specific prebiotics can have similar functionalities as human-milk oligosaccharides. Am $\mathrm{J}$ Clin Nutr. 2013;98(2):561S-71S.

5. Gibson GR, Roberfroid MB. Dietary modulation of the human colonic microbiota: introducing the concept of prebiotics. J Nutr. 1995;125(6):1401-12.

6. Bindels LB, Delzenne NM, Cani PD, Walter J. Towards a more comprehensive concept for prebiotics. Nat Rev Gastroenterol Hepatol. 2015;12(5):303-10.

7. Moro G, Arslanoglu S, Stahl B, Jelinek J, Wahn U, Boehm G. A mixture of prebiotic oligosaccharides reduces the incidence of atopic dermatitis during the first six months of age. Arch Dis Child. 2006;91(10):814-9.

8. Arslanoglu S, Moro GE, Boehm G, Wiens F, Stahl B, Bertino E. Early prebiotic oligosaccharide supplementation reduces the incidence of some allergic manifestations in the first 5 years of life. Journal of Biology Regulation \& Homeostatic Agents. 2012;26(3):49-59.

9. Grüber C, van Stuijvenberg M, Mosca F, Moro G, Chirico G, Braegger CP, et al. Reduced occurrence of early atopic dermatitis because of immunoactive prebiotics among low-atopy-risk infants. Journal of Allergy and Clinical Immunology. 2010;126(4):791-7.

10. Boyle RJ, Tang ML, Chiang WC, Chua MC, Ismail I, Nauta A, et al. Prebiotic-supplemented partially hydrolysed cow's milk formula for the prevention of eczema in high-risk infants: a randomized controlled trial. Allergy. 2016;71(5):701-10.

11. Matsuki T, Watanabe K, Fujimoto J, Kado Y, Takada T, Matsumoto K, et al. Quantitative PCR with $16 \mathrm{~S}$ rRNA-gene-targeted species-specific primers for analysis of human intestinal bifidobacteria. Appl Environ Microbiol. 2004;70(1):167-73.

12. Sim K, Cox MJ, Wopereis H, Martin R, Knol J, Li MS, et al. Improved detection of bifidobacteria with optimised 16S rRNA-gene based pyrosequencing. PLoS One. 2012;7(3):e32543.

13. Caporaso JG, Kuczynski J, Stombaugh J, Bittinger K, Bushman FD, Costello EK, et al. QIIME allows analysis of high-throughput community sequencing data. Nat Methods. 2010;7(5):335-6.

14. Pruesse E, Quast C, Knittel K, Fuchs BM, Ludwig W, Peplies J, et al. SILVA: a comprehensive online resource for quality checked and aligned ribosomal RNA sequence data compatible with ARB. Nucleic Acids Res. 2007;35(21):7188-96.

15. Bakker-Zierikzee AM, Alles MS, Knol J, Kok FJ, Tolboom JJ, Bindels JG. Effects of infant formula containing a mixture of galacto- and fructo-oligosaccharides or viable Bifidobacterium animalis on the intestinal microflora during the first 4 months of life. Br J Nutr. 2005;94(5):783-90.

16. Šmilauer P, Lepš. J. Multivariate Analysis of Ecological Data using CANOCO 5. Cambridge Books Online: Cambridge University Press; 2014. Available from: http://dx.doi.org/10.1017/CBO9781139627061. 


\section{Chapter 4}

17. Paulson JN, Stine OC, Bravo HC, Pop M. Differential abundance analysis for microbial marker-gene surveys. Nat Methods. 2013;10(12):1200-2.

18. Benjamini Y, Hochberg Y. Controlling the False Discovery Rate: A Practical and Powerful Approach to Multiple Testing. Journal of the Royal Statistical Society Series B (Methodological). 1995;57(1):289-300.

19. Ter Braak CJ. Canonical correspondence analysis: a new eigenvector technique for multivariate direct gradient analysis. Ecology. 1986;67(5):1167-79.

20. Legendre P, Legendre L. Numerical ecology. Amsterdam: Elsevier; 2012.

21. van den Brink PJ, den Besten PJ, bij de Vaate A, ter Braak CJ. Principal response curves technique for the analysis of multivariate biomonitoring time series. Environ Monit Assess. 2009;152(1-4):271-81.

22. Shannon CE. A mathematical theory of communication (parts I and II). Bell System Technical Journal. 1948:379-423.

23. Lozupone C, Knight R. UniFrac: a new phylogenetic method for comparing microbial communities. Appl Environ Microbiol. 2005;71(12):8228-35.

24. Sato T, Matsumoto K, Okumura T, Yokoi W, Naito E, Yoshida Y, et al. Isolation of lactate-utilizing butyrate-producing bacteria from human feces and in vivo administration of Anaerostipes caccae strain L2 and galacto-oligosaccharides in a rat model. FEMS Microbiol Ecol. 2008;66(3):528-36.

25. Kanauchi O, Fujiyama Y, Mitsuyama K, Araki Y, Ishii T, Nakamura T, et al. Increased growth of Bifidobacterium and Eubacterium by germinated barley foodstuff, accompanied by enhanced butyrate production in healthy volunteers. International journal of molecular medicine. 1999;3(2):175-9.

26. Backhed F, Roswall J, Peng Y, Feng Q, Jia H, Kovatcheva-Datchary P, et al. Dynamics and Stabilization of the Human Gut Microbiome during the First Year of Life. Cell Host Microbe. 2015;17(5):690-703.

27. Martin R, Makino H, Cetinyurek Yavuz A, Ben-Amor K, Roelofs M, Ishikawa E, et al. Early-Life Events, Including Mode of Delivery and Type of Feeding, Siblings and Gender, Shape the Developing Gut Microbiota. PLoS One. 2016;11(6):e0158498.

28. West CE, Ryden P, Lundin D, Engstrand L, Tulic MK, Prescott SL. Gut microbiome and innate immune response patterns in IgE-associated eczema. Clin Exp Allergy. 2015;45(9):1419-29.

29. Prescott SL, Noakes P, Chow BW, Breckler L, Thornton CA, Hollams EM, et al. Presymptomatic differences in Toll-like receptor function in infants who have allergy. J Allergy Clin Immunol. 2008;122(2):391-9, 9 e1-5.

30. Tulic MK, Hodder M, Forsberg A, McCarthy S, Richman T, D'Vaz N, et al. Differences in innate immune function between allergic and nonallergic children: new insights into immune ontogeny. J Allergy Clin Immunol. 2011;127(2):470-8 e1.

31. Knol J, Scholtens P, Kafka C, Steenbakkers J, Gro S, Helm K, et al. Colon microflora in infants fed formula with galacto- and fructo-oligosaccharides: more like breast-fed infants. J Pediatr Gastroenterol Nutr. 2005;40(1):36-42.

32. Fukuda S, Toh H, Hase K, Oshima K, Nakanishi Y, Yoshimura K, et al. Bifidobacteria can protect from enteropathogenic infection through production of acetate. Nature. 2011;469(7331):543-7.

33. Knol J, Boehm G, Lidestri M, Negretti F, Jelinek J, Agosti M, et al. Increase of faecal bifidobacteria due to dietary oligosaccharides induces a reduction of clinically relevant pathogen germs in the faeces of formula-fed preterm infants. Acta Paediatrica. 2005;94(s449):31-3.

34. Li R, Dee D, Li CM, Hoffman HJ, Grummer-Strawn LM. Breastfeeding and risk of infections at 6 years. Pediatrics. 2014;134 Suppl 1(Supplement 1):S13-20. 
35. Ip S, Chung M, Raman G, Chew P, Magula N, DeVine D, et al. Breastfeeding and maternal and infant health outcomes in developed countries. Evidence report/technology assessment. 2007(153):1-186.

36. Duncan SH, Louis P, Flint HJ. Lactate-Utilizing Bacteria, Isolated from Human Feces, That Produce Butyrate as a Major Fermentation Product. Appl Environ Microbiol. 2004;70(10):5810-7.

37. Flint HJ, Duncan SH, Scott KP, Louis P. Links between diet, gut microbiota composition and gut metabolism. Proc Nutr Soc. 2015;74(1):13-22.

38. Belenguer A, Holtrop G, Duncan SH, Anderson SE, Calder AG, Flint HJ, et al. Rates of production and utilization of lactate by microbial communities from the human colon.2011 2011-07-01 00:00:00. 107-19 p.

39. Vernia P, Caprilli R, Latella G, Barbetti F, Magliocca FM, Cittadini M. Fecal lactate and ulcerative colitis. Gastroenterology. 1988;95(6):1564-8.

40. Hove H, Nordgaard-Andersen I, Mortensen PB. Faecal DL-lactate concentration in 100 gastrointestinal patients. Scand J Gastroenterol. 1994;29(3):255-9.

41. Nylund L, Nermes M, Isolauri E, Salminen S, de Vos WM, Satokari R. Severity of atopic disease inversely correlates with intestinal microbiota diversity and butyrate-producing bacteria. Allergy. 2015;70(2):241-4.

42. Steinmeyer S, Lee K, Jayaraman A, Alaniz RC. Microbiota metabolite regulation of host immune homeostasis: a mechanistic missing link. Curr Allergy Asthma Rep. 2015;15(5):24.

43. Stefka AT, Feehley T, Tripathi P, Quu J, McCoy K, Mazmanian SK, et al. Commensal bacteria protect against food allergen sensitization. Proc Natl Acad Sci U S A. 2014;111(36):13145-50.

44. Smith PM, Howitt MR, Panikov N, Michaud M, Gallini CA, Bohlooly YM, et al. The microbial metabolites, short-chain fatty acids, regulate colonic Treg cell homeostasis. Science. 2013;341(6145):569-73.

45. Arpaia N, Campbell C, Fan X, Dikiy S, van der Veeken J, deRoos P, et al. Metabolites produced by commensal bacteria promote peripheral regulatory T-cell generation. Nature. 2013;504(7480):451-5. 



\section{CHAPTER 5}

\section{A specific synbiotic-containing amino}

acid-based formula restores gut microbiota in non-IgE mediated cow's milk allergic infants

Wopereis $\mathrm{H}^{1,2}$, Van Ampting MTJ1, Yavuz AC ${ }^{1}$, Slump $\mathrm{R}^{1}$, Candy $D C A^{3}$, Butt $A M^{3}$, Peroni $\mathrm{DG}^{4}$, Vandenplas $\mathrm{Y}^{5}$, Fox $\mathrm{AT}^{6}$, Shah $\mathrm{N}^{7}$, Roeselers $\mathrm{G}^{1}$, Harthoorn $\mathrm{LF}^{1}$, Michaelis $\mathrm{LJ}^{8}, \mathrm{Knol} \mathrm{J}^{1,2}$, West $\mathrm{CE}^{9}$, on behalf of the ASSIGN study group ${ }^{10}$

${ }^{1}$ Danone Nutricia Research, Utrecht, the Netherlands ${ }^{2}$ Laboratory of Microbiology, Wageningen University, Wageningen, the Netherlands

${ }^{3}$ Royal Alexandra Children's Hospital, Brighton, UK ${ }^{4}$ University Hospital Verona, Verona, Italy (current affiliation: Department of Clinical and Experimental Medicine, University of Pisa, Pisa, Italy) ${ }^{5} \mathrm{KidZ}$ Health Castle, UZ Brussel, Vrije Universiteit Brussel, Brussels, Belgium ${ }^{6}$ Guy's \& St Thomas' Hospitals NHS Foundation Trust, London, UK

${ }^{7}$ Great Ormond Street Hospital, London, UK ${ }^{8}$ Great North Children's Hospital, Royal Victoria Infirmary, Newcastle upon Tyne, UK 'Umeå University, Umeå, Sweden

${ }^{10}$ Additional investigators to the ASSIGN study group: Francoise Smets, U.C.L. Saint-Luc, Brussels, Belgium; Sandra Mullier, HUDERF, Brussels, Belgium; Lee Noimark, Barts/Royal Hospital, London, United Kingdom; Antonella Muraro, University Hospital of Padova, Padova, Italy. 


\section{Abstract}

Background: Altered gut microbiota is implicated in cow's milk allergy (CMA) and differs markedly from healthy, breastfed infants. Infants who suffer from severe CMA often rely on cow's milk protein avoidance and, when breastfeeding is not possible, on specialised infant formulas such as amino-acid based formulas (AAF). Herein, we report the effects of an $A A F$ including specific synbiotics on oral and gastrointestinal microbiota of infants with non-IgE mediated CMA with reference to healthy, breastfed infants.

Methods: In this prospective, randomized, double-blind controlled study, infants with suspected non-IgE mediated CMA received test or control formula. Test formula was AAF with synbiotics (prebiotic fructo-oligosaccharides and probiotic Bifidobacterium breve M-16V). Control formula was AAF without synbiotics. Healthy, breastfed infants were used as a separate reference group (HBR). Bacterial compositions of faecal and salivary samples were analysed by $16 \mathrm{~S}$ rRNA-gene sequencing. Faecal analysis was complemented with the analysis of $\mathrm{pH}$, short-chain fatty acids (SCFAs) and lactic acids.

Results: The trial included 35 test subjects, 36 controls, and 51 HBR. The $16 \mathrm{~S}$ rRNA-gene sequencing revealed moderate effects of test formula on oral microbiota. In contrast, the gut microbiota was substantially affected across time comparing test with control. In both groups bacterial diversity increased over time but was characterised by a more gradual increment in test compared to control. Compositionally this reflected an enhancement of Bifidobacterium spp. and Veillonella $\mathrm{sp}$. in the test group. In contrast, the control-fed infants showed increased abundance of adult-like species, mainly within the Lachnospiraceae family, as well as within the Ruminococcus and Alistipes genus. The effects on Bifidobacterium spp. and Lachnospiraceae spp. were previously confirmed through enumeration by fluorescent in situ hybridization and were shown for test to approximate the proportions observed in the HBR. Additionally, microbial activity was affected as evidenced by an increase of L-lactate, a decrease of valerate, and reduced concentrations of branched-chain SCFAs in test vs control. 
Conclusions: The AAF including specific synbiotics effectively modulates the gut microbiota and its metabolic activity in non-lgE mediated CMA infants bringing it close to a healthy breastfed profile.

\section{Introduction}

The prevalence of food allergy in infancy and childhood is increasing in many countries worldwide. Cow's milk allergy (CMA) is among the most common food allergies in early life and is associated with growth retardation throughout childhood, particularly in children suffering from persistent milk allergy (1). Comorbidity is common, and many children develop other allergic conditions over time, also referred to as the allergic march (2). The microbes that colonize the mucosal tissues after birth have a pivotal role in both innate and adaptive immune development (3) and may have long-term effects both on the susceptibility and the persistence of allergic disease $(4,5)$.

Breastfeeding provides the infant gastrointestinal (GI) tract with a plethora of bioactive factors and has profound effects on gut microbiota composition and functions (6-8) and, as more recently reported, on oral microbiota development (9, 10). Infants who suffer from severe CMA rely on cow's milk protein avoidance and, when breastfeeding is not possible, require specialised infant formulas such as extensively hydrolysed formula (eHF) or amino acid-based formula (AAF)(11). Incorporation of prebiotics, probiotics, or their combination (synbiotics) in these formulas offers a safe, suitable and effective strategy for both the dietary management and for potentially optimizing microbiota development in both lgE- and non-IgE-mediated CMA infants $(12,13)$.

In a randomized controlled trial with non-lgE-mediated CMA infants (ASSIGN study), an improvement of gut microbiota was observed in infants receiving an AAF with specific synbiotics (test) compared to infants receiving the same AAF without synbiotics (control). This improvement was based on an enhancement of bifidobacteria and a decrease of the Eubacterium rectale/Clostridium coccoides $(E R / C C)$ group; in both test levels were close to the levels observed for a separate 
healthy, breastfed reference (HBR) group (14). The fluorescence in situ hybridization (FISH) method used is an effective approach to quantify specific bacterial groups, but it does not provide information on the full bacterial composition and diversity of the community. For this, application of next-generation sequencing technologies is typically needed $(15,16)$. We hypothesized that synbiotics would have a more comprehensive effect on the microbiota composition and activity. Therefore, we performed an in-depth characterisation of the microbial compositions of both faecal and saliva specimens collected in the ASSIGN study through $16 \mathrm{~S}$ ribosomal RNA-gene sequencing, and in addition investigated the effects on gut physiology and bacterial metabolic activity by analysis of faecal $\mathrm{pH}$, short-chain fatty acids (SCFA) and lactate.

\section{Materials and methods}

\section{Study design}

ASSIGN was a prospective, randomized, double-blind controlled study (Netherlands Trial Register NTR3979) including infants with suspected non-IgE mediated CMA and a separate non-randomized healthy, breastfed reference group (HBR). Detailed methods on how the trial was conducted, and the primary and secondary outcome measures, have been published previously (14).

In brief, subjects $<13$ months of age with non-IgE mediated CMA were stratified based on predominant, investigator-assessed symptoms (skin or gastrointestinal) and randomly allocated to receive test $(n=35)$ or control formula $(n=36)$. Study duration was 26 weeks with allocation to study product for at least 8 weeks. After 8 weeks, randomized subjects continued to use the allocated study product or switched to commercially available eHF, or other milk substitute as per clinical practice guidelines of each medical centre. Subjects in the HBR group were age-matched to week 8 of the randomized groups $(n=51)$. Infants in the test group received an AAF (Neocate LCP; Nutricia Advanced Medical Nutrition, Liverpool, UK) including a prebiotic blend of chicory-derived neutral oligofructose and long-chain inulin (BENEO-Orafti SA, Oreye, Belgium) (9:1 ratio at a total concentration of $0.63 \mathrm{~g} / 100 \mathrm{ml})$ and a probiotic 
strain Bifidobacterium breve M-16V (Morinaga Milk, Tokyo, Japan) at a concentration of $1.47 \times 10^{9}$ colony-forming units (CFU)/100 mL formula. The control formula was a commercially available AAF (Neocate LCP; Nutricia Advanced Medical Nutrition, Liverpool, UK).

\section{Collection of saliva and stool samples}

Saliva samples were collected from randomized infants at baseline and 8 weeks by a healthcare professional using the SalivaBio Children's Swab method (Salimetrics, Carlsbad, USA) at least 1 hour after feeding. Stool samples from randomized infants were collected, as reported previously (14), by parents/guardians at baseline, 8, 12 and 26 weeks. Parents/guardians of the age-matched non-randomized infants in the HBR group were asked to collect stool samples only. Saliva and stool specimens collected in the clinic were immediately frozen at $-80^{\circ} \mathrm{C}$. Stool specimens collected at home were immediately frozen in home-freezers and transported with ice-packs to the clinic by parents/guardians or by courier for storage at $-80^{\circ} \mathrm{C}$. Thereafter, both saliva and stools were transported on dry-ice (solid CO2) to Nutricia Research and stored at $-80^{\circ} \mathrm{C}$ until analysis.

\section{DNA extraction}

DNA extraction from saliva samples was performed with DNeasy Blood \& Tissue Kits (Qiagen, Venlo, the Netherlands) according to the manufacturer's protocol, except for an adaptation in the enzymatic lysis step and the addition of a mechanical lysis step as pre-treatment before the DNA isolation procedure. In brief, $150 \mu \mathrm{l}$ of saliva sample was diluted up to $350 \mu \mathrm{l}$ in PBS buffer $(150 \mathrm{mM} \mathrm{NaCl}, 10 \mathrm{mM}$ Na2HPO4, $20 \mathrm{mM} \mathrm{NaH2PO4,} \mathrm{pH} \mathrm{7.4)} \mathrm{to} \mathrm{which} 50 \mu$ l of lytic enzymatic cocktail was added (50 mg/mL lysozyme, Sigma-Aldrich, St. Louis, Missouri, United States, USA and $20 \mu \mathrm{l}$ proteinase $\mathrm{K}$ from Qiagen kit) and $300 \mathrm{mg}$ of $0.1 \mathrm{~mm}$ glass beads (Biospec, Bartlesville, Oklahoma, USA). This suspension was incubated at $37^{\circ} \mathrm{C}$ for 30 minutes, followed by one round of bead-beating for 10 minutes at $25 \mathrm{~Hz}$ (Tissuelyser I, Qiagen, Venlo, the Netherlands) and followed by the QIAcube isolation procedure (Qiagen).

DNA extraction from stools samples was performed with QIAmp DNA Stool Mini Kit (Qiagen, Venlo, the Netherlands) according to the manufacturer's protocol except 
for the addition of two bead-beating steps as described before (17). Extracted DNA from stools were purified from extraction impurities using spin columns (DCC ${ }^{\mathrm{TM}}$, Zymo research, Irvine, California, USA).

\section{Microbiota profiling}

Faecal and salivary microbiota compositions were profiled by sequencing the hypervariable V3-V4 regions of the 16S rRNA gene. Sequencing was performed by LifeSequencing S.L. (Valencia, Spain) on an Illumina MiSeq instrument (San Diego, California, USA). The V3-V4 region was PCR-amplified with universal primers S-D-Bact-0341-b-S-17 primer (forward 5'-CCTACGGGNGGCWGCAG-3') and S-D-Bact-0785-a-A-21 primer (reverse 5'-GACTACHVGGGTATCTAATCC-3')(18) designed for dual indexing following the Illumina 16S Metagenomic Sequencing Library Preparation protocol (Part \# 15044223 Rev. B). In brief, PCR amplification was performed in two steps: i) In a first step, the V3-V4 region was amplified with the addition of universal adaptors to the amplification products. All amplicons were purified (AMPure XP, Beckman, Danvers, MA) to remove short amplification products and quantified using the Quant-iT PicoGreen dsDNA kit (Invitrogen, Carlsbad, California, USA). ii) In the second PCR step, the amplicons from the first step were amplified by targeting the universal adapters and with the addition of sample specific indexes and sequencing adaptors. The final amplicons were purified (AMPure XP) and quantified using the Quant-iT PicoGreen ds DNA kit (Invitrogen). All samples were pooled in equal amounts and sequenced in a $300 \mathrm{bp}$ paired-end mode.

\section{Bioinformatic analysis of sequence data}

Illumina reads were trimmed (removal of primers) and quality filtered by removing all reads with a mean q-score lower than 20 with 'cutadapt v1.4.1' (19). Paired-end reads were merged using the program 'PEAR v0.9.6' (20). Merged reads with $q>15$ over a window of 5 bases, no ambiguous bases and a minimal length of 300 were retained and analysed with the 'Quantitative Insights Into Microbial Ecology' (QIIME) v1.9.0 package (21). Sequences were clustered into Operational Taxonomic Units (OTUs) based on $97 \%$ sequence identity as proxy for bacterial species using VSEARCH v2.03 with exclusion of chimeric sequences identified against the RDP 
gold database $(22,23)$. Taxonomic assignment was performed using the RDP classifier (24) against the SILVA119 database (25). Singleton OTUs, and OTUs with eukaryotic assignments, as well as OTUs with a low relative abundance (counts of an OTU as proportion of total reads of a sample) up to $0.005 \%$ were excluded from further downstream analysis. Representative sequences of OTUs were aligned using PyNAST (26) and used to build a phylogenetic tree with FastTree (27). Rarefaction of the OTU tables was applied to account for the differences in sequencing depths (number of reads per sample) between the samples with default settings (10 equal depths from 10 sequences/sample up to the median number of sequences/sample with 10 iterations at each sequencing depth). The tree and rarefied OTU tables were used to calculate the species diversity (a-diversity) of the samples using Faith's phylogenetic diversity (PD)(28) and the Shannon index for diversity (29).

The sequences within an OTU of interest (i.e. identified as differentially abundant from the statistical comparisons performed) were further partitioned into homogenous nodes with high sequence identity using the MED v2.1 algorithm (30). Taxonomic assignment of the MED nodes were performed using the RDP classifier (24) against the SILVA119 database (25). The assignment of the node with the largest number of reads and highest sequence identity was subsequently used as a more accurate proxy to the taxonomy of that OTU.

\section{Additional faecal sample parameters}

To assess overall bacterial metabolic activity, the following faecal sample parameters were measured as described previously (31): $\mathrm{pH}$, concentrations of short-chain fatty acids (SCFA) (i.e., acetate, propionate, butyrate, iso-butyrate, valerate, and iso-valerate), and $\mathrm{D}$ - and L-lactate.

FISH was applied to quantify the Bifidobacterium genus and Eubacterium rectale/Clostridium coccoides group (ER/CC) as described previously (16) using the 16S rRNA-targeted oligonucleotide probes S-G-Bif-0164m-a-A-18 $\left(5^{\prime}\right.$-CATCCGGYATTACCACCC-3') (32, 33) and S- ${ }^{*}$-Erec-0482-a-A-19 (5'-GCTTCTTAGTCARGTACCG-3') (15), respectively. 


\section{Data handling and statistical analyses}

All analyses were performed on intention-to-treat data set (ITT), defined as all randomized subjects. Overall, the statistical analyses were performed comparing test with the control group per specimen analysed (saliva or faecal). The HBR group data was used as reference only and not as an intervention group. Statistical analyses were performed by using $S A S \circledR$ (SAS Enterprise Guide version 4.3 or higher) for Windows (SAS Institute Inc., Cary, NC) unless indicated otherwise. Results are expressed and presented as mean values and standard deviations unless stated otherwise.

16S rRNA-gene sequencing data:

The species diversity ( $\alpha$-diversity) indexes calculated in QIIME from the $16 S$ rRNA-gene sequencing data were analysed at one single rarefied sequencing depth. The sequence depth which was selected for comparison was based on the maximum rarefaction depth where all or most of the samples were still included. Differences between treatment groups across time were tested using a random intercept mixed model including baseline in the outcome vector, adjustment for stratification factor (skin or gastrointestinal symptoms), treatment, time and treatment by time interaction as fixed factors. For assessing the treatment effect over time, significance of the treatment by time interaction was used.

The non-rarefied OTU tables obtained from QIIME were trimmed, removing sparse OTUs with at most 10 non-zero observations. Statistical analysis of the bacterial compositions was performed by applying a combination of multivariate analysis with Canoco 5 software (34), followed by differential abundance testing using the two-part statistics method (35). Firstly, the constrained ordination method, known as redundancy analysis (RDA), was used to test time-dependent treatment effects with adjustment for stratification factor. The Monte Carlo Permutation test (MCPT) with 1000 permutations was used to evaluate statistically significant differences ( $P \leq 0.05)$ of the resulting model. If found significant, the top-15 responding OTUs identified from the RDA model were subsequently tested for differential abundance at the different timepoints using the two-part statistics method (35). If the two-part statistics method 
could not be applied due to a small number of non-zero observations, then only presence-absence was considered by applying the Chi-square test (if $\geq 5$, but $<10$ non-zeros in both groups) or Barnard test (if $<5$ non-zeros in one group). The Benjamini-Hochberg false-discovery rate (FDR) was used to correct for multiple comparisons in the differential abundance tests (36) and significance was considered when FDR $\leq 0.1$ at week 8 or when FDR $\leq 0.1$ for at least two visits (i.e. 12 and 26 weeks).

\section{Other faecal parameters ( $\mathrm{pH}$, FISH outcomes, SCFAs, lactic acids):}

The following rule was applied to faecal parameters that were subject to limit of detection (LOD): If a value was below detection limit and the percentage of values below detection limit was at most 30\%, then the value was replaced with LOD/2. For parameters with more than $30 \%$ of the values below LOD only presence-absence was considered, and $\mathrm{P}$-values were based on a logistic regression model. The P-values for continuous data were based on the analysis of covariance (ANCOVA) or Van Elteren test depending on normality of the residuals. All statistical models were corrected for baseline levels (if applicable) and stratification factor, and for statistical significance $\mathrm{P} \leq 0.05$ was considered.

\section{Results}

Subject characteristics were well balanced between groups as reported previously (14). In total, 378 (125 saliva and 253 faecal) samples were successfully sequenced with a sequencing depth ranging from 15265 to 129780 , and a median depth of 39761 sequences per sample (Table S1). Principal component analysis (PCA), which is an unconstrained ordination method (34), was used to explore the taxonomic compositions of saliva and faecal samples. A clear clustering by sample origin was observed (Figure 1A), which confirms that community composition is primarily determined by body habitat (37). A summary of the most dominant taxa identified at the bacterial family level showed that saliva compared to faecal samples were typically characterized by increased relative abundance of Streptococcaceae (53.3 $\pm 17.8 \%)$, Microcrococcaceae $(9.7 \pm 6.4 \%)$ and Actinomycetaceae $(5.2 \pm 5.8 \%)$. 
Faecal samples were typically characterized by Bacteroidaceae $(20.9 \pm 18.7 \%)$, Lachnospiraceae (15.4 $\pm 12.8 \%), \quad$ Enterobacteriaceae $\quad(14.2 \pm 14.2 \%)$, Bifidobacteriaceae (7.6 $\pm 9.2 \%), \quad$ Ruminococcaceae $\quad(6.7 \pm 8.2 \%) \quad$ and Verrucomicrobiaceae (5.3 $\pm 10.7 \%)$ (Figure 1B).

(A)

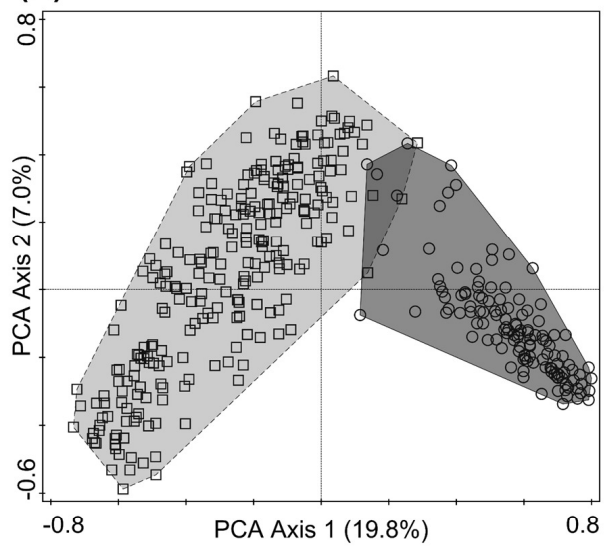

Samples

$\bigcirc \square$ saliva $\square \quad$ faecal
(B)

\begin{tabular}{|c|c|c|}
\hline Taxa at family level & saliva & faecal \\
\hline Firm_f_Streptococcaceae & $53.3(17.8) \%$ & $2.0(4.0) \%$ \\
\hline Bact_f_Bacteroidaceae & $0.6(1.3) \%$ & $20.9(18.7) \%$ \\
\hline Firm_f_Veillonellaceae & $7.9(6.6) \%$ & $13.3(11.9) \%$ \\
\hline Firm_f_Lachnospiraceae & $1.8(3.3) \%$ & $15.4(12.8) \%$ \\
\hline Prot_f_Enterobacteriaceae & $2.1(4.2) \%$ & $14.2(14.2) \%$ \\
\hline Acti_f_Bifidobacteriaceae & $3.8(8.0) \%$ & $7.6(9.2) \%$ \\
\hline Firm_f_Ruminococcaceae & $0.3(1.9) \%$ & $6.7(8.2) \%$ \\
\hline Verr_f_Verrucomicrobiaceae & $0.2(0.7) \%$ & $5.3(10.7) \%$ \\
\hline Acti_f_Micrococcaceae & $9.7(6.4) \%$ & $0.1(0.4) \%$ \\
\hline Acti_f_Actinomycetaceae & $5.2(5.8) \%$ & $0.1(0.4) \%$ \\
\hline Bact_f_Porphyromonadaceae & $0.1(0.2) \%$ & $2.4(5) \%$ \\
\hline Firm_f_Clostridiaceae 1 & $0.0(0.1) \%$ & $1.8(6) \%$ \\
\hline Firm_f_Erysipelotrichaceae & $0.6(0.9) \%$ & $1.4(2.3) \%$ \\
\hline Bact_f_Prevotellaceae & $1.0(1.8) \%$ & $1.1(5.7) \%$ \\
\hline Firm_f_P5D1-392 & $2.9(3.1) \%$ & $0.1(0.1) \%$ \\
\hline Acti_f_Coriobacteriaceae & $0.5(0.6) \%$ & $1.2(2) \%$ \\
\hline Firm_f_BacFamily XI & $2.5(2.4) \%$ & $0(0.1) \%$ \\
\hline Firm_f_Peptostreptococcaceae & $0.2(0.3) \%$ & $1.1(2.8) \%$ \\
\hline Bact_f_Rikenellaceae & $0.0(0.0) \%$ & $1.2(2.7) \%$ \\
\hline Prot_f_Neisseriaceae & $2.0(4.1) \%$ & $0.0(0.2) \%$ \\
\hline Coverage (\% of total) & $\mathbf{9 4 . 8 \%}$ & $\mathbf{9 5 . 9} \%$ \\
\hline
\end{tabular}

Figure 1: Principal Component Analysis (PCA) of faecal and salivary microbiota composition $(A)$ and summary of major bacterial families identified $(B)$. The PCA sample scatterplot is displayed on the first two axes summarizing most of the species variation, which is based on the OTU count data for each sample. The distance between the sample symbols (rounds for saliva and squares for faecal) approximates the dissimilarity of their species composition as measured by their Euclidean distance. Mean relative abundances $( \pm S D)$ are summarized at the family level ("_f_") for taxa > 1\% and summarized in the heat map (Red-Yellow-Green color scheme indicating high to low relative abundance). Abbreviations used for bacterial phylum levels: Acti = Actinobacteria, Bact $=$ Bacteroidetes, Firm = Firmicutes, Prot $=$ Proteobacteria, Verr = Verrucomicrobia .

\section{Bacterial diversity}

The species diversity indexes (PD and Shannon) were analysed at a rarefaction depth of 16114 sequences per sample, which omitted one saliva sample (control, week 8) from comparison. Control and test group did not differ in salivary species 
diversity based on PD (Figure 2A) or Shannon index (Figure 2C). A treatment effect over time was observed for faecal species diversity, which was characterized by a more gradual increment (from baseline until 26w) in test compared to control for both PD (Figure 2B, estimated difference per week $=-0.022, P=0.069$ ) and Shannon index (Figure 2D, estimated difference per week $=-0.026, P=0.005$ ). The estimated average difference between test vs control was significantly different at week 12 (PD=-0.349, $\mathrm{P}=0.031$ and Shannon=-0.236, $\mathrm{P}=0.049)$ and week $26(\mathrm{PD}=-0.653, \mathrm{P}=0.012$ and Shannon=-0.596, $P=0.002$ ). The HBR group showed the lowest average diversity $(P D=4.37 \pm 1.14$ and Shannon=3.63 \pm 0.80$)$ compared to both test $(P D=4.89 \pm 1.05$ and Shannon=3.75 \pm 0.67$)$ and control $(P D=5.17 \pm 0.88$ and Shannon=4.01 \pm 0.71$)$ at week 8.

(A)

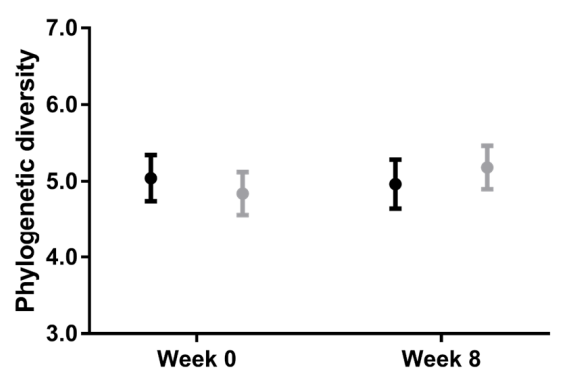

(C)

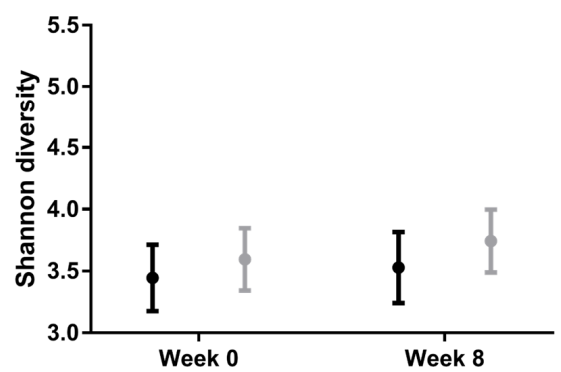

(B)

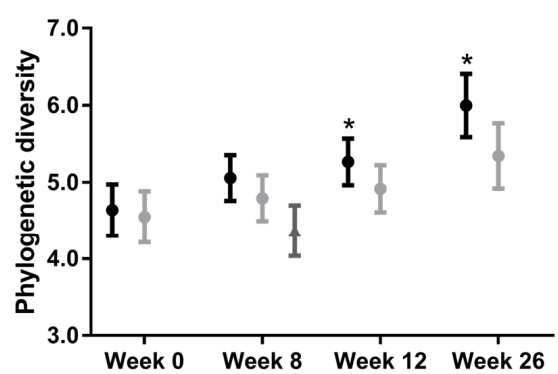

(D)

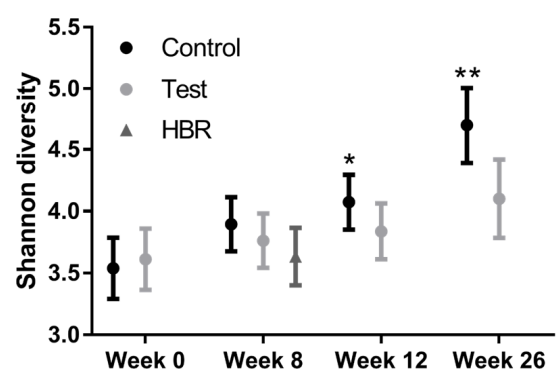

Figure 2: Least square (LS) means with $95 \% \mathrm{Cl}$ of phylogenetic diversity in saliva (A) and faecal samples (B), and Shannon diversity in saliva $(C)$ and faecal samples (D) for treatment by time. The HBR reference values (age-matched to week 8 ) are plotted as well. P-values are based on a random intercept mixed model with Week $8 / 12 / 26$ values as outcome, stratification factor and baseline values as covariate and treatment as fixed effect: ${ }^{*} \mathrm{P} \leq 0.05$ and ${ }^{* *} \mathrm{P} \leq 0.01$. 


\section{Time-dependent treatment effects on oral microbiota}

Redundancy analyses (RDA) were carried out to test the effect of treatment (test/control) across time on the salivary community composition. We fitted both an RDA with and without correction for timepoint (baseline and week 8) and compared the results of the MCPT on the first axis of the model. The P-value for the RDA with correction for timepoint (0.3816) was larger than our pre-set threshold of 0.05 , so we used the simpler model (with $\mathrm{P}=0.003$ ) as a basis for interpreting the time-dependent treatment effects.

\section{(A)}

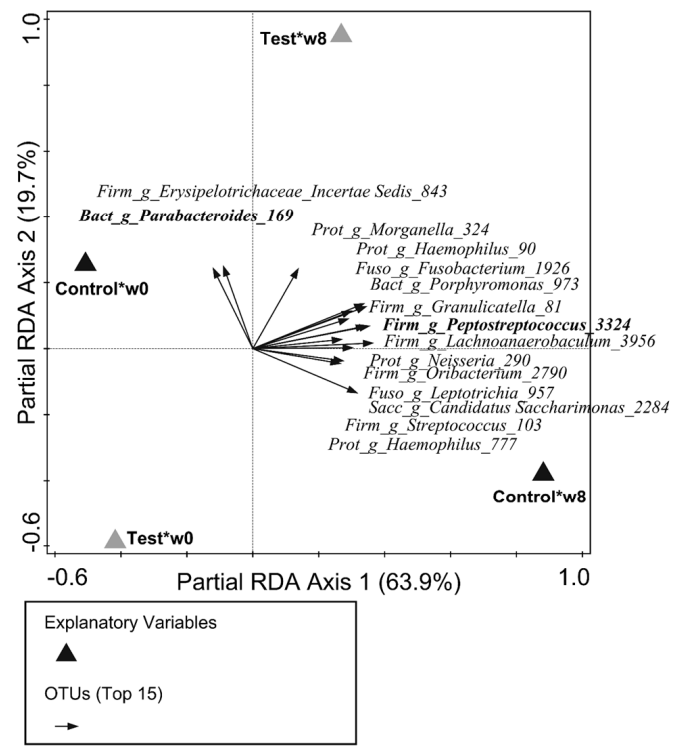

(B)

Firm_g_Peptostreptococcus_3324

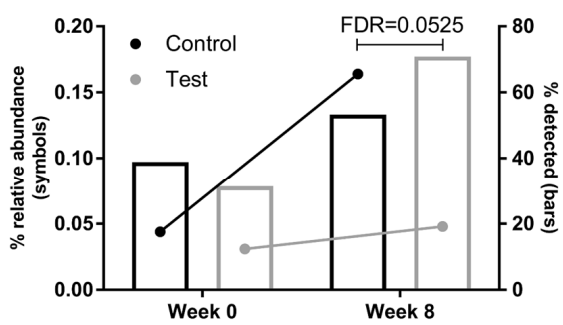

(C)
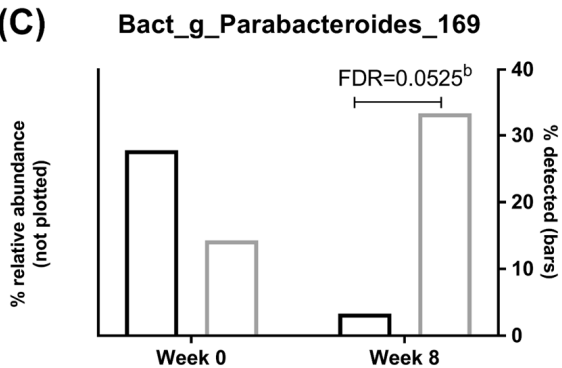

Figure 3: Redundancy Analysis (RDA) plot of salivary microbiota composition based on treatment by time (week $0 / 8$ ) interaction with adjustment for stratification factor $(A)$. The top 15 OTUs are plotted based on best fit with the first two RDA axes. In bold the OTUs that were significantly different at week 8 between test vs control as confirmed with the two-part statistics. The two-part statistics combines a test to compare the proportion of zeros (plotted as bars) and one to compare the median of the non-zero values (plotted as points) and are displayed for the two taxa ( $B$ and $C$ ) identified as differentially abundant. False Discovery Rate (FDR) was used to correct the raw $\mathrm{P}$-values for multiple testing with significance at 0.1 . b: only the Barnard test was performed (if $<5$ non-zeros in one group) to compare the proportion of zeros. Taxa are summarized at the OTU level with unique (but arbitrary) numbers as identifiers, genus level ("_g_") and phylum level: Acti = Actinobacteria, Bact $=$ Bacteroidetes, Firm = Firmicutes, Fuso $=$ Fusobacteria, Prot $=$ Proteobacteria, Sacc $=$ Saccharibacteria . 
The top 15 OTUs with the best fit on the first two axes (explaining most of the variation) were plotted in the RDA (Figure $3 \mathrm{~A}$ ) and further evaluated for differential abundances between test and control using the two-part statistics method (35). No differences were observed at baseline (based on FDR $\leq 0.1$ ), but two OTUs out of this top 15 were found differentially abundant between test and control at week 8 . This included a decreased relative abundance of Peptostreptococcus sp. (Figure 3B, $\mathrm{FDR}=0.0525$ ) and an increased presence of Parabacteroides sp. (Figure 3C, $\mathrm{FDR}=0.0525)$.

\section{Time-dependent treatment effects on gut microbiota}

In order to assess the time-dependent treatment effects for the faecal community composition we used the Principal Response Curves (PRC) method (38). The PRC is based on the RDA method, in which the principal component is plotted against time (baseline, week 8, 12 and 26) to enable the assessment and visualization of time-dependent treatment effects. The MCPT applied to test the significance of the resulting $P R C$ model was significant for the first axis $(P=0.001)$. The top 15 OTUs with the best fit on the first axis were plotted (Figure 4A) and further evaluated with the two-part statistics method (35). No differences were observed at baseline, but a total of 13 OTUs out of the top 15 were confirmed to be differentially abundant between test and control at week 8 or at 2 or more timepoints. This included increased relative abundances in test vs control of 6 OTUs, of which 5 were assigned to Bifidobacterium and 1 was assigned to the Veillonella genus. The other 7 OTUs showed decreased relative abundances, of which 5 were assigned to 3 genera within the Lachnospiraceae family (Tyzzerella, Blautia and Lachnoclostridium) and 2 were assigned to the genera Ruminococcus and Alistipes, respectively.

\section{FISH quantification of faecal bacterial groups}

The treatment effects on gut microbiota, as revealed by $16 \mathrm{~S}$ rRNA-gene sequencing, were mostly associated with a relative increase of several species of the genus Bifidobacterium and a decrease of several species of the family Lachnospiraceae. FISH enumeration of these two bacterial groups was used to verify the absolute differences in abundance between treatments, of which results have 
been reported before (14). In summary, FISH analysis confirmed a significant enrichment of bifidobacteria in test vs control across time (Figure 4B). Moreover, the proportions for test $(36.0 \pm 22.4 \%)$ as compared to that of the control group at week 8 $(14.5 \pm 16.4 \%)$ were close to the levels observed for the HBR group (48.1 $\pm 26.5 \%)$. The FISH probe used to quantify the ER/CC group targets the majority of Lachnospiraceae spp. including the differentially abundant OTUs associated with the genera Tyzzerella, Blautia and Lachnoclostridium as identified with 16S rRNA-gene sequencing.

(A)

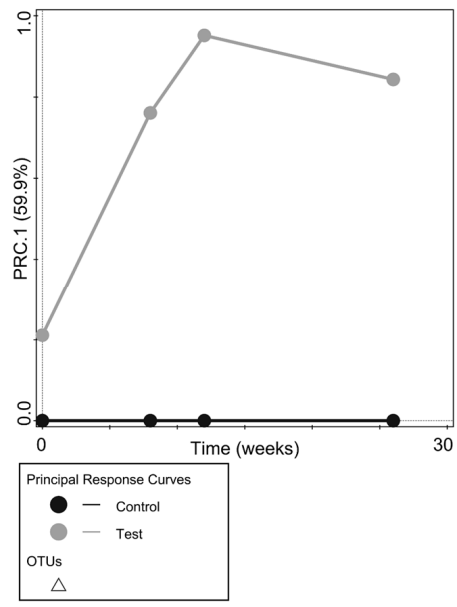

(B) Bifidobacterium spp.

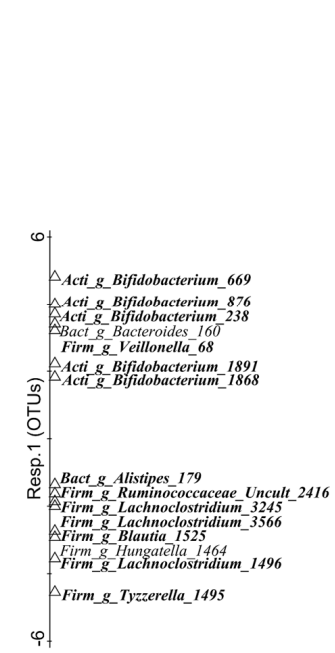

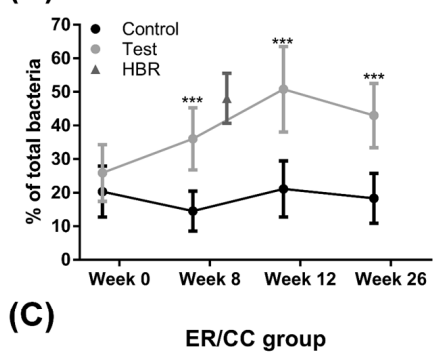

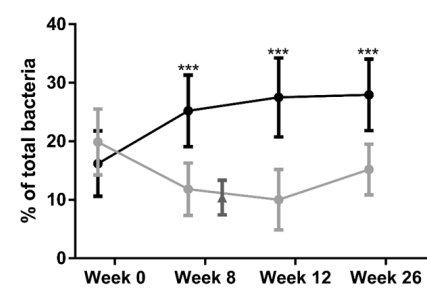

Figure 4: Principal Response Curves (PRC) of faecal microbiota composition testing the treatment by time interaction with adjustment for stratification factor and time $(A)$. The treatments are presented as a single response curves across time (on the horizontal axis) with Control as reference with zero PRC values (on the vertical axis) and so its curve lays over the horizontal axis. The top 15 OTUs are plotted on the separate vertical (one-dimensional) plot based on best fit with the first PRC axis. In bold the OTUs that were significantly increased $(>0)$ or decreased $(<0)$ in Test vs Control at week 8 or at two or more timepoints (week $8 / 12 / 26)$ as confirmed by the two-part statistics (FDR $\leq 0.1$ ). Percentages (means with $95 \% \mathrm{Cl}$ ) of bifidobacteria $(\mathrm{B})$, and ER/CC group (C) quantified by FISH at week 0/8/12/26. The HBR reference values (age-matched to week 8 ) are plotted as well. $\mathrm{P}$-values are based on ANCOVA comparing Test vs Control with Week 8/12/26 values as outcome, stratification factor and baseline values as covariate and treatment as fixed effect: ${ }^{* *} P \leq 0.01 ;{ }^{* * *} P \leq 0.001$. Taxa names are given at the OTU level with unique (but arbitrary) numbers as identifiers, genus level ("_g_"), family level (“_f_"): Bact = Bacteroidaceae, Bifi = Bifidobacteriaceae, Lach = Lachnospiraceae, Rumi = Ruminococcaceae, Veil = Veillonellaceae; and phylum level: Acti = Actinobacteria, Bact = Bacteroidetes, Firm = Firmicutes. 
A decreased abundance of the ER/CC group in test vs control across time confirm these findings (Figure 4C). Additionally, the levels for test (11.8 $\pm 10.9 \%$ ) as compared to that of the control group at week $8(25.2 \pm 16.9 \%)$ were close to the levels observed for the HBR group (10.4 $\pm 10.6 \%)$.

\section{Faecal pH, SCFA and lactate}
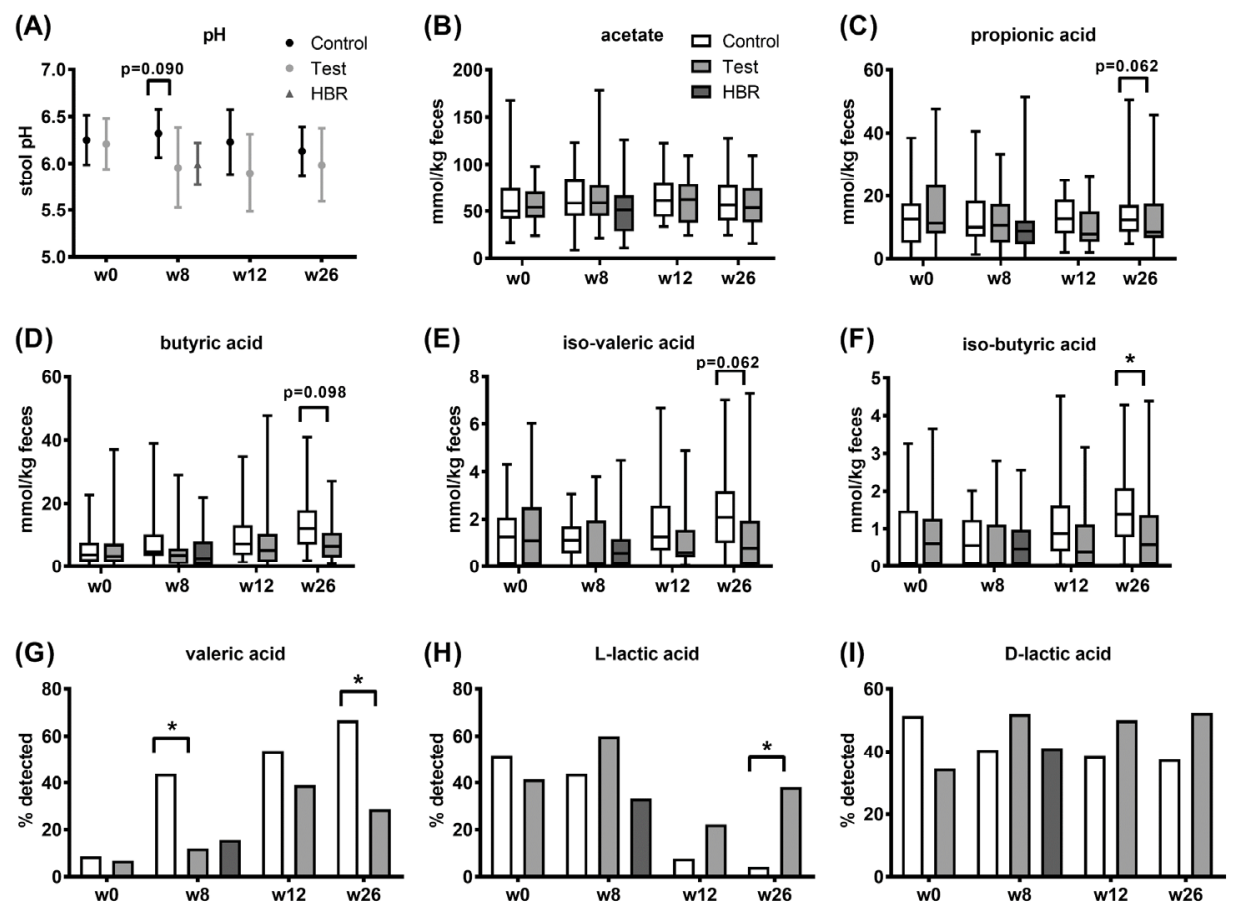

Figure 5: Mean with $95 \% \mathrm{Cl}$ of stool $\mathrm{pH}(\mathrm{A})$ for treatment by time. The box-plots summarize the amounts (in $\mathrm{mmol} / \mathrm{kg}$ ) of acetate $(B)$, propionate $(C)$, butyrate $(D)$, iso-valerate $(E)$, iso-butyrate $(F)$ for treatment by time, respectively. Percentage of faecal samples (plotted as bars) with detectable levels of valerate $(G)$, L-lactate $(H)$, and D-lactate (I) for treatment by time, respectively. The HBR reference values (age-matched to week 8 ) are plotted as well. P-values for stool $\mathrm{pH}$ and acetate are based on ANCOVA comparing Test vs Control with Week $8 / 12 / 26$ values as outcome, stratification factor and baseline values as covariate and treatment as fixed effect. P-values for the variables summarized in Figure C-E are based on Van Elteren test comparing test vs control with respect to change from baseline at Week 8/12/26, taken the stratification factor into account. $\mathrm{P}$-values for the variables summarized in Figure G-I are obtained from a logistic regression model comparing test vs control at Week 8/12/26 with adjustment for baseline values. * $\mathrm{P} \leq 0.05$. 
To assess whether the observed changes in gut microbiota composition also led to changes in gut physiology and microbial metabolites produced, the faecal $\mathrm{pH}$ and levels of SCFA and lactate were determined. No statistically significant differences were observed for faecal $\mathrm{pH}$, acetate, propionate, butyrate, iso-valerate (Figure 5A-E) and D-lactate (Figure $5 \mathrm{I}$ ) at the different timepoints. L-lactate was detected in a greater number of samples in test vs control at week 26 (38 vs $4 \%, P=0.020$ ) (Figure $5 \mathrm{H})$. In contrast, valerate was detected in a smaller number of samples in test vs control at week 8 (44 vs $12 \%, P=0.036$ ) and week 26 (67 vs $29 \%, P=0.021$ ) (Figure $5 \mathrm{G})$. Moreover, the concentration of iso-butyrate was lower in test vs control at 26 weeks $(P=0.050)$ (Figure 5F).

\section{Correlations of faecal microbiota composition and metabolic activity across time}

A redundancy analysis was used to summarize the faecal microbiota composition over time as explained by treatment (Test or Control) and the HBR group (Figure 6A). The RDA recapitulates the results of the PRC analysis, but in addition confirmed the proximity in community composition of the test group at week 8 with the HBR. The additional faecal parameters measured (FISH, pH, SCFAs and lactic acids) were supplemented to this RDA in a separate biplot (Figure 6B). An inverse correlation was observed for the FISH quantified levels of Bifidobacterium spp. with the ER/CC group, which reflects the major differences observed for test (and HBR) with the control group. Moreover, the increase of Bifidobacterium spp. in test was positively correlated with increased levels of L-lactate. In contrast, the more abundant levels of the ER/CC group across time in control was associated with increased levels of butyrate, valerate, iso-butyrate and iso-valerate. In test, the ER/CC group gradually increased from 12 to 26 weeks, which was associated (similarly as for control) with an increment of butyrate, valerate, iso-butyrate and iso-valerate at 26 weeks. 
(A)

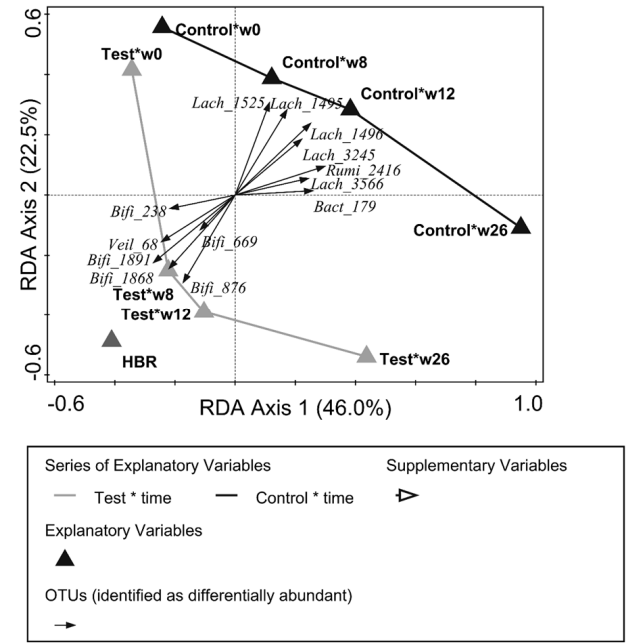

(B)

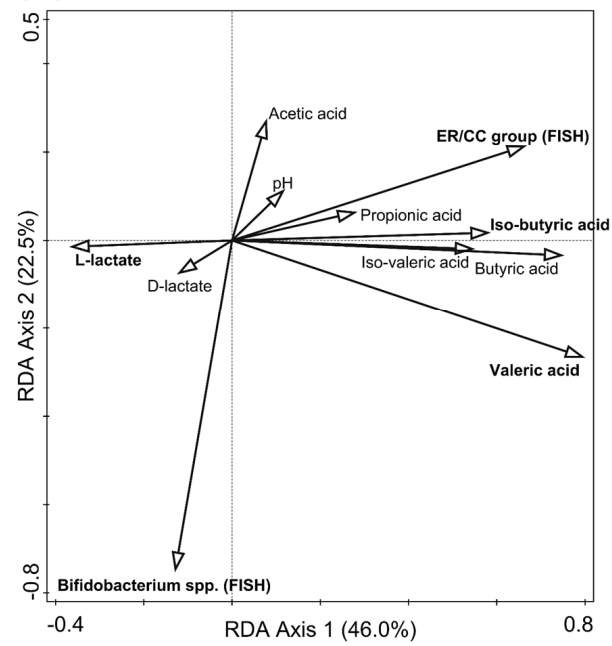

Figure 6: RDA plot of faecal microbiota composition based on treatment by time interaction and the HBR reference group (age-matched to week 8 ) as explanatory variables $(A)$. OTUs that were identified as differentially abundant between test and control are plotted as biplot arrows in the RDA plot on the left. The same RDA plot is shown on the right $(\mathrm{B})$, but then supplemented with faecal pH, FISH counts and levels of SCFA and lactic acids as correlation biplot. Variables that were significantly different between test and control are shown in bold. Taxa names are given at the OTU level with unique (but arbitrary) numbers as identifiers and the family level ("_f_"): Bact $=$ Bacteroidaceae, Bifi $=$ Bifidobacteriaceae, Lach $=$ Lachnospiraceae, Rumi $=$ Ruminococcaceae, Veil $=$ Veillonellaceae

\section{Discussion}

We previously reported the specific enhancement of bifidobacteria and decrement of the ER/CC group in the faeces of infants receiving the AAF with synbiotics consisting of a prebiotic blend of oligofructose and long-chain inulin and the probiotic strain Bifidobacterium breve M-16V (14). In this study, we applied a 16S rRNA-gene sequencing approach on both faecal and saliva specimens to elucidate more specifically which taxa responded to the intervention within the respective bacterial communities and what the effect was on their diversity and functionality.

We demonstrated that the effect of the synbiotic-containing AAF on infant microbiota was most pronounced for the gastro-intestinal tract and only minimally affected the oral microbiota. The AAF including synbiotics compared to the AAF 
without synbiotics showed a more gradual increment over time of bacterial diversity, which is also typically observed in longitudinal studies investigating early life gut microbiota development of breastfed infants as compared to formula-fed infants $(6,7$, $39,40)$. These studies showed that the lower diversity of gut microbiota in breastfed infants is not only observed during the exclusive human milk-feeding period, but also during the complementary feeding-period until full transition to family foods, which reflects the sustained effects of human milk oligosaccharides on the bifidobacterial species that effectively thrive on these compounds $(6,7)$. The AAF including synbiotics was found to enhance the bifidobacterial community, as several bifidobacterial species had increased, which was also reflected by an increase of the fermentation end-product L-lactate in the faeces of these infants. Interestingly, the concordant increase observed in this study for Veillonella sp. is most likely explained by the ability of this species to utilize and convert lactate into propionate (41). In contrast, the infants receiving the control formula showed an early adoption of adult-like bacterial taxa belonging to the ER/CC group (resembling Lachnospiraceae spp.), namely Tyzzerella, Blautia and Lachnoclostridium spp., as well as species of Ruminococcus and Alistipes. This increase of adult-like taxa was associated with an increase of valerate and the branched-chain SCFA iso-butyrate, which are fermentation products that result from the degradation of proteins and amino acids $(42,43)$. Overall, these results indicate that the synbiotic-supplemented AAF induced a saccharolytic fermentation profile, while infants receiving the AAF without synbiotics showed a more proteolytic fermentation activity, which is generally associated with metabolite profiles that may be less beneficial for colonic health $(44,45)$.

To date, several case-control studies have specifically investigated the gastrointestinal microbiota of infants and children with confirmed CMA compared to age-matched healthy controls (46-50). All of them reported altered gut microbiota in infants and children with CMA, although with mixed findings. However, the common characteristics that were identified in these studies included lower levels of bifidobacteria (47-50) and increased levels of members of the heterogenous ER/CC group (46-48). In analogy with our study, the case-control study of Thompson-Chagoyan et al. (46) in addition observed increased fecal butyrate and 
branched-chain SCFA (iso-butyrate, iso-valerate) concentrations in CMA infants compared to healthy infants. Interestingly, our study demonstrated that 8-weeks use of the synbiotic-supplemented AAF approximated the composition and activity of the gut microbiota of the age-matched healthy, breastfed reference group.

Our study has several limitations as addressed before (14), which includes the challenges in making and confirming a specific and accurate diagnosis of non-lgE mediated allergy. The chance of including infants with other (food) allergy presentations were mitigated by applying a robust diagnostic work-up (14). For a number of subjects, no specimens were available due to insufficient material or not completing the study until 26 weeks (Table S1), which limited the number of evaluable samples at week 12 and 26. This limitation was however similar in test and control groups and would, therefore, not have affected the observed differences between groups. Moreover, the identified microbial signatures showed very consistent patterns across time and were, regarding the relative abundances of bifidobacteria and the ER/CC group, independently confirmed by $16 \mathrm{~S}$ rRNA-gene sequencing and FISH. Although, we specifically studied subjects with non-lgE-mediated CMA, Burks et al. (13) showed that an AAF, including ingredients from the current synbiotic blend, was safe in patients with $\lg E$ and non-lgE-mediated CMA, and affected the microbial signatures in an equal manner. Importantly, this study was primarily designed to investigate the effects of the synbiotic-containing AAF on gut microbiota and the suitability for the use in dietary management of CMA. As reported previously $(13,14)$, the AAF including synbiotics showed reduction of allergic symptoms as seen for the control AAF, and in addition showed potential beneficial systemic effects based on the adverse events, which reported fewer subjects in test with infections and need for anti-infective medication, including antibiotics $(13,14)$. Currently investigations are ongoing to assess whether the AAF including synbiotics influences cow's milk tolerance acquisition in a clinical trial conducted in infants with confirmed IgE-mediated CMA (Netherlands Trial Register NTR3725).

Based on the data showing pronounced effects on gut microbiota composition, diversity and metabolic activity, we conclude that the AAF including the specific 
synbiotics offers an effective nutritional strategy to modulate the gut microbiota of infants with suspected non-IgE-mediated CMA closer to a healthy breastfed profile.

\section{Acknowledgement}

The authors would like to thank all infants and their caregivers for their participation in the ASSIGN study. The authors also would like to thank: The Analytical Sciences team and Heleen de Weerd of the Gut Biology and Microbiology team of Nutricia Research, The Netherlands for the support in metabolite analysis and bioinformatic analysis, respectively. We also thank the Clinical Study and Data sciences teams of Nutricia Research, The Netherlands, for suggestions and critical review of the manuscript. 


\section{Supporting Information}

Table S1: Summary of saliva and faecal samples of subjects with CMA (ITT) and the healthy reference group (age-matched to week 8 ). Sequence depth, after filtering for low quality reads, is given as mean $( \pm S D)$.

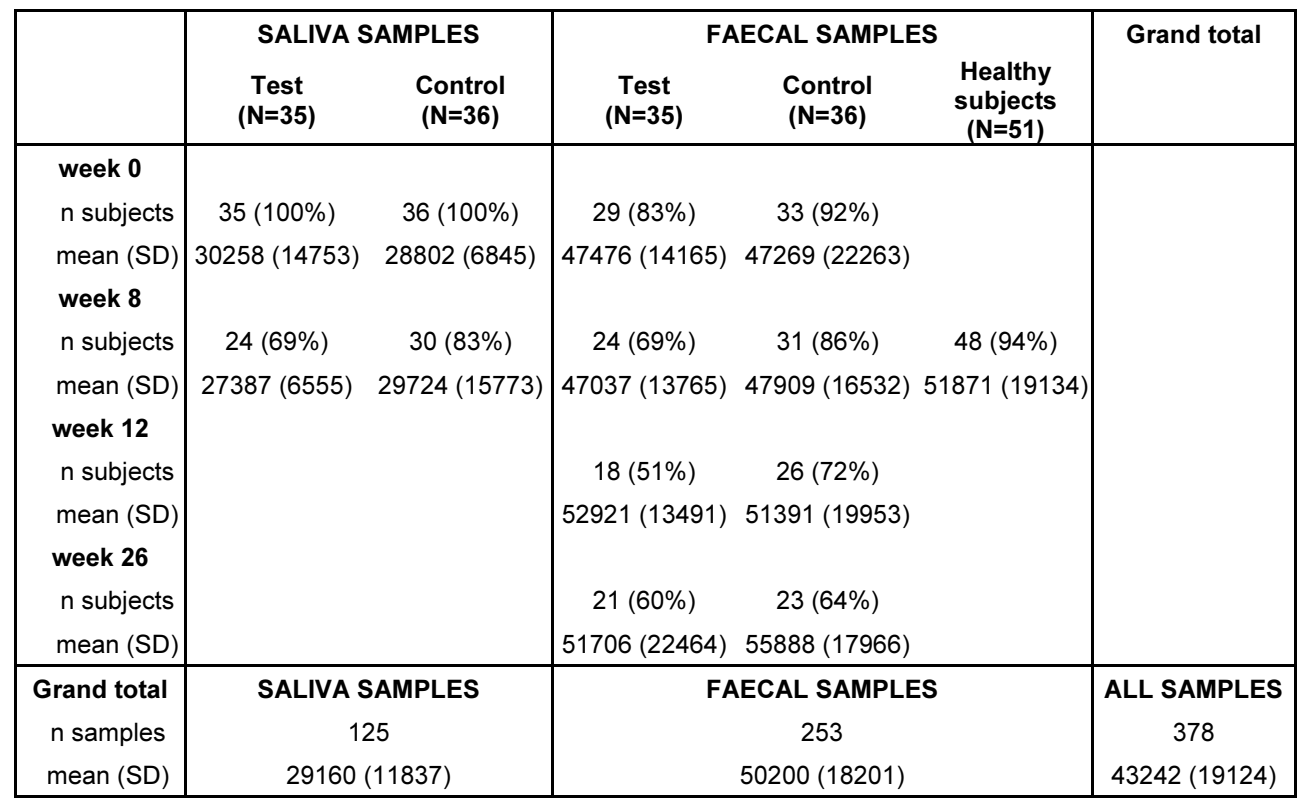




\section{References}

1. Robbins KA, Wood RA, Keet C. Persistent Cow's Milk Allergy is Associated with Decreased Growth: A Longitudinal Study. Journal of Allergy and Clinical Immunology. 2018;141(2):AB150.

2. Tran MM, Lefebvre DL, Dharma C, Dai D, Lou WYW, Subbarao P, et al. Predicting the atopic march: Results from the Canadian Healthy Infant Longitudinal Development Study. J Allergy Clin Immunol. 2018;141(2):601-7 e8.

3. West CE, Ryden P, Lundin D, Engstrand L, Tulic MK, Prescott SL. Gut microbiome and innate immune response patterns in IgE-associated eczema. Clin Exp Allergy. 2015;45(9):1419-29.

4. Huang YJ, Marsland BJ, Bunyavanich S, O'Mahony L, Leung DY, Muraro A, et al. The microbiome in allergic disease: Current understanding and future opportunities-2017 PRACTALL document of the American Academy of Allergy, Asthma \& Immunology and the European Academy of Allergy and Clinical Immunology. J Allergy Clin Immunol. 2017;139(4):1099-110.

5. Bunyavanich S, Shen N, Grishin A, Wood R, Burks W, Dawson P, et al. Early-life gut microbiome composition and milk allergy resolution. J Allergy Clin Immunol. 2016;138(4):1122-30.

6. Bergstrom A, Skov TH, Bahl MI, Roager HM, Christensen LB, Ejlerskov KT, et al. Establishment of intestinal microbiota during early life: a longitudinal, explorative study of a large cohort of Danish infants. Appl Environ Microbiol. 2014;80(9):2889-900.

7. Backhed F, Roswall J, Peng Y, Feng Q, Jia H, Kovatcheva-Datchary P, et al. Dynamics and Stabilization of the Human Gut Microbiome during the First Year of Life. Cell Host Microbe. 2015;17(5):690-703.

8. Fiocchi A, Dahda L, Dupont C, Campoy C, Fierro V, Nieto A. Cow's milk allergy: towards an update of DRACMA guidelines. World Allergy Organ J. 2016;9(1):35.

9. Al-Shehri SS, Sweeney EL, Cowley DM, Liley HG, Ranasinghe PD, Charles BG, et al. Deep sequencing of the 16S ribosomal RNA of the neonatal oral microbiome: a comparison of breast-fed and formula-fed infants. Sci Rep. 2016;6:38309.

10. Timby N, Domellof M, Holgerson PL, West CE, Lonnerdal B, Hernell O, et al. Oral Microbiota in Infants Fed a Formula Supplemented with Bovine Milk Fat Globule Membranes - A Randomized Controlled Trial. PLoS One. 2017;12(1):e0169831.

11. Venter C, Brown T, Meyer R, Walsh J, Shah N, Nowak-Wegrzyn A, et al. Better recognition, diagnosis and management of non-lgE-mediated cow's milk allergy in infancy: iMAP-an international interpretation of the MAP (Milk Allergy in Primary Care) guideline. Clin Transl Allergy. 2017;7(1):26.

12. Harvey BM, Langford JE, Harthoorn LF, Gillman SA, Green TD, Schwartz RH, et al. Effects on growth and tolerance and hypoallergenicity of an amino acid-based formula with synbiotics. Pediatr Res. 2014;75(2):343-51.

13. Burks AW, Harthoorn LF, Van Ampting MT, Oude Nijhuis MM, Langford JE, Wopereis $\mathrm{H}$, et al. Synbiotics-supplemented amino acid-based formula supports adequate growth in cow's milk allergic infants. Pediatr Allergy Immunol. 2015;26(4):316-22.

14. Candy DCA, Van Ampting MTJ, Oude Nijhuis MM, Wopereis H, Butt AM, Peroni DG, et al. A synbiotic-containing amino-acid-based formula improves gut microbiota in non-lgE-mediated allergic infants. Pediatr Res. 2018;83(3):677-86. 
15. Franks AH, Harmsen HJ, Raangs GC, Jansen GJ, Schut F, Welling GW. Variations of bacterial populations in human feces measured by fluorescent in situ hybridization with group-specific 16S rRNA-targeted oligonucleotide probes. Appl Environ Microbiol. 1998;64(9):3336-45.

16. Sim K, Cox MJ, Wopereis H, Martin R, Knol J, Li MS, et al. Improved detection of bifidobacteria with optimised 16S rRNA-gene based pyrosequencing. PLoS One. 2012;7(3):e32543.

17. Mischke M, Arora T, Tims S, Engels E, Sommer N, van Limpt K, et al. Specific synbiotics in early life protect against diet-induced obesity in adult mice. Diabetes Obes Metab. 2018;20(6):1408-18.

18. Klindworth A, Pruesse E, Schweer T, Peplies J, Quast C, Horn M, et al. Evaluation of general 16S ribosomal RNA gene PCR primers for classical and next-generation sequencing-based diversity studies. Nucleic Acids Res. 2013;41(1):e1.

19. Martin M. Cutadapt removes adapter sequences from high-throughput sequencing reads. 2011. $2011 ; 17(1)$.

20. Zhang J, Kobert K, Flouri T, Stamatakis A. PEAR: a fast and accurate Illumina Paired-End reAd mergeR. Bioinformatics. 2014;30(5):614-20.

21. Caporaso JG, Kuczynski J, Stombaugh J, Bittinger K, Bushman FD, Costello EK, et al. QIIME allows analysis of high-throughput community sequencing data. Nat Methods. 2010;7(5):335-6.

22. Rognes T, Flouri T, Nichols B, Quince C, Mahe F. VSEARCH: a versatile open source tool for metagenomics. PeerJ. 2016;4:e2584.

23. Haas BJ, Gevers D, Earl AM, Feldgarden M, Ward DV, Giannoukos G, et al. Chimeric 16S rRNA sequence formation and detection in Sanger and 454-pyrosequenced PCR amplicons. Genome Res. 2011;21(3):494-504.

24. Wang Q, Garrity GM, Tiedje JM, Cole JR. Naive Bayesian classifier for rapid assignment of rRNA sequences into the new bacterial taxonomy. Appl Environ Microbiol. 2007;73(16):5261-7.

25. Pruesse E, Quast C, Knittel K, Fuchs BM, Ludwig W, Peplies J, et al. SILVA: a comprehensive online resource for quality checked and aligned ribosomal RNA sequence data compatible with ARB. Nucleic Acids Res. 2007;35(21):7188-96.

26. Caporaso JG, Bittinger K, Bushman FD, DeSantis TZ, Andersen GL, Knight R. PyNAST: a flexible tool for aligning sequences to a template alignment. Bioinformatics. 2010;26(2):266-7.

27. Price MN, Dehal PS, Arkin AP. FastTree: computing large minimum evolution trees with profiles instead of a distance matrix. Mol Biol Evol. 2009;26(7):1641-50.

28. Faith DP, Baker AM. Phylogenetic diversity (PD) and biodiversity conservation: some bioinformatics challenges. Evol Bioinform Online. 2007;2:121-8.

29. Shannon CE. A mathematical theory of communication (parts I and II). Bell System Technical Journal. 1948:379-423.

30. Eren AM, Morrison HG, Lescault PJ, Reveillaud J, Vineis JH, Sogin ML. Minimum entropy decomposition: unsupervised oligotyping for sensitive partitioning of high-throughput marker gene sequences. ISME J. 2015;9(4):968-79.

31. Wopereis H, Sim K, Shaw A, Warner JO, Knol J, Kroll JS. Intestinal microbiota in infants at high risk for allergy: Effects of prebiotics and role in eczema development. J Allergy Clin Immunol. 2018;141(4):1334-42 e5.

32. Langendijk PS, Schut F, Jansen GJ, Raangs GC, Kamphuis GR, Wilkinson MH, et al. Quantitative fluorescence in situ hybridization of Bifidobacterium spp. with genus-specific 16S rRNA-targeted probes and its application in fecal samples. Appl Environ Microbiol. 1995;61(8):3069-75. 


\section{Chapter 5}

33. Satokari RM, Vaughan EE, Akkermans AD, Saarela M, De Vos WM. Polymerase chain reaction and denaturing gradient gel electrophoresis monitoring of fecal bifidobacterium populations in a prebiotic and probiotic feeding trial. Syst Appl Microbiol. 2001;24(2):227-31.

34. Šmilauer P, Lepš. J. Multivariate Analysis of Ecological Data using CANOCO 5. Cambridge Books Online: Cambridge University Press; 2014. Available from: http://dx.doi.org/10.1017/CBO9781139627061.

35. Wagner BD, Robertson CE, Harris JK. Application of two-part statistics for comparison of sequence variant counts. PLoS One. 2011;6(5):e20296.

36. Benjamini Y, Hochberg Y. Controlling the False Discovery Rate: A Practical and Powerful Approach to Multiple Testing. Journal of the Royal Statistical Society Series B (Methodological). 1995;57(1):289-300.

37. Costello EK, Lauber CL, Hamady M, Fierer N, Gordon JI, Knight R. Bacterial community variation in human body habitats across space and time. Science. 2009;326(5960):1694-7.

38. Van den Brink PJ, Braak CJFT. Principal response curves: Analysis of time-dependent multivariate responses of biological community to stress. Environmental Toxicology and Chemistry. 1999;18(2):138-48.

39. Laursen MF, Andersen LBB, Michaelsen KF, Mølgaard C, Trolle E, Bahl MI, et al. Infant Gut Microbiota Development Is Driven by Transition to Family Foods Independent of Maternal Obesity. mSphere. 2016;1(1).

40. Thompson AL, Monteagudo-Mera A, Cadenas MB, Lampl ML, Azcarate-Peril MA. Milk- and solid-feeding practices and daycare attendance are associated with differences in bacterial diversity, predominant communities, and metabolic and immune function of the infant gut microbiome. Front Cell Infect Microbiol. 2015;5:3.

41. Zoetendal EG, Raes J, van den Bogert B, Arumugam M, Booijink CCGM, Troost FJ, et al. The human small intestinal microbiota is driven by rapid uptake and conversion of simple carbohydrates. ISME J. 2012;6(7):1415-26.

42. Rasmussen HS, Holtug K, Mortensen PB. Degradation of amino acids to short-chain fatty acids in humans. An in vitro study. Scand J Gastroenterol. 1988;23(2):178-82.

43. Macfarlane GT, Cummings JH, Allison C. Protein degradation by human intestinal bacteria. J Gen Microbiol. 1986;132(6):1647-56.

44. Russell WR, Gratz SW, Duncan SH, Holtrop G, Ince J, Scobbie L, et al. High-protein, reduced-carbohydrate weight-loss diets promote metabolite profiles likely to be detrimental to colonic health. Am $\mathrm{J}$ Clin Nutr. 2011;93(5):1062-72.

45. Scott KP, Gratz SW, Sheridan PO, Flint HJ, Duncan SH. The influence of diet on the gut microbiota. Pharmacol Res. 2013;69(1):52-60.

46. Thompson-Chagoyan OC, Fallani M, Maldonado J, Vieites JM, Khanna S, Edwards C, et al. Faecal microbiota and short-chain fatty acid levels in faeces from infants with cow's milk protein allergy. Int Arch Allergy Immunol. 2011;156(3):325-32.

47. Berni Canani R, Sangwan N, Stefka AT, Nocerino R, Paparo L, Aitoro R, et al. Lactobacillus rhamnosus GG-supplemented formula expands butyrate-producing bacterial strains in food allergic infants. ISME J. 2016;10(3):742-50

48. Guo L, Bai H, Dong Y, Huang DX, Zhang X, Gong S, et al. Comparative Analysis of Fecal Microbiota in 5 8-Year-old Children with and without Cow Milk Protein Allergy. Iran J Pediatr. 2016;26(6):e6397.

49. Dong P, Feng JJ, Yan DY, Lyu YJ, Xu X. Early-life gut microbiome and cow's milk allergy- a prospective case - control 6-month follow-up study. Saudi J Biol Sci. 2018;25(5):875-80. 
Synbiotics in CMA

50. Thompson-Chagoyan OC, Vieites JM, Maldonado J, Edwards C, Gil A. Changes in faecal microbiota of infants with cow's milk protein allergy--a Spanish prospective case-control 6-month follow-up study. Pediatr Allergy Immunol. 2010;21(2 Pt 2):e394-400. 



\section{CHAPTER 6}

\section{Gut microbiota from infant with cow's milk allergy leads to atopic orientation in a murine model}

Mauras $\mathrm{A}^{1^{*}}$, Wopereis $\mathrm{H}^{2,3^{*}}$, Yeop $\mathrm{I}^{4}$, Esber $\mathrm{N}^{1}$, Delannoy $\mathrm{J}^{1}$, Labellie $\mathrm{C}^{1}$, Reygner $\mathrm{J}^{1}$, Kapel $\mathrm{N}^{1}$, Slump $\mathrm{R}^{2}$, Van Eijndthoven $\mathrm{T}^{2}$, Rutten $\mathrm{L}^{2}$, Knol J $\mathrm{J}^{2,3}$, Garssen $\mathrm{J}^{2,5}$, Harthoorn LF², Butel MJ1 , Bajaj-Elliott $\mathrm{M}^{4}$, Hartog $\mathrm{A}^{2,5}$, Waligora-Dupriet AJ1

*Joint first

${ }^{1}$ EA 4065 Ecosystème intestinal, Probiotiques, Antibiotiques, Université Paris Descartes, Faculté de Pharmacie, Paris, France, ${ }^{2}$ Danone Nutricia Research, Utrecht, The Netherlands ${ }^{3}$ Laboratory of Microbiology, Wageningen University, Wageningen, The Netherlands ${ }^{4}$ Great Ormond Street Institute of Child Health, University College of London, London, UK, ${ }^{5}$ Department of Pharmacology, Utrecht Institute for Pharmaceutical Sciences, Utrecht University, Utrecht, The Netherlands

Accepted for publication by The European Journal of Allergy and Clinical Immunology (Allergy) as a Letter to the Editor 


\section{Abstract}

Background: Cow's milk allergy (CMA) is a significant health burden affecting up to $5 \%$ of children. Emerging data raises the hypothesis that an altered gut microbiota in infants with CMA contributes to disease onset and persistence. Herein, we report the effects of fecal microbiota transplantation (FMT) of a healthy control $(\mathrm{HC})$ and CMA infant into germ-free mice using a murine model of sensitization and challenge.

Methods: Infants (5-16 months of age) were recruited and their stools extensively characterized prior to selection of a representative for FMT in germ-free mice. Using an established murine model of CMA; we investigated the establishment of the gut microbiota and its effect on clinical features, sensitization markers, humoral and T-cell immunity in response to antigenic challenge.

Results: Decreased levels of Bifidobacterium and increased levels of Lachnospiraceae spp. characterized the CMA microbiota, which was maintained upon transplantation. In the murine model, clinical scores (scratching, puffiness, loss of mobility) were significantly higher in CMA sensitized group (S) versus non-sensitized group (NS) and HC-S group. Interestingly, minimal differences in mMCP-1 and allergen-specific sensitization markers were observed between the groups suggesting a non-IgE mediated pathway in CMA-S group was involved. Additionally, CMA-S and CMA-NS groups showed increased total IgE-levels and IgG1/lgG2a ratio when compared to the HC-S and HC-NS groups, respectively. Further, the CMA microbiota induced significant increases in colonic gata3 and foxp3 mRNA expression.

Conclusion: The presence of a CMA-associated infant gut microbiota promoted clinical and immune parameters of an atopic orientation in a murine model of CMA. 


\section{Graphical Abstract}

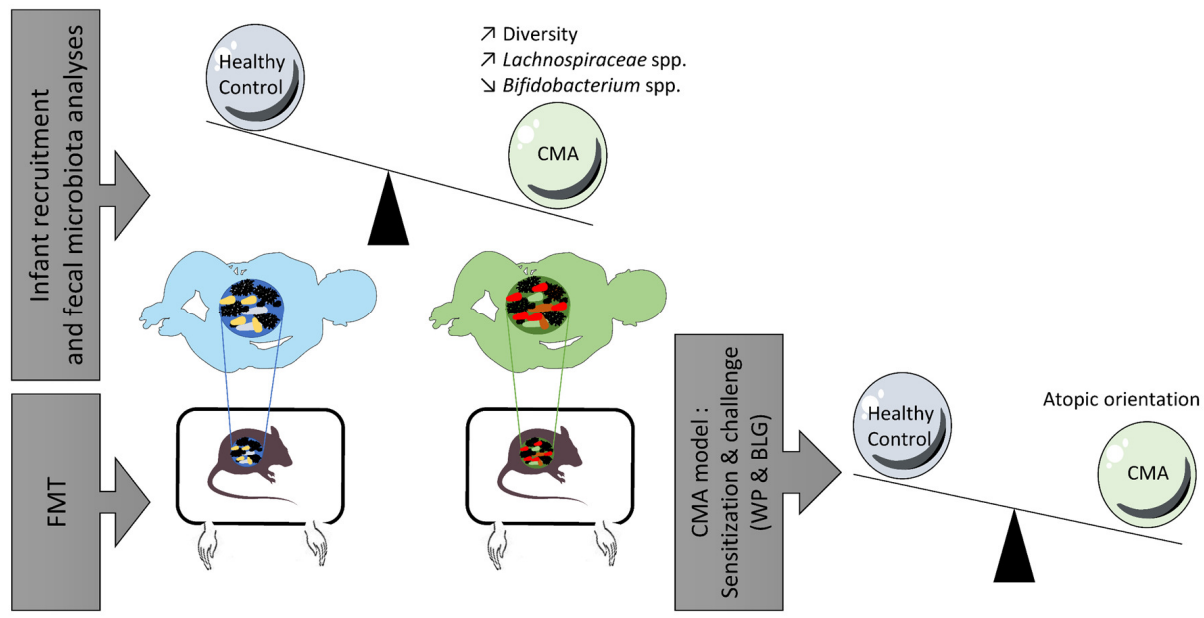

\section{Introduction}

Cow's milk allergy (CMA) is a significant health burden estimated to affect up to $5 \%$ of the population during the first years of life (1). CMA can be classified as IgE-mediated (immediate), non-lgE-mediated (delayed) or a less prevalent dual form $(2,3)$. Although most infants and children outgrow CMA before the age of 5 years, an increasing number suffer from persistent symptoms or develop other related conditions, known as the allergic march (4).

Clinical and epidemiological studies suggest an association between abnormal development of the gut microbiota in early life to clinical manifestations of allergy (5, 6). At present however, there is no consensus on a clear signature of a CMA-microbiota and, whether the observed microbial alterations are a cause or consequence of allergy (6). In case-control studies of infants with CMA, a decrease in bifidobacteria and an increase in Eubacterium rectale-Clostridium coccoides (ER/CC) group was reported (7-10). Moreover, a fecal transplant of healthy infant microbiota dominated by Bifidobacterium and Bacteroides spp. showed a protective effect on sensitization and food allergy in a murine model of CMA $(11,12)$. However, none of the studies investigated the impact of a CMA-associated infant gut microbiota 
compared to a healthy infant gut microbiota in triggering sensitization and development of allergic responses.

In this study, we recruited infants who were either healthy or with paediatrician-diagnosed CMA. After detailed analyses of their fecal microbiota, samples from a representative CMA-donor and HC-donor were transferred into germ-free mice to assess the role of microbiota in the development of CMA.

\section{Methods}

\section{Subjects, allergic workup}

Allergic infants under the care of Great Ormond Street Hospital, London, UK, were recruited alongside healthy infants from the community (REC No 14/LO/0364). The CMA was diagnosed based on clinical presentation (immediate reaction with urticaria) and this was confirmed subsequently following oral challenge. Only term, healthy infants who were fully or partially breastfed, with no family history of atopy, no exposure to antibiotics (in the antenatal or postnatal period), nor any other medications were recruited for comparison with the allergic cohort. Stool from 1 nappy were separated into three containers (1 container with $5 \mathrm{ml} 10 \%$ glycerol in $0.9 \%$ $\mathrm{NaCl}$ ), then stored and transported at $4^{\circ} \mathrm{C}$ until storage at $-80^{\circ} \mathrm{C}$ within 24 hours.

\section{Colonization of germ-free mice}

The protocol was approved by the Regional Council of Ethics for animal experimentation (Île-de-France, Paris Descartes, CEEA34.AJWD.062.12).

Germ-free $\mathrm{C} 3 \mathrm{H} / \mathrm{HeN}$ mice (Anaxem, INRA, Jouy-en-Josas, France) were housed in sterile isolators in the animal care facilities of CRP2-UMS 3612 CNRS-US25 INSERM-IRD at the Faculté de Pharmacie de Paris, Université Paris Descartes, France. Mice were allowed ad libitum intake of autoclaved water and pellet AIN93G based chow sterilized by y-irradiation at 50 kGy (ssnifspezialdiäten, Soest, Germany). They received the two selected fecal microbiotas by oral gavage at weaning age ( $21 \pm 3$ days of life) producing 2 groups, i.e. healthy infant microbiota-associated mice (HC group) and CMA infant microbiota-associated mice (CMA group). This transfer 
was performed on 3 consecutive days. Stool was cultured in Tryptone-Glucose-Yeast-Hemin medium at $37^{\circ} \mathrm{C}$ for $24 \mathrm{~h}$ under aerobic conditions or 48h under anaerobic conditions (MACS anaerobic cabinet; AES-Chemunex, Bruz, France; $\mathrm{N}_{2} / \mathrm{H}_{2} / \mathrm{CO}_{2} ; 80: 10: 10$ ). On day 3 (D3), $100 \mu$ of the aerobic culture was administered to mice; on $\mathrm{D} 4,100 \mu \mathrm{l}$ mix of anaerobic/aerobic culture $(2: 1, \mathrm{v} / \mathrm{v})$ was administered and on D5, the mice received $100 \mu$ l of stool diluted in PBS at 1:10 (Figure 1). In total, 2 independent mice experiments were performed.

\section{Oral sensitization and immune challenge}

Each FMT group was divided into 2 subgroups of 6 to 12 mice each: the non-sensitized group included 5 to 6 mice and sensitized groups included 12 to 15 mice. The first subgroup (S group) was sensitized with whey proteins (WP, lacprodan 80, Arla, Lyon, France; 15mg per mouse) and adjuvant cholera toxin (CT) (List Biological Laboratories, Campbell, CA; $10 \mu \mathrm{g} \mathrm{mouse}^{-1}$ ) in PBS. The second subgroup received only CT in PBS as a control (non-sensitized group, NS). Sensitizations were performed by oral gavage once a week for 5 weeks (Figure 1). One week after the last sensitization (D50), all mice received an oral challenge with $60 \mathrm{mg}$ of $\beta$-lactoglobulin (BLG, Sigma Aldrich, Saint-Quentin-Fallavier, France).

\section{Evaluation of allergic response}

Clinical scoring was performed on D50, 30min after the BLG challenge, by two investigators blinded to the sensitization protocol and the mouse groups for 15 min. As previously described (11), allergic symptoms were evaluated based on three criteria: scratching behavior, loss of mobility, and puffiness (details in Supporting Information). Rectal temperature was taken before the challenge and after the observation period.

\section{Sampling}

Fecal pellets were collected after the $1^{\text {st }}, 3^{\text {rd }}$ and $5^{\text {th }}$ sensitization and the day after (Figure 1) and scored as follows: normal=0, wet=1, glairy and very soft=2, diarrhea=3, no feces or anal inflammation $=1$. The fecal score was defined as the sum of the two scores (consistency and inflammation) and therefore, ranged from 0 to 4 . 
On day 50, blood was recovered in K3-EDTA tubes, centrifuged immediately, and plasma was stored at $-80^{\circ} \mathrm{C}$ for immunoglobulin and mast cell protease-1 (mMCP-1) measurements. Spleens and mesenteric lymph nodes (MLN) were used for lymphocyte cultures followed by cytokine dosages. Two-cm of duodenum, jejunum, ileum and colon were collected and stored in RNA-later (Sigma-Aldrich, France) for relative expression gene measurements. Cecum contents were stored in microtubes. Samples were stored at $-80^{\circ} \mathrm{C}$ until analysis. All methods are further detailed in Supporting Information.

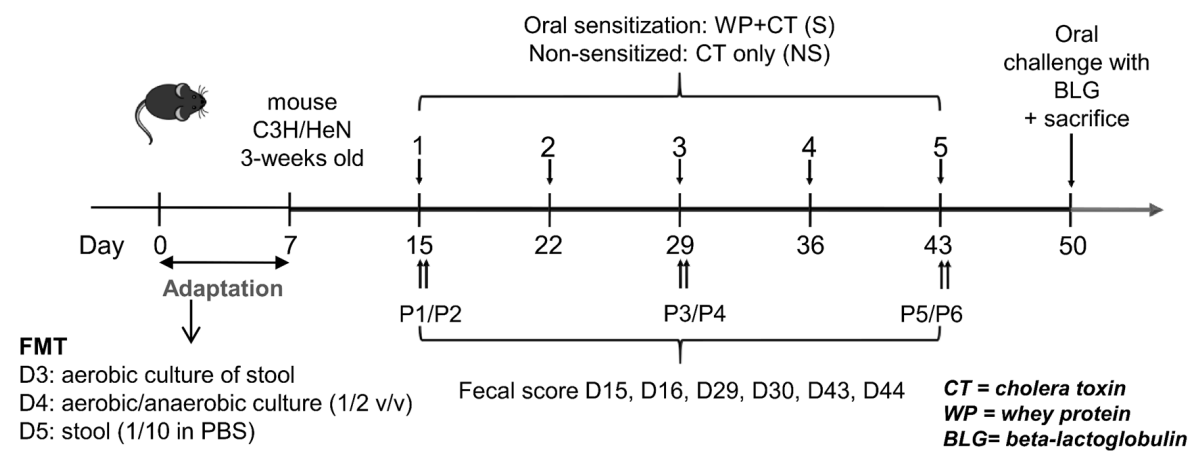

Figure 1: Experimental design. Three-week old mice were orally inoculated with selected healthy infant microbiota (HC group) or CMA infant microbiota (CMA group) cultured aerobic and anaerobic at D3, D4 and with fresh diluted stool at D5. From days 15 to 43, mice were orally sensitized with whey protein and cholera toxin once a week (S group). Control mice were treated with cholera toxin alone (C group). At D15, 16, D29, 30, D43 and 44, feces were collected and scored ( $4 \mathrm{~h}$ and $24 \mathrm{H}$ after the sensitization). All mice were orally challenged with BLG one week after the last sensitization, followed by an allergic response score and sacrifice.

\section{Gut microbiota and other parameters in infant and mice samples}

The gut microbiota composition and diversity were determined by $16 \mathrm{~S}$ rRNA-gene sequencing and, in the case of infant stools, complemented by fecal $\mathrm{pH}$-analysis plus the quantification of Bifidobacterium spp. and Eubacterium rectale/Clostridium coccoides group (ER/CC) by fluorescent in situ hybridization (FISH) (13), as well as the analysis of the immune markers eosinophil-derived neurotoxin (EDN) (14), calprotectin (15), and secretory $\lg A(16)$ as previously described. Bacterial metabolic 
activity in both infant and mice samples was assessed through the analysis of short-chain fatty acids (SCFA) (i.e., acetate, propionate, butyrate, iso-butyrate, valerate, and iso-valerate) and lactic acids (D- and L-lactate) as described previously (17).

Detailed information on the extraction of fecal and cecal DNA, and the $16 \mathrm{~S}$ rRNA-gene sequencing analysis are available in the Supporting Information.

\section{Statistical analysis}

For statistical analysis and visualization of microbiota community data, Graphpad Prism software version 7.00 for Windows (La Jolla California USA) was adopted for comparisons of species diversity and Canoco 5 software was used for Principal Component Analysis (PCA) (18) with Aitchison log-ratio transformation of bacterial genus compositional data (19). Differential abundance analysis was performed at the bacterial family and genus level using the R-package ANCOM (20) and the iTOL version 4 for visualization of the discriminant taxa (21). Corrections for multiple comparisons were controlled using the Benjamini-Hochberg false discovery rate (FDR) method with significance below 0.05 (22). Other fecal and cecal parameters, mice clinical response data and immune data were analyzed with Graphpad Prism software applying Mann-Whitney test for two-group comparisons and Kruskal-Wallis to compare more groups, with Dunn's correction for multiple testing. A $P$ value of less than 0.05 was considered significant.

\section{Results}

\section{Infant characteristics}

Infants were recruited over a period of 4 months. All CMA infants ( $n=5,7-16$ months of age, all girls) had a family history of atopy and had previous exposure to medications with 2 infants having regular medications during sample collection (Table S1 and S2). Two CMA infants were born by vaginal delivery and all were initially breastfed. All CMA-infants were on amino acid-based formula (4 on Neocate and 1 on Nutramigen AA) and 3 infants were diagnosed with multiple food allergies. Six healthy infants (5.5-9 months of age, 3 girls) were recruited with 4 infants born by vaginal 
delivery. All healthy infants were breastfed with 2 infants also receiving standard infant formula (Aptamil). All infants were weaned onto solids when fecal samples were collected.

Gut microbiota from CMA infants showed increased diversity and decreased Bifidobacterium /Lachnospiraceae ratio

All samples were successfully sequenced with a median sequencing depth of 61282(41953-76653) reads per sample (Table S3), except one sample with insufficient fecal material available for DNA extraction (nr. 10, Table S1). Microbial richness $(P<0.05$, Figure $2 A)$ and Shannon diversity $(P=0.067$, Figure $2 B)$ were both higher in CMA infants compared to HC. Bifidobacteriacea spp. and its genus Bifidobacterium were less abundant in CMA-infants than in HC-infants, while Lachnospiraceae spp. and one of its genera, i.e. Eisenbergiella (FDR $<0.05$, Figure 2C) were observed to be more abundant in CMA-infants. FISH quantification of Bifidobacterium spp. and the ER/CC group (which includes most of the Lachnospiraceae family) confirmed the patterns observed by $16 S$ rRNA-gene sequencing $(\mathrm{P}<0.05$, Figure S1A and S1B). Significant increases of bacterial SCFAs butyrate, iso-valerate and iso-butyrate - were observed in CMA-infants compared to healthy controls $(P<0.05$, Figure S1F-H). No significant differences were observed in stool $\mathrm{pH}$, levels of acetate, D-lactate, L-lactate, slgA, calprotectin and EDN (Figure S1B, S1D, S1I-M, respectively).

Principal component analysis (PCA) revealed distinct microbial compositions for CMA versus HC (Figure 2D). The other fecal parameters analyzed were incorporated into this PCA and projected as biplot (Figure 2D), which clearly visualizes the aberrances observed in microbiota composition (driven by differential abundances of Bifidobacterium and Lachnospiraceae spp.) and associated bacterial metabolites (SCFAs and lactic acid) and immune parameters (SIgA, calprotectin and EDN). 
A.

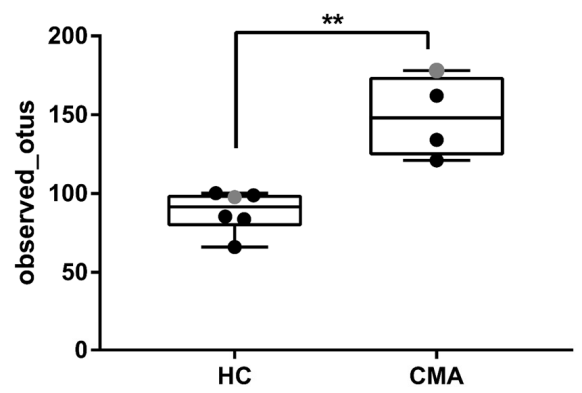

C.

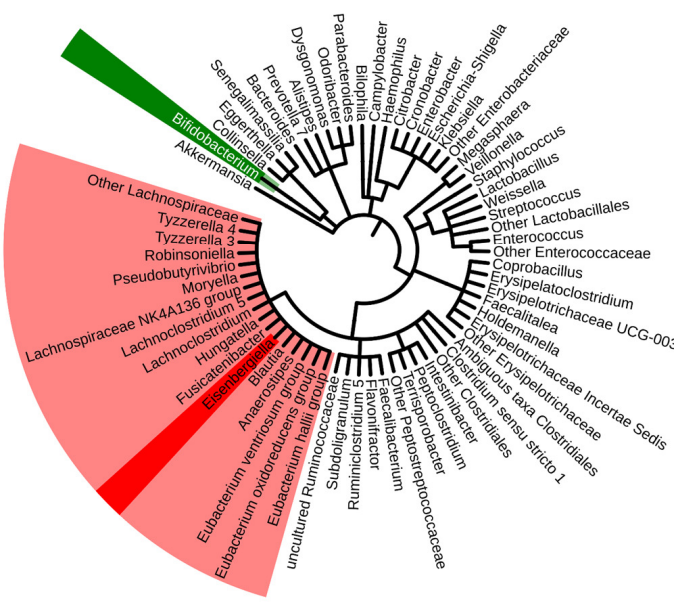

B.
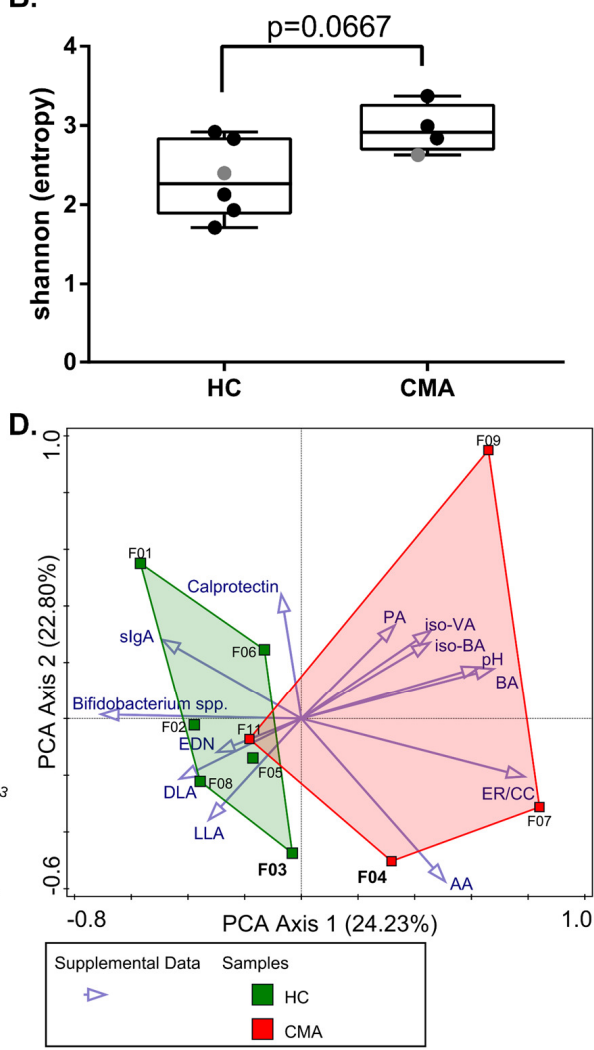

Figure 2: Donor screening and selection for FMT. Box-whisker plots of richness (A) and shannon diversity (B) of fecal samples collected from infants with cow's milk allergy (CMA) or without (HC). Samples selected for FMT indicated as grey symbols. Cladogram with discriminant taxa identified when comparing CMA-infants with HC using the ANCOM method (C). The cladogram visualizes the phylogenetic relatedness at the different taxonomic levels with from the outside to the inside: genus, family, order, class and phylum level, respectively. Discriminant taxa identified at the genus level (darkest colour) and/or at the family level (lighter colour) are highlighted. Green colours indicate increased relative abundances in $\mathrm{HC}$, and red colours indicate increased relative abundances in CMA (FDR at 0.05). PCA of gut microbiota compositions of CMA and HC-infants at the taxonomic genus level (D) supplemented all fecal parameters measured. Donor samples selected for fecal transfer to germ-free mice are shown in bold (F03 and F04). $A A=$ acetic acid, BA=butyric acid, PA=propionic acid, $V A=$ valeric acid, iso-BA=iso-butyric acid, iso-VA=iso-valeric acid, DLA=D-lactic acid, LLA=L-lactic acid, ER/CC=Eubacterium rectale-Clostridium coccoides group, EDN=Eosinophil-derived neurotoxin. 


\section{Selection for FMT}

We selected representative infant fecal microbiota for transplantation to obtain healthy infant microbiota-associated mice (HC group) and cow's milk allergic infant microbiota-associated mice (CMA group). The selected infants were matched for age, gender and delivery-mode. Based on these criteria and the results of the fecal workup, we selected a healthy infant of 9 months old (Infant 3, Table S1) and a 10-month-old CMA-infant (Infant 4, Table S1), both female and born by caesarean section.

\section{Sustained microbial signatures of CMA and HC upon establishment in mice}

To determine if the microbiota patterns were replicated in the recipient gnotobiotic mice, we sequenced the fecal microbiota at the start of the 5-week sensitization period (D15), and the cecum microbiota at the end of the experiment (D50).
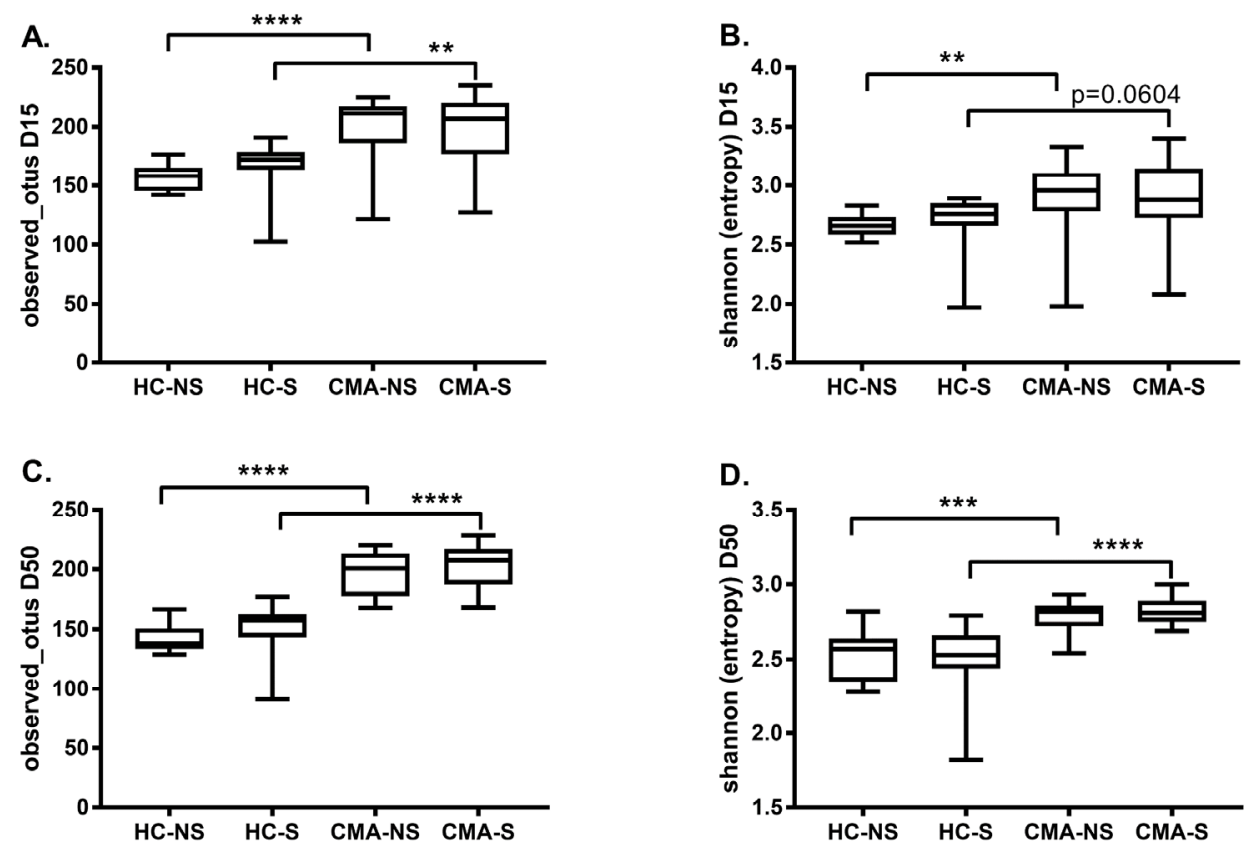

Figure 3: Microbiota diversity in murine model of CMA. Box-whisker plots of richness and shannon diversity analysed in fecal pellets collected at D15 (A and B) and in cecum content collected at D50 (C and D). Comparisons were performed by Kruskal-Wallis test with Dunn's correction for multiple testing. ${ }^{* *} P \leq 0.01 ;{ }^{* *} P \leq 0.001$, $* * * * 0.0001$. 
The increased richness and diversity in $\mathrm{CMA}$ vs $\mathrm{HC}$ was preserved in the recipient mice at D15 (Figure $3 A$ and $3 B$ ) and sustained to the end of the experiment (Figure $3 C$ and $3 D$ ). No differences were observed between sensitized and non-sensitized mice receiving the same fecal transfer.

A.

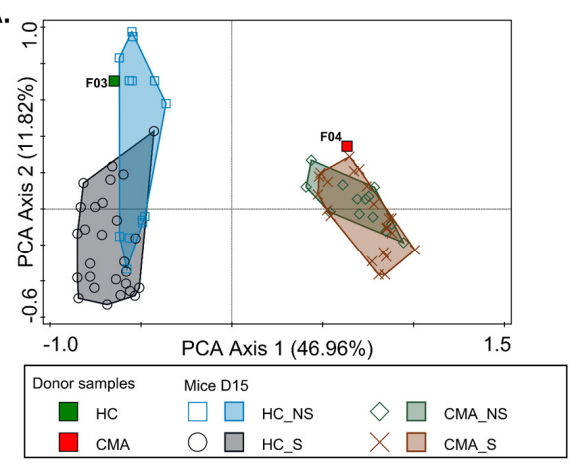

C. Mice D15

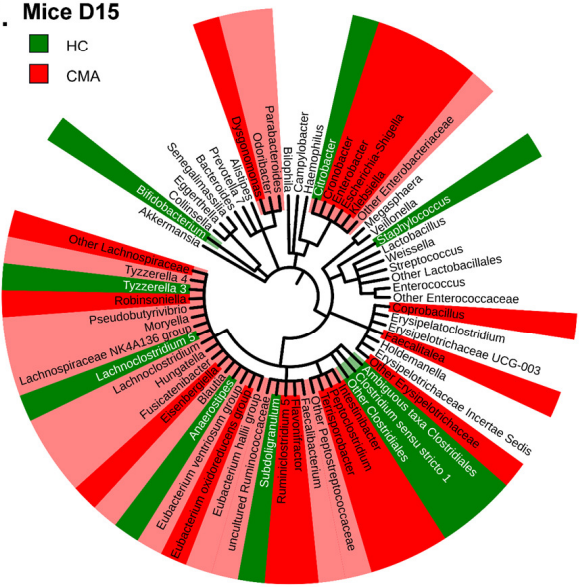

B.

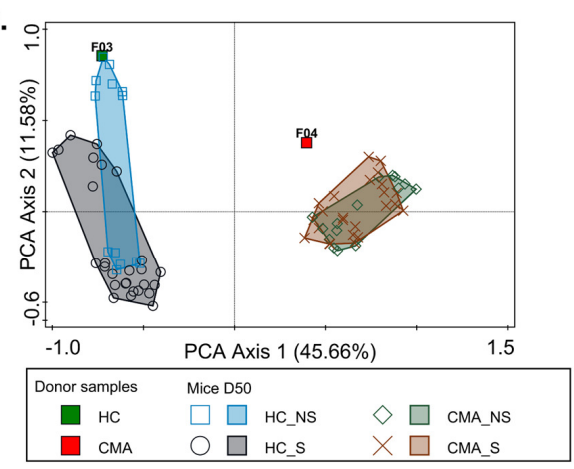

D. Mice D50

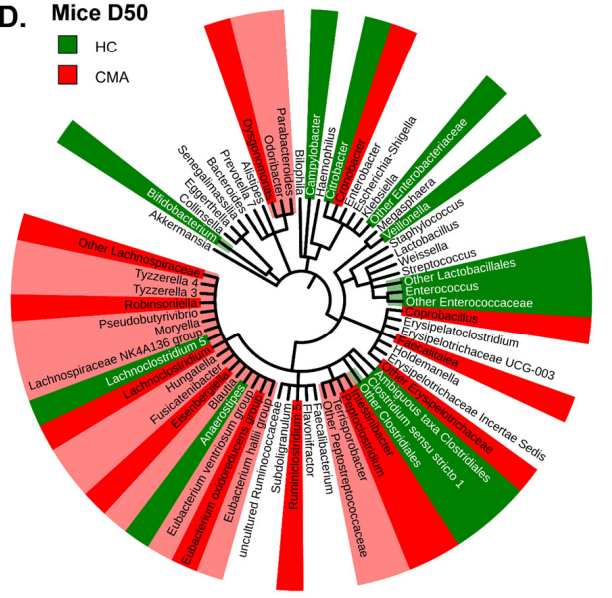

Figure 4: Establishment of donor microbiota in mouse recipients. PCA of gut microbiota compositions of selected donors with mice fecal pellets collected at D15 (A), and with mice cecal samples at D50 (B) at the taxonomic genus level. Cladogram with discriminant taxa identified in mice at D15 (C) and at D50 (D) using the ANCOM method. Taxa that were differentially abundant when comparing HC-mice with CMA-mice are highlighted at the genus (darkest colour) and family level (lighter colour). Green colours indicate an increase of relative abundances in $\mathrm{HC}$, and red colours indicate increased relative abundances in CMA (FDR at 0.05). 
PCA showed distinct profiles for the CMA-transfer compared to the HC-transfer at D15 and D50, which closely resembled the two donor compositions (Figure 4A and 4B). Moreover, the differential abundance of families and genera between the two transfers included the taxa associated with the recruited infants and replicated the decreased levels of Bifidobacteriaceae spp. (and Bifidobacterium) and increased levels of Lachnospiraceae spp. (and Eisenbergiella) in CMA vs HC at both time points (FDR<0.05, Figure 4C and 4D). Additionally, differential abundances observed at both time points were consistent for other genera within the family of Lachnospiraceae, most of which were higher in CMA (Eubacterium oxidoreducens group, Robinsoniella and an unknown genus), with the exception of Anaerostipes and Lachnoclostridium 5, which were higher in $\mathrm{HC}$. Other bacterial families that were consistently increased in CMA were Porphyromonadaceae (associated with Dysgonomonas spp.) and Peptostreptococcaceae (associated with increases of Intestinibacter and Peptoclostridium), while an unknown family of Clostridiales was consistently higher in HC-mice (FDR<0.05, Figure 4C and 4D).

Cecal levels of SCFAs and lactic acids revealed significantly increased concentrations of acetate, butyrate and iso-valerate in CMA-S compared to HC-S (Figure S2A, S2C and S2D), as well as increased prevalence of valerate and iso-butyrate, with the latter also more prevalent in CMA-NS vs HC-NS (Figure S2G and $\mathrm{S} 2 \mathrm{H}$ ). No differences were observed for propionate, D-lactate and L-lactate (Figure S2B, S2E and S2F).

CMA microbiota, but not HC microbiota, was associated with diarrhea-related symptoms following the oral administration of allergen

The fecal scoring, recording consistency and anal inflammation, showed different responses between the two fecal transfers during the five-week period of oral sensitization. After the first sensitization, with presentation of antigen, no significant differences in fecal scores between allergen-exposed (S) and non-sensitized (NS) mice were observed; however, the CMA-groups showed higher fecal scores (reflecting softer stools and signs of inflammation) compared to the HC-groups. Four hours after the third and the fifth sensitization, the fecal scores were higher in CMA-S group compared to CMA-NS group $(p<0.001)$. Approximately $24 \mathrm{~h}$ after the third but 
not after the fifth sensitization, the enhanced fecal scores normalized $(P<0.05$ at day 44, comparison CMA-S vs CMA-NS). In contrast, no significant differences were noticed between HC-S as compared to HC-NS at the third and the fifth sensitization, which may indicate a protective effect of healthy microbiota upon allergen exposure (Figure 5A).
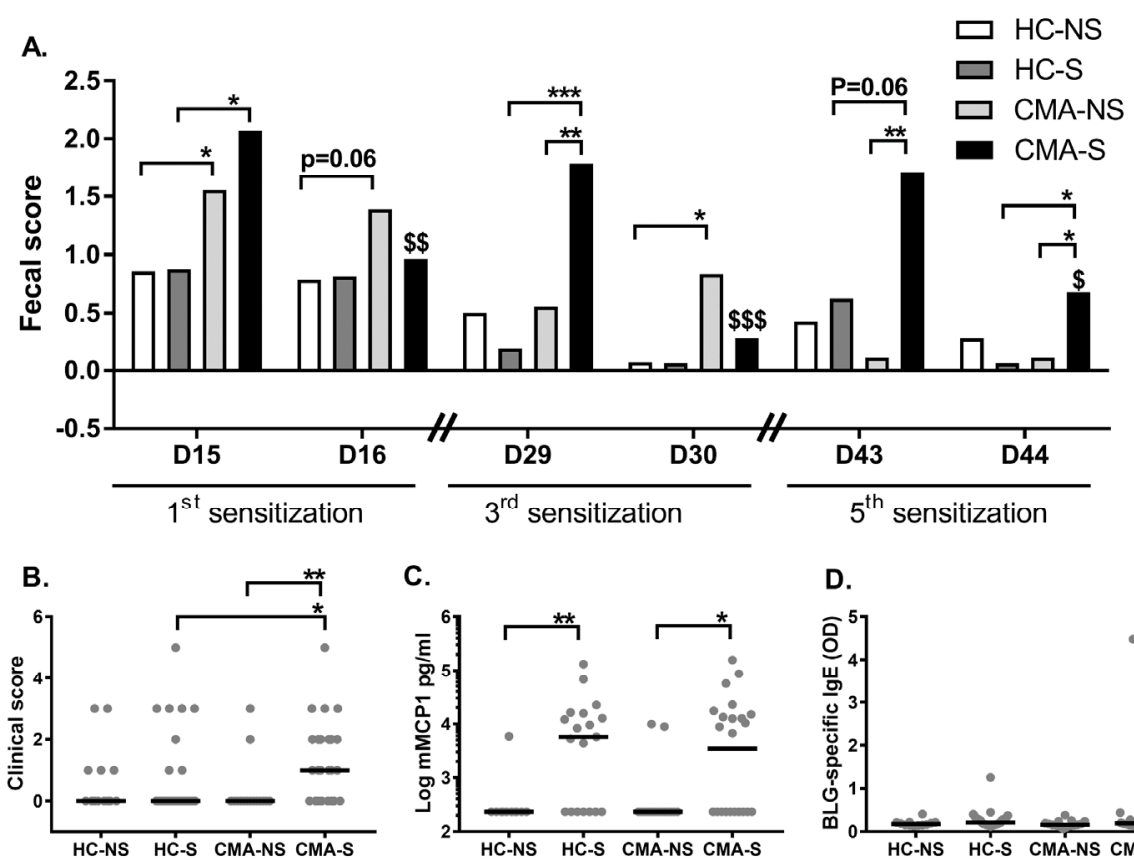

C.

D.
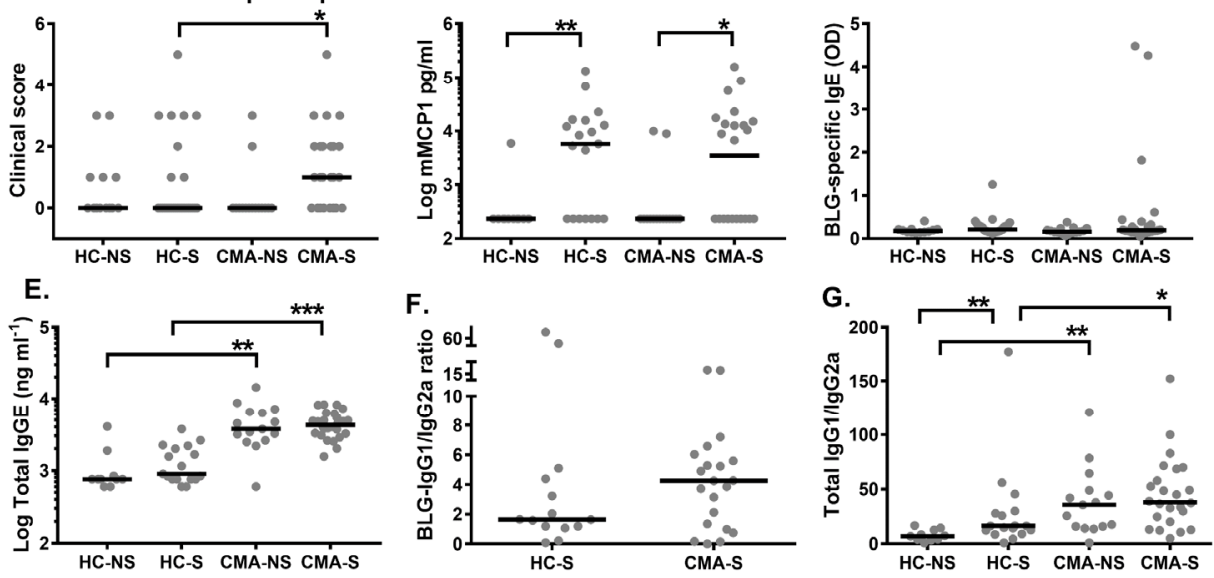

Figure 5: (A) Fecal scores on a scale from 0-4, with 0 indicating normal pellets and increased scores indicating softer to diarrheic pellets and/or anal inflammation. Fecal pellets were scored after the first sensitization at D15 then D16, after the third sensitization at D29 then D30 and after the fifth sensitization at D43 then D44. (B) Clinical score on a scale from 0 to 6 with line at median. Increased scores indicate increased allergic symptoms based on monitoring (i) scratching behavior, (ii) loss of mobility, and (iii) puffiness scored during a 15 min interval (30 min after BLG-challenge). (C) Concentrations of mMCP-1, (D) BLG specific IgE, (E) total IgE, (F) BLG-specific $\lg 1 / \lg 22 a$ ratio and $(\mathrm{G})$ total $\operatorname{lgG} 1 / \lg 22$ a ratio are shown in dot plots with line at median. $P$-values were calculated using Mann-Whitney test ( $\left.{ }^{*} \leq 0.05,{ }^{* *} P \leq 0.001,{ }^{* * *} P \leq 0.0001\right)$. 
CMA-associated microbiota induces increased susceptibility to develop an allergic reaction, without allergen-specific sensitization

The clinical scores were significantly higher in the CMA-S group compared to non-sensitized CMA-mice $(p<0.001)$. Additionally, the clinical score of the CMA-S group was significantly higher than that of the HC-S group $(p<0.05)$ (Figure $5 B)$. The rectal temperature was also measured but only two mice (one in both sensitized groups) developed an anaphylactic reaction (data not shown). The increased clinical score in CMA-S versus HC-S was not correlated with differences in mast cell degranulation (Figure 5C), or specific markers of sensitization (IgE and IgG1/lgG2a ratio, Figure $5 \mathrm{D}$ and $5 \mathrm{~F}$, respectively). Independent of $\mathrm{FMT}$, mMCP-1 levels were higher in sensitized mice compared to non-sensitized controls (Figure $5 \mathrm{C}$ ). However, levels of total IgE in CMA-mice, independent of sensitization status, were increased in comparison with HC-mice $(p<0.001)$ (Figure $5 E$ ). Similarly, the ratio of total IgG1/lgG2a representing the Th2/Th1 balance was increased in CMA-mice compared to $\mathrm{HC}$-mice (Figure $5 \mathrm{G}$ ). The ratio of total $\operatorname{lgG} 1 / \mathrm{lgG} 2 \mathrm{a}$ in $\mathrm{HC}$-S group was also increased compared to the HC-NS group $(p<0.001)$.

\section{Colonic gata 3 and foxp3 gene expression are impacted by the CMA-microbiota}

The mRNA gene expression of tbet, gata3, roryt and Foxp3 were measured in duodenum, jejunum, ileum and colon tissue and relative expression levels of the CMA-S groups were compared to HC-S group (Figure 6). In small intestinal tissue only roryt expression was decreased in CMA-S group compared to HC-S group $(p=0.05$, Figure $6 D)$. In contrast, colonic tissue showed significantly increased expression of gata3 and foxp3 in CMA-S group compared to HC-S ( $p<0.05$ and $p<0.001$, Figure $6 \mathrm{~B}$ and $6 \mathrm{C}$, respectively) and non-significant increased expression of $f c y R I I I(p=0.07$, Figure $6 \mathrm{H})$. No differential expressions were observed for tbet, fcer2a, $\operatorname{tgf} \beta$ and il17. 
A.

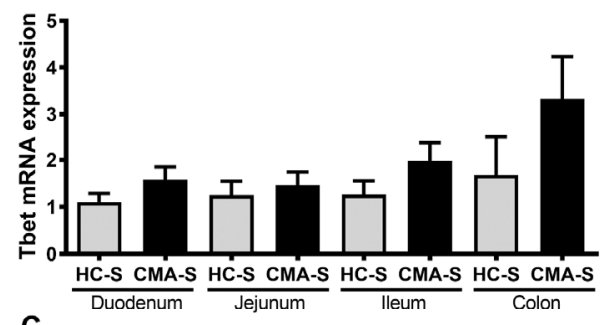

C.

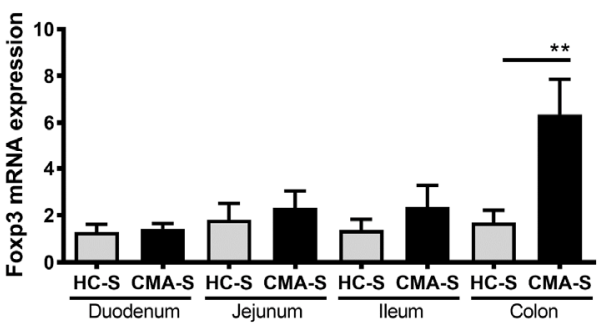

E.

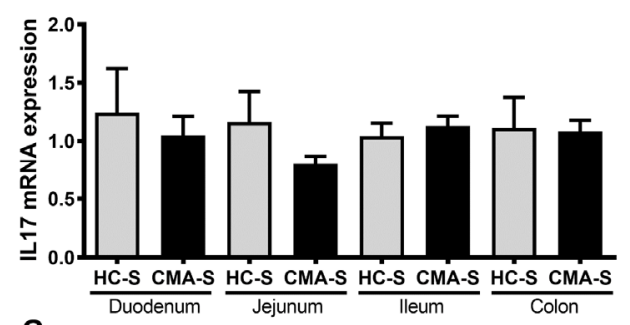

G.

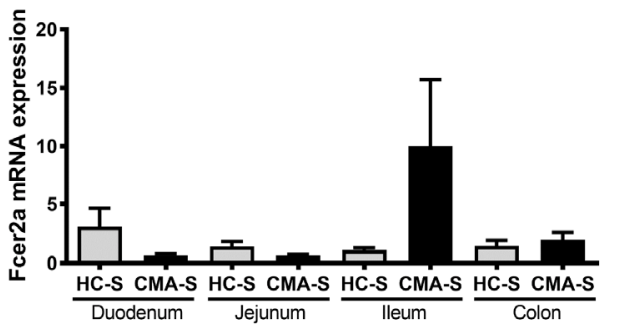

B.

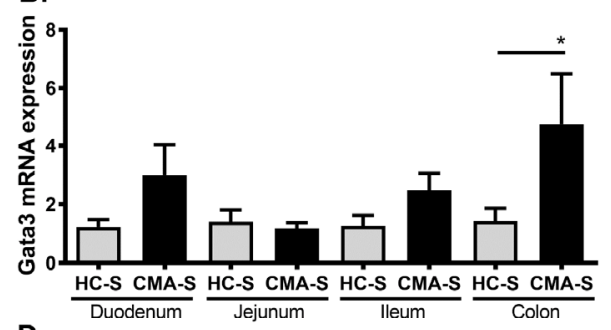

D.

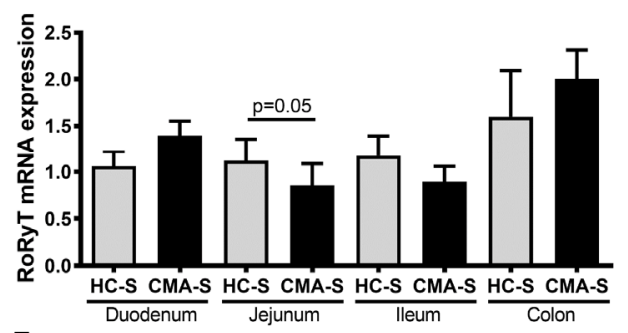

F.

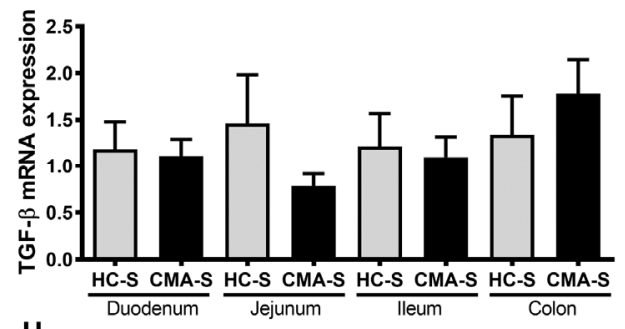

$\mathrm{H}$.

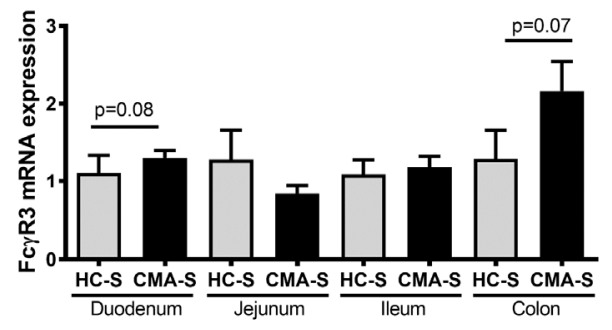

Figure 6: Gene mRNA expression in the small intestine (duodenum, jejunum, ileum) and colon of $\mathrm{HC}$ and $\mathrm{CMA}$ sensitized groups. The mRNA gene expression was normalized against the reference gene of $\mathrm{HC}$ sensitized $(\mathrm{HC}-\mathrm{S})$ mice. The relative gene expression of $(\mathrm{A})$ tbet, (B) gata3, (C) foxp3, (D) roryt, (E) IL17, (F) tgf- $\beta$, (G) fcer2a and $(\mathrm{H})$ fcyrlll genes are shown as bar plots (mean with SEM). P-values were calculated using Mann-Whitney test $\left({ }^{*} \mathrm{P} \leq 0.05,{ }^{* *} \mathrm{P} \leq 0.001\right)$. 


\section{CMA-microbiota and its activity induce an enhanced atopic orientation}

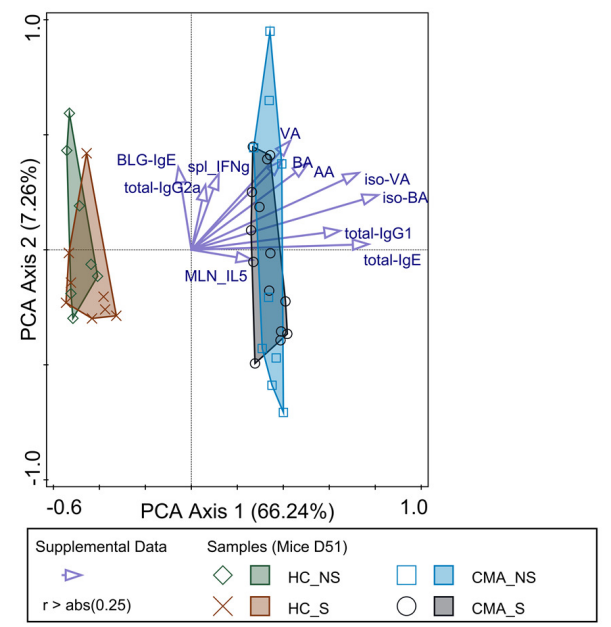

Figure 7: Microbiota compositions associated with bacterial metabolites and immune responses. PCA based on genus composition of mice for the different groups at D50 supplemented with immune data (cytokines and serum markers), SCFAs and lactate data when available. In total the data of 38 mice was used with inclusion of variables with less than $10 \%$ of missing values. Supplemental variables were plotted as biplot if the absolute correlation coefficient with one of the ordination axes $\geq 0.25$. BLG= $\beta$-lactoglobulin, $M L N=$ mesenteric lymph nodes, spl=splenocytes, $A A=$ acetic acid, $B A=$ butyric acid, $V A=$ valeric acid, iso-BA= iso-butyric acid, iso-VA=iso-valeric acid.
We evaluated the systemic response with the concentration of cytokine produced by splenocytes and MLN cells following in vitro BLG stimulation. No differences between CMA-S group and HC-S group in cytokine levels were observed (Figure S3). We performed a PCA analysis of mice microbiota compositions at D50 incorporating immune (serum and cytokine data) and bacterial metabolites (SCFAs and lactate) for samples with data available (Figure 7). CMA-associated microbiota was associated with increased levels of SCFAs, which was most pronounced for iso-butyric acid and iso-valeric acid, which corroborates with the differences observed in infant stool samples. The CMA-associated microbiota composition and activity positively correlated with increased serum IgE, IgG1, and IL-5 levels in the MLN (Figure 7).

\section{Discussion}

Herein, we investigated whether an altered gut microbiota in CMA-infants as compared to healthy infants may contribute to allergic disease. Fecal microbiota signatures associated with CMA, which were characterised by decreased levels of bifidobacteria and increased levels of the ER/CC-group (resembling Lachnospiraceae spp.), were associated with enhanced allergic response in a gnotobiotic murine model 
of CMA. Importantly, these specific microbiota signatures corroborate findings of paediatric studies comparing CMA-infants with healthy breastfed infants $(7-10,13)$. These data strengthen the importance of the early life acquisition and establishment of bifidobacteria for healthy development $(23,24)$, and builds upon our previous findings with the same model, in which we demonstrated protective effects against CMA-development upon colonization of germ-free with healthy breastfed infant gut microbiota (12).

The enhanced allergic responses observed in the CMA-colonized mice compared to HC-colonized mice were associated with diarrhea-like symptoms and signs of colonic inflammation following sensitization and challenge with the allergen. Moreover, we observed increased total $\operatorname{IgE}$ and increased total $\lg \mathrm{G} 1 / \lg \mathrm{g} 2 \mathrm{a}$ ratio, which reflects an enhanced Th2/Th1 status. These observations were consistent with increased gata3 mRNA expression in the colon, which is a marker of Th2 lymphocytes. In addition, IL-5 production by mesenteric lymph nodes was correlated with the microbiota of allergic children (Figure 7). Interestingly, the expression of fcyRIII gene was increased in CMA-S group in the colon. FCYRIII is an activating receptor binding mouse IgG1 (25), which is expressed on mastocytes and basophils. These results suggest a pathway linked to $\lg G 1$ and basophils, which has been implicated in anaphylaxis $(26,27)$. In our model, BLG-IgG1 levels were not increased in CMA-S group, showing the complexity of allergic mechanisms. All these elements confirm a Th2 orientation of the immune system following transplantation of the CMA-associated microbiota. However, this Th2 profile was not associated with differences in mMCP-1 levels or allergen-specific immunoglobulin levels between the CMA-S and HC-S groups, which possibly points to a non-IgE mediated immune response in mice transplanted with CMA-microbiota. Moreover, human patients with non-lgE dependent allergy pre-dominantly present gastro-intestinal tract symptoms (2). The diarrhoea-like symptoms and signs of colonic inflammation in mice transplanted with the CMA-associated microbiota support this hypothesis.

Several studies showed that germ-free mice have increased total IgE levels compared to conventional mice, and that levels can be normalized when germ-free mice are colonized with commensal microbiota until 8 weeks of age (28). It has been 
argued that high total $\lg E$ is a poor predictor for food allergy (29), while other studies linked increased lgE levels to poor long-term outcome in atopic dermatitis (30) or an increased risk of developing other allergic manifestations (31). We show that colonization with a HC-microbiota but not colonization with a CMA-microbiota maintains low total lgE levels like the non-sensitized control mice. This may be due to the observed enrichment of bifidobacteria and Anaerostipes spp. in HC-associated mice (Figure 4). We previously showed that Anaerostipes spp. can form a trophic chain in the developing infant gut by converting the bifidobacterial breakdown products of complex carbohydrate degradation and the resulting fermentation products lactate and acetate into butyrate, which was associated with protection from eczema in infants at increased risk for allergy $(17,32)$. Interestingly, Feehley et al. recently also identified Anaerostipes spp. as having a key role in allergy protection using a similar murine model for CMA (33).

Unexpectedly, we observed in the colon an increase in foxp3 mRNA gene expression in CMA-S group compared to HC-S group. Foxp3 has been associated with the production of Th2 cytokines in several cell lines, including Foxp $3^{+} \mathrm{Gata}^{+}$cells (34-36), as well as with regulatory T-cells (Treg) (37). If associated with Treg cells, this increase could be the hallmark of the immune response towards Th2 induction. Another explanation of the increased foxp3 expression could be linked to the increased ER/CC bacterial group and the associated increase of cecal butyrate, which have been implicated in the induction of foxp3 Treg cells $(38,39)$. In our study, CMA-infants as well as the recipient mice showed increased levels of butyrate, but also increased levels of the branched-chain SCFAs iso-butyrate and iso-valerate, which corroborate the observations of Thompson-Chagoyan et al. in paediatric patients (7). The increase of branched-chain SCFAs suggest an increased proteolytic activity in CMA-infants versus healthy infants, while these can only be derived from branched-chain amino acids and therefore provide an indicator of protein fermentation (40). Butyrate, which can be derived both from carbohydrates and protein fermentation (40), may therefore have partly resulted from the increased proteolytic activity of the CMA-associated versus $\mathrm{HC}$-associated gut microbiota. Several Clostridia and members of Peptostreptococcaceae spp. are involved in protein and 
amino acid fermentation (41) and were consistently increased in mice receiving the CMA-FMT. Protein degradation and its associated metabolites, as well as specific members of Peptostreptococcaceae, most notably Peptoclostridium (Clostridium) difficile, are generally associated with compromised health and may be implicated in the increased severity of allergic responses and symptoms observed in CMA-mice (42). In contrast, the increased saccharolytic activity as suggested by the increased abundances of bifidobacteria and Anaerostipes spp. in the HC-mice may form a more beneficial supply of butyrate to the host (40).

This study has several limitations. The CMA-infant selected was on concomitant medication and had clinically improved on an elimination diet, which are both factors known to influence the gut microbiota (43), but are also inherent to the medical condition. Moreover, only two representative microbiotas were chosen to avoid antagonistic effects that might arise by mixing different microbiota. Additionally, the FMT to germ-free mice results in adaptation to the new host (44). In our study however, despite this adaptation, the microbiota preserved its characteristic signatures. Therefore, we consider that our transfer led to a valid model to study the impact of microbiota on allergy development.

In conclusion, we demonstrated that infant microbiota with a low bifidobacteria: Lachnospiraceae ratio oriented the mice immune system towards a Th2 atopic profile resulting in enhanced allergic symptoms. Although the exact mechanism warrants further research, our data suggests that strategies to enrich the gut microbiota of infants with bifidobacteria may aid in the prevention and treatment of food allergy.

\section{Acknowledgements}

We would like to thank all infants and their caregivers for their participation in this study. We also would like to thank Iharilalao Dubail and her team from Animal Platform CRP2, Faculté de Pharmacie de Paris, for technical support in animal experiments. The authors also would like to thank: The Analytical Sciences team and Heleen de Weerd of the Gut Biology and Microbiology team of Nutricia Research, The Netherlands for the support in metabolite analysis and bioinformatic analysis, respectively. 


\section{Supporting Information}

\section{Supplementary Materials and methods}

\section{DNA extraction, 16S rRNA-gene sequencing and bioinformatics}

DNA was extracted from fecal and cecal samples using a phenol-chloroform based method combined with bead-beating as described previously (17). Infant and mice microbiota compositions were determined by sequencing and bioinformatic analysis as described in detail before (13). Briefly, extracted DNA samples were profiled by sequencing the PCR-amplified V3-V4 regions of the 16S rRNA gene on an Illumina MiSeq instrument (San Diego, USA). Illumina reads were preprocessed, quality filtered, merged and analyzed with an adapted version of the 'Quantitative Insights Into Microbial Ecology' (QIIME) v1.9.0 pipeline (45). Sequences were clustered into Operational Taxonomic Units (OTUs) based on 97\% sequence identity using VSEARCHv2.4.1 with exclusion of chimeric sequences identified against the RDP gold database $(46,47)$. Taxonomic assignment was performed using the RDP classifier (48) against the SILVA123 database (49). Singleton OTUs, OTUs with eukaryotic assignments, and OTUs with a low relative abundance up to $0.005 \%$ were excluded from further downstream analysis (50). The species diversity (a-diversity) metrics for richness (observed OTUs) and the Shannon index for diversity (51) were calculated using the R-package phyloseq with correction for the differences in sequencing depths by rarefaction (52).

\section{Clinical Scoring}

Scoring was adapted from Perrier et al (53). Allergic symptoms were evaluated based on three criteria: scratching behavior, loss of mobility, and puffiness (including bristled fur, oedema around nose and eyes, laborious breathing). Scratching was defined as the number of scratching episodes per 15-min interval as follows: 1-3 episodes $=0,4-5$ episodes $=1$, and $>6$ episodes $=2$. Loss of mobility was graded in terms of the duration of absence of any movement as follows: $<10 \mathrm{~min}=0 ;>10 \mathrm{~min}=$ 1 , during the $15 \min =2$. Puffiness was graded as none $=0$ and puffiness $=2$. The 
clinical score was defined as the sum of the three individual scores, and therefore, ranged from 0 to 6 .

Measurement of plasma mouse mast cell protease- 1 and sensitization markers

Plasma mMCP-1, total IgE, IgG1 and IgG2a were measured by ELISA according to manufacturer's recommendation (Ready-SET-Go!, Ebioscience, San Diego, USA). Measurements of BLG-specific IgE levels were performed by capturing with rat anti-mouse IgE (Pharmingen, BD Biosciences, Le Pont-de-Claix, France) antibody and by detecting with biotinylated BLG (Pierce, Rockford, USA) and streptavidin-horseradish peroxidase (HRP) (Clinisciences, Nanterre, France) as previously described (11). Data were expressed in terms of OD at $450 \mathrm{~nm}$. Levels of anti-BLG $\lg$ G1 and $\lg$ G2a were determined using BLG as the capture antigen, and goat anti-mouse IgG1 and IgG2a-HRP (Southern Biotech, Birmingham, USA) were labeled as detection antibodies as previously described (54).

Cytokine production by BLG-stimulated splenocytes and MLN lymphocytes

Spleens and MLN were crushed, filtered and treated to obtain $2 \times 10^{6}$ cells per well (54). Cells were cultured in $24-w e l l$ plates with and without $2.5 \mathrm{mg} / \mathrm{ml} \mathrm{BLG}$ at $37^{\circ} \mathrm{C}$ in a $5 \% \mathrm{CO} 2,95 \%$ air atmosphere for $48 \mathrm{~h}$. Culture supernatant levels of tumor necrosis factor- $\alpha$ (TNF- $\alpha$ ), interferon- $\gamma$ (IFN- $\gamma$ ) interleukin-4 (IL-4), IL-5, IL10, IL13, IL17, IL22 and IL33 were quantified using a ProcartaPlex (Fisher, Hampton, USA), according to the manufacturer's instruction.

Relative expression of T-helper cytokines and immunoglobulin receptor genes in the gut

Total RNA was isolated from 2-cm segment of duodenum, jejunum, ileum and colon, devoid of Peyer's patches, using a RNeasy Plus universal kit (Qiagen, Courtaboeuf, France). Extracted RNA was treated with DNase I and first-strand cDNA was synthesized using Invitrogen reagents (Thermo Scientific, Illkirch, France) (54).

Quantitative real-time PCR (qRT-PCR) was performed on an ABI Prism 7900HT sequence detection system (Applied Biosystems, Thermo Scientific, Illkirch, France). QuantiTect SYBR green and QuantiTect primer assays (Qiagen) were used to 
Chapter 6

quantify Transforming Growth Factor $\beta$ (TGF- $\beta$ ), FcyR3 and Fcer2a. TaqMan gene expression assays with TaqMan universal master mix II (Applied Biosystems) were used to quantify IL17-A, Foxp3, T-bet, Gata3 and RoryT. Measurement were performed in duplicate, and gene expression levels were calculated using the $2^{-\triangle \Delta C T}$ method (55), where CT is the threshold cycle, with the TATA box (TaqMan) assay as reference gene. 


\section{Supplementary Tables}

Table S1: Subject characteristics.

\begin{tabular}{|c|c|c|c|c|c|c|c|c|c|c|c|c|c|}
\hline$\underline{z}$ & & 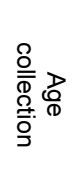 & $\underset{\infty}{\stackrel{\mathscr{d}}{\rightleftarrows}}$ & $\frac{\substack{\mathbb{D}\\
}}{\stackrel{\Phi}{\gtrless}}$ & 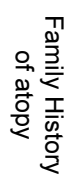 & 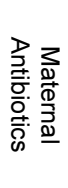 & 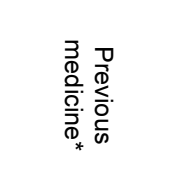 & 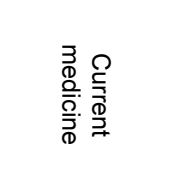 & 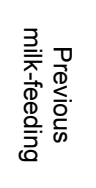 & 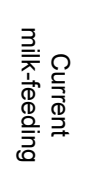 & 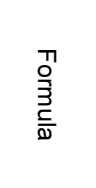 & 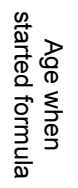 & 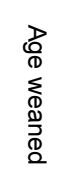 \\
\hline 1 & $M$ & $7 \mathrm{~m}$ & $\mathrm{HC}$ & NVD & No & No & No & No & $\mathrm{BF}$ & $\mathrm{BF}$ & NA & NA & $5.5 \mathrm{~m}$ \\
\hline 2 & $\mathrm{~F}$ & $5.5 \mathrm{~m}$ & $\mathrm{HC}$ & NVD & No & No & No & No & mixed & mixed & $\begin{array}{c}\text { SF } \\
\text { (1/day) }\end{array}$ & birth & $5 m$ \\
\hline 3 & $\mathbf{F}$ & $9 m$ & $\mathrm{HC}$ & LSCS & No & No & No & No & mixed & mixed & $\begin{array}{c}\text { SF } \\
\text { (2/day) }\end{array}$ & $1 w$ & $5.5 \mathrm{~m}$ \\
\hline 5 & $\mathrm{~F}$ & $7 \mathrm{~m}$ & $\mathrm{HC}$ & NVD & No & No & No & No & $\mathrm{BF}$ & $\mathrm{BF}$ & NA & birth & $5 m$ \\
\hline 6 & $M$ & $9 m$ & $\mathrm{HC}$ & NVD & No & No & No & No & $\mathrm{BF}$ & $\mathrm{BF}$ & NA & NA & $4.5 \mathrm{~m}$ \\
\hline 8 & $M$ & $9 m$ & $\mathrm{HC}$ & $\begin{array}{c}\text { El } \\
\text { LSCS }\end{array}$ & No & No & No & No & $\mathrm{BF}$ & $\mathrm{BF}$ & NA & NA & $6 m$ \\
\hline 4 & $\mathbf{F}$ & $10 \mathrm{~m}$ & All & LSCS & Yes & No & $\begin{array}{c}\text { Ranitidine, } \\
\text { Lansoprazole }\end{array}$ & $\begin{array}{l}\text { Montelukast, } \\
\text { Atrovent, } \\
\text { Salbutamol, } \\
\text { Abidec, } \\
\text { Sytron }\end{array}$ & BF & FF & AAF & $4.5 \mathrm{~m}$ & $4.5 \mathrm{~m}$ \\
\hline 7 & $\mathrm{~F}$ & $16 m$ & All & $\begin{array}{c}\text { El } \\
\text { LSCS }\end{array}$ & Yes & No & $\begin{array}{c}\text { Infacol, Colic } \\
\text { ease }\end{array}$ & No & $\mathrm{BF}$ & $\mathrm{FF}$ & AAF & $5 w$ & $6 m$ \\
\hline 9 & $\mathrm{~F}$ & $16 m$ & All & $\begin{array}{c}\text { El } \\
\text { LSCS }\end{array}$ & Yes & No & Paracetamol & No & $\mathrm{BF}$ & $\mathrm{FF}$ & AAF & $5 m$ & $6 m$ \\
\hline 10 & $\mathrm{~F}$ & $7 m$ & All & NVD & Yes & No & Paracetamol & No & $\mathrm{BF}$ & FF & AAF & $6 m$ & $6 m$ \\
\hline 11 & $\mathrm{~F}$ & $12 m$ & All & NVD & Yes & No & $\begin{array}{l}\text { Gaviscon, } \\
\text { Ranitidine, } \\
\text { Omeprazole }\end{array}$ & Ketotifen & $\mathrm{BF}$ & FF & AAF & $4 m$ & $6 m$ \\
\hline
\end{tabular}

Sex: M=Male, F=Female; Status: $\mathrm{HC}=$ healthy control, All =allergic; Delivery: NVD = normal vaginal delivery, LSCS $=$ lower segment caesarean section, El= Elective; *Previous medicine including antibiotics. Previous/Current milk-feeding: $B F=$ breastfed, $F F=$ formula-fed or receiving both breast- and formula-feeding (mixed), SF=standard cow's milk-based formula, AAF=Amino acid-based formula. Ages are indicated in months $(\mathrm{m})$ or in weeks $(\mathrm{w})$. In bold the infants selected for fecal microbiota transfer to murine model. 


\section{Chapter 6}

Table S2: Characteristics of CMA patients.

\begin{tabular}{|c|c|c|c|c|c|}
\hline & Patient 4* & Patient 7 & Patient 9 & Patient 10 & Patient 11 \\
\hline Age (months) & 10 & 16 & 16 & 7 & 12 \\
\hline Sex & Female & Female & Female & Female & Female \\
\hline $\begin{array}{c}\text { Clinical } \\
\text { manifestations }\end{array}$ & $\begin{array}{l}\text { Urticarial rash, } \\
\text { vomiting/GOR }\end{array}$ & $\begin{array}{l}\text { Immediate } \\
\text { vomiting, rash, } \\
\text { abdominal } \\
\text { pain, blood per } \\
\text { rectum }\end{array}$ & $\begin{array}{l}\text { Urticarial rash, } \\
\text { vomiting, } \\
\text { faltering } \\
\text { growth, loose } \\
\text { stools (with } \\
\text { blood and } \\
\text { mucus), } \\
\text { episodes of } \\
\text { chestiness }\end{array}$ & $\begin{array}{l}\text { Urticarial rash, } \\
\text { vomiting }\end{array}$ & $\begin{array}{c}\text { Immediate } \\
\text { swelling and } \\
\text { rash, } \\
\text { vomiting/GOR, } \\
\text { faltering growth, } \\
\text { constipation }\end{array}$ \\
\hline $\begin{array}{c}\text { Personal atopic past } \\
\text { history }\end{array}$ & $\begin{array}{c}\text { CMPA, } \\
\text { allergies to } \\
\text { wheat, egg and } \\
\text { soya; Reactive } \\
\text { airway disease }\end{array}$ & $\begin{array}{l}\text { CMPA, } \\
\text { allergies to } \\
\text { egg, wheat, } \\
\text { soya, seafood } \\
\text { and beef; } \\
\text { Eczema }\end{array}$ & $\begin{array}{l}\text { CMPA, } \\
\text { allergies to } \\
\text { egg, wheat, } \\
\text { soya, shellfish } \\
\text { and nut; } \\
\text { Eczema }\end{array}$ & CMPA & $\begin{array}{c}\text { CMPA, allergies } \\
\text { to egg, wheat, } \\
\text { soya and rice; } \\
\text { Eczema }\end{array}$ \\
\hline $\begin{array}{c}\text { Familial atopic past } \\
\text { history }\end{array}$ & Yes & Yes & Yes & Yes & Yes \\
\hline Final diagnosis & $\begin{array}{c}\text { Multiple Food } \\
\text { Protein } \\
\text { Allergies }\end{array}$ & $\begin{array}{c}\text { Food } \\
\text { protein-induced } \\
\text { enteropathy } \\
\text { syndrome }\end{array}$ & $\begin{array}{l}\text { Multiple Food } \\
\text { Protein } \\
\text { Allergies }\end{array}$ & CMPA & $\begin{array}{c}\text { Multiple Food } \\
\text { Protein Allergies }\end{array}$ \\
\hline $\begin{array}{c}\text { Amino acid-based } \\
\text { formula }\end{array}$ & $\begin{array}{c}\text { Nutramigen } \\
A A \circledast\end{array}$ & Neocate $\AA$ & Neocate $\AA$ & Neocate $\AA$ & Neocate $\AA$ \\
\hline
\end{tabular}

*Post-exclusive breast feeding, infant \#4 developed urticarial rash and classic CMA symptoms when challenged with dairy on repeat occasions; with symptom resolution on exclusion. Infant 4 was stable (amino acid-based formula with dairy/egg/wheat/soya exclusion) when FMT sample was obtained. CMPA=cow's milk protein allergy. GOR=gastroesophageal reflux

Table S3: Summary of sequence depths obtained with $16 \mathrm{~S}$ rRNA-gene sequencing across the different samples.

\begin{tabular}{|cccc|}
\hline Sample description & n samples & Average sequence depth & StdDev \\
\hline Donor samples (fecal samples) & 10 & 60285 & 10743 \\
Mice D15 (fecal pellets) & 84 & 47865 & 12625 \\
Mice D50 (cecal content) & 89 & 57996 & 11587 \\
\hline \hline Grand Total & $\mathbf{1 8 3}$ & $\mathbf{5 3 4 7 1}$ & $\mathbf{1 3 0 5 3}$ \\
\hline
\end{tabular}




\section{Supplementary Figures}
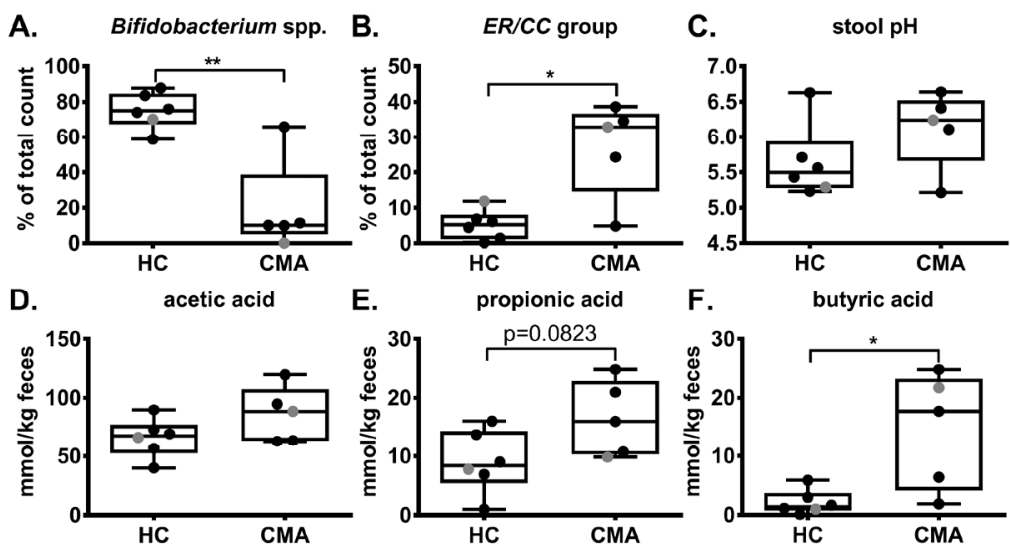

F. butyric acid

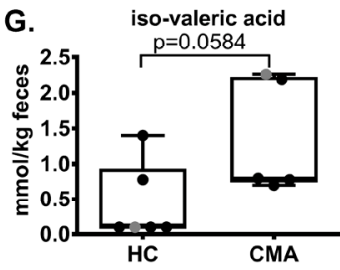

H. iso-butyric acid
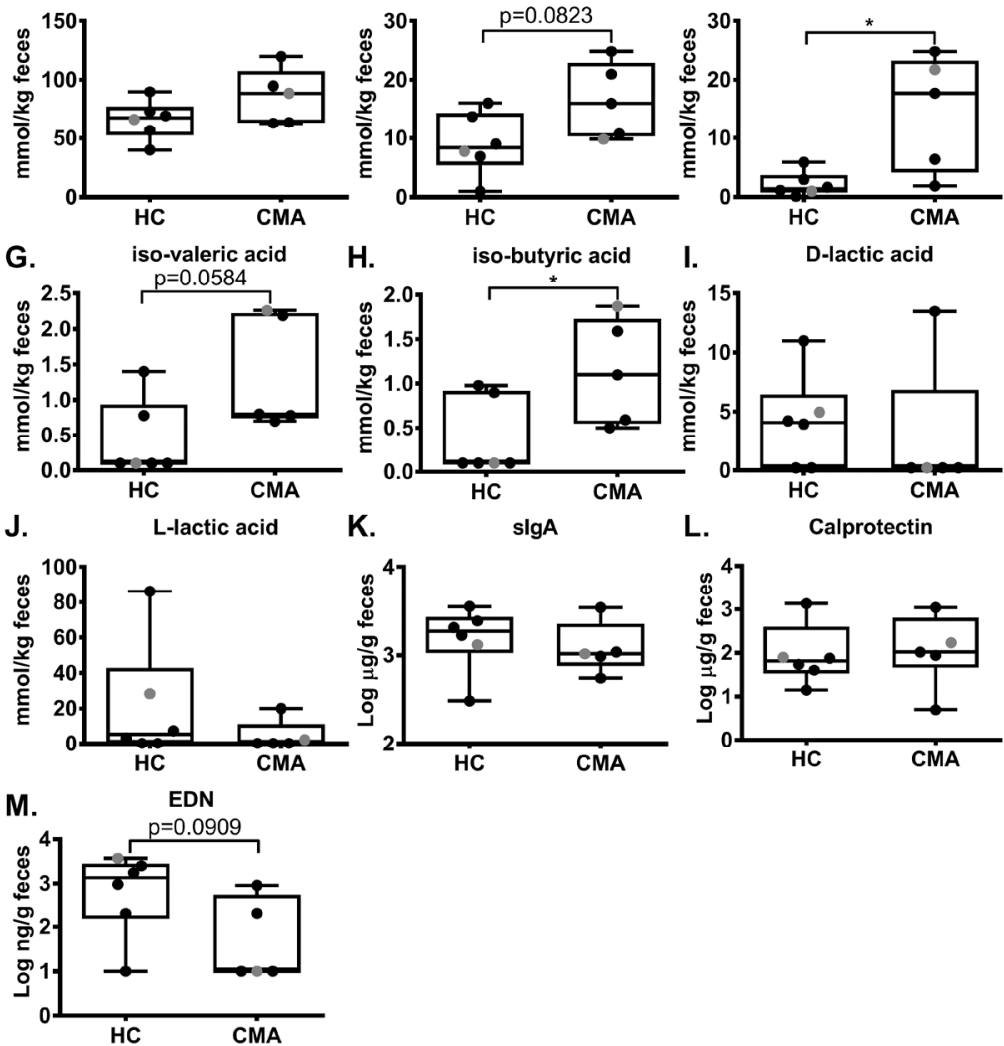

Figure S1: Fecal markers analyzed in infant donor samples. Box-whisker plots with FISH quantified levels of Bifidobacterium spp. (A), and Eubacterium rectale - Clostridum coccoides (ER/CC) group (B), and stool pH (C). Concentrations of fecal SCFAs (not valeric acid, due to majority of samples with undetectable levels) and lactic acids are summarized (D-J), as well as the Log-10 concentrations of secretory IgA (slgA) (K), Calprotectin (L) and eosinophil-derived neurotoxin (EDN). Final selected donors for fecal transfer to mice model are shown as grey symbols. Statistics comparing healthy control $(\mathrm{HC})$ with cow's milk allergic (CMA) infants were performed using Mann-Whitney test. ${ }^{*} \mathrm{P} \leq 0.05,{ }^{* *} \mathrm{P} \leq 0.001$. 


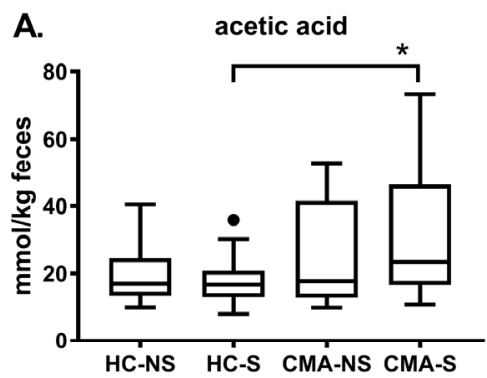

B. propionic acid

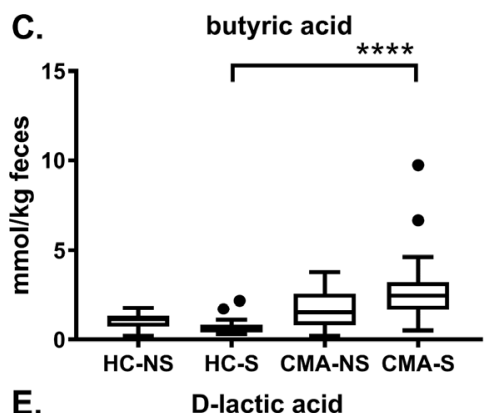

E. D-lactic acid

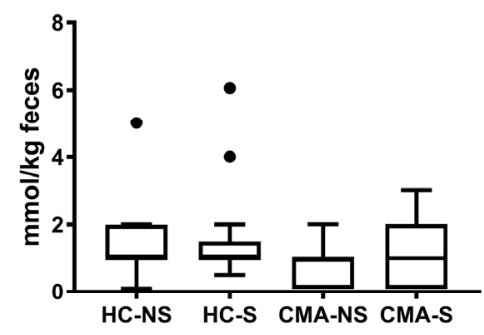

D. iso-valeric acid
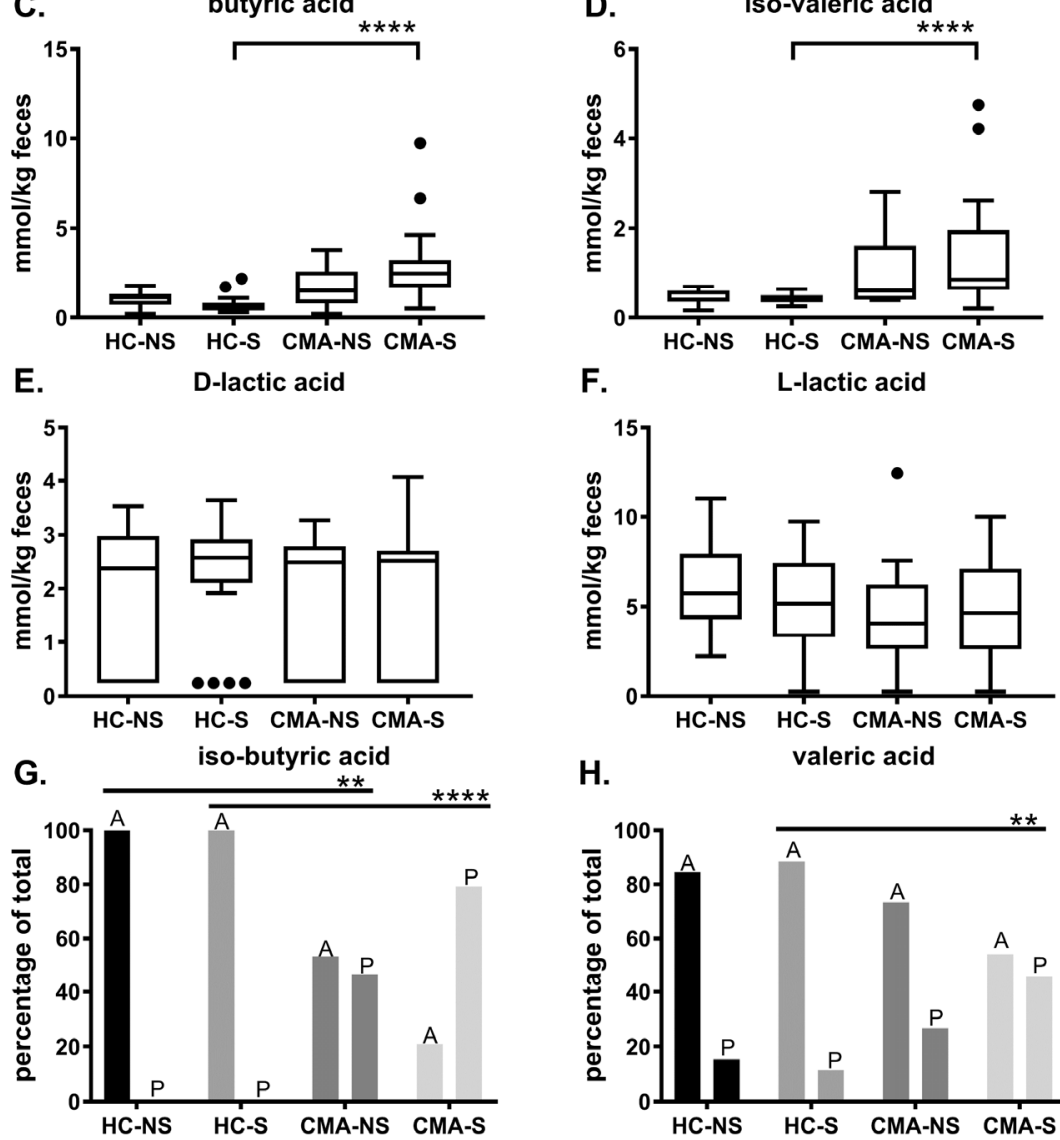

H.

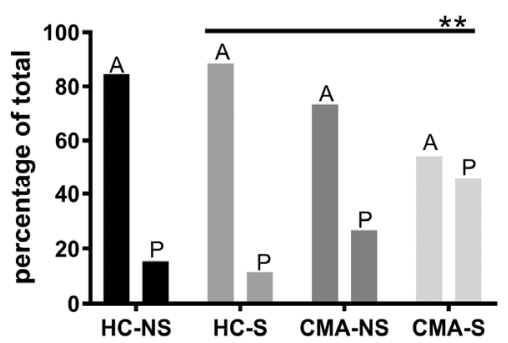

Figure S2: Levels of SCFAs and lactic acids in cecal content mice (D50). Box-whisker plots (Tukey method) with the concentrations of acetate $(A)$, propionate $(B)$, butyrate $(C)$, iso-valeric acid $(D)$, D-lactic acid $(E)$ and L-lactic acid $(F)$. The detection of iso-butyrate $(G)$ and valerate $(H)$ are presented as percentage of samples with detectable levels $(\mathrm{P})$ and undetectable levels $(\mathrm{A})$. Statistics comparing the $\mathrm{HC}$-groups with the CMA-groups were performed using Kruskal-Wallis test with Dunn's correction for multiple comparisons and applying fisher's exact test for presence $(P)$-absence $(A)$ data. ${ }^{*} P \leq 0.05,{ }^{* *} P \leq 0.001,{ }^{* * *} P \leq 0.0001,{ }^{* * * *} P \leq 0.00001$. 
A. Th-2 cytokines $\rightarrow$
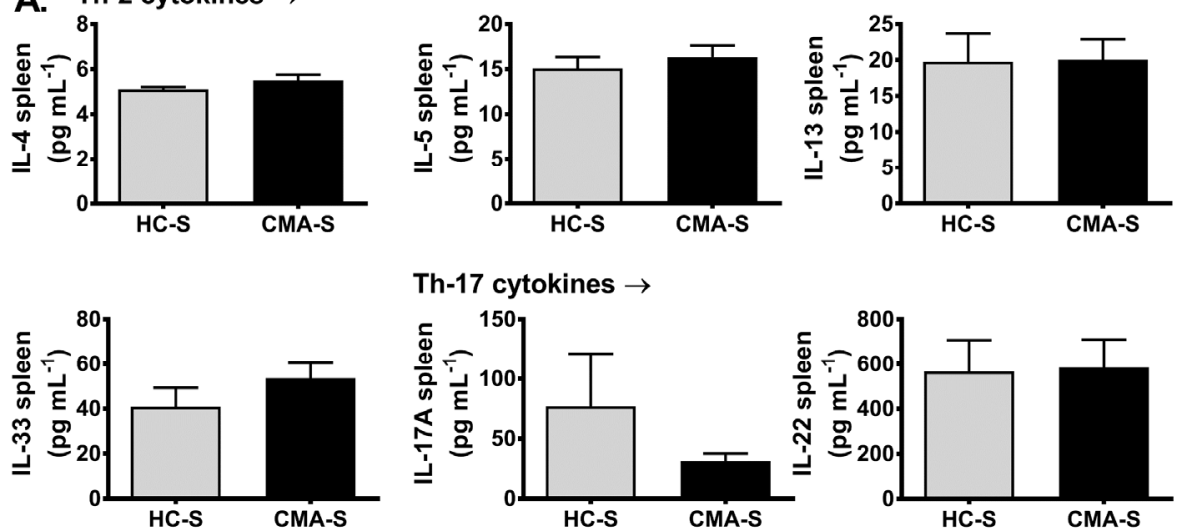

Th-17 cytokines $\rightarrow$

Th-1 cytokines $\rightarrow$
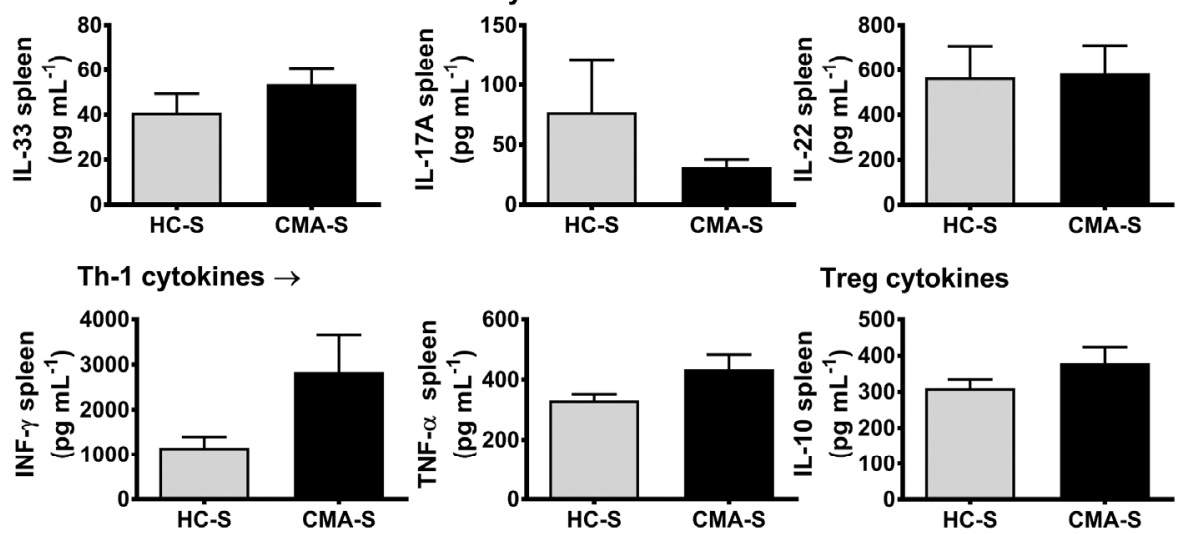

Treg cytokines
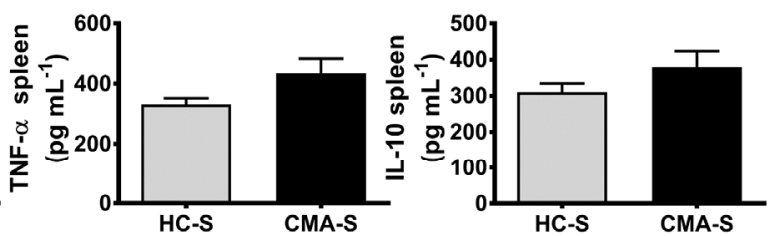

B. Th-2 cytokines $\rightarrow$
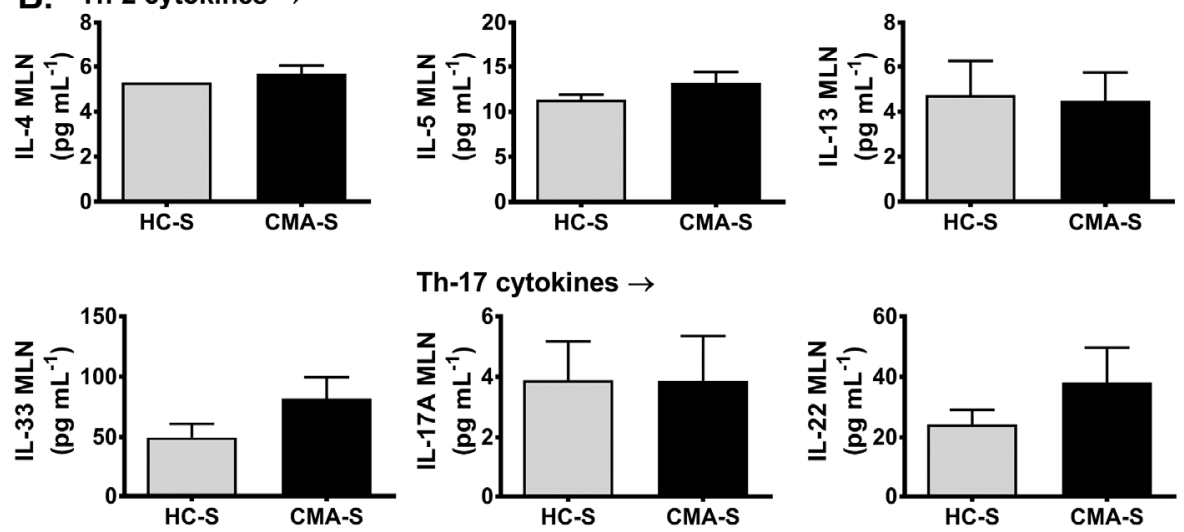

Th-1 cytokines $\rightarrow$
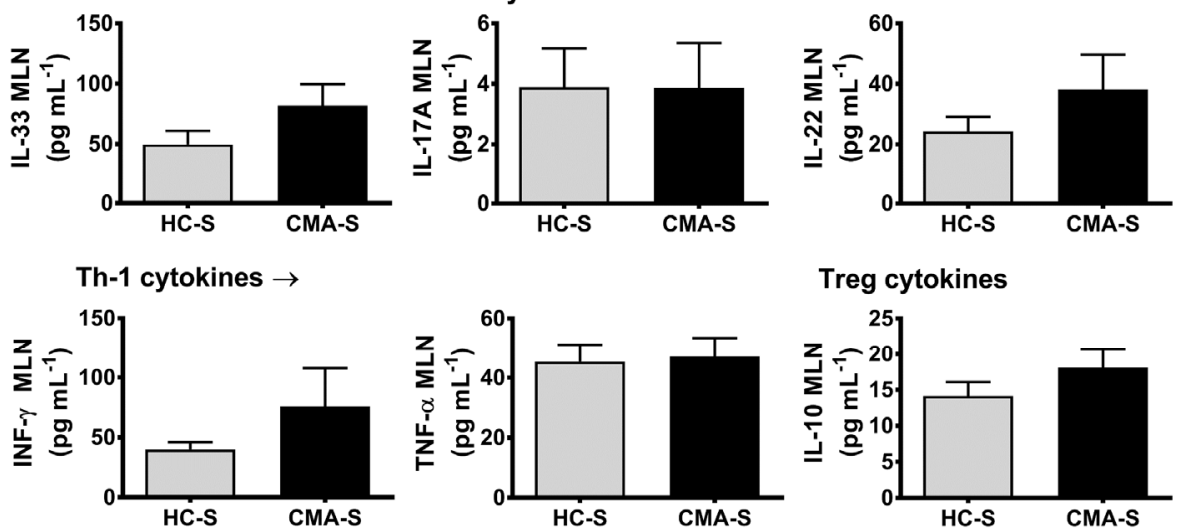

Treg cytokines

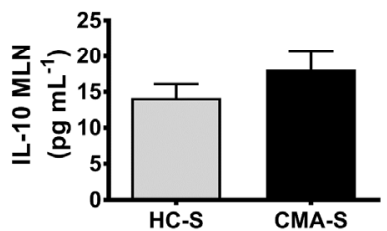

Figure S3: Cytokines produced after BLG stimulation. (A) Splenocytes, (B) MLN lymphocytes shown as bar plots (mean with SEM). Statistics comparing HC-S with CMA-S were performed using Mann-Whitney test. 


\section{References}

1. Fiocchi A, Brozek J, Schunemann H, Bahna SL, von Berg A, Beyer K, et al. World Allergy Organization (WAO) Diagnosis and Rationale for Action against Cow's Milk Allergy (DRACMA) Guidelines. Pediatr Allergy Immunol. 2010;21 Suppl 21:1-125.

2. Sampson HA. Food allergy: Past, present and future. Allergol Int. 2016;65(4):363-9.

3. Abrams EM, Sicherer SH. Diagnosis and management of food allergy. Cmaj. 2016;188(15):1087-93.

4. Alduraywish SA, Standl M, Lodge CJ, Abramson MJ, Allen KJ, Erbas B, et al. Is there a march from early food sensitization to later childhood allergic airway disease? Results from two prospective birth cohort studies. Pediatr Allergy Immunol. 2017;28(1):30-7.

5. Wopereis $\mathrm{H}$, Oozeer R, Knipping K, Belzer C, Knol J. The first thousand days - intestinal microbiology of early life: establishing a symbiosis. Pediatr Allergy Immunol. 2014;25(5):428-38.

6. Butel MJ, Waligora-Dupriet AJ, Wydau-Dematteis S. The developing gut microbiota and its consequences for health. J Dev Orig Health Dis. 2018;9(6):590-7.

7. Thompson-Chagoyan OC, Fallani M, Maldonado J, Vieites JM, Khanna S, Edwards C, et al. Faecal microbiota and short-chain fatty acid levels in faeces from infants with cow's milk protein allergy. Int Arch Allergy Immunol. 2011;156(3):325-32.

8. Berni Canani R, Sangwan N, Stefka AT, Nocerino R, Paparo L, Aitoro R, et al. Lactobacillus rhamnosus GG-supplemented formula expands butyrate-producing bacterial strains in food allergic infants. ISME J. 2016;10(3):742-50.

9. Guo L, Bai H, Dong Y, Huang DX, Zhang X, Gong S, et al. Comparative Analysis of Fecal Microbiota in 5 8-Year-old Children with and without Cow Milk Protein Allergy. Iranian Journal of Pediatrics. 2016; In Press(In Press):e6397.

10. Dong P, Feng JJ, Yan DY, Lyu YJ, Xu X. Early-life gut microbiome and cow's milk allergy- a prospective case - control 6-month follow-up study. Saudi J Biol Sci. 2018;25(5):875-80.

11. Rodriguez B, Prioult G, Bibiloni R, Nicolis I, Mercenier A, Butel MJ, et al. Germ-free status and altered caecal subdominant microbiota are associated with a high susceptibility to cow's milk allergy in mice. FEMS Microbiol Ecol. 2011;76(1):133-44.

12. Rodriguez B, Prioult G, Hacini-Rachinel F, Moine D, Bruttin A, Ngom-Bru C, et al. Infant gut microbiota is protective against cow's milk allergy in mice despite immature ileal T-cell response. FEMS Microbiol Ecol. 2012;79(1):192-202.

13. Candy DCA, Van Ampting MTJ, Oude Nijhuis MM, Wopereis H, Butt AM, Peroni DG, et al. A synbiotic-containing amino-acid-based formula improves gut microbiota in non-IgE-mediated allergic infants. Pediatr Res. 2018;83(3):677-86.

14. Kalach N, Kapel N, Waligora-Dupriet AJ, Castelain MC, Cousin MO, Sauvage C, et al. Intestinal permeability and fecal eosinophil-derived neurotoxin are the best diagnosis tools for digestive non-IgE-mediated cow's milk allergy in toddlers. Clinical chemistry and laboratory medicine : CCLM / FESCC. 2013;51(2):351-61.

15. Huet F, Abrahamse-Berkeveld M, Tims S, Simeoni U, Beley G, Savagner C, et al. Partly Fermented Infant Formulae With Specific Oligosaccharides Support Adequate Infant Growth and Are Well-Tolerated. J Pediatr Gastroenterol Nutr. 2016;63(4):e43-53. 
16. Scholtens PAMJ, Alliet P, Raes M, Alles MS, Kroes H, Boehm G, et al. Fecal Secretory Immunoglobulin A Is Increased in Healthy Infants Who Receive a Formula with Short-Chain Galacto-Oligosaccharides and Long-Chain Fructo-Oligosaccharides. J Nutr. 2008;138(6):1141-7.

17. Wopereis H, Sim K, Shaw A, Warner JO, Knol J, Kroll JS. Intestinal microbiota in infants at high risk for allergy: Effects of prebiotics and role in eczema development. J Allergy Clin Immunol. 2018;141(4):1334-42 e5.

18. Šmilauer P, Lepš. J. Multivariate Analysis of Ecological Data using CANOCO 5. Cambridge Books Online: Cambridge University Press; 2014. Available from: http://dx.doi.org/10.1017/CBO9781139627061.

19. Aitchison J. Reducing the dimensionality of compositional data sets. Journal of the International Association for Mathematical Geology. 1984;16(6):617-35.

20. Mandal S, Van Treuren W, White RA, Eggesbo M, Knight R, Peddada SD. Analysis of composition of microbiomes: a novel method for studying microbial composition. Microb Ecol Health Dis. 2015;26:27663.

21. Letunic I, Bork P. Interactive Tree Of Life (iTOL): an online tool for phylogenetic tree display and annotation. Bioinformatics. 2007;23(1):127-8.

22. Benjamini Y, Hochberg Y. Controlling the False Discovery Rate: A Practical and Powerful Approach to Multiple Testing. Journal of the Royal Statistical Society Series B (Methodological). 1995;57(1):289-300.

23. Fujimura KE, Sitarik AR, Havstad S, Lin DL, Levan S, Fadrosh D, et al. Neonatal gut microbiota associates with childhood multisensitized atopy and T cell differentiation. Nat Med. 2016;22(10):1187-91.

24. Korpela K, Blakstad EW, Moltu SJ, Strommen K, Nakstad B, Ronnestad AE, et al. Intestinal microbiota development and gestational age in preterm neonates. Sci Rep. 2018;8(1):2453.

25. Nimmerjahn F, Ravetch JV. Fcgamma receptors as regulators of immune responses. Nat Rev Immunol. 2008;8(1):34-47.

26. Miyajima I, Dombrowicz D, Martin TR, Ravetch JV, Kinet JP, Galli SJ. Systemic anaphylaxis in the mouse can be mediated largely through IgG1 and Fc gammaRIII. Assessment of the cardiopulmonary changes, mast cell degranulation, and death associated with active or IgE- or IgG1-dependent passive anaphylaxis. J Clin Invest. 1997;99(5):901-14.

27. Finkelman FD. Anaphylaxis: lessons from mouse models. J Allergy Clin Immunol. 2007;120(3):506-15; quiz 16-7.

28. Cahenzli J, Köller Y, Wyss M, Geuking Markus B, McCoy Kathy D. Intestinal Microbial Diversity during Early-Life Colonization Shapes Long-Term IgE Levels. Cell Host \& Microbe. 2013;14(5):559-70.

29. Lock RJ, Unsworth DJ. Food allergy: which tests are worth doing and which are not? Ann Clin Biochem. 2011;48(Pt 4):300-9.

30. Kiiski V, Karlsson O, Remitz A, Reitamo S. High serum total IgE predicts poor long-term outcome in atopic dermatitis. Acta dermato-venereologica. 2015;95(8):943-7.

31. Gordon BR. The allergic march: can we prevent allergies and asthma? Otolaryngologic clinics of North America. 2011;44(3):765-77, xi.

32. Chia LW, Mank M, Blijenberg B, Bongers RS, Aalvink S, van Limpt K, et al. Cross-feeding between Bifidobacterium infantis and Anaerostipes caccae on lactose and human milk oligosaccharides. bioRxiv. 2018.

33. Feehley T, Plunkett CH, Bao R, Choi Hong SM, Culleen E, Belda-Ferre P, et al. Healthy infants harbor intestinal bacteria that protect against food allergy. Nat Med. 2019.

34. Reubsaet L, Meerding J, Giezeman R, de Kleer I, Arets B, Prakken B, et al. Der p 1-induced CD4(+)FOXP3(+)GATA3(+) T cells have suppressive properties and contribute to the polarization of the TH2-associated response. J Allergy Clin Immunol. 2013;132(6):1440-44. 


\section{Chapter 6}

35. Ohnmacht C, Park JH, Cording S, Wing JB, Atarashi K, Obata Y, et al. The microbiota regulates type 2 immunity through RORgammat(+) T cells. Science. 2015;349(6251):989-93.

36. Noval Rivas M, Burton OT, Wise P, Charbonnier LM, Georgiev P, Oettgen HC, et al. Regulatory T cell reprogramming toward a Th2-cell-like lineage impairs oral tolerance and promotes food allergy. Immunity. 2015;42(3):512-23.

37. Sakaguchi S, Miyara M, Costantino CM, Hafler DA. FOXP3+ regulatory T cells in the human immune system. Nat Rev Immunol. 2010;10(7):490-500.

38. Stefka AT, Feehley T, Tripathi P, Qiu J, McCoy K, Mazmanian SK, et al. Commensal bacteria protect against food allergen sensitization. Proc Natl Acad Sci U S A. 2014;111(36):13145-50.

39. Furusawa Y, Obata Y, Fukuda S, Endo TA, Nakato G, Takahashi D, et al. Commensal microbe-derived butyrate induces the differentiation of colonic regulatory T cells. Nature. 2013;504(7480):446-50.

40. Louis $\mathrm{P}$, Flint HJ. Formation of propionate and butyrate by the human colonic microbiota. Environ Microbiol. 2017;19(1):29-41.

41. Galperin MY, Brover V, Tolstoy I, Yutin N. Phylogenomic analysis of the family Peptostreptococcaceae (Clostridium cluster XI) and proposal for reclassification of Clostridium litorale (Fendrich et al. 1991) and Eubacterium acidaminophilum (Zindel et al. 1989) as Peptoclostridium litorale gen. nov. comb. nov. and Peptoclostridium acidaminophilum comb. nov. Int J Syst Evol Microbiol. 2016;66(12):5506-13.

42. Scott KP, Gratz SW, Sheridan PO, Flint HJ, Duncan SH. The influence of diet on the gut microbiota. Pharmacol Res. 2013;69(1):52-60.

43. Jackson MA, Verdi S, Maxan ME, Shin CM, Zierer J, Bowyer RCE, et al. Gut microbiota associations with common diseases and prescription medications in a population-based cohort. Nature communications. 2018;9(1):2655

44. Arrieta MC, Walter J, Finlay BB. Human Microbiota-Associated Mice: A Model with Challenges. Cell Host Microbe. 2016;19(5):575-8

45. Caporaso JG, Kuczynski J, Stombaugh J, Bittinger K, Bushman FD, Costello EK, et al. QIIME allows analysis of high-throughput community sequencing data. Nat Methods. 2010;7(5):335-6.

46. Rognes T, Flouri T, Nichols B, Quince C, Mahe F. VSEARCH: a versatile open source tool for metagenomics. PeerJ. 2016;4:e2584.

47. Haas BJ, Gevers D, Earl AM, Feldgarden M, Ward DV, Giannoukos G, et al. Chimeric 16S rRNA sequence formation and detection in Sanger and 454-pyrosequenced PCR amplicons. Genome Res. 2011;21(3):494-504

48. Wang Q, Garrity GM, Tiedje JM, Cole JR. Naive Bayesian classifier for rapid assignment of rRNA sequences into the new bacterial taxonomy. Appl Environ Microbiol. 2007;73(16):5261-7.

49. Pruesse E, Quast C, Knittel K, Fuchs BM, Ludwig W, Peplies J, et al. SILVA: a comprehensive online resource for quality checked and aligned ribosomal RNA sequence data compatible with ARB. Nucleic Acids Res. 2007;35(21):7188-96.

50. Bokulich NA, Subramanian S, Faith JJ, Gevers D, Gordon JI, Knight R, et al. Quality-filtering vastly improves diversity estimates from Illumina amplicon sequencing. Nature methods. 2013;10(1):57-9.

51. Shannon CE. A mathematical theory of communication (parts I and II). Bell System Technical Journal. 1948:379-423.

52. McMurdie PJ, Holmes S. Waste not, want not: why rarefying microbiome data is inadmissible. PLoS Comput Biol. 2014;10(4):e1003531. 
53. Perrier C, Thierry AC, Mercenier A, Corthesy B. Allergen-specific antibody and cytokine responses, mast cell reactivity and intestinal permeability upon oral challenge of sensitized and tolerized mice. Clin Exp Allergy. 2010;40(1):153-62.

54. Neau E, Delannoy J, Marion C, Cottart CH, Labellie C, Holowacz S, et al. Three Novel Candidate Probiotic Strains with Prophylactic Properties in a Murine Model of Cow's Milk Allergy. Appl Environ Microbiol. 2016;82(6):1722-33.

55. Livak KJ, Schmittgen TD. Analysis of relative gene expression data using real-time quantitative PCR and the 2(-Delta Delta C(T)) Method. Methods (San Diego, Calif). 2001;25(4):402-8. 

CHAPTER 7

General discussion \& Summary 


\section{General discussion}

The aim of this thesis was to investigate normal gut microbial trajectories in early life and to identify deviating patterns that are associated with allergic manifestations, such as atopic dermatitis and food allergy. Generally, it is estimated that the gut microbiota reaches its adult-like configuration around 3 years of age (Chapter 2), although some taxa are even not yet fully established before 5 years of age (1). We hypothesized that a suboptimal implementation of the gut microbiome may contribute to the onset of allergy and/or enhancement of allergic symptoms. Perturbation of gut microbiome at critical time windows during early life development may be particularly important, because that is when the immune system, with most of its cells residing in the gut, matures (2). Modern lifestyle and associated factors, such as antibiotic-exposure, caesarean-section delivery and low breastfeeding rates, that are associated with depletion of key gut microbial taxa, may have disrupted the mechanisms of mucosal immunologic tolerance against innocuous antigens, such as food proteins. These factors in addition to genetic risk factors have been implicated in the rising trend of allergies observed in affluent countries (Chapter 2).

\section{The sequencing era}

The number of observational paediatric studies, both prospective and case-controlled, that report on the association between altered gut microbiota and allergic disease have rapidly increased since our 2014 review of existing literature (Chapter 2). The decline in costs for DNA sequencing technologies that allow for rapid and accurate characterization of microbial communities greatly contributed to the expansion of this field of research. The plethora of $16 \mathrm{~S}$ and metagenomic surveys of human samples have vastly improved our understanding of the microbiota composition and functional potential in both healthy and diseased states. However, the accurate description of these surveys critically depends on sample collection, storage, processing, and on the downstream bioinformatic and statistical analyses applied (3-7). In this thesis the importance of PCR primer choice in 16S rRNA-gene sequencing was shown by curating one of the recommended primer-pairs from the 
NIH Human Microbiome Project (8). The primer-set was found to contain a one-base mismatch in the reverse primer for bifidobacteria, which may explain the relatively low abundance of this genus reported in several US birth cohorts (9). We showed that application of the 'bifido-optimised' primer-pair successfully detected and quantified bifidobacteria without distorting proportions of other taxa (Chapter 3 ).

\section{The development of gut microbiota}

\section{Early life nutrition}

We applied the 16S rRNA-gene sequencing technology to investigate the gut microbiota development and the pivotal role of early life nutrition in two clinical trials, which included infants with a family history of allergic disease (and therefore deemed 'high-risk for allergy') (Chapter 4), as well as infants with cow's milk allergy (CMA) (Chapter 5). Since more than 100 years it has been known that breastfed babies have a different gut microbiota compared to infants receiving a formula based on cow's milk (10-13), which is explained by a wide array of non-digestible oligosaccharides present in human milk, known as human-milk oligosaccharides (HMO) (14). A growing number of studies indicate that the addition of specific prebiotic or synbiotic ingredients to infant formula can have similar functionalities as HMOs on gut microbiota composition and activity (15). Hence, such microbiota modulators are of interest in nutritional strategies for allergy prevention and treatment in infants for whom breastfeeding is not possible or insufficient. Based on HMO-research a specific mixture of short-chain galacto-oligosaccharides and long-chain fructo-oligosaccharides (scGOS/IcFOS) (9:1) was developed to mimic the molecular weight profile and partly building blocks of HMOs in breast milk (15), and its supplementation to infant formula has been shown to reduce the risk of allergy in not-exclusively breastfed infants, both at high- $(16,17)$ and at low-risk for developing allergy (18), which contributed to new guidelines from the World Allergy Organization that recommend prebiotics for allergy prevention under certain conditions (19). Current international guidelines for the dietary management of allergic diseases for not exclusively breastfed infants also include the recommendation of partially 
hydrolysed cow's milk protein-based formulas (pHP) for high-risk infants (20). However, the preventive effects of reduced allergen exposure by such formulas is currently being debated and challenged (21). Infants suffering from cow's milk allergy (CMA) rely on the dietary avoidance of cow's milk to resolve symptoms, which include specialized infant formula for those who cannot be breastfed (22). While most infants respond to extensively hydrolysed cow's milk-based formulas (eHP), some require amino acid-based formulas (AAF) due to an increased risk to an anaphylactic reaction, or more complex symptoms, or when symptoms do not resolve on eHP (22-24). In the cohort with infants that were high-risk for developing allergy (Chapter 4), we investigated the modulatory effects of a partially-hydrolyzed cow's milk protein formula (pHP) including the scGOS/lcFOS (9:1) mixture on gut microbiota in the first 6 months of life. In chapter 5 the modulatory effects of an amino acid-based formula (AAF) with short-chain and long-chain fructo-oligosaccharides (scFOS/lcFOS) (9:1) and the probiotic strain Bifidobacterium breve M-16V was investigated in infants suffering from cow's milk allergy (CMA). This synbiotic concept was based on the scGOS/lcFOS-mixture, however in which scGOS was replaced by scFOS, since the former is produced from cow's milk-derived lactose, which may pose risks in infants with severe CMA that rely on an elimination diet for the resolution of allergic symptoms (25). Importantly, the combination of the prebiotic with the probiotic Bifidobacterium breve $\mathrm{M}-16 \mathrm{~V}$ provided preclinical proof to be more effective in treating the allergic response in a murine model of food allergy than the sole administration of the scFOS/lcFOS-mixture (26).

\section{The healthy reference in gut microbiota development}

In both trials, we reaffirmed that the microbiota of breastfed infants was characterized by a low diversity and Bifidobacterium domination. Moreover, we showed that the addition of prebiotics to pHP (Chapter 4) and the addition of synbiotics to AAF (Chapter 5 ) led to a taxonomic profile and diversity closer to that of the breastfed reference. Infants who received infant formula without prebiotics or synbiotics, however, adopted a more diverse adult-type of microbiota, which was characterized by an increase of microbes belonging to the order of clostridia and its main bacterial family of Lachnospiraceae. Importantly, we observed these 
closer-to-breastfed effects during the exclusive milk-feeding period (typically before 4 months of age), but also during the complementary feeding period, namely at 6 months of age (Chapter 4 ) and 8 months of age (Chapter 5), respectively. This period, when the first solid foods are introduced and gradually replace the milk-based diet (i.e. human milk and/or infant formula when breastfeeding is not possible), marks an important shift of the microbial ecosystem to the diversifying infant diet (27). The WHO guidelines recommend to phase in solids at six months of age with continued breastfeeding up to 24 months of age $(28,29)$. European guidelines recommend to phase in complementary feeding between 4-6 months of age with continued breastfeeding (30). The increased Bifidobacterium/Lachnospiraceae ratio (B/L-ratio) indicate that the addition of these specific prebiotic or synbiotic ingredients may also normalise the rate of gut microbiota establishment during weaning towards that observed in breastfed infants. The establishment of gut microbiota in breastfed infants is namely characterized by a more gradual transition from infant- to adult-like composition compared to non-breastfed infants, which was confirmed in several recent longitudinal $16 \mathrm{~S}$ and metagenomic surveys of infant samples (31-33), as well as in a number of meta-analyses performed on publicly available data (9, 34-36). The timely establishment of gut microbiota as observed in breastfed infants may therefore be essential in forming a stable ecosystem (34-36), and may contribute to the association of breastfeeding with several health benefits, such as a lower risk of diarrhoeal diseases and infections in early childhood (37), a lower risk of metabolic diseases later in life (38), and possibly also a lower risk of developing allergy and asthma $(20,39-41)$.

\section{Diversity and ecosystem development}

The decreased microbial diversity observed in breastfed infants, but also observed in infants receiving prebiotic- and synbiotic-supplemented formula, may seem counterintuitive. Especially since low gut microbiome diversity in early infancy has been reported to precede allergic manifestations, such as eczema (42-44), which we however did not confirm in our study with high-risk infants (Chapter 4). Arguably, an increased diversity does not necessarily reflect improved ecosystem function, stability or resilience to perturbation, but should be viewed in its ecological context 
$(45,46)$. In that respect, the lower diversity of breastfed versus formula-fed infants versus the lower diversity associated with later-life allergic manifestations likely reflects different underlying ecologic causes and consequences. For instance, Abrahamsson et al. (43) linked the lower diversity at 1 month of age in infants developing atopic eczema by 2 years of age to a decreased diversity of the bacterial phylum/genus Bacteroidetes / Bacteroides, also when limiting their analysis to exclusively breastfed infants (47). This may indicate decreased maternal transmission of these pioneering infant gut colonizers upon birth (48), which seemed unrelated to delivery by caesarean section or exposure to perinatal antibiotics, both well-known risk-factors for decreased vertical transmission and allergic disease (49). In contrast, the lower microbial diversity that we observed in breastfed, prebiotic-fed and synbiotic-fed infants as compared to control-fed infants, reflected the increased Bifidobacterium/Lachnospiraceae ratio (B/L-ratio). These compositional differences resulted in specific changes in gut eco-physiology with a slightly acidic $\mathrm{pH}$, increased concentrations of lactate, and a specific short-chain fatty acid (SCFA)-profile, which was high in acetate and low in butyrate, propionate and branched-SCFAs (iso-valerate and iso-butyrate) (Chapter 4 and Chapter 5). The enhanced levels of colonic lactate and acetate, both fermentation end-products of bifidobacteria, are typically associated with increased colonization resistance to potential pathogens (50-52) and may contribute to the protection against infections associated with breastfeeding (37). Interestingly, lower incidence of infections was also reported for infants receiving a formula with scGOS/IcFOS $(16,53)$, as well as for infants receiving the AAF formulation with synbiotics $(54,55)$ that was reported on in this thesis (Chapter 5). The increased levels of branched-SCFAs observed in the guts of control-fed infants possibly reflect an increased proteolytic microbial metabolism (56, 57), due to the deprivation of fermentable carbohydrates (HMOs or prebiotics) that may lead to a shift from saccharolytic processes to lower yield proteolytic processes (46). It was recently observed in adult populations that a firm stool consistency, which is a proxy for long colonic transit time, correlates with high gut microbial diversity and increased proteolytic activity $(58,59)$. These observations in adults show interesting parallels to observations in infants, in which lower stool consistency and increased 
stool frequency are observed for infants being breastfed or receiving formula supplemented with scGOS/IcFOS when compared to formula without prebiotics (60, 61). The softer stools and increased stool frequency were also confirmed for the prebiotic and synbiotic formulations investigated in this thesis $(62,63)$. Together, this suggests that a high gut microbial diversity does not per se imply a healthy gut microbial ecosystem and points at the sachharolytic/proteolytic ratio as an important factor to consider in microbiome and metabolomics studies, since several end-products of microbial proteolysis are considered detrimental to host health (46, $58,64)$.

\section{Gut microbiota and allergic disease}

In the cohort of infants that were high-risk for developing allergy (Chapter 4), we found that infants who went on to develop atopic dermatitis (AD) showed discordant temporal development of bacterial taxa and the metabolites lactate, propionate and butyrate around the time that complementary feeding started. This nested case-control comparison was controlled for the factors that were identified as influencing the microbiota of these infants including feeding group, ethnicity and household exposure to siblings. At first, infants developing $A D$ showed decreased levels of lactate and increased levels of propionate and butyrate at 12 weeks of age (before weaning); in contrast, they showed increased levels of lactate and decreased levels of propionate and butyrate at 26 weeks of age (during weaning). Microbially produced lactate is only intermediately present in the healthy adult, as it is converted into propionate or butyrate by a subset of lactate-utilizing bacteria (65). Indeed, we found that both Eubacterium and Anaerostipes spp., which are known to utilize lactate and acetate to produce butyrate, were enhanced in healthy infants compared to infants with $A D$. Importantly, we also found that infants developing $A D$ showed decreasing levels of bifidobacteria over the first 6 months of life, which was in contrast with the increasing levels observed for healthy infants. This possibly indicates that the bifidogenic environment with high levels of lactate and acetate and their consumption by such specialist microbes may have a key role in establishing a stable community in the gradually diversifying infant gut and may protect from developing allergy. The start of weaning may form a critical step in the development of oral tolerance, while 
experiments with germ-free mice have shown that the presence of both diet- and microbe-induced populations of regulatory T-cells (Treg) were required for induction of complete tolerance to food antigens $(66,67)$. Moreover, there is accumulating evidence that many of the microbially-derived colonic Tregs are induced via SCFAs that act as histone-deacetylase (HDAC) inhibitors and ligands for G-protein cell surface receptors (GPRs) (68-70). Indeed, several murine studies have shown that high-fiber diets effectively modulate gut microbiota and increase SCFAs, particularly acetate and butyrate, which exert regulatory effects on host immunity, including anti-inflammatory and anti-allergic effects (71-74). Interestingly, infants receiving the pHP-prebiotics demonstrated increased systemic Treg-numbers compared to control-formula at 6 months of age, although no reduction of $A D$ incidence was observed at 12 or 18 months (75). However, the incidence of $A D$ seemed to be affected by the age the infant was introduced to solid foods, which deviated in most infants $(55 \%)$ from the standard recommendation to start after 18 weeks of age (71). In infants who were fed according to this recommendation lower levels of total-IgE and hen's-egg IgE were observed at 6 months, and a reduction of allergic manifestations was observed in the follow-up study at 3-5 years comparing the pHP-prebiotics group with the control-group (76). This indicates that exposure to food allergens during the weaning-period may be critical for the induction of oral tolerance.

In Chapter 6 we investigated whether the increased B/L-ratio that differentiated healthy breastfed infants from CMA-infants (Chapter 5) impacted immune and allergic response in a murine model of sensitization and challenge with cow's milk protein. In a small case-control study with infants with suspected CMA and healthy breastfed infants, we could confirm the shift in B/L-ratio. Faecal microbiota transplantation (FMT) into germ-free mice from representative infants (matched for age, gender and birth-mode) largely replicated the characteristic compositional differences in microbiota, including the decreased diversity and proteolytic activity of the healthy breastfed infant (9 months of age) compared to the CMA-infant (10 months of age). Interestingly, the CMA-associated infant gut microbiota induced systemic Th-2 immunity with increased total lgE-levels and showed more severe clinical symptoms upon sensitization with cow's milk allergen and cholera toxin as 
adjuvant. Whether similar results would have been obtained with microbiota showing a decreased B/L-ratio but obtained from an otherwise healthy infant or when treated with prebiotics or synbiotics warrant further investigation. However, these results do suggest that perturbation of gut microbiome in infants with CMA contributes, at least in part, to disease onset and severity of symptoms.

\section{Overall conclusion and future perspectives}

Clearly the development of the gut microbiome from birth through to childhood is critical to establish a healthy symbiosis, since this is the period in which infants encounter external stimuli for the first time and the body is trained to respond to these stimuli. Human milk is the reference, effectively shaping the infant microbiome, which is associated with optimal immune maturation and protection against infections and potentially also allergy. Specific prebiotic and synbiotic ingredients can modulate the microbiota closer to that of breastfed infants leading to clinical benefits related to infection and allergy. However, much is yet to be learnt about how and when microbes or their functional triggers optimally impact the host and protect from allergic disease. Moreover, it is crucial to understand how the many covariates, such as birth mode, antibiotics and household exposures, interfere with the colonisation pattern. Future studies in allergy need to carefully consider the effect of complementary feeding (type and timing) and treat it as an integral part of the dietary strategy for prevention and treatment. Longitudinal studies are needed to better comprehend the timely establishment of key species to develop a gut eco-physiology to form a stable ecosystem, which supports optimal gut and immune development. The omics tools currently available to perform characterization of microbiome functionality and bioactive compounds like proteomics or metabolomics integrated with 16S surveys or metagenomics will certainly bring our understanding to the next level. These tools and the identification of different endotypes of allergic disease based on clinical symptoms and immunomes, will improve our understanding of the structure and function of the microbiome in both diseased and healthy states. This integrated approach may lead to novel personalized preventive and therapeutic nutritional strategies in allergic disease. 


\section{Summary}

The development of the gut microbiome from birth through to childhood is thought to be important for establishing a healthy symbiosis, but much is yet to be learnt about this phase of microbiome development. Perturbations of gut microbiome during this development have been associated with the pathology of diseases, such as allergy. In Chapter 2, we describe this dynamic period of gut microbiome development, the various factors involved in shaping its composition and the importance for the concurrent maturation of the immune system. Environmental factors including birth mode, exposure to antibiotics and household exposures (such as siblings and furry pets) represent important factors impacting its development, and which also have been epidemiologically implicated in the risk to develop allergic disease. Several paediatric studies indeed associated altered gut microbiota with development of allergic disease. Breastfeeding represents the most significant factor in shaping early life microbiome and is associated with several short-term and long-term health benefits, including a lower risk of developing allergic disease. Specific prebiotic or synbiotic (when combined with probiotics) ingredients added to infant formula may exert similar effects on gut microbiota composition and activity, which may benefit infants for whom breastfeeding is not possible.

Bifidobacteria are the most abundant bacteria in breastfed infants, but often under-represented in $16 \mathrm{~S}$ rRNA surveys of diversity, due to poor DNA extraction techniques, poor PCR primer choice or a combination of both. In Chapter 3, we optimized a commonly used "universal" PCR primer set and demonstrated the effective recovery of this genus without compromising the detection of other genera. In Chapter $\mathbf{4}$ we applied the optimized pyrosequencing method described in Chapter 3 to analyse the gut microbiota of infants at high-risk of developing allergy, who participated in a clinical trial that investigated the effects of a partially hydrolysed protein formula supplemented with prebiotics on the prevention of eczema. We showed that the taxonomic composition of infants receiving the prebiotic-supplemented formula was closer to that of breastfed infants when compared to infants receiving an infant formula based on intact protein without prebiotics, which was driven by increased abundance of Bifidobacterium spp. and 
decreased abundances of Clostridium spp. and Lachnospiraceae spp. Importantly this also led to specific changes in gut eco-physiology characterized by a more acidic $\mathrm{pH}$ and increased levels of lactate and acetate as also characteristic for breastfed infants. In a nested case-control, we found that infants who developed eczema by 18 months of age showed an altered development of bacterial taxa and metabolites around the time that complementary feeding was started. The patterns identified suggested that the establishment of specific bacteria that utilize lactate and acetate to produce butyrate may have a role in protecting from the development of eczema.

Infants who suffer from severe CMA often rely on cow's milk protein avoidance and, when breastfeeding is not possible, on specialised infant formulas such as amino-acid based formulas (AAF) to meet their nutritional needs and in order to resolve the allergic symptoms they suffer from. In Chapter 5, we investigated the modulatory effects of an AAF supplemented with synbiotics on the gut microbiota and showed that both composition and activity approximated that of an age-matched breastfed reference group as opposed to infants receiving the AAF without synbiotics. Similar as observed in Chapter 4 this was driven by an increase of the Bifidobacterium spp./ Lachnospiraceae spp. ratio (B/L-ratio).

In Chapter $\mathbf{6}$ we screened the intestinal microbiota of a small set CMA-infants and healthy controls to select donor samples for faecal microbiota transplantation into germ-free mice. We confirmed the decreased B/L-ratio in CMA versus healthy infants as observed in Chapter 5, which was maintained upon transplantation into the germ-free mice. Herein, we showed that CMA-associated infant microbiota resulted in an atopic orientation, with increased immunoglobulin $E$ levels and an enhanced responsiveness to cow's milk allergen upon sensitization, which suggested that the pathobiology of allergic disease is mediated at least in part by gut microbiome perturbation. 


\section{References}

1. Cheng J, Ringel-Kulka T, Heikamp-de Jong I, Ringel Y, Carroll I, de Vos WM, et al. Discordant temporal development of bacterial phyla and the emergence of core in the fecal microbiota of young children. ISME J. 2016;10(4):1002-14.

2. Gensollen T, Blumberg RS. Correlation between early-life regulation of the immune system by microbiota and allergy development. J Allergy Clin Immunol. 2017;139(4):1084-91.

3. McMurdie PJ, Holmes S. Waste not, want not: why rarefying microbiome data is inadmissible. PLoS Comput Biol. 2014;10(4):e1003531.

4. Gloor GB, Wu JR, Pawlowsky-Glahn V, Egozcue JJ. It's all relative: analyzing microbiome data as compositions. Ann Epidemiol. 2016;26(5):322-9.

5. Weiss S, Xu ZZ, Peddada S, Amir A, Bittinger K, Gonzalez A, et al. Normalization and microbial differential abundance strategies depend upon data characteristics. Microbiome. 2017;5(1):27.

6. Knight R, Vrbanac A, Taylor BC, Aksenov A, Callewaert C, Debelius J, et al. Best practices for analysing microbiomes. Nat Rev Microbiol. 2018;16(7):410-22.

7. Costea PI, Zeller G, Sunagawa S, Pelletier E, Alberti A, Levenez F, et al. Towards standards for human fecal sample processing in metagenomic studies. Nat Biotechnol. 2017.

8. Peterson J, Garges S, Giovanni M, Mclnnes P, Wang L, Schloss JA, et al. The NIH Human Microbiome Project. Genome Res. 2009;19(12):2317-23.

9. Korpela K, de Vos WM. Early life colonization of the human gut: microbes matter everywhere. Curr Opin Microbiol. 2018;44:70-8.

10. Savage DC. Microbial ecology of the gastrointestinal tract. Annu Rev Microbiol. 1977;31:107-33.

11. Stark PL, Lee A. The microbial ecology of the large bowel of breast-fed and formula-fed infants during the first year of life. J Med Microbiol. 1982;15(2):189-203.

12. Harmsen HJ, Wildeboer-Veloo AC, Raangs GC, Wagendorp AA, Klijn N, Bindels JG, et al. Analysis of intestinal flora development in breast-fed and formula-fed infants by using molecular identification and detection methods. J Pediatr Gastroenterol Nutr. 2000;30(1):61-7.

13. Tissier $\mathrm{H}$. Recherches sur la flore intestinale des nourrissons:(état normal et pathologique) 1900.

14. Kunz C, Rudloff S, Baier W, Klein N, Strobel S. Oligosaccharides in human milk: structural, functional, and metabolic aspects. Annu Rev Nutr. 2000;20:699-722.

15. Oozeer R, van Limpt K, Ludwig T, Ben Amor K, Martin R, Wind RD, et al. Intestinal microbiology in early life: specific prebiotics can have similar functionalities as human-milk oligosaccharides. Am $\mathrm{J}$ Clin Nutr. 2013;98(2):561S-71S.

16. Arslanoglu S, Moro GE, Schmitt J, Tandoi L, Rizzardi S, Boehm G. Early dietary intervention with a mixture of prebiotic oligosaccharides reduces the incidence of allergic manifestations and infections during the first two years of life. J Nutr. 2008;138(6):1091-5.

17. Moro G, Arslanoglu S, Stahl B, Jelinek J, Wahn U, Boehm G. A mixture of prebiotic oligosaccharides reduces the incidence of atopic dermatitis during the first six months of age. Arch Dis Child. 2006;91(10):814-9.

18. Grüber C, van Stuijvenberg M, Mosca F, Moro G, Chirico G, Braegger CP, et al. Reduced occurrence of early atopic dermatitis because of immunoactive prebiotics among low-atopy-risk infants. Journal of Allergy and Clinical Immunology. 2010;126(4):791-7. 
19. Cuello-Garcia C, Fiocchi A, Pawankar R, Yepes-Nunez JJ, Morgano GP, Zhang Y, et al. Prebiotics for the prevention of allergies: a systematic review and meta-analysis of randomized controlled trials. Clin Exp Allergy. 2017:n/a-n/a.

20. Muraro A, Halken S, Arshad SH, Beyer K, Dubois AE, Du Toit G, et al. EAACl food allergy and anaphylaxis guidelines. Primary prevention of food allergy. Allergy. 2014;69(5):590-601.

21. Boyle RJ, lerodiakonou D, Khan T, Chivinge J, Robinson Z, Geoghegan N, et al. Hydrolysed formula and risk of allergic or autoimmune disease: systematic review and meta-analysis. BMJ. 2016;352:i974.

22. Fiocchi A, Brozek J, Schunemann H, Bahna SL, von Berg A, Beyer K, et al. World Allergy Organization (WAO) Diagnosis and Rationale for Action against Cow's Milk Allergy (DRACMA) Guidelines. Pediatr Allergy Immunol. 2010;21 Suppl 21:1-125.

23. Hill DJ, Murch SH, Rafferty K, Wallis P, Green CJ. The efficacy of amino acid-based formulas in relieving the symptoms of cow's milk allergy: a systematic review. Clin Exp Allergy. 2007;37(6):808-22.

24. Fiocchi A, Dahda L, Dupont C, Campoy C, Fierro V, Nieto A. Cow's milk allergy: towards an update of DRACMA guidelines. World Allergy Organ J. 2016;9(1):35.

25. Chiang WC, Huang CH, Llanora GV, Gerez I, Goh SH, Shek LP, et al. Anaphylaxis to cow's milk formula containing short-chain galacto-oligosaccharide. J Allergy Clin Immunol. 2012;130(6):1361-7.

26. van Esch BC, Abbring S, Diks MA, Dingjan GM, Harthoorn LF, Vos AP, et al. Post-sensitization administration of non-digestible oligosaccharides and Bifidobacterium breve M-16V reduces allergic symptoms in mice. Immun Inflamm Dis. 2016;4(2):155-65

27. Martin R, Makino H, Cetinyurek Yavuz A, Ben-Amor K, Roelofs M, Ishikawa E, et al. Early-Life Events, Including Mode of Delivery and Type of Feeding, Siblings and Gender, Shape the Developing Gut Microbiota. PLoS One. 2016;11(6):e0158498.

28. Organization WH. Complementary feeding: report of the global consultation, and summary of guiding principles for complementary feeding of the breastfed child. 2003.

29. Organization WH. Guiding principles for feeding non-breastfed children 6-24 months of age. 2005.

30. Fewtrell M, Bronsky J, Campoy C, Domellof M, Embleton N, Fidler Mis N, et al. Complementary Feeding: A Position Paper by the European Society for Paediatric Gastroenterology, Hepatology, and Nutrition (ESPGHAN) Committee on Nutrition. J Pediatr Gastroenterol Nutr. 2017;64(1):119-32.

31. Bergstrom A, Skov TH, Bahl MI, Roager HM, Christensen LB, Ejlerskov KT, et al. Establishment of intestinal microbiota during early life: a longitudinal, explorative study of a large cohort of Danish infants. Appl Environ Microbiol. 2014;80(9):2889-900.

32. Backhed F, Roswall J, Peng Y, Feng Q, Jia H, Kovatcheva-Datchary P, et al. Dynamics and Stabilization of the Human Gut Microbiome during the First Year of Life. Cell Host Microbe. 2015;17(5):690-703.

33. Stewart CJ, Ajami NJ, O'Brien JL, Hutchinson DS, Smith DP, Wong MC, et al. Temporal development of the gut microbiome in early childhood from the TEDDY study. Nature. 2018;562(7728):583-8.

34. Laursen MF, Bahl MI, Michaelsen KF, Licht TR. First Foods and Gut Microbes. Front Microbiol. 2017;8:356.

35. Ho NT, Li F, Lee-Sarwar KA, Tun HM, Brown B, Pannaraj PS, et al. Effects of exclusive breastfeeding on infant gut microbiota: a meta-analysis across studies and populations. bioRxiv. 2018.

36. Dogra S, Sakwinska O, Soh SE, Ngom-Bru C, Bruck WM, Berger B, et al. Rate of establishing the gut microbiota in infancy has consequences for future health. Gut Microbes. 2015;6(5):321-5. 


\section{Chapter 7}

37. Horta BL, Victora CG, Organization WH. Short-Term Effects of Breastfeeding: A Systematic Review on the Benefits of Breastfeeding on Diarrhea and Pneumonia Mortality. . Geneva, Switzerland: World Health Organization; 2013.

38. Horta BL, Loret de Mola C, Victora CG. Long-term consequences of breastfeeding on cholesterol, obesity, systolic blood pressure and type 2 diabetes: a systematic review and meta-analysis. Acta Paediatrica. 2015;104(S467):30-7.

39. Odijk J, Kull I, Borres MP, Brandtzaeg P, Edberg U, Hanson LA, et al. Breastfeeding and allergic disease: a multidisciplinary review of the literature (1966-2001) on the mode of early feeding in infancy and its impact on later atopic manifestations. Allergy. 2003;58(9):833-43.

40. Lodge CJ, Tan DJ, Lau MX, Dai X, Tham R, Lowe AJ, et al. Breastfeeding and asthma and allergies: a systematic review and meta-analysis. Acta paediatrica (Oslo, Norway : 1992). 2015;104(467):38-53.

41. Sitarik AR, Kasmikha NS, Kim H, Wegienka G, Havstad S, Ownby D, et al. Breastfeeding and Delivery Mode Modify the Association between Maternal Atopy and Childhood Allergic Outcomes. J Allergy Clin Immunol. 2018.

42. Abrahamsson TR, Jakobsson HE, Andersson AF, Bjorksten B, Engstrand L, Jenmalm MC. Low gut microbiota diversity in early infancy precedes asthma at school age. Clin Exp Allergy. 2014;44(6):842-50

43. Abrahamsson TR, Jakobsson HE, Andersson AF, Bjorksten B, Engstrand L, Jenmalm MC. Low diversity of the gut microbiota in infants with atopic eczema. J Allergy Clin Immunol. 2012;129(2):434-40, 40 e1-2.

44. Low JSY, Soh SE, Lee YK, Kwek KYC, Holbrook JD, Van der Beek EM, et al. Ratio of Klebsiella/Bifidobacterium in early life correlates with later development of paediatric allergy. Benef Microbes. 2017;8(5):681-95.

45. Shade A. Diversity is the question, not the answer. ISME J. 2017;11(1):1-6.

46. Falony G, Vieira-Silva S, Raes J. Richness and ecosystem development across faecal snapshots of the gut microbiota. Nat Microbiol. 2018;3(5):526-8.

47. Abrahamsson TR, Jakobsson HE, Andersson AF, Bjorksten B, Engstrand L, Jenmalm MC. Reply: To PMID 22153774. J Allergy Clin Immunol. 2013;131(1):248-9.

48. Ferretti P, Pasolli E, Tett A, Asnicar F, Gorfer V, Fedi S, et al. Mother-to-Infant Microbial Transmission from Different Body Sites Shapes the Developing Infant Gut Microbiome. Cell Host Microbe. 2018;24(1):133-45 e5. 49. Blaser MJ. The theory of disappearing microbiota and the epidemics of chronic diseases. Nat Rev Immunol. 2017;17(8):461-3.

50. Knol J, Boehm G, Lidestri M, Negretti F, Jelinek J, Agosti M, et al. Increase of faecal bifidobacteria due to dietary oligosaccharides induces a reduction of clinically relevant pathogen germs in the faeces of formula-fed preterm infants. Acta Paediatr Suppl. 2005;94(449):31-3.

51. Fukuda S, Toh H, Hase K, Oshima K, Nakanishi Y, Yoshimura K, et al. Bifidobacteria can protect from enteropathogenic infection through production of acetate. Nature. 2011;469(7331):543-7.

52. van Limpt C, Crienen A, Vriesema A, Knol J. Effect of Colonic Short Chain Fatty Acids, Lactate and PH on The Growth of Common Gut Pathogens. Pediatric Research; 09/01/online: International Pediatrics Research Foundation, Inc.; 2004. p. 487.

53. Bruzzese E, Volpicelli M, Squeglia V, Bruzzese D, Salvini F, Bisceglia M, et al. A formula containing galacto- and fructo-oligosaccharides prevents intestinal and extra-intestinal infections: an observational study. Clin Nutr. 2009;28(2):156-61. 
54. Burks AW, Harthoorn LF, Van Ampting MT, Oude Nijhuis MM, Langford JE, Wopereis $H$, et al. Synbiotics-supplemented amino acid-based formula supports adequate growth in cow's milk allergic infants. Pediatr Allergy Immunol. 2015;26(4):316-22.

55. Fox AT, Wopereis H, Van Ampting MT, Oude NMM, Butt AM, Peroni DG, et al. A specific synbiotic-containing amino acid-based formula in dietary management of cow's milk allergy- a randomized controlled trial. Clin Transl Allergy. 2018.

56. Heavey PM, Savage SA, Parrett A, Cecchini C, Edwards CA, Rowland IR. Protein-degradation products and bacterial enzyme activities in faeces of breast-fed and formula-fed infants. Br J Nutr. 2003;89(4):509-15.

57. Yao CK, Muir JG, Gibson PR. Review article: insights into colonic protein fermentation, its modulation and potential health implications. Aliment Pharmacol Ther. 2016;43(2):181-96.

58. Roager HM, Hansen LBS, Bahl MI, Frandsen HL, Carvalho V, Gøbel RJ, et al. Colonic transit time is related to bacterial metabolism and mucosal turnover in the gut. Nature Microbiology. 2016;1:16093.

59. Vandeputte D, Falony G, Vieira-Silva S, Tito RY, Joossens M, Raes J. Stool consistency is strongly associated with gut microbiota richness and composition, enterotypes and bacterial growth rates. Gut. 2016;65(1):57-62.

60. Piemontese P, Gianni ML, Braegger CP, Chirico G, Gruber C, Riedler J, et al. Tolerance and safety evaluation in a large cohort of healthy infants fed an innovative prebiotic formula: a randomized controlled trial. PLoS One. 2011;6(11):e28010.

61. Moro G, Minoli I, Mosca M, Fanaro S, Jelinek J, Stahl B, et al. Dosage-related bifidogenic effects of galacto- and fructooligosaccharides in formula-fed term infants. J Pediatr Gastroenterol Nutr. 2002;34(3):291-5.

62. Boyle RJ, Tang ML, Chiang WC, Chua MC, Ismail I, Nauta A, et al. Prebiotic-supplemented partially hydrolysed cow's milk formula for the prevention of eczema in high-risk infants: a randomized controlled trial. Allergy. 2016;71(5):701-10.

63. Harvey BM, Langford JE, Harthoorn LF, Gillman SA, Green TD, Schwartz RH, et al. Effects on growth and tolerance and hypoallergenicity of an amino acid-based formula with synbiotics. Pediatr Res. 2014;75(2):343-51.

64. Scott KP, Gratz SW, Sheridan PO, Flint HJ, Duncan SH. The influence of diet on the gut microbiota. Pharmacol Res. 2013;69(1):52-60.

65. Flint HJ, Duncan SH, Scott KP, Louis P. Links between diet, gut microbiota composition and gut metabolism. Proc Nutr Soc. 2015;74(1):13-22.

66. Kim KS, Hong SW, Han D, Yi J, Jung J, Yang BG, et al. Dietary antigens limit mucosal immunity by inducing regulatory $T$ cells in the small intestine. Science. 2016;351(6275):858-63.

67. Cahenzli J, Köller Y, Wyss M, Geuking Markus B, McCoy Kathy D. Intestinal Microbial Diversity during Early-Life Colonization Shapes Long-Term IgE Levels. Cell Host \& Microbe. 2013;14(5):559-70.

68. Steinmeyer S, Lee K, Jayaraman A, Alaniz RC. Microbiota metabolite regulation of host immune homeostasis: a mechanistic missing link. Curr Allergy Asthma Rep. 2015;15(5):24.

69. Smith PM, Howitt MR, Panikov N, Michaud M, Gallini CA, Bohlooly YM, et al. The microbial metabolites, short-chain fatty acids, regulate colonic Treg cell homeostasis. Science. 2013;341(6145):569-73.

70. Arpaia N, Campbell C, Fan X, Dikiy S, van der Veeken J, deRoos P, et al. Metabolites produced by commensal bacteria promote peripheral regulatory T-cell generation. Nature. 2013;504(7480):451-5.

71. Trompette A, Gollwitzer ES, Yadava K, Sichelstiel AK, Sprenger N, Ngom-Bru C, et al. Gut microbiota metabolism of dietary fiber influences allergic airway disease and hematopoiesis. Nat Med. 2014;20(2):159-66. 


\section{Chapter 7}

72. Stefka AT, Feehley T, Tripathi P, Quu J, McCoy K, Mazmanian SK, et al. Commensal bacteria protect against food allergen sensitization. Proc Natl Acad Sci U S A. 2014;111(36):13145-50.

73. Mariño E, Richards JL, McLeod KH, Stanley D, Yap YA, Knight J, et al. Gut microbial metabolites limit the frequency of autoimmune T cells and protect against type 1 diabetes. Nature Immunology. 2017;18:552.

74. Tan J, McKenzie C, Vuillermin PJ, Goverse G, Vinuesa CG, Mebius RE, et al. Dietary Fiber and Bacterial SCFA Enhance Oral Tolerance and Protect against Food Allergy through Diverse Cellular Pathways. Cell Rep. 2016;15(12):2809-24.

75. Boyle RJ, Tang MLK, Chiang WC, Chua MC, Ismail I, Nauta A, et al. Prebiotic-supplemented partially hydrolysed cow's milk formula for the prevention of eczema in high risk infants: a randomised controlled trial. Allergy. 2016:in press.

76. Boyle R, Brown N, Chiang WC, Chien CM, Gold M, Hourihane J, et al. Partially hydrolysed, prebiotic supplemented whey formula for the prevention of allergic manifestations in high risk infants: a multicentre double-blind randomised controlled trial. Clinical and Translational Allergy. 2015;5(Suppl 3):P30. 
General discussion \& Summary 



\section{Appendices}

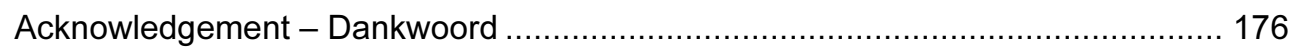

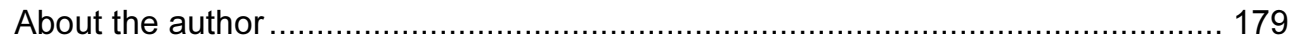

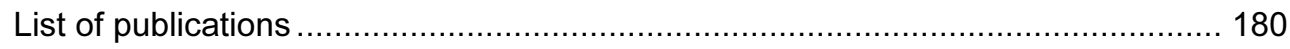

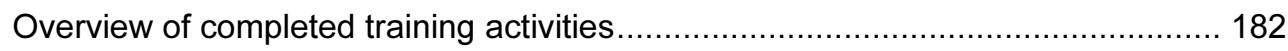




\section{Acknowledgement - Dankwoord}

De eindstreep is in zicht! Om mij heen waarschuwen verschillende mensen voor het 'zwarte gat' waar ik straks geheid in zal donderen. Hoogste tijd dus voor het laatste deel van mijn 'boekie': het dankwoord.

Allereerst wil ik mijn mentoren van het eerste uur bedanken: Thank you Kaouther, Raish and Rocio for supporting me to 'grow within Danone' since I started my career at Nutricia Research in 2006. Under your supervision I developed from technician to scientist and finally felt sufficiently confident to pursue a $\mathrm{PhD}$ in microbiology. Guus, dank voor de steun tijdens 'de laatste loodjes' van mijn promotietraject. Ik heb zeer veel profijt gehad van jouw scherpe en kritische blik op veel van de hoofdstukken in dit proefschrift. Bovenal wil ik natuurlijk Jan bedanken, die als $n+2$ en promotor mij heeft geïnspireerd, gestimuleerd en ondersteund in mijn wetenschappelijke loopbaan. Dank dat je me de mogelijkheid hebt geboden om in 2012 de stap voor een promotieonderzoek te gaan wagen. Hoewel, voordat ondergetekende ook daadwerkelijk de stap zette, duurde toch nog wel even (daarom ook dank voor je geduld). Maar zo rond jouw inauguratie in Mei 2013 als bijzonder hoogleraar bij de leerstoelgroep van Willem de Vos had ik toch eindelijk een promotievoorstel en applicatie voor toelating bij de Wageningen Universiteit ingediend. Dank Willem! Veel respect voor jouw inhoudelijke kennis en manager-capaciteiten. Nooit eerder zulke snelle en efficiënte meetings meegemaakt waarin ik zoveel bruikbare en intensieve feedback kreeg! De belangrijkste hobbel voor mijn toelating (ik moest even terug de schoolbanken in gezien mijn HBO-achtergrond) was dan ook snel genomen, zodat ik in November 2013 dan ook echt officieel van start kon als gast promovendus bij de WUR.

Veel dank ook aan mijn co-promotor Clara Belzer, die door haar praktische instelling en hartelijke welkom op het Laboratorium voor Microbiologie het makkelijk maakte om mijn weg te vinden binnen de Wageningen Universiteit. A big thank you to all staff and fellow PhD candidates at the Laboratory of Microbiology; it was always great to interact with you during the PhD-meetings, symposia and teaching-activities! Special thanks to the Early Life Microbiology-club: Romy, Lennart, Petra and LooWee 
as fellow-pioneers, and to the new colonizers of the club: Ioannis, Emmy, Jannie, Kevin and Patrick.

Of course, l'd like to express my gratitude to all my Nutricia teammates of the Gut Biology and Microbiology platform in Utrecht and Singapore. It is a pleasure to work with you and I am looking forward to all that is yet to come. Speciale dank voor Sebastiaan en Jolanda; voor alle inhoudelijke en persoonlijke steun tijdens mijn promotietraject. Ik heb jullie beiden zonder jullie medeweten als 'other supervisors' opgeschreven in mijn PhD projectvoorstel, maar kon dan ook altijd bij jullie terecht om even te sparren. Daarnaast heb ik een belangrijk deel van de resultaten in dit proefschrift te danken aan Rob, Tiemen en 'stand-in' Kees. Heel veel dank voor de 'niet lullen - maar scheppen' mentaliteit, de vele FISH en qPCR analyses en de oneindige stroom aan goede en slechte grappen. En ook zeker niet te vergeten: Heleen en Martin, de wizards die alle bio-informatica hobbels wegnamen. Jullie hebben mijn leven zoveel makkelijker gemaakt. Dank daarvoor!

I also want to acknowledge all co-authors and all internal and external members of the PATCH, ASSIGN and HEALMI study teams. I felt privileged to collaborate with you in this exciting multidisciplinary field of nutrition and health! This would not have been possible without your valuable contributions and support during the past years. Also, thanks to many more Nutricia-colleagues that were not directly involved in the work presented in this thesis: Thank you for your moral support and interest and in making Nutricia Research a great place to work.

Dan mijn paranimfen: Jolanda en Roger. Beiden belangrijke aanjagers voor de nodige afleiding naast het werk, zoals Roger's fameuze bierproeverijen, de lerse-pub avonden bij Mick O'Connels en de vuur-en-voer sessies bij Jolanda. Ook zorgden jullie ervoor dat ik niet de hele dag achter de computer bleef zitten d.m.v. de (bijna verplichte) dagelijkse lunch-wandelingen om even de kop leeg te maken. Ik ben dan ook zeer blij dat jullie mij bij willen staan op de grote dag en de weg ernaartoe!

Lieve familie, schoonfamilie, vrienden en de kameraden van d'n Achterhoek Tsjoek: het is klaar! Hoogste tijd weer voor een borrel, dank voor alle steun, afleiding en mooie momenten. Meer van dat graag! Deze keer geef ik een rondje. 
Lieve pa, ma en zus. Hier is die dan, alles op zijn tijd. Met pa's precisie en doorzettingsvermogen, ma's zorgzaamheid en creativiteit, en Suzan's onderzoeksgeest (helaas soms met mij als onwetend proefkonijn, want hoe scherp is een spaanse peper nu eigenlijk?). Heel veel dank voor alle steun en vertrouwen!

Lieve Leyla en Jonne, ik kreeg jullie er 'gewoon' bij tijdens mijn promotietraject iets beters had ik niet kunnen wensen. Niet als studieobjecten (hoewel ik natuurlijk wel een paar poepluiers van jullie ingezet heb voor wetenschappelijk onderzoek), maar voor al het moois dat jullie brengen. Elke dag geniet ik van jullie!

Liefste Tetske, voor wie jij bent, voor wat wij samen hebben, voor dat ik gewoon mijzelf kan zijn en voor alle liefde. Dank voor alles!

Harm

January 2019 


\section{About the author}

Harm Wopereis was born in Groenlo, the Netherlands, on 22 April 1981. After completing his secondary education at Marianum Scholengemeenschap in Groenlo in 1999, he continued his education in Biotechnology at Noordelijke Hogeschool Leeuwarden \& Van Hall Larenstein (1999-2003). After obtaining his BSc degree, he started working for the knowledge institute of Van Hall Larenstein (2003-2006) on innovation projects for small and

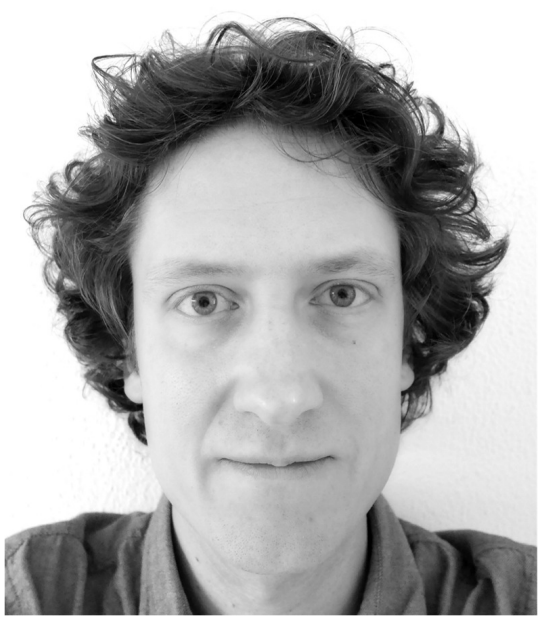
medium-sized enterprises in the field of environmental microbiology. Due to his interest in gut microbiology and applied research, he joined Danone Nutricia Research (at that time called Numico Research) to study the effects of nutrition on the gastrointestinal microbiota and health in early life. In the Gut Biology \& Microbiology department headed by Professor Jan Knol, Harm developed from Assistant Scientist to Senior Assistant Scientist (2009) to Scientist (2012). In 2013, he was admitted as a guest PhD at the Laboratory of Microbiology of the Wageningen University. In his PhD project, he focused on the development of early life gut microbiota in health and allergic disease. The work was done under the supervision of Dr Clara Belzer, Prof. Dr Willem M. de Vos and Prof. Dr Jan Knol, and the results are presented in this thesis. Harm will continue his research as Senior Scientist at Danone Nutricia Research on bringing health through nutrition by supporting the gut microbiota to positively influence the gastrointestinal, immune and metabolic systems. 


\section{List of publications}

\section{Reviews}

1. Wopereis H, Oozeer R, Knipping K, Belzer C, Knol J. The first thousand days intestinal microbiology of early life: establishing a symbiosis. Pediatr Allergy Immunol. 2014;25(5):428-38.

2. Ceapa C, Wopereis H, Rezaiki L, Kleerebezem M, Knol J, Oozeer R. Influence of fermented milk products, prebiotics and probiotics on microbiota composition and health. Best Pract Res Clin Gastroenterol. 2013;27(1):139-55.

\section{Research articles}

1. Mauras A, Wopereis $\mathbf{H}^{*}$, Yeop I, Esber N, Delannoy J, Labellie C, Reygner J, Kapel N, Slump R, Van Eijndthoven T, Rutten L, Knol J, Garssen J, Harthoorn LF, Butel MJ, Bajaj-Elliott M, Hartog A, Waligora-Dupriet AJ. Gut microbiota from infant with Cow's Milk Allergy promotes clinical and immune features of atopy in a murine model. Allergy. 2019.

2. Cortes L, Wopereis $\mathbf{H}^{*}$, Tartiere A, Piquenot J, Gouw JW, Tims S, Knol J, Chelsky D. Metaproteomic and 16S rRNA gene sequencing analysis of the infant fecal microbiome. Int J Mol Sci. 2019;20(6):1430.

3. Szklany $K^{*}$, Wopereis $\mathbf{H}^{*}$, De Waard C, Van Wageningen TA, An R, Van Limpt K, Knol J, Garssen J, Knippels LMJ, Belzer C, Kraneveld AD. Supplementation of dietary non-digestible oligosaccharides from birth onwards improve social and reduce anxiety-like behaviour in male BALB/c mice. Nutr Neurosci. 2019:1-15.

4. Fox AT, Wopereis H, Van Ampting MTJ, Oude Nijhuis MM, Butt AM, Peroni DG, Vandenplas Y, Candy DCA, Shah N, West CE, Garssen J, Harthoorn LF, Knol J. Michaelis LJ. A specific synbiotic-containing amino acid-based formula in dietary management of cow's milk allergy: a randomized controlled trial. Clin Transl Allergy. 2019;9(1):5.

5. Wopereis H, Sim K, Shaw A, Warner JO, Knol J, Kroll JS. Intestinal microbiota in infants at high risk for allergy: Effects of prebiotics and role in eczema development. J Allergy Clin Immunol. 2018;141(4):1334-42 e5. 
6. Chia LW, Mank M, Blijenberg B, Bongers RS, Aalvink S, van Limpt K, Wopereis H, Tims S, Stahl B, Belzer C, Knol J. Cross-feeding between Bifidobacterium infantis and Anaerostipes caccae on lactose and human milk oligosaccharides. bioRxiv. 2018.

7. Candy DCA, Van Ampting MTJ, Oude Nijhuis MM, Wopereis $\mathbf{H}$, Butt AM, Peroni DG, Vandenplas Y, Fox AT, Shah N, West CE, Garssen J, Harthoorn LF, Knol $\mathrm{J}$, Michaelis LJ. A synbiotic-containing amino-acid-based formula improves gut microbiota in non-IgE-mediated allergic infants. Pediatr Res. 2018;83(3):677-86.

8. Rogier R, Ederveen THA, Boekhorst J, Wopereis H, Scher JU, Manasson J, Frambach SJCM, Knol J, Garssen J, van der Kraan PM, Koenders MI, van den Berg WB, van Hijum SAFT, Abdollahi-Roodsaz S. Aberrant intestinal microbiota due to IL-1 receptor antagonist deficiency promotes IL-17- and TLR4-dependent arthritis. Microbiome. 2017;5(1):63.

9. Burks AW, Harthoorn LF, Van Ampting MT, Oude Nijhuis MM, Langford JE, Wopereis H, Goldberg SB, Ong PY, Essink BJ, Scott RB, Harvey BM. Synbiotics-supplemented amino acid-based formula supports adequate growth in cow's milk allergic infants. Pediatr Allergy Immunol. 2015;26(4):316-22.

10. de Theije $\mathrm{CG}^{*}$, Wopereis $\mathbf{H}^{*}$, Ramadan M, van Eijndthoven $\mathrm{T}$, Lambert $\mathbf{J}$, Knol J, Garssen J, Kraneveld AD, Oozeer R. Altered gut microbiota and activity in a murine model of autism spectrum disorders. Brain Behav Immun. 2014;37(0):197-206.

11. Sim K, Cox MJ, Wopereis H, Martin R, Knol J, Li MS, Cookson WO, Moffatt MF, Kroll JS. Improved detection of bifidobacteria with optimised $16 \mathrm{~S}$ rRNA-gene based pyrosequencing. PLoS One. 2012;7(3):e32543.

12. Oosting A, Kegler D, Wopereis HJ, Teller IC, van de Heijning BJ, Verkade HJ, van der Beek EM. Size and phospholipid coating of lipid droplets in the diet of young mice modify body fat accumulation in adulthood. Pediatr Res. 2012;72(4):362-9.

13. MacDonald A, Cochrane B, Wopereis $\mathbf{H}$, Loveridge $\mathbf{N}$. Specific prebiotics in a formula for infants with Phenylketonuria. Mol Genet Metab. 2011;104 Suppl(0):S55-9.

*Joint first 


\section{Overview of completed training activities}

\section{Discipline specific activities}

\section{Courses}

The Light in the Intestinal Tract Tunnel

Systems Biology: Statistical Analysis of Omics Data

\section{Meetings}

Gut Day Symposium

International Human Microbiome

Congress

The European Academy of Allergy and Clinical Immunology (EAACI) - Annual congress (poster presentation)

KNVM/NVMM Scientific Spring Meeting (oral presentation)

EAACl - Annual congress (poster pitch presentation)

Microbiology Centennial Symposium (poster presentation)

Pediatric Allergy and Asthma Meeting (poster pitch presentation)

Mini-symposium 'Intestinal Microbiology of Early Life' (oral presentation)
ABS / VLAG

EPS / VLAG

Gut Flora Foundation

MetaHIT / IHMC

EAACI

KNVM / NVMM

$\mathrm{EAACl}$

Laboratory of Microbiology, WUR

EAACI

Laboratory of Microbiology, WUR / Nutricia Research
Helsinki, FI, 2009

Wageningen, NL, 2014

Amsterdam, NL, 2014

Paris, FR, 2012

Copenhagen, DK, 2014

Arnhem, NL, 2016

Vienna, AT, 2016

Wageningen, NL, 2017

London, UK, 2017

Utrecht, NL, 2017

\section{General courses}

R\&D presentation skills

Statistics for clinical studies

Convince in 15 minutes
Nutricia research / Wageningen, NL, Kenhardt 2010

Nutricia research

Wageningen, NL, 2010

Nutricia Research / Wageningen, NL, Agent Majeure
2011 
General courses (continued)

Key Message Writing

R\&D Project Management foundations

Danone Leadership course

Getting Things Done Workshop

Powerworkshop

Patents Basic Training

R-workshop

The Essentials of Scientific Writing \& WGS Presenting

Scientific Writing
Nutricia Research

Schuttelaars \&

Partners

Nutricia Research

Nutricia Research

Nutricia Research /

Tijdwinst.com

Nutricia Research / Qidos

Nutricia Research / Utrecht, NL, 2013 Nederlands

Octrooibureae

Patrick Schloss

(University of

Michigan)

Wageningen, NL, 2011

Wageningen, NL, 2011

Wageningen, NL, 2012

Wageningen, NL, 2012

Utrecht, NL, 2013

Detroit, USA, 2015

Wageningen, NL, 2016

Nutricia Research / Reinschrift Science Communication

\section{Optionals}

Preparation of $\mathrm{PhD}$ project proposal

VLAG

2013

$\mathrm{PhD} /$ postdoc meetings

Laboratory of Microbiology, WUR

Early Life Microbiology team meetings

Laboratory of

2013-17

Microbiology, WUR

Gut Microbiology and Probiotics team Nutricia Research meetings

2013-17 
Appendices

The research described in this thesis was financially supported by Danone Nutricia Research.

Printing of this thesis was financially supported by Danone Nutricia Research.

Cover design by Rene Seure | Kreatuur

Printed by GVO drukkers \& vormgevers B.V. 

